

\section{No 40}

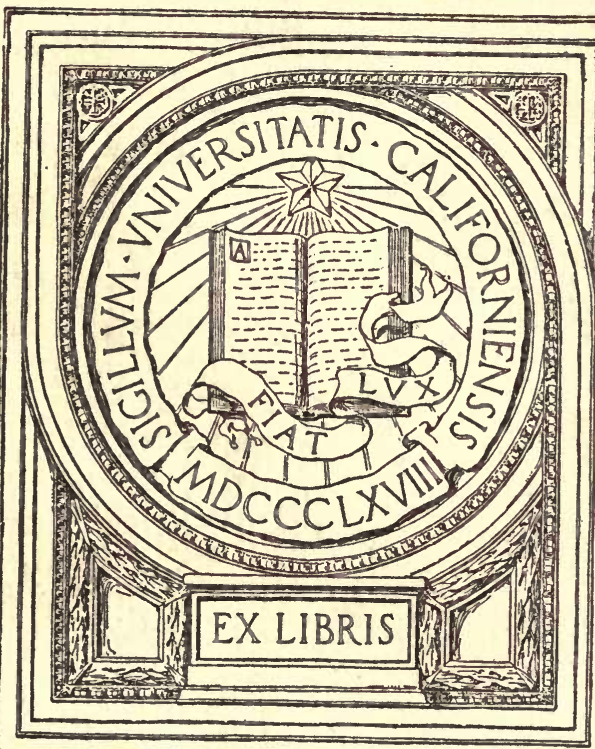

MAIO LIURARY.AGRICULTURE PTCPE

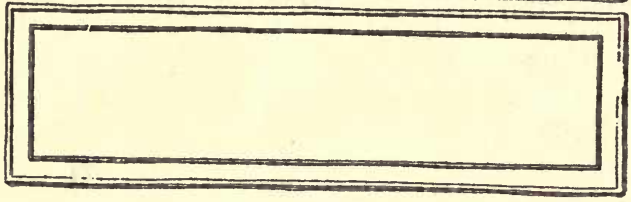







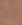

13.

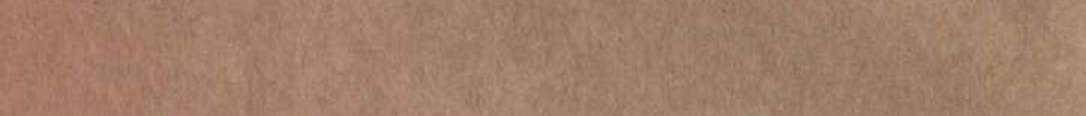

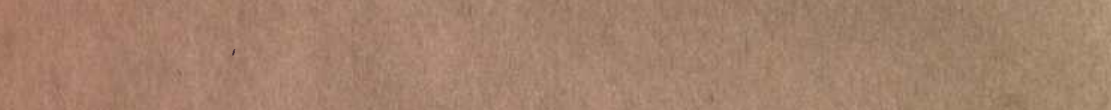

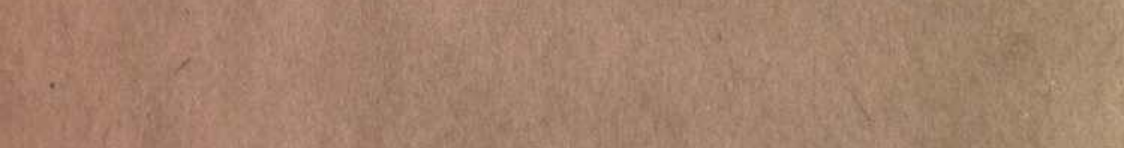

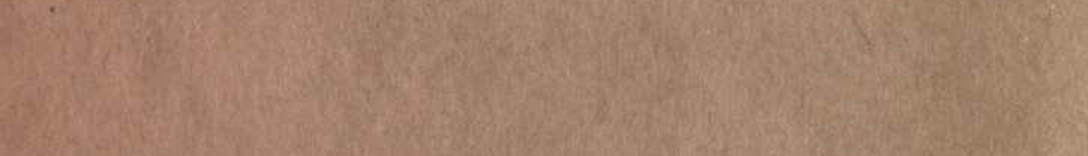

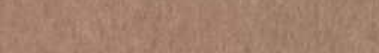




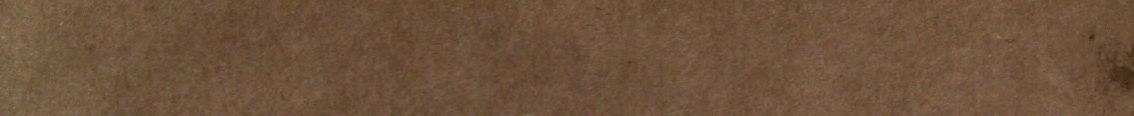

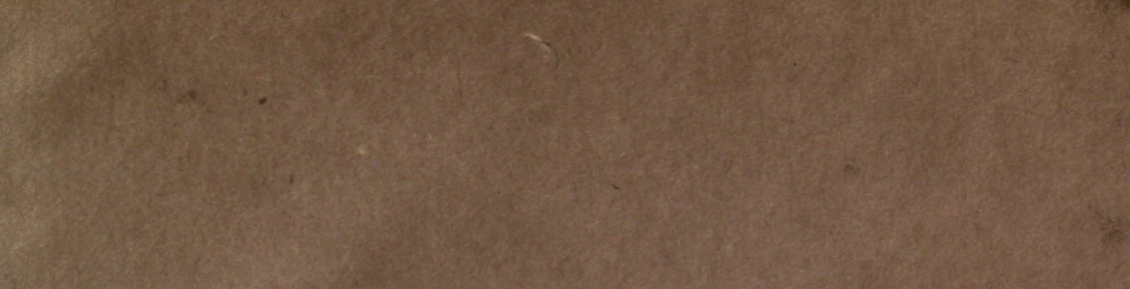





$$
1523
$$




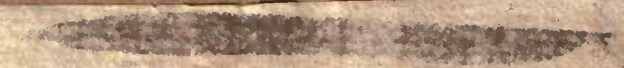

$*$
3

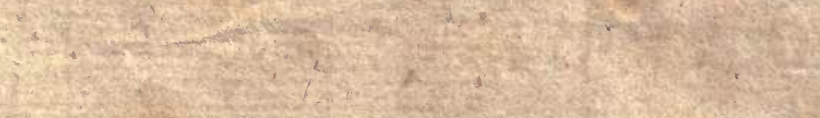
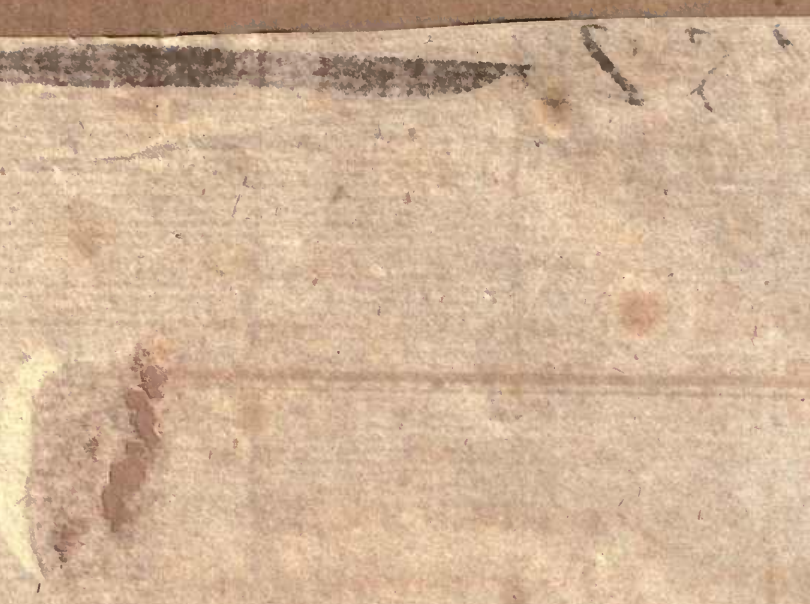

Sin.

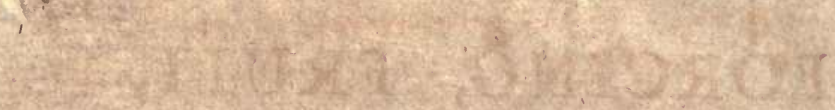

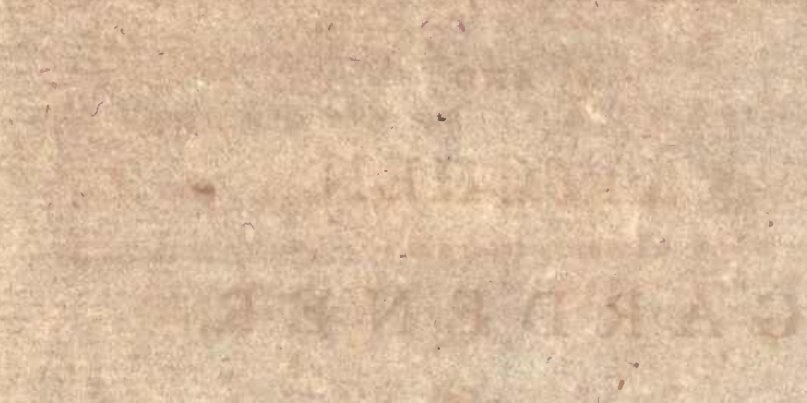

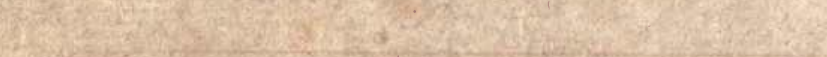

(5)

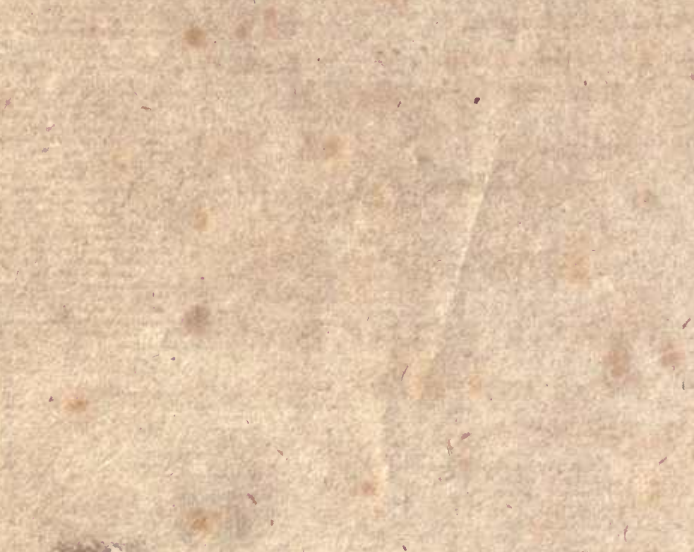




\title{
)
}

THE

\section{FORCING, FRUIT,}

\author{
- AND
}

KITCHEN

G A R D E N E R. 



\section{FORCING, FRUIT, AND KITCHEN}

\section{G A R D E N E R:}

\section{COMPREHENDINO TBE FORCING OF}

$\begin{array}{lll}\text { ASPARAGUS, } & \text { GRAPES, } & \text { PEACHES, } \\ \text { CUCUMBERS, } & \text { MELONS, } & \text { PINE APPLES, } \\ \text { CHERRIES, } & \text { MUSHROOMS, } & \text { AND } \\ \text { FIGS, } & \text { NECTARINES, } & \text { STRAWBERRIES. } \\ & & \end{array}$

Management of the GREEN-Housz-Culture of Wall and Orchard Fruits-Kitghen Vegetables, Sallads and Herbs.

THIRD EDITION, WITH LARGE ADDITIONS.

Illuftrated with Six NEW COPPERzLATES; CONTAINING TEN DIFFERENT DESIGNS OF HOT-HOUSES, HOT-WALLS, \&C, ON THE NEWEST $\triangle N D$ MOST IMPROVED CONSTRUCTIONS.

\section{BY WALTER INICOL,}

Author of "Tre Practicial Plakter," and of an "Essar on GardetsING," drawn up by Defire, and for Confrderation of the Board of Agriculture ; and Correfponding Member of the Natural Hiftury Society of Edinburgh.

\section{EDINBURGH :}

PRINTED FOR WILLIAM CREECH;

AFD SOLD IN LONDON BY T. CADELI JUN. \& W. DAVIES ; J. SCATCHERD, AND T. HURST. 


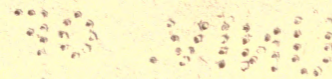

$S B 127$

N5

1802

MaIN LIERARYAAGKICULTUME DERTE.

entereo in stationers allo

EDINBURET,

TRINTED EY A. NEILI \& CO. 


\section{A DVERTISEMENT.}

The Author of the following Work, gives Defigns for Gardens, Hot-Houfes, Shrubbries, Plantations, Parks, Approaches, \&c. in the neweft Tafte. Alfo, gives advice and examples for Thinning and Pruning neglected Plantations, in every ftage of their growth; with proper memoranda refpecting their future Culture.

** Letters addreffed to W. Nicos, Planner, \&ce. Zeith-Walk, Edinburgh, will be duly attended to.

PRE- 



\section{P R E F A C E}

TO THE THIRD EDITION.

SINCE the publication of the Second Edition of this Work, in March $179^{8}$, many important Difcoveries have been made in Gardening. The Author, in a pretty extenfive practice, as a Defigner of Gardens, Hot-Houfes, \&c., has had an opportunity of minutely obferving, and has carefully attended to, every valuable improvement; whether in the conftruction of Hot-Houfes, \&c., or in the Culture of the different Plants treated of. He therefore fubmits this Edition to the Public, enlarged and greatly improved; with the hope that it will, like the two former, be favourably received. 



\section{O N T E N T S,}

\section{BOOK FIRST.}

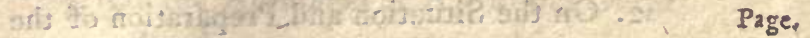

INTRODUCTION, - -40 - - I I

Chap. I. Afparagus, 9

II. Cucumbers, 24

III. Cherries, - 46

Sect. I. On the Conftruction of the Cherry-houfe, $i b$,

2. On Preparing the Border, and Planting the Trees, - : 47

3. On Training the Dwarfs,

4. On the Temperature of the Cherryhoufe, 54

5. On the Admifion of Air to the Cherry-houfe, - $\quad 56$

6. On Watering, Wafhing, and Steaming - the Cherry-houfe, - $\quad 5^{8}$

7. On the Infects that infent the Cherryhoufe, and how to deftroy them, 60

8. On the Cultivation of Cherries in the Confervatory and Peach.houfe,

Sect. I. On the Conftruction of the Fig-houfe, ib.

2. An preparing the Border, and planting the Trees,

3. On Training and Pruning, - $\quad 69$

4. On the Temperature of the Fig-houfe, 70

5. On the Admiftion of Air to the Fig houfe,

6. On Watering and Steaming the Fighoufe, 
Chap. V. Grapes,

Sect. x. On the Confruction of the Grape-houfe, $i b$.

2. On the Situation and Preparation of the

Border,

3. On Preparing the Plants,

4. On Planting, and the Kinds beft adapted to the Grape-houfe,

I. White fweet Water,

2. White Mufcadine, $i b$.

3. Royal Mufcadine,

ib.

4. Black Mufcadine,

5. Black Frontinac,

ib.

6. White Frontinac, $i b$.

7. Red Frontinac, ib.

8. Grifly Frontinac,

9. Black Hamburgh, $i b$.

I0. White Hamburgh, or Portugal, ib.

II. White Raifin,

x. Red Raifin, $i b$.

3. Syrian,

14. White Tokay,

$i b$.

\$5. Flame-coloured Tokay, ib.

r6. White Paffe Mofque,

9 I

17. Grecian, or Greek Grape, $i b$.

3. White Mufcat of Alexandria,

$i b$.

9. Black Mufcat, 92

20. Large Black Clufter, $i b$.

21. Black Conftantia, $i b$.

22. White Conftantia, 93

23. St Peter's Grape,

24. Lombardy, ib. $i b$.

5. On Training and Pruning, $i b$. 
Sect. 6. On the Temperature of the Grapehoufe,

7. On the Admiflion of Air to the Grapehoufe, ros

8. On Watering, Wafhing, and Steaming the Grape-houfe,

9. On the Formation, Thinning, and Maturation of the Clufters,

10. On the Infects which infeft the Grapehoufe; and how to deftroy them,

11. On the Prolongation of the Grape Seafon, where there are more than one compartment for its Culture,

12. On the Cultivation of Grapes in the Pine Stove,

Chap. VI. Melons,

VII. Mufhrooms,

Sect. x. On the Conftruction of the Mufhroomhoufe,

2. On Preparing the Muhroom-beds,

3. On the Temperature of the Mufhroomhoufe,

4. On Watering the Mufhroom-beds,

5. On the Prolongation of the Mufhroom Seafon,

Cinap. VIII. Peaches and Nectarines,

Sect. I. On the Conftruction of the Peach-houfe, $i b$.

2. On the Situation and Preparation of the Border,

3. On Planting, and the Kinds beft adapted to the Peach-houfe, 
Sect. 4. On Training and Pruning,

Page.

5. On the Temperature of the Peachhoufe,

6. On the Admiflion of Air to the Peachhoufe,

7. On Watering, Wafhing, and Steaming the Peach-houfe,

8. On Thinning and Gathering the Fruit $\mathrm{I}_{2}$

9. On the Infects that infert the Peachhoufe, and how to deftroy them,

10. On the Prolongation of the Peach Seafon, where there is more than one Compartment for its $\mathrm{Cu}$ e,

x. On the Cultivation of Peaches and Nectarines on Flued Walls, with Canvas Screens, Nets, \&c.

Sect. r. On the Conftruction of the Pinery,

2. On the Preparation of the Bark-bed, I 77

3. On Propagating the Plants, ? 182

4. On Preparing the Mould; and what Kind is fitteft for the Pine Plant in its different States,

5. On the Treatment of the Plants the Firft Year,

6. On the Treatment of the Plan $*$ the Second Year,

7. On the Treatment of the Plants the Third Year, - - I9I

8. On the Temperature of the Pinery, 195

9. On the Admiflion of Air to the Pinery, ${ }^{96}$

70. On Watering and Steaming the Pinery, 198 


\section{CONTEN T S.}

sitiz

Page.

Sest. II. On the Maturation and Cutting of the Fruit,

12. On the Infects that infert the Pine; and how to deftroy them, - 203

Chap. X. Strawberries, _ _ 206

XI. The Green-honfe, - 209

Sect. I. On the Conftruction of the Green-houfe, ib.

2. On the Temperature of the Greenhoufe,

3. On the Admiflion of Air to the Greenhoufe,

4. On Watering the Green-houfe,

5. On the Compoft Mould to be ufed in the Green-houfe,

6. General Obfervations,

CHAp. XUI. Explanatory of the Plates,

Sect. I. Explanation of Plate I. ib.

2. Explanation of Plate II. 222

3. Explanation of Plate III. 226

4. Explanation of Plate IV. - $\quad 228$

5. Explanation of Plate V. $23^{\circ}$

6. General Obfervations on the Conftruction of Hot-houfes,

\section{BOOK SEGOND.}

Chap, I. On the Making of Eruit-tree Borders; Planting, and Training Fruit-trees againt Walls, Efpaliers, \&cc. - - 243

Sect. r. On the Conftruction and Situation of Garden-walls and Efpaliers, 
Seet, 2. On the Breadth, Depth, and Compolition of the different Borders, for Apricots, Apples, Cherries, Figs, Pears, and Plums,

3. On the different Kinds of the above Trees adapted to this Climate; the Afpect they thould be placed in; and the Diftance from each other, according to the Height of the Wall, \&c.

4. On Training the different Kinds of the above Trees on Walls and Efpaliers, 259 I. Apples, it. Fan-training, - - $\quad 260$ Horizontal training, - $\quad 263$ 2. Apricots, - - $\quad 265$

3. Cherries, - $\quad-\quad 267$

4. Figs, - - $\quad 268$

5. Pears, - - 269

6. Plums, - - $27 \mathrm{I}$

5. General Obfervations on Training and Pruning, and on Thinning and Gathering the Fruit, \&c.

6. On the Infects which generally infert

Wall-trees; and how to deftroy them, 280

Chap. II. Culture of Orchard Fruits, 283

Sect. 1. On the Situation for Orchards, _ - ib.

2. On the Soil for Orchards, _ $\quad 287$

3. On the Kinds of Manure fit for Orchards,

4. Of the Kinds of Orchard Fruits,

5. Culture,

6. On Pruning, \&c. 
Sect. 7. Of Cattle in Orchards,

8. On the Gultivation of Small Fruit,

Currants and Goofeberries, - 302

Rafpberries,

$3 \circ 3$

Strawberries,

304

\section{BOOK THIRD.}

\section{INTRODUCTION,}

Chap. I. On the Proper Depth and Situation of Garden Land, _ $\quad 318$

II. On the Nature and Variety of Garden Land; with the means of Improvement, - $\quad 325$

III. On Manures, and their Application,

IV. Culture of Kitchen Vegetables, 339

Sect. 1. Artichokes,

ib.

2. Afparagus,

$34 \pi$

3. Beans,

$34^{8}$

4. Beet,

$35^{\circ}$

5. Brocoli,

352

6. Bruffels Sprouts,

354

7. Cabbage,

ib.

8. Cauliflower,

9. Carrot,

10. Celery,

357

II. Cardoons, 360

12. French Beans,

I3. Garlick,

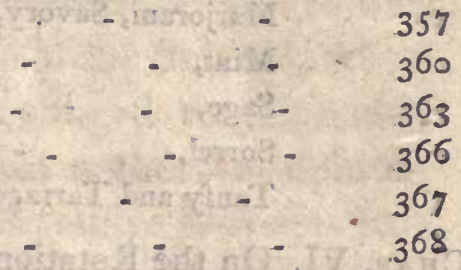


Sect. r4. Greens,

I 5. Horfe-radifh,

I6. Leeks,

r7. Onions,

18. Parfnip,

I9. Peas,

20. Potatoes,

21. Salfafy, Scorzonera, and Skirret,

22. Shallots,

23. Spinage,

24. Sea Cale,

25. Turnips,

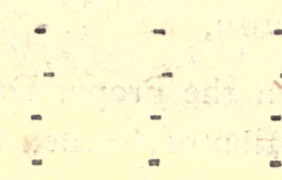

Pagè.

$3^{68}$

369

370

372

375

376

379

$3^{85}$

$3^{86}$

$3^{87}$

$3^{88}$

$39^{\circ}$

Chap. V. Culture of Sallads and Herbs, 393 Sect. r. Sallads,

Chervil, Crefs, and Muftard, - ib.

Endive, $\quad-\quad$ - $\quad 394$

Indian Crefs, - - $\quad 395$

Lettuce; - - - 396

Parley, $\quad-\quad \begin{array}{llll}4 & - & \ldots & 397\end{array}$

Purflane, - - $\quad 398$

Radifh, - - _ $\quad i b$.

2. Pot Herbs, - $\quad 399$

Bafil, - + - ib.

Borage, - - 400

Fennel, - - - - 401

Marigold, - $\quad-\quad \ldots \quad-\quad i b$.

Marjoram, Savory, and Thyme, ib.

Mint, - - $\quad-\quad 402$

Sage, _ . . $\quad . \quad i b$.

Sorrel, - - $\quad 403$

Tanfy and Tarragon, $\quad i b$,

Chap. VI. On the Rotation of Crops, 404

INDEX,

$=\quad 2$

$=$

409 


\section{BOOK FIRST.}

THE

\section{FORCING GARDENER.}

\section{INTRODUCTION.}

THIS branch of Gardening certainly L favours more of luxury than any other; at the fame time it muft be allowed to be a moft rational amufement, profit and pleafure being in fome meafure blended together.

Hereby, not only the moft rare European plants, but alfo thofe of Africa, Afia, and America, are cultivated and brought to very confiderable perfection, and to the intimate acquaintance of the Botanift, who, otherwife, would be obliged to place implicit confidence in the authors of diftant countries, or take expenfive voyages to enable him fully to purfue his ftudies.

Hereby, 
Hereby, alfo, the fineft fruits of France, Spain, Italy, Perfia, and the Weft Indies, are cultivated and brought to early perfection in our Northern Clime, which, otherwife, would only be known by name.

What are reckoned luxuries when firft introduced, are by ufe converted into neceflaries. Witnefs coffee, tea, fugar, \&c. which, although lately introduced, were they prohibited, would not only be miffed, but even longed for by the loweft claffes of the community.

May not the wealthy eat a melon, peach, bunch of grapes, or pine-apple, with as much propriety as drink a bottle of port, claret, champaign, or madeira? Are thefe not, if well ripened, equally wholefome? Have they not the moft rational amufement in the production of them? And does it not, to the contemplative mind, afford a fource of real pleafure? We are certainly juftified in thinking fo, by recollection of the many extenfive additions and improvements which have lately taken place in this elegant branch of horticulture.

Neverthelefs, there is ftill ample room for improvement, which, in a fcience for complicated, 
complicated, muft neceflarily happen for a confiderable length of time after intreduction. It is even probable, that this branch, in refpect of improvement, is but in a ftate of infancy. And this fuppofition arifes, by confidering the many opinions and ideas entertained by profeffional men on this fubject; for until tbofe of any fience are agreed, refpecting points of the firlt confequence, perfection cannot be fuppofed near.

A fettled plan of conftructing hot-houfes, \&c. is by no means yet fixed, moft gardeners and hot-houfe builders differing in fome point or other. This is an article of importance, and there are extremes which fhould be avoided. But it would appear, that the failure of fuccefs in this fpecies of horticulture is lefs in confequence of improper conftruction of the houfe, than in the preparation of proper foil, and the general management; fince in fome inftances we find excellent crops produced in houfes very indifferently conftructed; and in others, very indifferent crops, in houfes well conftructed. 
Situation is alfo a material point. Every hot-houfe thould be placed, if not in a fheltered, at leaft in a dry one, or which is capable of being rendered fo, by draining.

It is alfo of importance to have a perfect command of fire-heat. For this purpofe, refpect muft be had to proportioning the content of the houfe, to the power of the furnace or furnaces, and that, too, according to the purpofe for which it is appropriated, as whether it be a Pinery, Vinery, or Peach-houre, and if either of the latter, whether it be intended for early or late forcing.

But there are thofe who lay more than fufficient ftrefs on this fubject: Thinking, perhaps, to demonftrate, that by building a capacious houfe, with a furnace lefs than another would advife, or which in the end is found neceffary, how great a faving there might be of fuel.

Of this, however, experience has convinced me, that by allotting fpace which a furnace cannot well command, inftead of being a faving, is a great wafte of fuel. Nor will the gardener ever have fuccefs, but with much difficulty. 
For inftance, if a furnace thall be placed at one end of a capacious houfe, which with difficulty can be raifed to the degree required on a fcale hung in the middle, will not the end of the houfe whereat the furnace is placed, be over-heated? and will the other end ever rife to the degree required, before all other parts of the houfe be over-heated? Is not this both a wafte of fuel, and a thwarting of intention?

And what faving is there in the firft onfet? or rather, what wafte is there by rending the furnace and flue with immoderate heat? Is there an inch of flue lefs? - There is, to be fure, a grate and furnace more, which may coft fome forty or fifty fhillings; but which will, in one feafon, be repaid by the faving in fuel. Nor will either fiue or furnace require any repair for many years afterwards.

But, laying all confideration of expence afide, if it is found that a hot-houfe may be more fteadily worked with two furnaces than with one, Why not erect two? Does the trifling fum of a few hillings in any meafure weigh with the infurance of fuccels, in the production of good crops? 
I do not here prefume, that for every hot-houfe, there are to be two furnaces erected. I would be underftood, as fpeaking of large houfes, that is, grape and pine houfes above forty feet in length, and peach houfes above fifty, \&c. But for a full explanation of my ideas on this fubject, I beg to refer the reader to the accompany. ing plates, and their explanations.

Forcing, that is, producing flowers and fruits in hot-houfes at an untimely feafon, is attended with more or lefs fuccers, according to the nearnefs we approach nature in the procefs.

Hence the neceflity of introducing the impofed climate, as it were by ftealth, admitting air freely, unlefs of an impure nature, and making artificial dews and fhowers to nourifh and refiefh, not only the root, but alfo the foliage:

Alfo, as the plants are forced out of their natural inclinations in a great meafure, do not perfpire fo copiounly, nor have an opportunity of imbibing nutritive matter from the natural atmofphere in fuch quantity as if they were growing in the open air, of compofing a richer and deeper bo- 
dy of foil, for the fupport of vegetable life, than otherwife might be required.

In the cultivation of exotic plants and fruits in hot-houfes, regard muft be had to the climate of their nativity; and the , beft endeavours fhould be ufed to imitate it in the hot-houfe; introducing the natural changes of the feafons with equal care.

This, however, is done with confiderable difficulty, as may be conceived, by confidering the difference of latitude, and the variation of the fun's altitude thronghout the feafon, which is greater as we approach the pole.

Hence the difference of trouble attending early and late forcing. And hence, alfo, the difference of injury done the plants in the operation; and, that they may fuftain the lefs, the neceffity of a more moderate treatment in the one than the other. The one is friving, the other firiving hard againft the ftream.

Sudden checks of any kind are to be avoided, particularly while the bloom or fruit is in a tender and infant ftate, otherwife difappointments may be apprehended. This is to be more particularly attended 
to in the forcing of fone, than other fruits; thefe being more impatient of fudden changes in the climate, particularly while fetting and foning.

For the production of fruits in a high ftate of flavour and perfection, a large and free circulation of frefh air, as they approach maturity, is effential. Alfo denying, in a great meafure, the quantity of water the plants may feem to crave, that the fruit be not rendered infipid by the plants imbibing too much of that element; which, however, at all other times, thould be freely beftowed according to the nature of the plant in queftion.

Finally, forcing of any kind being an outrage done nature, the more we avoid it the greater will be our fuccefs. She fhould be kindly aflifted, nor fpurred, nor thwarted, when it can be avoided.

Hence the neceffity of the niceft obfervation in difcovering the natural inclinations of the different plants, which fhould be kindly treated and encouraged, on all occafions. 


\section{FORCING GARDENER.}

\section{CHAPTER I. ASPARAGUS.}

5 HIS delicious and wholefome vege1 table being required in moft families at an early feafon, the forcing of it is . pretty generally underftood; yet, for the fake of thofe who may not have had an opportunity of feeing the common methods practifed, and on account of fome fuccersful experiments, made in this branch of forcing, I hope what I have to advance on the fubject will be acceptable and ufeful to my readers.

WHERE there is not the conveniency of a forcing pit, (See Plate I. Fig. I.) a frame and lights, fuch as is ufed for melons, muft be employed: but I have found by experience, that a flued pit is much to be preferred; as in it the grafs may be produced 
ced of a much better colour, and higher flavour, than on a dung hot-bed.

It frequently occurs, particularly in large families, and where much company is kept, that the gardener is put to a nonplus, by not being timounly advifed that fuch articles are wanted. The conveniency of having a pit, will be found a great relief in this refpect; as it is much eafier, by aid of the flues, to forward or protract the growth of the plants here, than in a common hot-bed: on the one hand, if the plants are advancing too rapidly, there is a neceffity for cooling the bed in a certain degree; and, on the other, if they are not advancing fo faft as could be withed, the application of linings becomes neceflary, which is attended with much trouble and lofs of time.

A pit, twenty-five or thirty feet long, and fix wide, and which one fire can perfectly command, is fufficient to force Afparagus to ferve a large family from November to May, in a conftant and regular fucceflion: after which, it may be advantageounly employed in raifing a late crop of melons or cucumbers, or in ftriking young 
young pine-apple plants, \&c._-But, as many may not have the conveniency of a pit, I thall firft treat of the method of forcing Afparagus on a dung hot-bed, and then in flued pits, according to my mode of practice.

Firft, let it be prefumed, that a good ftock of roots, not younger than four years, nor older than feven or eight, are provided; which, by being covered with litter, \&c. accefs may be had to, in cafe of froft, at any time; and alfo, that it is required Afparagus may be on the table againft a certain day, fuppofe the Ift of December*.

About the If of November, let a fufficient quantity of fable-dung be thrown together

* It may be new to fome, that, by cutting over all the ftalks of Arparagus, about the end of May, or beginning of June, it will put forth fine grafs in Autumn; which, if the feafon happens to be fine, will continue till the middle or latter end of November. This is the reafon I have fixed on the Ift of December for forced Afparagus, being required as above: but I do not mean this to be confidered as a rule. 
gether to heat and fweeten; for a three light box; and after it has lain fix or eight days, let it be turned over, and haken well up a fecond time; in which ftate let it lie four or five days more. A moderate degree of heat is required, and confequently the dung thould be carefully fermented, by turning the outfides or littery parts of the heap into the middle, one, two, or three times, at intervals of a few days each, as circumftances thall direct.

When the dung is judged to be in a proper condition, proceed to build the bed. This mut be done, in the common way, to the height of four feet in the back, and three in front, and about a foot larger than the frame all round. Level it well ; and cover the whole with fquares of turf, cut fo as to join again exactly; which lay green fide down, and fmooth with the back of the

fpade.

Sometimes it may be required much fooner, and fometimes not till Chriftmas. - I beg to obferve here, that, where there is a great ftock of Afparagus, it is a good way to cut over a part in May or June, to come in in Autumn: but let not the gardener expect any more good from the grafs fo cut, as fome pritend;-it is a. fpecies of forcing, and confequently muft exhauft nature. 
fpade. By aid of turfs carefully placed in this manner, a rank fteam is effectually prevented, which is of no fmall importance in the forcing of Afparagus; the fteam arifing from rank dung of this defcription, not only difcolouring the grafs, but tainting its flavour. Place on the frame: It thould be thirty inches deep in the back, and twenty in front: Let dry, well-reduced old tan, to the thicknefs of fix or eight inches be laid in it; which level and fmooth with the fpade.

The roots being ready, (which thould be taken up with great care), proceed to lay them, crowns up, as clofe as they will lie together; endeavouring to keep them as level as poffible, and divefting them of all the, old hulm and rotten roots. Cover the whole with old tan as above, to the thicknefs of three inches; and put on the lights.

The bed will begin to beat in twentyfour hours; and mult then have air admitted, to pafs off any fteam that may rife, which will, however, be inconfiderable, I prefume. Indeed, the only caufe for turfing the furface is to prevent fteam; which, if carefully done, will have the defired effect ; 
fect; yet, it fometimes happens that a little will rife, efpecially if the dung did not undergo a proper fermentation: but, until the grafs begin to appear, it is not material if there is a little fteam in the frame; nor, provided there is not much fteam, whether it has any air admitted or not. But, from the moment the buds begin to appear, the greateft attention muft be paid to prevent, or to draw off the fteam; which is fure to give the grafs a very difagreeable flavour and bad colour.

In order to prevent the grafs from drawing up weakly, a large portion of air muft be admitted every day, if the weather be not ftormy; and a little air hould alfo be left at night, while a rank heat prevails in the bed: Fahrenheit's thermometer fhould not ftand above $5^{\circ}$ at any time, unlefs in fun-thine, and even then, not above $60^{\circ}$. By this rule, it will be feen whether matting at night is neceffary, and to. what extent; therefore, it may be unneceffary to fay more on that head: but the article feam mult be farther confidered, and indeed kept in view till it is entirely fuppreffed. If, then, by leaving a little air at 
each ligbt in the night, does not completely draw off the fteam and damp, recourfe muft be had to boring the bed; which is done by thrufting a large ftick fuch as the handle of a pitch-fork, \&c. into the fides and ends, in fix or eight places, lefs or more, according to the heat of the bed. The holes ought to be kept open, by probing them every day, fo long as any fteam remains; and then thould be clofed, to prevent it from cooling too much.

I have feldom found it neceffary to line Afparagus beds; yet fometimes, in ftormy weather, it is requifite. This thould be done with caution; and never more than one fide of the bed fhould be lined at a time. Let the dung for this purpofe be prepared in the fame manner as for the bed, at firft; then cut, with a tharp fpade or dung-knife, the part to be lined, perpendicularly by the fide of the frame : reject the tan and turf, and the reft may be ufed along with the new dung, unlefs very much wafted. From twenty-four to thirty inches will be a fufficient breadth for the lining; raifing it to about fix inches above the bottom of the frame, obferving to tread it 
well towards the old dung, and to give it a confiderable flope on the outfide, which naturally makes it lean that way.

If the lining thould raife too great a heat in the bed, or caufe any fteam, it muft be drawn off, as directed above; and, when it has done fubfiding, let it be turfed in the fame manner the bed was at firft:

Water has not yet been fpoken of; and I can truly, though frivoloufly, affert, that I have frequently produced a whole crop of Afparagus without " either earth or water." This, however, is not always the cafe, nor is it defirable; as; if a little water is not required, the dung muft be in too moift a ftate, and confequently, too much noxious vapour muft have attended the whole procefs. It will be advifable, however, to be fparing in the ufe of that element; as, at this feafon of the year, and in this country, we have but too much caufe to lament the abfence of that luminary which is the very effence of vegetation.

When the buds have advanced to the height of three inches above the furface, they are then fit to be cut, as, by that time, they 
they will be fix inches in length: and this operation mult be performed with great care, as the buds will be found to rife very thick. The tan being of a loofe nature, there is no difficulty in thrufting down the finger and thumb to the crown of the root; and, as forced roots are of no ufe afterwards, I prefer twifting off the bud to cutting it, left the others that are rifing be injured.

A three-light frame (which is generally ten or twelve feet long, and five or fix broad) will contain a number of roots; and, after it is fairly begun to produce, will yield an ordinary dith every day, for fifteen or twenty days. If, therefore, a fucceflion of grafs is required, it will be necelfary to make up a fecond bed about eight or ten days after the firft, and a third about three weeks after the fecond; which laft time will be a good medium for each fucceflive bed: but of this, the operator will be the beft judge; as much depends on the ftrength and quality of the roots, and on the confumpt of the family.

In many places, it is probable, there may not be fuch a thing as old tan: as a fub-

ftitute, 
ftitute, I would recommend light, fandy, mixed with a fourth part of vegetable, mould. Indeed I am convinced, that entire vegetable mould produced from decayed tree leaves, would be the beft for forcing Afparagus in:- but this I do not know from practice; as I have ever found that article too precious an ingredient for more valuable purpofes, to lavinh it on the forcing of Afparagus. But, to wave this confideration, I do not think it is very material in what kind of mould Afparagus be forced, provided it be light enough; as I am convinced, from long obfervation, that the roots draw little nourifhment from the mould, a fmall degree of moifture being all that is neceffary to the production of their buds, after which the roots perifh. My only reafon for ufing old tan was, the fcarcity of light, or vegetable mould, and the plenty of the former (otherwife almoft ufelefs) article. But this much I can affirm, that, by the ufe of tan, the grafs may be produced five or fix days fooner, in as high perfection, and with a better colour, (provided it be ufed perfectly dry,) than with mould of any kind. 
I come now to the forcing of Afparagus in flued pits; which, in my opinion, is the moft eligible method. I would not wifh to infer from this, that any gentleman ought to be at the expence of erecting a pit folely for the forcing of this article. A pit, fuch as is reprefented by Fig. r. Plate I. will completely anfwer this, and many other purpofes : and the trifling confumpt of fuel, even where that article is moft valuable, fhould not deter any, who are lovers of gardening, have fine gardens and hothoufes, and require Afparagus, French beans, fallads, \&c. at an early feáfon, from building fo ufeful a compartment in the forcing garden. Farther, if a fcrupulous attention is paid to the defign in general, particularly to the conftruction of the fireplace and flues, I can with confidence prefume, that it will give more fatisfaction to the gardener than any hot-bed whatever, and in the end will be found a faving to the proprietor *.

$\mathrm{B} 2$

The

* In the confruction of this pit, as will be feen by the plate, the firft courfe of the flue runs along the front, the bottom of which is about the ground-level; and, as 
The pit (fee the plan) is about four feet in the back, and three in front, deeper than the bottom of the flues: which great depth is made on the prefumption that it may be frequently ufed in raifing of pineapple plants; but, were it intended for Afparagus alone, half this depth would be fufficient.

It is immaterial whether the pit be entirely filled with tan or not: I have frequently ufed three-fourths ftable-dung, prepared in the fame manner as for a hot-bed, with equal fuccefs : but have always found that the dung is more difficult to manage than the tan, being liable to heat violently : befides, from the nature of the building,

the outer wall of the flue is only a brick on bed, it is obvious, that early celery, carrots, lettuce, radifh, cauliflower, \&c. \&c. fown on a well-prepared border about two feet broad, immediately adjoining the breaft of the pit, would reap infinite advantage from the flue. At the time of any operation within the pit, a broad plank, fupported by bricks, \&c. would defend the crop on the border from injury. This hint is not from fpeculation; I have practifed it for many years; and would ferioully advife every gardener to do fo on all occafions, where it will anfwer. I have always found the plants fo raifed, to be preferable to thofe raifed on hot-beds. 
ing, there is no poffibility of drawing off the rank heat, as in a hot-bed: for which reafon, if dung alone is to be ufed, it ought to be more carefully fermented.

A fmall degree of bottom heat is fufficient for the purpofe; and, if the pit has been previouny employed in the culture of young pines, it will require no preparation whatever for the reception of the Afparagus roots, excepting to level and put a few inches of well-reduced $\tan$ on the furface. But, if melons were the laft article produced in the pit, it will be neceffary to trench the bed about two feet deep, and add a little new tan or dung; then level the furface with old rotten tan, as before. In either cafe, let the furface be levelled in a floping manner, to the fun, and about fix inches above the bottom of the flues, allowing for the tan fettling fo much; then let the roots be placed and covered, as directed for the common hot-bed.

If the pit is from twenty to thirty feet long, one half will be fufficient to be filled at a time; and, to keep a conftant fucceffion of grafs, fill the other half with roots

B 3 in 
in fifteen or twenty days, which will begin to produce before the firft is all ufed; after which, once a month or fix weeks, according to the fize of the pit and confumpt of the family, will be fufficient, till grafs be fit for cutting in the open ground.

Make no fires, if the thermometer ftand fo high as from $48^{\circ}$ to $50^{\circ}$; and, if neceffary, cover with mats at night; alfo, admit air freely through the day, if the weather will permit. When it is neceffary to make fires, let it be done with caution: A fmall fire made in the evening will generally ferve the whole night; and it will be unneceflary to make any fires in the morning, unlefs the weather be ftormy. I have fometimes, however, found it convenient to make a fmall fire in the morning, that I might have it in my power to admit air, and at the fame time keep up a proper degree of heat.

Water will be required in a more plentiful degree than has been recommended for the hot-bed, as the fire heat will abforb the moifture confiderably. Let a due obfervation of the ftate of the tan, the health of 
the buds, and the difcretion of the gardener, always determine this matter.

In filling the firft end of the pit a jecond time with frefh roots, it will be unneceffary to ftir up the tan, \&cc. and perhaps may be fo, even the third filling; but, by keeping a thermometer plunged in the bed, or watch-fticks, this matter may be determined. At all events, there will not be a neceflity of adding frem materials. I have generally found, that trenching the bed to the depth of two feet, or fo, has anfwered the purpofe for the whole feafon.

If dung alone, or oak-leaves are ufed, let the bed be turfed; and at leaft a foot of very rotten tan or light mould be laid on, before the roots are placed.-This precaution is unneceffary when tan only is ufed; in which cafe, however, not more than an eighth part of new tan fhould be trenched in. 


\section{CHAPTER II.}

\section{CUCUMBERS.}

7 HIS fruit is in fuch eftimation, partiL cularly about London, that the early production of it has become an object of contention amongft gardeners; which has given rife to many experiments for the attainment of their object, viz. to have cucumbers on the table in the months of January and February.

Various are the methods that have been practifed in other parts of the country, for attainment of this matter; and a few have been fuccersful, in one or two inftances: but, the trouble and expence attending the operation, has generally been found inadequate to the fatisfaction of the purfuers of this truly trivial object.

The objections to the old-faßioned method of forcing Cucumbers and melons on hot-beds compofed entirely of dung, are, 
that the plants are apt to be burnt with too violent a heat, and blanched with the rank fteam wherewith thefe beds abound.Thefe objections, I confers, are weighty; and, I believe, but too well-founded in general. But, I have the happinefs to fay, that I have forced Cucumbers and melons many years, and, twice excepted, have never had my plants injured in the fmallent degree by too violent a heat, or too rank a fteam; and, if my mode of practice, which I thall endeavour to explain below, is followed, I prefume it will be found to be the leaft perplexing, the leaft expenfive, and perhaps the molt productive, of any yet laid before the public.

It is a fubject of regret*, that Mr MacPhial's method has failed of the defired fuccefs. Neverthelers, I believe not many gardeners regret it much; for. (the object of trouble afide) it evidently tends to empoverifh the kitchen-garden, by depriving it, in a great meafure, of its common and neceflary refource for manure.

Trials have been made to force thefe fruits on the old beds of the former year,

by

- For himfelf. 
by the aid of new linings. This has alfo failed of fuccefs; as it hath been found, that the old dung contains a more noxious damp than the new; and the frequent lofs of heat in the linings occafions a conftant perplexity. The fame caufe, too rank a heat and fteam, gave rife to the trial of this method as the former.

Late crops of Cucumbers and melons may be raifed with fuccefs in flued pits, (I fpeak experimentally); but I have ever found that early ones may be much better produced on a dung hot-bed. The caufe is obvioufly, that thefe plants delight in a mild, moift heat, and are impatient in a dry, fire heat. The latter, however, is of infinite fervice late in the Autumn, by drying off the external damp, and haftening the maturity of the late fruit.

Where tanner's bark is plenty, and the more valuable material, dung, is fcarce; thefe fruits may be fuccefsfully produced by compofing the bed of bark, with as much dung or litter as will fuffice to build the outfides; or by building retaining' walls, 
of brick, ftone, turf, \&c. and fitting the frame thereto: but care ought to be taken, that the roots of the plants, at no ftage of their growth, touch the bark, which never fails to canker them.

It is a practice with many to fink their hot-beds, or at leaft partly; and this is generally done with too little difcrimination. I am far from difapproving the practice, provided it can be done with propriety, as, by doing fo, a degree of neatnefs is given to that department of the garden: but this ought to be a fecondary confideration; for, if the fituation is naturally damp, and if care is not taken to render it perfectly dry, difappointments will doubtlefs attend the labours of the gardener.

It is cuftomary to prepare feed-beds for Cucumbers about the middle of December, or firft of January. The latter time I prefer, but moft of all, the firft of February; as I have often myfelf been, and frequently have feen others, put to more trouble and perplexity with a feed-bed at that early feafon, than with the reft of the framing for the whole feafon afterwards, and all to 
no purpofe : for experience thows, that plants.* fown about the firft of February will fucceed better, and produce fruit fooner, than thofe fown at any period preceding.

Some raife feedling Cucumbers and melons in pine ftoves, dry ftoves, early-forcing houfes, \&c. and tranfplant them into dung hot-beds. But, it muft be confeffed, they are not equal to thofe raifed in a feedbed prepared for the purpole; as in the one they are but a fecondary object, whereas in the other, they are the principal: befides, there is a great difparity of climate.

Cucumbers are often fuccefsfully produced in boxes, placed in the pine ftove, \&c. at an early feafon: but, as the heat of the ftove is not regulated for their fakes, it may be unneceffary to fay more on that head, than that they thould be placed in the moft airy fituation, fhould be filled with rich light comport, and be duly refrethed with water.

Having

* I wifh to be underfood as fpeaking generally; there may be many exceptions.: I alfo mean plants of the fame fort. 
Having premifed this much, I proceed to treat on the culture of the Cucumber on a dung hot-bed, fuppofing the plants being (or rather to be) fown the Ift of February.

On, or about the 2 oth of January, let a fufficient quantity of the very beft mixed ftable-dung be thrown together in a heap to fweeten; let it lie for five or fix days, and then turn it over, and fhake it well up in a fecond heap: in this condition, it may remain till the If of February, when it will be ready for building into a bed; which I Thall fuppofe is for a one-light box of any convenient fize.

If the dung is littery, dry, and fiery, it will be advifable to pour on a quantity of water, in the procefs of thaking up, or turning it. This will excite its fermentation, and reduce it fooner into a proper ftate; on which depends much of the future fuccefs.

Proceed to build the bed; obferving to keep it a foot larger than the box all round, and to the height of five feet in the back, and four in the front; obferving to beat it well with the fork; and, if the dung is 
very littery, to tread it equally once or twice.

Some tread in all cafes, and others tread none in any cafe; but the propriety of treading the bed once or twice in the time of building, provided the dung be rank and littery, may not be difputed; as, by treading, it is feen where the bed is lean, or otherwife. And that the whole fettle equally, is of confequence to the welfare of the plants, particularly in the ridging-bed; for, if the dung fall in holes, the mould will unavoidably crack, to the evident injury of the tender roots.

When at the proper height, let it be carefully turfed in the fame manner as directed for the afparagus bed: place on the frame; in which lay fea or pit fand of the fineft quality, previounly rendered perfectly dry, in a floping manner, correfponding with the ligbt, and to within fix inches of it : over this lay two inches of light fandy loam: then, in a garden pot or pan, about fix inches in diameter, being filled with entire vegetable mould * from decay ed

* The methôd of prcparing this mould will be treated of in another part of this work. 
ed tree-leaves, fow the feeds, and cover them with half an inch of the fame: Plunge the pot or pan to the brim, in the centre of the bed the one way, and at a foot from the back, the other: Put on the light; and cover at night with a double mat.

The feeds fhould be carefully guarded from mice, an animal too frequently found about hot-beds at this early feafon, by placing a pot on that in which the feeds were fown, whofe brim or margin coincides with it, having a hole at bottom, too fmall for admitting the enemy. This cover fhould be removed in the morning, and replaced in the evening, until the feeds germinate, and the plants are an inch high. Thefe vermin commit their depredations chiefly in the night; and it is neceffary that the plants enjoy the full fun.

The bed will begin to heat in twentyfour hours, and muft then have a little air admitted by tilting the back of the light an inch or fo; and the front half as much*,

* This rule ought always to be obferved, unlefs the feverity of frofty wind renders it hurtful to the plants. 
in order to pafs off any noxious vapour that may have arifen. Let the frame be matted every night at fun-fet, and uncovered by eight in the morning, or fooner, if the ftate of the weather will permit; and, from the moment the plants begin to appear, as due attention ought to be - paid to this article as that of air and water. Every gardener has to lament, that, in this country, and at this feafon of the year, our days are not only thort, but dull and hazy, to a degree that is but little known on the Continent; and it follows, that the leaft neglect in admitting the rays of light, which is fo neceffary to the health and vigour of the plants, is, ftrictly fpeaking, unpardonable. Even the glaffes thould be frequently waihed, wiped, and at all times kept clean of duft or litter, that the rays of light, or the fun-beams, may not be obftructed.

A little kindly fteam in the morning is a good fymptom; but this thould never be encouraged to any great extent: more than what entirely difappears with the firft hour after the frame has been uncovered, is not 
CH:2.]

defirable *. Examine the bottom of the pot or pan frequently. If the heat thould rife too violently, raife it a little, to prevent the young fibres from being fcorched; if neceffary, place it entirely on the furface; and, if requifite, give a little water, which, however, fhould have ftood in the frame, or any other place of equal temperature, for feveral hours before.

It is not a common practice to work by the thermometer in hot-beds, but it is certainly as eligible here as in the ftove, \&c. The air of the feed-bed fhould raife the mercury on Fahrenheit's fcale to $65^{\circ}$ on a medium, allowing $5^{\circ}$ of a fall onife for the changeablenefs of the weather at this feafon. By this, alfo, it will be feen to what extent matting is necefiary.

When the plants have arrived to the height of about an inch, they will be fit to prick out, into nurfing pots, which thould be about four inches in diameter, and the fame

* In treating of the cultivation of afparagus on - a dung hot-bed, I have given directions for drawing off the rank fteam; which I hope will fuffice the reader for that operation, when neceffary, in hot-beds, at any. time. 
fame in depth. Put them into the fame kind of mould they were fown in, and three or four in a pot; placing them as far apart in the pot as poflible. They thould not be dibbled, or preffed into the mould with the finger, a practice too common; but the pot fhould firft be filled one-half, or two-thirds, according to the fize of the plants; which fhould then be placed againt the fide of the pot, fo as that their leaflets may be juft above its margin, and that the covering of (fifted) mould may be laid on loofely, to the level of the brim. Settle the whole with a little water. Plunge them, to the bitim, in the bed again; which fhould previouny be worked over to the depth of the fand, and about two inches of the fame fandy loam thould be laid on the furface, as at firft. Attend to them in the articles of air, fteam, and water, duly, while they remain here, according to the ftate of the weather; and frequently examine the bottom of the pots, left their roots thould be fcorched.

If a rank fteam prevail in the bed, it may be advifable to leave half an inch of tilt in the night, over which the end of the 
the mat fhould hang, that the air may, as it were, fift through it. The lap, however, thould not be let hang fo low as to embrace the lining of the bed, left fteam from without be induced, inftead of that from within efcaping. In the day, admit a moderate quantity of air, at front and back, in order to clear the bed of fteam or damp; taking advantage of fun-fhine, and frequently ftir the furface of the fand, \&c., which in this cafe has a good effect, in purifying the intemal air of the bed. Little water will be required, perhaps only once in three or four days; but at each application, it thould be given in quantity fufficient to reach the extremities of the roots.

If the weather is fevere, it may be found expedient to line one or more fides of the bed. This fhould be feen to in time, that the plants may not experience a check: but proceed with caution in this matter: they are alfo liable to injury by fudden or violent heat.

In the mean time, let dung be in preparation for a one, two, or three light frame, or more, according to the quantity required, in the manner as directed above; and, 
when the plants have each got four rough leaves, let the bed or beds be built for their reception, in the fame way as directed for the feed-bed. If, from the ftate of the dung, there is reafon to dread its heating too violently, let the beds be turfed all over, as before hinted ; but, if it has undergone a proper fermentation, a large round turf being placed in the middle of each light, exactly under where the plants are to be fot, will generally anfwer the purpofe. But, previous to the turf being laid on, in the latter cafe, let the furface of the dung be covered, to the thicknefs of half a foot, with light fand, or well-reduced old tan, which fhould be rendered perfectly dry beforehand.

Put on the frame $*$ and lights, and cover at night with mats, to draw up the heat; which, when it has arrived to a moderate degree, let three wheel-barrow loads of mould + , previounly rendered quite dry,

be

* The frame ought to be thirty inches deep in the back, and, fifteen in front.

+ Three-fourths of the richeft black loam that can be got, (from a pafture, if poflible), and one fourth of vegetable 
be fpread equally over each light-breadth of the bed. In twenty-four hours after, the bed will be fit for the reception of the plants. But, previous to planting, gather up a fufficient quantity of mould, from the furface of the bed, to raife hills, exactly above each turf, or in the middle of each light, to within five or fix inches of the glafs, the depth of fifteen inches, and to the breadth of ten or twelve inches at top: Make a hole in each to receive the ball entire, which mutt be carefully taken out of the pot, and to the level of the furface of the hill; and fettle the whole with a little aired water. At the time of planting, the leaflets of the plants fhould generally be extended to a diameter of about three inches, more or lefs, according to the kind of cucumber, fome growing more robuft than others.

On the prefumption, that the heat, fteam, airing, and watering, thall be regulated according to the directions already giren, the ftate of the weather, and the vigour of the

C 3 plants,

vegetable mould from decayed tree-leaves, mixed well with a competent fhare of ftable-dung, is what I bave ufed for years with much fuccefs. 
plants, till they begin to fhew fruit; I will fay no more on that head, but fhall return to it after having confidered the article pruning or ftopping. That it is indifpenfably neceflary, as fome pretend, to pick out the heart-bud when the plant hath formed its rough leaves, I can by no means fubfcribe to; for, from the molt minute obfervation, and the faireft trials, which I have repeatedly made, I am convinced it is of no confequence whether the bud is picked out or not: I feldom think of picking or pinching, till the plant begins to put forth runners or vines, nor even (unlefs it happens to put forth too few to furnith its fide of the frame) till I perceive the rudiment of the fruit. It is then time to ftop thofe vines which have fruit fhewn: but the others may be fuffered to 'run to the length of fix or eight joints; and thould then be ftopped, to make them put forth fertile ones, which they will feldom fail of doing, if the plants are healthy.

If an extraordinary quantity of male bloffom thould appear, let a part of it be gently rubbed off with the finger and thumb; 
thumb *; but I do not approve of this being done when an ordinary thew of thefe bloffoms only appears. Nature fhould be kindly affifted; but neither furred nor thwarted, where it can be avoided. When the female bloffoms are fufficiently advanced, let them be carefilly impregnated with the ftrongeft and moft healthy of the males, which will greatly promote the fwelling of the fruit. And let it be here obferved, that, if the fruit or female bloom is not impregnated with the male, it will not ripen its feed, although the fruit may fwell to a good fize, and be very fit for the table: and although it often happens that the farina of the male is carried, by infects, \&c. and the wind pafling through the frame, to the object of its deftination, yet it is a more certain way to be at the trifling trouble of doing it with the hand; as handfomely fet fruit can be marked for feed with a greater degree of certainty,

$$
\text { C } 4
$$

and

* I would here obferve, that the knife ought never to be employed in the pruning of Cucumbers and melons, unlefs in cutting out any ftrong, old vines; and as nothing is more brittle than the leaves of thefe plants, when in a healthy ftate, they ought to be handled at all times with the greateft care and delicacy. 
and thofe which are impregnated will fwell, and be fit to cut much fooner. The method of performing it is this : Choofe a ftrong healthy-looking male flower; pinch it off with the ftalk; divent it of the corolla or flower-leaves, carefully retaining the ftamens and anthers; taking it between the finger and thumb, apply the anthers to the bofom of the female flower, which is dittinguithable by the newly-formed fruit; and give the ftalk a fharp twirl, whereby - the farina of the male will be rubbed off, and depofited on the ftigma, the female organ of fructification.

If no accident hath happened the plants, they will have made good progrefs before the bed has, in any great degree, loft its heat; and indeed, generally a few of the firft fet fruit are cut by that time*; which, fuppofing the bed was built about the middle of February, and the plants were planted about the 23 d or 24 th, thould be fit for cutting

* This depends much on the kind of Cucumber fown; and, as the kinds are now fo nunflerous, and alnoft every gardener having his particular favourite, it might be deemed prefumptuous in me to fay which ought to be preferred, efpecially as many known kinds have an equal title. 
cutting by the middle or latter end of March, if the weather has been tolerably favourable.

If the heat has by this time confiderably decreafed, let preparations be made for lining the back and both ends, by nightly fermenting a quantity of frefh ftable-dung, and mixing it, in the operation, with the old fide and ends of the bed; which let be cut off, in the manner as directed for the afparagus bed (See page I 5.), and let it be made up as it fubfides: after which, cover it with turf or mould. The frame muft be raifed with bricks or tiles occafionally, as the plants advance in ftrength; fo as to keep the glafs free of the foliage.

By this time, alfo, the hills will require to be enlarged; as the roots will have made great progrefs. Therefore, let the furface of the bed be forked up with a fmall handfork, fuch as is ufed for plunging pine-pots, \&c., to the depth of the furface of the fand or tan; and, if any of it has been burnt, (which I have but twice experienced in any hurtful degree), let it be replaced with frefh mould: Work gently into the fides of the hills with the fork, till the roots be- 
gin to appear, and, if needful, pour in a little water; after which, let the furface be levelled up to the height of the hills, with frefh mould of the fame quality as at firf *. This operation, however, fhould either be done a few days before the application of the linings, or fhould be deferred till a few days after; that the plants may not experience a check, by the bed being cooled both without and within at the fame time.

The plants will now grow vigoroufly, and produce fruit in abundance : and muft forthwith have a large thare of frefh air admitted every day, increafing the quantity as the feafon advances; and, when the month of May arrives, in fine, mild weather, the glaffes may be entirely taken off in the day. Let them have large and frequent quantities of water given from the rofe

* I have here directed the bed to be earthed entirely up at once; which, if the forcing is not begun fooner than recommended above, will be found quite fufficient : but, if the forcing were begun a month or fix weeks earlier, it would be imprudent to earth up the bed entirely at once, as a ftronger bed and more linings would be required; and, confequently, the rifk of burning the roots would be greater. 
rofe of a watering pan; taking the advantage of warm fhowers as the feafon advances. Few plants require more of this element than the Cucumber; and if it is withheld, the plants will, to the nice obferver, quickly complain.

The moft proper time for the application of water, is either in the morning about eight, or in the evening about four o'clock, an hour fooner or latter, according to the feafon of the year. The water, if poffible, fhould always be of equal temperature with the air in which the plants grow; in which cafe, no check is felt, or unneceffary effort made by the tender fibrils, the purveyors of the plant. Nor fhould an extraordinary quantity be applied at a time, for the fame reafons.

Keep them moderately thin of vines and leaves; taking care to lay them all out in regular order, and not to have them croffing one another. Be alfo careful to diveft them of all withered and damped leaves, as they appear. It is as obnoxious for a plant as an animal, to breathe the air wherein its own corruption is confined. Neither fhould the Cucumber be pruned musb at a time, 


\section{4}

time, otherwife, by the wounds bleeding, the plant will be greatly exhaufted.

About the beginning or middle of April, it may be neceffary to line the front of the bed, which let be done in the fame manner as the back and ends; but it will be quite

- unneceffary to renew thefe, as that of the front will throw in a kindly heat, which will laft all that month, and afterwards bottom heat is of little confequence.

Succeffional beds for Cucumbers may be built in March, and in April. The fame culture, as above, is to be practifed; obferving to make the beds a little lighter, as the feafon advances.

As. I am to treat of the raifing of melons in flued pits, when the culture of that plant is treated of, and as the culture of the two plants there are fo nearly fimilar; I thall only obferve here, that the fame mould mutt be ufed for the Cucumbers as is recommended above, and a greater portion of air and water muft be given, than to the melons.

The culture of Cucumbers under hand and bell glaffes, although a fpecies of forcing, 
cing, being fo generally underftood, and infufceptible of improvement; it may be unneceflary to wafte time in faying more on that head, than that they fhould be planted in mould of the fame quality as above directed, thould have plenty of water given them in hot weather, and, as much as poffible, thould be defended from cold and damp in Autumn.

I Thall conclude this article, by obferving, that I have feldom known any infect to infeit the Cucumber, except the aphis, which, in any ftate or fituation, is quickly deftroyed by the fumigation of tobacco; a procefs that is familiar to almoft every gardener. 
CHAPTER IH.

CHERRIES.

\section{SECTION I.}

\section{On the Confruction of the Cherry-Houfe.}

$7 \mathrm{HE}$ production of this juftly-efteemed 1. fruit, at an early feafon, has much obtained of late years; infomuch, that many of our capital gardens are furnithed with a compartment for the purpofe. Thefe

$\therefore$ are of various conftructions; occafioned fometimes by the fancy of the confructors, the fubferviency to other purpofes, and the converting of places that were originally erected for the production of other fruits or plants, to that of the Cherry: in all which, where properly managed, it has given general fatisfaction. Confequently, it might be thought ambiguous in me to fay, that a Cherry-houfe fhould be of fuch and fuch a conftruction; nor do I wifh to advance fuch a propofition. But, where it is in contemplation to erect one, I would recommend fuch as is reprefented by Fig. I.

Plate 
Plate II., which, befides being perfectly adapted to the forcing of Cherries, is alfo to that of ftrawberries, kidney-beans, flowers, \&c.

The fire (See the plan) communicates firft with the front flue, and then has two returns in the back-wall; which returns are made on the prefumption that the houfe may be converted into a vine or peachhoufe at pleafure: but, while it is appropriated to the forcing of Cherries, it will be improper to ufe any but the front flue; and of confequence, the back flues muft be fhut by a damper. My reafons for which are, that a fmall degree of fire heat only is requifite, even at an early feafon; and, the Cherry being fo fubject to be injured by the red fpider, the working of the back flues would greatly encourage the breeding of that deftructive infect.

\section{SECTION II.}

On Preparing the Border, and Planting the Trees.

F the fituation is dry, the bottom a kindIl ly fand, gravel, or foft clay, and the foil a fandy loam to the depth of two feet; the 
the border will require no other preparation than being well enriched with ftabledung, and if poffible, a little marl; which ought to be trenched and well mixed, twice or thrice during the Summer before planting.

But, if the fituation is wet, the bottom a cankering gravel or cold clay, and the foil either a poor fand, gravel, or ftubborn clay; care mult be taken to render them otherwife, by paving the border to the breadth of twelve or fourteen feet, running a drain in front to carry off the wet, and removing the bad, and bringing in good foil; fo as to compofe a rich fandy loam to the depth of thirty inches at the wall, and twenty-four in front, allowing three or four inches for fettling. If a new building is erecting for Cherries, it is immaterial whether the building or border is completed firft, provided the latter has a fufficient time allowed for the mixing and incorporation of the foil; as the front-wall and flue ftand on pillars, whofe foundations ought to be at leaft fix inches deeper, if the border is not paved, than the foil. 
About the Ift of January is a good time to plant; although a month fooner or later at this feafon is of little confequence, as no fire heat mult be applied the firft year. Having provided the neceffary number of healthy, well-rooted, maiden, or one-yeartrained May-dukes*; let them be planted againft the trellis at the diftance of eight, nine, or ten feet, as the length of the houfe will beft divide; filling in the pits with vegetable mould from decayed tree-leaves, and fettling all with a little water. Riders, having five or fix feet boles, which have been trained two or three years againft a wall, and have produced a crop or two, thould be provided to fill the upper part of the trellis; where they will produce a few crops before the dwarfs will have extended, fo as to require their removal. Thefe will generally produce a few fruit the firf, and probably will yield a full crop the fecond year.

Let the furface of the border be forked over once or twice a-year; and let a little well-rotten dung occafionally be

* Experience fhews that no other Cherry deferves a place in a forcing houfe. 
worked in. This may be performed in any of the winter months.

SECTION III.

On Training the Dwarfs.

7 HE dwarfs or principals being the only plants intended ultimately to fill the trellis, I thall difcufs what relates to training the riders by obferving, that, as thefe are planted folely for the purpofe of obtaining a crop or two, while tbofe are making their wood and forming their fruit fpurs, and, by being checked by their removal, may not be expected to put forth much young wood while they remain here, it will be unneceffary to thin them out much; but let them be dreffed regularly to the trellis, and, unlefs neceffary to fill a blank, diveft them of any fhoots they make; paying refpect to their fruit fpurs only; for when they have ferved the purpofe here, they will be of no further ufe.

After planting, let each fhoot of the dwarfs, if maiden trees, be headed down to two or three eyes; in order to make them 
put forth vigorous fhoots, to furnilh the trellis, from the bottom : and, if they have been one year in training, let the bottom branches be laid well down, and let the reft be dreffed in a regular manner to the trellis, ufing ftrings of freth matting to tie with; being careful to allow full room * in the ties, as much mifchief is done to fruit, efpecially Cherry-trees, which are fo apt to gum, if not allowed a fufficiency of room.

The Cherry-tree being apt to gum, and the branches to decay, from the flighteft injury, it would be imprudent to train it horizontally; in which cafe, the lofs of a branch is fupplied with much more difficulty, than when trained in the fan manner: this laft method I would therefore recommend.

When the tree hath produced its fhoots to the length of five or fix inches, let them be gone over and thinned, fo as that they may be laid in at about the diftance of ten or twelve inches; obferving to pinch off

$$
\mathrm{D} 2
$$

fuch

* I make it a rule to allow every fhoot as much room in the thred, or tie, as will at leaft admit another of the fame fize along with it. 
fuch as are produced fore-right, and which are, from their appearance, not forming for fruit fpurs: and, as they advance, let them be regularly difpofed, and divefted of any laterals they may produce. If all has gone well, at the end of the firft year they will have produced fhoots from twelve to thirty inches long; which fhould then be thortened down to about two-thirds of their length. This is neceflàry, in order to make them fhoot ftrongly, and that the trellis may be furnifhed from the bottom, in a regular manner.

The fecond feafon, they will thoot vigoroufly, and will begin to form many fruit fpurs on the preceding year's wood; which mutt be encouraged, for the production of a few fruit next feafon. Keep the tree clear of all fuperfluous and lateral thoots; and lay in the leading ones at the diftance of eight or nine inches, which forthwith muft be confidered as the medium : and, at the end of the feafon, fhorten a few of the ftrongeft branches alternately, fo as to make them break their buds in the fpring, in a regular manner; as, henceforth, they will not require to be fhortened. 
The third feafon, they will produce a few fruit, make fine fpurs and moderate fhoots; which, as they advance towards the riders, give place to, by lopping off their branches, or thinning away their foliage, fo as to afford a free circulation of air and admiffion of fun.

The fourth feafon, they will produce a full crop of fruit; and will poflibly make fuch progrefs towards the riders, that thefe muft be difpenfed with : in which cafe, it will be advifable to facrifice whatever fruit, or appearance thereof, there may be on them, to the encouragement of the principals.

After the trees have filled their fpaces, and have begun to bear plentiful crops of fruit, they will make little or no wood; and will require no further care, on the fcore of training, than to fupply the place of any branch that by accident may die out. 


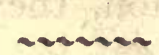

SECTION IV.

On the Temperature of the Cherry Houfe.

THE Cherry, from its nature, will bear

是 very little artificial (efpecially fire) heat. For which reafon, I would not advife the forcing of it too early, efpecially if there is only one compartment for its. culture; fince, in that cafe, there would not be a continued fucceflion for the fupply of a table, and furnifhing a defert, till they came in on the open walls. I confider the firft or middle of February to be an eligible time for the commencement of the forcing; but, for a new planted houfe, the third year ought to arrive before fire heat is applied. Were it not for the fake of other articles that may be placed or planted in the Cherry houfe, it would be better that the glaffes were not put on the firft feafon at all; but this is generally too great a facrifice: however, if they are put on, a free circulation of frefh air, even in the night, ought to be encouraged. 
Suppofe then, that, the third year after. planting, the trees have made good progrefs, plenty of fruit fpurs, and that a reafonable hope of fuccefs is entertained; let the glaffes be put on about the middle of January, plenty of air admitted through the day, and fhut up at night. On the firft of February, light the fire; which muft be made fo moderate, that at eight at night, and eight in the morning, Fahrenheit's thermometer may not ftand above $40^{\circ}$. In which condition keep it, as nearly as poffible, till about the 20 th of the month; and then increafe gradually to $45^{\circ}$ : at which point endeavour to keep it, till the fruit is fairly fet. Afterwards increafe the heat to $50^{\circ}$, but not more, till the ftoning is over, and the fruit have begun their fecond fwelling.

Although, for the fake of the fruit, all danger will now be paft; yet, if too ftrong a fire heat be afterwards indulged in, it will have the tendency of drawing the fhoots up too weak; and, therefore, I would not advife that the air of the houfe, at the fore-mentioned hours, fhould ever pafs $60^{\circ}$.

$\mathrm{D}_{4}$ \& SEC- 


\section{SECTION V.}

On the Admifion of Air to the Cherry Houfe.

A $\mathrm{S}$ has been already hinted, the houfe A1 ought to be uncovered all the firft feafon after planting: but, if this is not the cafe, and if, from the nature of what other plants are placed therein, it would be imprudent to leave a little air in the night; let the houfe be opened by fun-rife in the morning, have a large and free circulation all day, and be fhut up at fun-fet. However, when the month of May arrives, it ought to be entirely uncovered.

The fecond feafon, let the glaffes be put on by the firft of. March; let large portions of air be admitted, as directed above; and let the glafles be removed by the firft of Auguft.

From the commencement of the forcing, this article muft be attended to more particularly :-The firft ten days after which, a very large thare of air hould be given, to prevent the buds from breaking too fuddenly, and of confequence too weakly: 
for, vegetation, in forcing, ought always to be brought on, as it were, by ftealth : the juices flow more kindly; and the plant fuffers the firft impulfe of reviving activity with more patience, than when hurried on in a violent manner. But, after the buds begin to appear turgid, a more moderate quantity may be admitted; ftill having refpect to the temperature of the houfe, and the prevention of frofty winds from hurting the bloom. At all events, take advantage of fun-fhine; which will allow a larger portion to be given, than at other times. Neverthelefs, let no day pafs, (unlefs in a fevere froft), wherein lefs or more air is not admitted; and, in fun-thine, to the extent that the thermometer may not rife more than to degrees above the fireheat medium.

After the crop is all gathered, if confiftent with the welfare of the other articles contained in the houfe, let the glaffes be removed, and the trees be expofed to the weather till the next feafon. 


\section{nome \\ SECTION VI.}

On Watering, Waßsing, and Steaming the Cherry Houfe.

A FTER planting, let the mould be fetL tled to the roots of the plants by a moderate watering; and, if the houfe remain uncovered the firft feafon, little attention, except in dry weather, will be required in this article. Let due attention, however, be paid the fecond year, to keep the border in a moderately moift ftate, that the plants may grow freely; and, when their growth is ftopt for the feafon, withhold the water, that the wood may ripen perfectly before they are expored to the weather.

From the commencement of the forcing, give plentiful waterings to the border, until the bloom begins to open; and then in a more moderate degree, till the fruit is fairly fet. After which, again increafe the quantity, till the fruit begins to colour; and then diminith it by degrees, till it be entirely withheld, which ought to be 
done fome little time previous to the fruit's being ripe; as otherwife, it would be rendered infipid.

Wathing with the hand-engine, fhould commence with the day the fire is lighted; and, except from the time the bloom begins to appear, till the fruit is fairly fet, fhould be repeated thrice a-week in the evening, and that with a confiderable degree of force, till the fruit begins to ripen. The ufe of the engine here, and indeed in all forcing houfes, is much preferable to the pampered trafh of fteaming apparatus. It is not merely to refrefh the foliage that the engine is employed, but alfo to clear it. of duft, infects, \&c., a matter of evident neceflity; for, the leaves being, as it were, the lungs of the plant, how can we fuppofe it in health while thefe remain clogged? Hence it becomes a duty, in the ufe of this inftrument, to apply it with force: more fo in the hot-houfe than out of doors, for the plain reafon, that here the wind is not equally helping to this effect.

In the interval of warhing, (viz: while in bloom, and till the fruit is fet), let a little water 
water be poured on the flue every evening when the fire is ftrongeft; which will caufe a fine agreeable fteam * to arife in the houfe, greatly to the benefit of the flowers and foliage: For at this time, water from the engine cannot, with pro. priety, be applied, left the tender bloffoms might be injured.

Soft and tempered water fhould be ufed at all times, and on all occafions.

\section{SECTION VII.}

On the Infects that infel the Cherry Houfe, and how to deftroy them.

7 HESE are, the aphis, or green fly; the 每 acarus, or red fpider; the caterpillar;

* I do not confider the Cherry houfe of fuch importance as to be at the expence of erecting fteaming apparatus purpofely for its ufe; nor, indeed, do I think it worth the while to do fo for the ufe of any kind of forcing, except a range of peach houfes: in the near neighbourhood of which were it placed, a pipe might (if at a fmall expence) be borrowed for its uie. But, at all events, I prefer fteam which is produced from an earthen flue, to that produced from boiling water. 
pillar; and the grub*. The firft, and leaft hurtful, is eafily deftroyed by a fumigation of tobacco. The fecond, may be fuppreffed by the procefs of wathing with the engine, which is indifpenfably neceffary to the health and vigour of the trees. Therefore, when they begin to make their appearance at any time, let the water, in the ordinary courfe of wahing, be thrown againft the trees with greater force; making a point of beginning at the contrary end of the houfe each time; whereby, if any part thall be miffed the one way, it may be hit the other.

The caterpillar and grub, have given me more trouble than the preceding, or indeed any fpecies of infect whatever; and, after trying a variety of prefcriptions, and having been at much trouble and expence, I can venture to affure the reader, that I have at laft difcovered a cure : the receipt of which I

fhall

* Not the land-grub:- a fmall greenith-black worm, of the caterpillar kind, with a black head, about threeeights, or half an inch in length, often called " the "grub" by gardeners. It' is generally found rolled up in a kind of down or wool, in the leaves of cherries, apricots, \&c. 
thall candidly give; and hope that none - will attempt to ufe it without giving it a fair and impartial trial.

Take of foft foap, two pounds; flowers of fulphur, two pounds; leaf, or roll tobacco, one pound; nux vomica, two ounces; and oil of turpentine, half an Englifh gill : boil them all together in eight Englifh gallons of foft or river water to fix; and fet it afide for ufe.

Any time in winter, at leaft a confiderable time before the trees begin to vegetate, let them be all untied or unnailed from the trellis or wall; brufh every part of the branches and buds clean with a foft brufh, fuch as is ufed for painting: make the liquor milk warm; and, with a punge, carefully anoint every part of the tree, trellis, \&c. Drefs the trees neatly to the trellis again; but ufe none of the old ties or threds: and let this operation be repeated every winter $*$ without referve. The firft fummer after anointing there may at few appear, whofe eggs have, by being concealed, efcaped the action of the liquor, which

* This precaution is neceffary, thefe infects being evi- । dently blown by a fly in Summer. 
which muft be picked off, to prevent their breeding; but, if any, there will very few remain, as it is of the moft penetrating nature.

This liquor muft on no account be ufed in fummer, as it inftantly deftroys the foliage; the fatal effects of which myfelf once experienced, through inadvertency. The moft proper feafon for its application is between the fall of the leaf and the firft of February, for trees growing out of doors; for trees in hot-houfes, a month at leaft before the forcing commences. Fruit-trees of all kinds thould be anointed with this compofition every year; as it is equally deftructive of all infects, anci their eggs, which infeft them : but furely none, who have the health and beauty of the trees contained in their hot-houfes at heart, after being convinced of its efficacy, will be fo neglectful of their own.intereft, as to omit doing it, fince neither the trouble nor expence are great. 


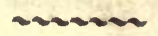

SECTION VIII.

On the Cultivation of Cherries in the Confervatory and Peach Houfe.

CHERRIES are often brought to early perfection in thefe forcing compartments ; by being fometimes planted in pots, fometimes in the borders as low ftandards, and fometimes as rider ftandards : all which methods are attended with various fuccefs, from the circumftance of their being a fecondary object.

Having, in the feven preceding fections, treated methodically of the cultivation of this fruit; it may be unneceffary to enlarge more on it here. I thall therefore pafs over the further confideration of trees planted in the border; and conclude this chapter by dropping a few hints on the utility of cultivating a few dwarfs in pots or boxes.

Where there is an extenfive variety of forcing, and a green houfe, or confervatory, Cherries may not only be produced at an early feafon; but may be continued in 
a long fucceflion, by removing the pots or boxes from one houfe to another. Suppofe there are forty trees provided for this purpofe; let them be divided into four or five equal parts, to make as many fucceffions; and let them be placed in equal rotation: firf, in November or December, in the green-houfe, where let them remain till the fruit are fairly fet; then, in an early peach or vine houfe, till they begin to colour; and, laftly, in the pine or dry ftove, to come to maturity.

Let very rich compoft, fuch as is recommended for cucumbers or melons, be made ufe of ; and water the boxes frequently with the drainings of a dunghill. Wafh or water the plants alfo frequently over head with a hand fquirt or watering pot; and place them in the moft airy fituations, in the confervatory, ftove, \&c.

It may be neceffary to remark, that after plants are inured to this mode of culture, provided due attention is paid to the ftate of their roots, they are, and will continue to be, very prolific of fruit, though dwarfifh, and unproductive of thoots and foliage. Their roots fhould therefore be 
examined each feafon, and, if neceffary, the fpace about them fhould be enlarged, by removing the plants into other pots, boxes, \&c.; ufing frefh, rich mould'; and undoing any matted part about the bottom or edges of the ball, before it is replaced. When the plants are all fhifted, give the roots a moderate watering, and let them be placed in a dry, free expofure in the open air, till again wanted for forçing. 


\section{CHAPTER IV.}

FIGS.

\section{SECTION I. \\ On the Conftruction of the Fig-Houfe.}

HOrcing of this fruit is in pretty ge1 neral practice, particularly in England, but I believe there are few houfes built folely for the purpofe. Figs are moft fiequently forced in other compartments, as peach-houfes, vineries *, \&c. ; but I am of opinion the cherry-houfe ought to be preferred; the foil and climate which fuits the one, nearly agreeing with the nature of the other, in forcing.

However, were a houfe to be erected for the forcing of this fruit alone, I hefitate not to fay, that I am convinced fuch as is reprefented by fig. I. Plate II. would be E 2 found

* Figs may be cultivated with fuccels, in the fame manner as advifed for cherries, Section VIII. of the preceding Chapter. 
found to anfwer the purpole perfectly. In this cafe, the trees are to be planted and trained to the trellis placed againft the back-wall; and a row of dwarfs may alfo be planted in the border, provided it is not to be otherwife occupied.-See Section I. of the preceding Chapter.

\section{SECTION II.}

On preparing the Border, and planting the Trces.

HAT has been faid in Section II.
of the preceding Chapter, refpecting the preparation of the border, will alfo apply here, except that the foil fhould be made fomewhat richer for Figs than for cherries.

Plants which have been a year or two in pots, and which have good roots, are to. be preferred.

The kinds - fitteft for forcing are, The Blue Ifchia, the White Ifchia, the Brown Ifchia, and the Black Genoa.

They may be placed on the trellis, at the diftance of nine or ten feet apart; and in the border, to be kept dwarfifh, at about 
five or fix afunder. The feafon of planting is from the firft of November to the firft of March.

Rider cherries may, with propriety, be planted between thofe on the back-wall; as, efpecially if they have been a year or two in training, a few crops may be expected before it would be necellary to remove them. Fill in the pits with rich, light compoft, and fettle all with a little water.

SECTION IIT.

\section{On Training and Pruning.}

7 HE chief art in training the Fig is,

1 to keep every part of the trellis full of young thoots, the plant naturally running into, naked unfightly branches in the middle. Shoots, however, may be produced with facility, by fbortening: they alfo rife abundantly from the root, round the ftem of the plant. Producing its fruit on the thoots of the preceding year, theie, if well ripened, fiould not be fhortened, but thould be laid in at full length, and at the 
diftance of about twelve or fourteen inches from each other.

When the trees arrive at a bearing ftate, the knife thould be ufed with caution; for the more their branches are lopped, the greater a profufion of thoots will follow in confequence; nor will fuch generally be fruitful, but foft and fpongy. The moft fruitful thoots of the Fig are thort-jointed, round, and of little length in proportion to their thicknefs. But

The reader may fee farther on this fubject in Book II. Chap. I. Sect. IV.

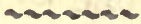 \\ SECTION IV.}

On the Temperature of the Fig-Houfe.

1 HE Fig will bear but a fmall degree
of fire heat; nor thould it be forced much at any period. Keeping this in view, I would not advife that fire be lighted the two firft feafons after planting; but the third year, a gentle fire heat may be kept up in the months of March and April, in order to forward the wood for forcing the fourth. At this time, Fahrenheit's ther- 
mometer fhould not ftand, at eight at night, and feven or eight in the morning, above $50^{\circ}$.

The fourth feafon, provided the plants have fucceeded tolerably well, they may be forced from the firft or middle of $\mathrm{Fe}$ bruary. If the houfe has been uncovered for the winter, or if the glaffes have been kept on, let it be fhut up at night, encouraging a free circulation of air in the day, from the middle of January: Make the fires fo moderate for the firft fortnight, that the thermometer may not ftand above 45 at the above-mentioned hours. In the courfe of the fecond fortnight, increafe the heat to $55^{\circ}$ in a gradual manner; and in the courfe of ten more days, to $60^{\circ}$, at which continue for the feafon, with as little variation as pollible.

The following, or fifth feafon, the houfe may be forced from the middle of January; but earlier than this I cannot approve. The rules above are to be followed the more fcrupulouly that the plants are forced early. 
On the Admifion of Air to the Fig-Houfe.

7 HE three firft feafons, large portions of 1 air fhould be admitted every day; varying the quantity, however, according to the ftate of the weather, and the ftate of growth the plants may be in; for fud'den checks are hurtful to this plant, as to others, although their bad effects may not be fo immediately perceptible.

In the fourth and fifth feafons from the commencement of the forcing, and for the firft month or fix weeks, admit air in fuch quantity in the day, that the thermometer may not rife to more than five degrees above the fire-heat medium. As the feafort advances, air may be more freely admitted. Let this be done in a liberal manner, and to the extent that the mercury, at no time, may rife to more than $10^{\circ}$ above the forementioned medium.

From the middle of May, or the firft of June, the houfe may ftand open night and day, in moderate weather. But the glafles 
fhould not be entirely removed till the crop is ripened off; becaufe, by keeping them on, the flavour of the fruit may be confiderably enhanced. The thoots may be better ripened, and the fruit, for the fucceeding year's crop, may be better fet and forwarded by retaining the glafles for a while, than by removing them too foon.

\section{SECTION VI.}

On Watering and Steaming the Fig-Houfe.

T $\mathrm{HE}$ border hould be kept moderately I moint at all times, except when the fruit is ripening off, when it thould be kept rather in a dry ftate. This is neceffary, becaufe, otherwife, the fruit would be apt to drop; nor would it be well flavoured, but infipid. After the fruit are gathered, however, the border fhould again be brought to a proper ftate, by the application of a few hearty waterings.

Let the foliage be duly refrefhed, twice or thrice a-week, by the hand-engine; which thould be applied with fome degree of force, in order to keep the leaves clear 
of duft, \&c. As the fruit approaches to maturity, this may be withheld in a great meafure, and unlefs the plants are afflicted with the red fpider*, entirely, till the fruit is gathered.

Steaming can be little neceffary to the welfare of the Fig, fince the engine may be worked at all times. The fear of hurting the bloom, unlefs the watering be performed in a very wanton manner, cannot poffibly attach here, as in the cherry, grape, or peach houfe: And this is a circumftance fo far happy, as the temperature of the fig-houfe is fuch, as feldom to admit of the flue being heated enough to excite fteam in any great quantity.

\section{H A P-}

* I have not known any other infect materially to afflict the Fig in the hot houfe. Wafps, however, are fond of the fruit. 
CH. 5.]

GRAPES.

\section{CHAPTER V.}

\section{GRAPES.}

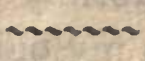

SECTION I.

On the Confruciion of the Grape-Houfe.

THIS delicious and juftly-efteemed fruit 1 is now cultivated with fuch general eagernefs in this country, that a garden 95 unprovided with one or more compartments for its production is not only reckoned incomplete, but hardly to be met with*. Thefe vary exceedingly in conftruction; and, although fome lay great ftrefs on this article, and there are extremes which ought not to be followed, yet $I$ am convinced the failure of fuccef's, in the production of the Grape, is much lefs a confequence of bad conftruction in the houfe, than in the preparation of the border,

* I would here be underftood as fpeaking of noblemen's or gentlemen's gardens in general, although there are alfo fome Grape-houfes found in market gardens. 
76 THE FORCING GARDENER. [B. Io border, the choice of the kinds, and the general management. I have formerly had the conftruction of three feveral and differently-conftructed Grape-houfes in the fame garden*, under my care, for years, which then uniformly produced excellent crops. This, in my opinion, is a proof of the neceflity of a greater nicenefs in the formation of the border being obferved, than in the conftruction of the houfe; the fire-place and flues excepted.

A perfect command of fire heat is abfolutely neceffary in the Grape-houfe; to effect which, proper attention fhould be paid to the conftruction of the fire-place and flues.

Fig. I. Plate V. reprefents a furnace, and the entrance to the flue, on a plan that has given the higheft fatisfaction for many years: and although I thould be forry to advife unneceffary alterations in houfes already built, yet I could wifh to fee all hot-houfe furnaces conftructed on the fame plan; from a conviction of the utility, not only in faving fuel, but in enabling the operator to work with a degree

* Wemyfs Caftle: 
of exactnefs, and to enjoy a lefs difturbed repofe in winter nights, than is generally done.

Fig. I. and 2. Plate III. reprefent two different plans of Grape-houfes; which, if minutely copied, it is prefumed, will not fail of giving fatisfaction. Any alteration in the breadth and height, I would beg to caution againf; but the length may be extended or leffened at pleafure, provided refpect is paid to the proportion of fire heat here allowed.

\section{SECTION II.}

On the Situation and Preparation of the Border.

THE fite of the Grape-houfe is an ob-

1 ject of fuch confequence to the welfare of the plant, and fuccersful cultivation and production of well-flavoured fruit, that the greateft care is neceffary in the choice of it; and, where the fituation is not naturally good, the fparing expence, in rendering it fo, is the caufe of many difappointments. I fhall, therefore, point put what I efteem a good fituation, and the 


\section{$7^{8}$}

method of rendering a bad one comfortable.

A gentle hill, having a fouth afpect *, and confiderable declivity that way, the foil a ftrong brown loam of two feet, over a bottom of dry fand, gravel, or foft clay; is the moft defirable, and in forming the border, would be the leaft expenfive of all fituations. In which cafe, the fite would require no paving or draining; and would atdmit of a proper mixture of fandy loam, vegetable mould, marl, and dung, (by the removal of two feet of the natural bottom), with the natural foil, to form a border, perfectly adapted to the growth of the vine, in the following proportion, viz. One half ftrong brown loam, a quarter light fandy loam, an eighth vegetable mould of decayed tree-leaves, and an eighth ftabledung; to which add about a fiftieth part of thell-marl. Such was the compofition of the vine borders at Wemyfs Caftle; none of which were formed lefs than four feet deep, and one (owing to the accidental fituation of the houfe) was fix.

Neverthelefs,

* All hot-houfes fhould face the meridian fun, if conveniency will by any means permit; but a fmall variation to the eaft or weft, is not attended with any injufious confequence. 
Neverthelefs, I would not wifh to infer, that of the above mixture only, vine borders thould be made. Every candid gardener will difcriminate here, and choofe the compofition he thinks moft fuitable to the nature of the plant in queftion. But I would remark, that I have never known any to err, by forming vine borders too deep, or of too rich materials. :

The nature of the plant, is to purh its roots downwards, and extend them widely; confequently, our duty is to cherifh, and not to thwart, its inclinations. We perhaps do them a violence, even by our greateft care and attention, in this mode of culture; fince we impofe-on them a foil, climate, and an air, altogether artificial.

The breadth of the border for a houfe, as reprefented by fig. I. Plate III. thould be all the width of the houfe within, and at leaft ten feet without; and for fuch a one as is reprefented by fig. 2 . Thould be to the extent of twelve or fourteen feet be: yond the front-wall.

Having thewn the compofition, breadth, and depth, the borders fhould be of, in a good fituation; I thall only obferve, in re- 
fpect of the contrary, that, if it lies low, damp, and flat, it will be advifable to raife an artificial hill, to the height of three feet above the common level, (allowing the furface to be one foot deep of tolerably good foil), compofed of the above-mentioned materials, which may be mixed with the natural earth, and of the full breadth, as aforefaid :-pave * the bottom in a floping manner all round, and, if neceflary, run drains to carry off the wet; and here erect the Grape-houfe.

As the plants are to be planted within the houfe, it is obvious, that both the front wall and flues muft ftand on pillars; whofe foundations muft be to the depth of the pavement in the one cafe, and fix inches deeper than the foil in the other.

The compoft muft be well prepared, by trenching and mixing it, three or four feveral times during the Summer preceding the planting; and the building may be going on at the fame time.

Let the furface of the border, both without and within the houfe, be forked up annually,

* For a more economical method of making a bottom; fee Book II. Chap. I. Sect. 2. 
annually, and let a little rotten dung be worked in. Hence it appears, that I do not approve of the border without the houfe being made a walk of, as directed by fome; nor even do I approve of its being cropped with vegetables, unlefs in a very flight manner. Wooden walks thould be ufed within the houfe, which ought to be compofed of fpars, placed within two inches of each other, to the breadth of eighteen inches; and thefe ought to be fupported from the ground by tiles or bricks, that a circulation of air may be admitted to the border underneath.

\section{SECTION III.}

On Preparing the Plants.

TF plants of proper kinds, and which 1. have been one or two years in pots, cannot be procured, recourfe muft be had to producing young ones by cuttings, which is the moft certain and fpeedy method.

The vine may alfo be propagated with facility, by layers, and by feeds; both which methods, however, are in fome mea- 
fure objectionable; the former, becaufe that the plants thus obtained are apt to grow " much to vine and little to wine;" and the latter, on account of the difficulty of procuring effectually ripened feed; and that, even in this cafe, it is apt " to fport." Let us follow the moft approved mode, viz. by cuttings. And,

For this purpofe, in the pruning feafon, make choice of a quantity of the under part of the beft-ripened, roundeft, and fhorteft-jointed thoots of laft year; which let be cut off with two inches of the former year's wood *, headed down to three eyes, tied in parcels, numbered and regiftered according to their kinds, and ftuck into the earth in a dry fituation till wanted.

About

Mr Speechly mentions feveral methods of making vine cuttings; and particularly recommends that by one eye. I have given them all fair and frequent trials; and, after all, am inclined to ftick by the old-fanhioned Mallet method. I have always found the ftrongeft plants to be obtained by it.-But, to make the moft of a rare kind, the method by one eye is of great advantage. It is performed by cutting off the bud, with half an inch of the fhoot below, and one inch above, in a floping manner; and placing it againt the fide of the pot $f_{2}$ cing the fun, to the depth of half an inch. 
About the Ift of March, let a bed, in all refpects the fame as that which is recommended for afparagus, (See page 11 ), be provided; obferving to lay a few inches more of old $\tan$ on the furface, and of a fize correponding with the number of cuttings required. Take garden-pots about fix inches in diameter, and the fame in depth; fill them with entire vegetable mould of decayed tree-leaves; place two cuttings in each, fo deep as to cover the undermoft eye an inch; and plunge them to the brim in the tan. Cover at night with mats, if necelfary; admit plenty of air, in good weather, through the day; and refreh duly with well aired water.

The plants will grow a-pace: and, to their encouragement, let the bed be lined, when neceffary; and as the fhoots approach to the glafs, let the frame be raifed with bricks, \&c. that they may have full room to extend. By the time they have made thoots to the length of five or fix joints, they will require frefh potting; and muft be put, fingly, into pots of nine or ten inches in diameter, being filled with half yegetable and half melon or cucumber mould, 

mould, divefted of all but one hoot, and placed in a vine-houfe, pine-ftove, or a night hot-bed, previounly prepared; where let them be duly attended to in the articles of air and water.(fometimes the drainings of a dunghill) during the remainder of the feafon.

Pinch off all laterals and tendrils as they appear; drefs each thoot neatly to a rod; and, when their growth is over, and the wood ripe in the under part, head them down to three or four eyes, and place them in the open ground, in a dry and airy fituation, till the planting feafon

\section{SECTION IV.}

On Planting, and the Kinds beft adapted to the Grapes Houfeo.

A BOUT fix feet between the plants is A the diftance they fhould ultimately ftand at; but it will be proper to plant them at half that diftance, as a crop or two may be obtained before it will be neceffary to thin them out; obferving to place the kinds two and two together, that, in 
CH. 5.] GRAPES.

thinning alteruately, any of the kinds may not be totally extirpated.

Suppofe, then, that the houfe is built, and the border has been prepared conformably to the directions given in the laft fection, and that the plants are in readinefs; let pits be made, at the above diftances, eighteen inches deep, and as much in diameter; fill them half with vegetable mould; take the plants carefully out of the pots with the balls entire, and, unlers matted, place them fo in the pits, filling in with vegetable, or other rich, light mould, and fettling them with a little water. But if the plants have been a confiderable time in the pots without being thifted, and if their roots are in any meafure matted, it would be improper to plant them fo; therefore, let the ball, in this cafe, be reduced a little, and let the matted roots be fingled out; retaining all the fibres poffible, and fpreading them carefully out, in placing of the plant. This operation may be performed any time from the firt of November to the middle of March, with equal fuccefs *.

$$
\text { - F 3. Amongft }
$$

* On the firt day of May 1793, I planted a Grapehoufe with young plants, ftruek in Febtuary. In 1795 . 
Amongft the numerous variety of Grapes, I do not know above eighteen or twenty kinds worthy of a place in the vinery, and even that number cannot have places in an ordinary-fized houfe; but, where there are two or three houfes, a variety to the extent of twenty-four kinds may be encouraged, without tranfgrefling the bounds of moderation. The following is a lift, viz.

White fweet Water.

White Mufcadine.

Royal do.

Black do,

Black Frontinac.

White do.

Red do.

Grilly do.

Black Hamburgh.

White do.

White Raifin.

Red do.
Syrian.

White Tokay.

Flame-coloured do.

White Paffe Mofque.

Grecian.

White Mufcat of Alexandria. Black do.

Large black Clufter.

Black Conftantia.

White do.

St Peter's Grape.

Lombardy.

Out of which, according to the fancy of the proprietor, may be chofen an ample collection to ftock any Grape-houfe.

The following is a brief defcription of their properties and appearances; which, perhaps,

they had a few fruit; and in 2796 ; the beft crop I remember of having feen. 
CH. 5.] GRAPES.

perrhaps, may help to determine the choice of thofe who are unacquainted with their qualities.

\section{White freet Water.}

This is the beft early Grape we have. The berries grow clofe on the bunch, are white, or rather of a ruffet colour when ripe, round, large, and thin Akinned; and are replete with an agreeable, fweetifh juice. An error, too common, prevails of cutting this Grape ere it be fully ripe. Hence it is lefs in repute than it deferves to be.

\section{Wbite Mufcadine.}

The berries are of a moderate fize, white, roundifh, the Ikin thin, juicy and delicate; the bunch well formed, and moderately large. This Grape is alfo frequently cut before it be perfectly matured; but it is a good fruit, cones in early, and bears abundantly.

\section{Royal Mufcadine.}

This Grape nearly anfwers in defcription to the preceding, only that the bunches

$$
\text { F } 4
$$
grow 
88 THE FORCING GARDENER. [B. T. grow much larger, and the wood and foliage a good deal ftronger.

\section{Black Mufcadine.}

The berries of this kind are black, round, and juicy; the $\mathrm{kin}$ is thin, the bunch of a moderate-fize, and well formed. It is a plentiful bearer in general.

\section{Black Frontinac.}

The berries are round, black, of a moderate fize, and of the moft exquifite flavour,'as all the kinds of Frontinacs are; the bunch long, unfhouldered, but well formed.

\section{White Frontinac.}

The berries are large, round, and of a greenifh white colour, except the fide next the fun, which, when well ripened, is a pale ruffet. The bunch is large, and fomewhat more thouldered than the preceding.

\section{Red Frontinac.}

The berries are round, of a brownilh red colour, moderately large, and grow clofe on the bunch. I know many who efteem 
efteem this above all the kinds of Frontinacs, for its high mufky flavour. The plant is a moderate bearer, and produces well-fhaped, middle-fized bunches.

\section{Grifly Frontinac.}

The berries are round, of a grilly brown colour, moderately large, and very high flavoured; the bunch of a middle fize, rather longin, and unhouldered: a great bearer in general, when well managed.

\section{Black Hamburgh.}

The berries are large, black, of a roundin oval thape, and confift of a pulpy.fleft and thickith $\mathrm{kin}$; are not of a very high flayour, but agreeably fweetifh. The bunches are large, handfomely thouldered, and are produced in great abundance: few, if any, grapes exceeding this in luxuriance.

\section{I0. Wbite Hamburgl,,or Porlugal.}

The berries of this kind are large, oval, of a pale white, thick fkin, and hard pulpy. flefli; the bunches are large and long, and fomewhat fhouldered. The plant is a great 
90 THE FORCING GARDENER. [E. I。

bearer, and grows very ftrong, both in wood and foliage.

\section{I1. Wbite Raifin.}

The berries are large, white, oval, with a thick $\mathrm{kin}$, and hard, firm flefh. The bunch is long and handfome, in which the berries hang loofely.

\section{Red Raifin.}

The properties of this kind are much the fame as thofe of the preceding, only that the berries are of a reddifh black.

\section{I3. Syrian.}

Amongft the coarfeft of the grape kind, nor has it any property to recommend it, except that it is a good bearer, and produces enormounly large bunches. The berries are large, round, and white.

\section{I4. White Tokay.}

The berries are white, rather oval than round, of a moderate fize, thin Akinned, and grow clofe on the bunches; which are of a good fize, and well formed. This is 
an agreeably flavoured grape, and a pretty good bearer in general.

\section{Flame-coloured Tokay.}

The berries are large, of an oval thape, pretty thin fkinned, of a beautiful flamecolour when well ripened, but notivery high flavoured; the bunches are large, and elegantly formed with houlders; and the plant generally produces good crops.

\section{Wbite Paffe Mofque.}

br This is a good Grape. The berries are large, round, and of a yellowith white when fully ripe; the bunches are of a moderate fize, and well formed; and the plant is a pretty good bearer.

\section{Grecian, or Greek Grape.}

The berries are of a middle fize, of an oval caft, of a blueifh-white hue, and grow rather clofe in the bunches; which are of a moderate fize, and well-formed. This is a high-flavoured grape, and a plentiful bearer in good foil: 


\section{I8. White Mufcat of Alexandria.}

- The berries are large, oval, of an amber colour, and a high mufky flavour; but the fkin is thickifh, the pulp hard, and not very juicy. The bunch is large and handfome, on which the berries hang loofely. On the whole, it is an excellent Grape.

\section{I9. Black Mufcat.}

The berries are round, black, of a middle fize, thin 1kinned, and of a high-flavour; the bunch is moderately large and well-haped, on which the berries fit rather clofe. The plant is a pretty good bearer in general.

20. Large Black Clufter.

The berries are rather fmall, oval, black, grow clofe on the bunch, which is not very large, though pretty well thaped. The juice of this fruit is harfh, and makes the palate feel rough, as when having tafted Port wine; which is made from this plant alone. 


\section{Black Confiantia.}

The berries are of the middle fize, rather oval than round, black, but not very bigh flavoured. The buach is moderately large, and well formed.

\section{Wbite Conftantia.}

Much the fame as the preceding, but on the whole a larger and better fruit.

$$
\text { 23. St Peter's Grape. }
$$

The berries are large, round, and black; the Akin is thin, and the flefh delicate and juicy; the bunch is large, and handfomely formed; and the plant is a good bearer.

\section{Lombardy.}

The berries are pretty large, black, rather oval than round; the Ikin is thick, and the flen foft and juicy. The bunch is very long, and unfhouldered, on which the berries fit rather clofely. The plant is a pretty good bearer. 


\section{SECTION V.}

On Training and Pruning.

T $N$ the laft Section, I have obferved, that I the plants fhould be planted at double thicknefs, in order to furnifh the houfe, and obtain a crop or two while the temporary plants remain. Thefe muft be marked, and confidered as fuch from the beginning: and, as the farther mention of them in refpect of training and pruning would only tend to confufion, I hall fimply treat of the principals; leaving the thinning away, and final extirpation of the temporals, to the judgment and difcretion of the operator.

The plants being headed down to three or four eyes, as directed in Section III, will generally puh them all; in which cafe, rub * off the weakeft one, and drefs in the other three, as they advance, at the

diftance

* The knife fhould be ufed as little as poffible; and, the young fhoots being of fo tender and brittle a nature, there is no difficulty in doing all that is required in fummer dreffing, with the finger and thumb, except. 
diftance of from nine to twelve inches, Pinch off all tendrils and laterals as they appear; making a rule, however, of leaving all the laterals above the la fitie, which fhould not be nearer to the extremity of the thoot than ten or twelve inches; as that part, being fo very brittle, is apt to break, fhould it meet with any obftruction, and at the fame time be confined too near to the point: In cafe of which, it is advifable to leave the laterals, as above hinted, that one of them may lead on the growth, and become a fubftitute to the proper fhoot.

When the two fide-floots have arrived at the height of four or five feet, they fhould be ftopped, in order to throw in the more ftrength to the middle one, which mutt be encouraged, and fuffered to grow without interruption the whole feafon; not only on its own account, but on that of the roots, whofe progrefs always bears pace with that of the branches. The uppermoft

lateral

in cutting out any old fterile branch : which, however, ought never to be done before the flowering feafon; as, previous to that, much injury would be done by the plants bleeding, which never happens afterwards. 
96 THE FORCING GARDENER. [B. 1.

lateral of the fide fhoots, after being ftopped, will pufh a freth thoot; which fuffer to grow two or three joints, and then ftop it again, otherwife the uppermoft eye of the proper fhoot will break. Repeat this operation, on the lateral produced by the firt lateral, as occafion may require, till the growth of the thoot is quite ftopped for the feafon.

When the plant has done growing, the wood ripe, and when the leaves begin to drop; it is then the proper time for pruning*. Let the middle fhoot be headed down to three, fom, or five feet, according to its ftrength; and the two fide ones to two eyes each.

Next feafon, the plants will purh vigotrouny. Train the uppermolt fhoot of the middle

* This operation fhould never be deferred longer : for, if it is, it rarely happens that the plants do not bleed in a greater or lefs degree, the ftopping of which is attended with much dificulty; and, to effect which, an application of hot wax anfwers as well as any thing. Care fhould alfo be taken to keep the plants from the extremes of heat and cold for ten or twelve days after pruning, that the wounds may gradually heal, and the pores contract; otherwife they are apt, to burft out afrefh, when the forcing is begun. 
middle branch to the top of the houfe; ftop the lowermoft thoot of faid branch * when it touches the bottom of the former; and, if the intermediate ones thould thew fruit, leave two or three with a clufter at each, and rub off all the reft. Train the ftrongeft, from each fide branch, to the height of eight or ten feet; and ftop the others at four or five eyes each.

In autumn, prune them down as follows: The uppermoft fhoot on the middle branch to eight, ten, or twelve feet $t$, according to its ftrength; the undermaft on faid branch to two eyes; the ftrongent of the two uppermoft on the fide branches to five or fix feet; and the weakeft, to three or four; and the lowermoft on each fide branch, to two or three eyes each, which fininhes for the fecond year.

* Let this be dreffed to the old wood; paffing it over, under, or between the fruit fpurs.

+ It may be worthy of remark, that when the plants are in a vigorous ftate, and pufh forth ftrong thoots, the beft formed, largeft bunches, and fineft fwelled berries are produced from the extremities of thofe of this defcription. Indeed, in all cafes, the handfomeft clufters of the branch are produced on its extremities. And this obfervation is not applicable to the vine alone, but to fruit trees of every defcription. 
If all has gone well, the plants will be fit to produce a tolerable crop of fruit the third feafon; for which purpofe there are now three ranges of fhoots in height, and at the diftance of thirty or thirty-fix inches from each other; having fhort fpurs of two or three eyes each, for the production of a fucceffion of wood between them, at bottom.

Train the uppermoft fhoot on the middle branch to the top of the houfe; the lowermont till it touches the bottom of faid fhoot; rub off all the intermediate ones which have no clufters, and fhorten thofe that have, at one joint above the uppermoft clufter. Train that fhoot which was left longeft on the fide branch, to the top of the houfe : the lowermoft to the bottom of faid thoot; rub off what have not, and thorten thofe that have clufters, as above. Train that hoot which was left jorteft on the fide branch, to eight or ten feet; the lowermoft to fix or eight eyes; and rub off or thorten the intermediate ones, as above. Train the uppermoft eye of each of the fpurs, on the fide branches, to five or fix feet; and the lowermoft to as many joints. 
Thus will the trellis be completely filled with young wood to produce a full crop next feafon*.

In Autumn, prune down as follows : The uppermoft thoot on the middle branch, to within eighteen inches of the top of the houfe; the lowermolt $t$ to the length of fix feet ; the uppermoft fhoot on the longeft fide branch, to within nine feet of the top of the houfe; and the undermoft to the length of eight or nine feet ; the uppermoft thoot on the thorteft fide-branch, to within nine feet of the top of the houfe; and the undermoft to five or fix eyes; the longeft thoot from the fpurs on the fide branches, to three or four feet; and the fhorteft to two eyes each; - which concludes for the third year.

To the intelligent reader, it would be futile to go through the operation of train$\mathrm{G} 2$ ing

* Having made no diftinction between the two kinds of Grape-houfes in the culture; I wifh to be underfood here as meaning the large houfe, the roof of which admits of four ranges of bearing fhoots; whereas the roof of the fmall houfe will admit of only three ranges.

+ Next pruning feafon this muft become the middle branch, by the lopping off of all above the bottom of it. See fig. 2. Plate V. 
ing and pruning for the next feafon; I thall therefore conclude this fection after having made a few neceflary obfervations.

It may not be convenient to follow the above directions in all cafes; therefore, much muft be left to the judgment and candour of the gardener : but I would, in a general manner, caution him againft any great deviation, and particularly from fuffering too great a profufion of thoots and foliage in the Summer dreflings. Thefe, if the health and regularity of the plants are kept in view, will require to be repeated every five or fix days; and let not this be thought a hardfhip, for, from experimental practice, I can affure him, it is attended with more eafe and lefs perplexity, than when the plants are fuffered to grow wild as a bufh.

Therefore let all laterals, tendrils, and decayed leaves, be carefully removed as they appear; and when the fruit begins to colour, let at leaft one-third of the whole foliage be regularly thinned away, which xwill greatly promote the fwelling, and render the fruit of an infinitely higher flavour, by the free admilition of the fun and 
air, than when fhadec'by the whole foliage, laterals, and tendrils, as is too frequently the cafe.

As there are a great variety in the kinds, not only in the fruit, but in the ftrength of the thoots and fize of the leaves; refpect muft be had to the diftance they are placed at accordingly, and alfo to the thortening of them, both in the Summer and Winter dreffings.

Pay refpect to the regularity of the young fhoots only, no matter how near they lie to, or even if they cover, crofs, or are dreffed to the old wood; which laft, let be cut away, when it has done its office.

In the lopping of ftrong branches, be careful to make clean wounds with the knife; and drefs off, in a neat manner, the outward fhreddy bark or rind found on fuch; which generally becomes a harbour for infects of the acari tribe, and otherwife is very unfightly. The branches fhould then be wafhed with the liquor recommended in page 62, or at leaft with a folution of foap-fuds and fulphur.

$$
\text { G } 3
$$


And for an illuftration of Autumn or Winter prunings, fee Fig. 2. Plate V.

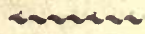

\section{SECTION VI.}

On the Temperature of the Grape-Houfe.

$H^{I R E}$ thould not be lighted the firft fea1 fon, unlefs it proves cold or wet, and the wood is not ripened in good time; in which cafe, a moderate fire heat, from the firft of September, would greatly encourage the growth, and promote, the ripening. of the wood.

As the plants will bear gentle forcing the third feafon, it will be advifable to forward them the fecond, in a moderate degree.

For this purpofe, let flow fires be made about the firft of April, (by which time the plants will begin to vegetate), fo as to raife the air of the houfe at fix in the morning and eight at night to about $55^{\circ}$; in the courfe of a fortnight increafe the heat to $60^{\circ}$; and in another fortnight to 70 degrees; at which let it continue till the firft or middle of June, and then let 
fire heat be totally difcontinued for the feafon.

The third feafon, the forcing may commence on the firft of March, without injuring the plants; and, if carefully performed, a fair crop of fruit may be obtained. Begin then, by making and regulating the fires, fo as that the thermometer may not ftand above 50 degrees at feven in the morning, and eight or nine at night; keep it fo till every eye in the houfe is broke; and then gradually increafe it to $60,65,70$, and, when the bloom begins to open, to 75 degrees.

I I have already hinted in another part of this work, that vegetation in forcing ought to be brought on as it were by ftealth; which is the caufe of my advifing the above gradual and progreflive rife in the climate of the houfe: and if this is not particularly attended to in the firft ftage of the operation, difappointments will follow, as the plants will not break their eyes (and of confequence will not how fruit) regular$1 y$.

Keep the air of the houfé as near to G 4 
75 degrees, till the fruit is fairly fet *, as polfible; and it may then be let down to 70 or 72 degrees. At this, endeavour to keep it, till the crop is all gathered; after which, farther attention to the climate is unneceffary.

In the following feafon, the forcing may (if fancy requires) be begun a month or fix weeks fooner; that is, about the middle of January or firft of February; in which early feafon, great attention muft be paid to the regulation of the fire heat. I believe I have been more fcrupulous in this particular than moft gardeners; fome of whom I know fcoff at the idea of too much uniformity in the climate, alledging no fuch ftrictnefs

* Grapes in general are found to fet beft in a moift heat of about 75 degrees. But I have found by experience, that all the kinds of frontinacs require a much greater degree of heat, not only when in flower, but from the time the clufters are diftinguifhable; while thofe of the white fweet water and white and royal mufcadines, require a much lefs degree: the former being apt to curl up and become fteril for want of heat, and the latter to produce a greater quantity of fmall berries in confequence of too much. Wherefore, if there is any difference of climate (which is fometimes occafioned by the placing of the furnaces) in the houfe, the above hint thould be taken advantage of. 
CHI. 5.]

Itrictnefs to be necentary, from the unfteadinefs of our own: not confidering the vaft difparity between the unfettled ftate of the climate in our ifland, and the regular ferenity that prevails, at all times, on the continent.

A month may be gained each year, where there are two or three Grape-houfes, and it is required to have Grapes at a very early feafon; until the forcing is begun fo early as the firft of October: dout where there is but one or two houfes, the firft of March in the one cafe, and of January in the other, is quite foon enough to light the fires. But of this fee farther in Sect. XI. of this Chapter.

\section{SECTION VII.}

On the Admifion of Air to the Grape-Houfe.

A FTER planting, let a due portion of A air be given every day from funrife to fun-fet, until the buds. begin to break; after which, obferve a more pointed regulation, being guided much by the temperature of the weather, and the quantity 
tity of fun-fhine; admitting lefs or more every day, unlefs the feverity of frofty winds renders it imprudent to do fo. But, as the Summer advances, be very liberal in this article in ferene weather: it will greatly tend to the ftrengthening of the young thoots.

It is a practice with many to uncover their Grape-houfes in Winter. This I never did, not fo much that I difapprove of the practice, but owing to the expence attending it, not only in removing and putting on, but in breaking the glaffes, and wafting the flues by the extremes of froft and blanching rains. But, my method has been to admit an equal and free circulation of air, by opening the fafhes alternately at top, bottom, and middle, to the extent of at leaft a third part of the whole covering, and letting them remain fo, day and night; never thutting up for-any caufe but that of too much wet.

The fecond feafon, obferve much the fame regulation as above; and, if fire is applied for the forwarding of the wood, (as hinted in Section VI.) pay due attention at that time, as the fudden breaking 
out of the fun in dull weather, when there is a good deal of fire heat in the houfe, is attended with much danger.

On the fuppofition that the plants have made good wood for the production of a crop the third year, and are to be forced from the firft of March; let the houfe be thut up at night from the middle of $\mathrm{Fe}$ bruary, and have the fame quantity of air admitted in the day it enjoyed all Winter. From the time the fire is lighted, give a moderate quantity, every day, if poflible, till the buds have all broke, to the extent that in fun-fhine the thermometer may not rife more than $10^{\circ}$ above the fire-heat medium : but, after the buds have broke, and the temperature of the houfe is increafed, be careful in the admiflion of frofty, or foul damp air. The latter may be entirely excluded, except, perhaps, for an hour or two in the middle of the day; and the bad effects of the former may in fome meafure be avoided, by opening the top fafhes*only, a little way, to pafs off the rarified

* Few people pay the attention to this article which, in my opinion, it deferves. I have often feen air admitted in a manner as if by mere chance; fometimes 
rarified air occafioned by the fun-heat; which is frequently very intenfe in clear frofty weather, in the months of March and April.

In clear fun-thining weather, my practice has been, to give and take away air by degrees; that is, by giving balf air about eight in the morning, full air about ten or eleven, reducing to half air about two or three, and fhutting up about four or five in the afternoon, fooner or later, according to the feafon of the year.

From the time the fruit begins to colour, give large portions of air till the crop is all gathered, the flavour being thereby much enhanced; and afterwards expofe the houfe night and day for the Winter, as

directed

by opening two or three fafhes at a place, fometimes in the middle of the houfe, the top, bottom, or either end, \&c. without the leaft difcrimination. The air ought to circulate freely in all parts of the houfe. To effect which, it thould be admitted at top, bottom, and middle, or at leaft at top and bottom; dividing it equally in every part of the houfe, according to the quantity to be given: and that too at all times; unlefs the feverity of froft renders it imprudent to do fo any whcre but at top, as here directed. 
directed above; fhutting up, however, if much wet, or hard froft, fhould happen during the firft ten or twelve days after the plants have been pruned for the feafon.

\section{SECTION VIII.}

On Watering, Waßsing, and Steaming the Grape-Houfe.

7 HE firft and fecond feafons, keep the 1 border in a moderately moift ftate while the plants are growing; but, after their growth begins to abate, (particularly the fecond feafon), withhold the waterings by degrees, in order to make them harden and ripen their fhoots for the production of a crop the third year. Water frequently with the drainings of a dunghill; which will be found infinitely ferviceable, and greatly to promote the growth of the plants. This is a method of manuring, perhaps inferior to none; and, whatever may have been faid by theorifts, refpecting its tainting the flavour of the fruit, ought not to prevent the practical gardener from applying it in moderate quantities, at any 
feafon of the year. At a dry time, when the moifture of the dunghill had been fuddenly exhaled by the heat of the fun, I have frequently laid dung in feep for this purpore.

Wafh with the hand-engine twice or thrice a-week in the evening, in order to refrefh and keep the plants clean. Steaming is unneceflary, unlefs there is fruit in the houfe.

The third feafon, keep the border alfo in a moderately moift ftate, till the fruit begin their laft fwelling. Give large quantities of water till they begin to colour : after which, entirely withhold it till the crop is gathered; and then give two or three hearty waterings, in order to recover the ftate the border ought to remain in for the Winter, which thould neither be dry, nor uncomfortably wet.

Wafh twice or thrice a-week, till the flowers begin to open; withhold till the fruit is fairly fet; wafh again till they begin to colour; and then withhold entirely for the feafon.

Some difapprove of ufing the engine in the Grape-houie; but it is equally neceffary 
fary here as in the cherry or peach houfe; nothing being more conducive to the health of the plants, than frequently to fprinkle their foliage with water. Befides, by throwing it with fome force, infects are thus deftroyed, and their breeding prevented. By a proper application of the engine, endeavour to render the plants quite clean of infects, particularly the red fpider, before the fruit begins to ripen off, as, after this time, it is not advifable to water the foliage, on a double account, viz. left, by moifture hanging about the clufters, the berries might rot through damp, and alfo become infipid in flavour.

In the interim of wanhing, fteam every night when the fire is at the ftrongeft, by pouring * water on the flues till an object cannot be feen at the diftance of two or three yards: and repeat this early in the - morning,

* In another part of this work, I have already hinted, that I do not think it worth the while to erect the fteaming apparatus for any fpecies of forcing, except peaches. For the Grape-houfe, it would be extravagant; as fteam can be produced there at any period of forcing, efpecially in the flowering feafon, when a ftrong fire heat is requifite at any rate. 
morning, if the temperature of the houfe thould require the making of fires, or if there is a fufficient heat in the flues to produce fteam, even in a middling degree.

\section{SECTION IX.}

On the Formation, Tlinning, and Maturation of the Clusfers.

TN the valt variety of Grapes, it happens, 1 that not only the berries, but the bunches, affume different forms: and although many kinds, from their nature, require little or no trouble, except thinning, in the formation of handfome clufters; yet, there are fome which, from the loofenefs of their compofition, require to have their fhoulders fupported from the body of the bunch, not only in order to promote the regular fwelling, but to prevent the rotting of the berries, which otherwife frequently happens, if damp weather in the time of ripening.

Amongtt thefe may be reckoned the Syrian, Tokay, Raifin, Lombardy, Royal Murcadine, St Peter's, and the Hamburgh; which, 
CH. 5.] G GRAPES.

which, when the berries have arrived at about the fize of peas, fhould have their fhoulders fupported to the trellis or branches by ftrands of matting, \&x. and, at the fame time, have their berries regularly thinned out, with fharp narrow-pointed fciffars, to the extent of about one-third of the whole. At this time, alfo, let the other kinds be thinned out in the fame manner; obferving to thin out the fmall, feedlefs berries only, of the Sweet Water, Flame-coloured Tokay, and Mufcadine.

If the culture of the grape is attended even with ordinary fuccefs, it will alfo frequently happen, that many kinds will fhew more clufters than, for the future welfare of the plants, ought to be fuffered to remain on them. In thinning of thefe, no rule can be laid down in cafes unfeen; therefore, in this, as in many others, we muft confide in the difcretion of the gardener. But I would beg to remark, that the fafe fide of error is, to thin too much rather than too little, efpecially on young plants.

After the berries begin their laft fwelling, and approach to maturity; care muft 
I I THE FORCING GARDENER. [B, I' be taken to keep the bunch clear of any which, from damp, bruifes, or the bites of wafps, or any other infects, may begin to mould, as thereby the whole clufter will be quickly affected and entirely fpoiled.

Grapes of all kinds thould hang on the tree till dead ripe, particularly the thick nkinned ones.

\section{SECTION $\mathrm{X}$.}

On the Infects which infeft the Grape-Houfe; and bow to deftroy them.

7 HESE are, the green fly, thrips, red 1 fpider*, and wafp.

The two firft are eafily deftroyed by a fumigation of tobacco. The third are kept under by the engine in Summer ; and effectually deftroyed, as directed in page 62 , in Winter. The laft, by the deftruction of their neits $\uparrow$, phials filled with honey and

water,

* Frontinacs are more fubject to the red fpider than moft other forts; and all kinds are more fo in the pine or dry ftove, than in the Grape-houfe.

+ The moft effectual method of deftroying the nefts of wafps is this: Make a fquib-cafe of cartouch paper, pafteboard, or of a ftrong ftem of hemlock ; mix up combuftible matter fufficient, of gunpowder and fulphur, to 
water, or fugar and fmall beer, and birdlime. All thefe methods are, however, fometimes ineffectual for the deftruction of wafps, where they abound in vaft quantity : and their fondnefs for Grapes renders it fometimes neceffary to inclofe the bunches in bags of gauze, or filken paper, which is truly a misfortune; as the Grapes, by being fo much excluded from the action of the fun and air, fall greatly off in flavour.

\section{SECTION $\dot{X I}$.}

On the Prolongation of the Grape Seafon, where there are more than one compartment for its Culture.

W $W$ HER there are two or three Grape houfes, and a fucceflion and fruiting

\section{$\mathrm{H}_{2}$}

pine.

fill it in the common manner; but firft put in as much clean gunpowder as will charge a piftol; fire the fquib; thruft it into the hole of the neft, and inftantly clofe it round with a little mud, previoufly prepared for the purpofe. When the fquib burns to the gunpowder, it will explode, and drive the whole fmoke back to the innermolt parts of the neft. - In a few minutes, dig it up and r each individual, if not already dead, will be found fo much fickened as that it cannot efcape. This operation thould be performed after fun-fet, when the enemy have returned from their depredations, 
pine ftove, the Grape feafon may be continued from the firft or middle of March to Chriftmas; and where there are two or three Grape-houfes only, from the firnt of June in the one cafe, and the middle of April or firft of May it the other : to effect which, the following methods have been my practice.

For the production of ripe Grapes in March *, I reverfed my fucceffion and fruiting ftoves $†$; by which means, I had it in my power to force, in fome meafure, the vines therein contained: as I found, without doing fo, I could not bring them in before April or May $\neq$. In this manner, (and from the way in which the plants were trained), the two ftoves fupplied a conftant fucceffion of fruit till the firft or middle of June To continue which, I began my firft Grape-houfe on new-year's day; my fecond on the firft of March; and my third, and laft, I kept as much back as

polfible,

* I have fometimes had them in the end of February.

$t$ They were both on one plan.

I A more conftant equality of climate being requifite in the thove than in the Grape-houfe, is obvioufly the caufe. 
pollible, by expofing it to the weather night and day till the natural feafon brought the plants into flower.

By this time, it was the firft of June. I then thut up at nights; and encouraged the growth of the plants and fruit, by lighting and continuing the fires the whole feafon; had ripe fruit about the firft of October, which, by part being hung up in the fruit room, continued till Chrittmas.

Previous to my introducing Grapes into - the pine ftoves; and in order to have a fupply of fruit from the month of April to Chrifmas; I began to force my firft houfe on the Ift of November, my fecond on the If of February, and my third I treated in the manner above fpecified.

The following feafon, I began to force the firft houfe on the Ift of October; and cut grapes on the laft day of March: but, in the night between that and the If of April, the front flue burft; by which accident was loft the whole foliage, wood, and about five hundred bunches of Grapes juft coming to maturity. Nothing could be more galling. I inftantly cut down every new thoot to one eye; continued the fame $\mathrm{H}_{3}$ degree 
degree of heat; and gave plenty of air and large quantities of water. The plants made the fineft wood that fame feafon; and had the beft crop of fruit the following, I have feen.

The above curious circumftance I have related, not merely on its own account; but to the end that, were the like happening to any perfon, the plants might not be thrown out in defpair; which had well nigh been the cafe with thefe. I alfo planted young plants between each of them; but, as the old ones far furpaffed them in vigour before the end of the feafon, I threw them out again.

Let it be here obferved, that although I found it neceffary to force the Vines in the ftoves alternately, by reverfing them from fruiting to fucceffion houfes, yet I by no means did, or would advife that to be done, with the Grape-houfes. Forcing of any kind is an outrage done to Nature; and the more it is avoided, the greater, will be our fuccefs; and confequently, the fame rotation being obferved, will be the lefs liable to error. 


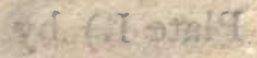

4hif se SETION XII. sils sii rried

On the Cultivation of Grapes in the Pine Stoves

5 HE cultivation of Grapes in the Pinte

1 Stove is in general práctice; and the plants are commonly planted on the) outfide of the houfe, introduced through holes in the parapet, and trained up the under-fides of the rafters.re e eillows stortw

This method I have prefumed to deviate from, for the following reafons if Firf, Becaufe I think it unnatural that one part of a plant fhould be, as it were, in Greenland, and the other in the Weft Indies i and, Secondly, Becaufe I am convinced that no plant (efpecially the Pine) will live and thrive as well under the thade of another, as when expofed to the free fun and air. To obviate thefe objections, I planted my Vines in the lobbies between the ftoves and peach and grape houfes; introduced them through the partitions; and trained them horizontally on trellifes fixed againft the back-walls, and upright

$\mathrm{H}_{4}$ at if , ostrow fafhes 
farhes in front, (See Fig. 2. Plate I.) by which means, each of the ftoves were rendered equal to any Grape-houfe, without being in the leaft injurions to the Pines.

The front-walls of the lobbies * were alfo built on pillars; and a border, both without and within, was prepared for the plants, in the fame manner as for the Grape-houfe.

(1) The fecond year after introduction into the ftove, the plants completely filled the whole trellis; and a fine crop, the third year, gave a lufte and richnefs to the houfe (in conjunction with a good crop of Pires ohighly gratifying.

The fine thethods, in regard to watering, wathing, and fteaming, is to be practifed here as in the Grape-houfe. Air is admitted folely for the fake, and to anfwer the nature, of the Pines; the temperature of the houfe is alfo regulated for their fakes. But, the mode of training and

pruning

* This method may be practifed in the fame manner, where a grape or peach houfe adjoins the ftove; and where a ftove ftands detached, it is cuftomary, and in. deed neceffary, to build porches with double doors; and, of confequence, it is eafy to render them fubfervient to this purpofe. 
pruning here is very different from that in the Grape-houfe. Here, it is impoffible to bring on vegetation in that flow and regular manner which may be done in the Grape-houfe ; and, confequently, were the Thoots to be laid in at as great lengths, they would only break, perhaps, a few eyes at the extremities, and the remaining parts would remain naked.

This I found, from experience, to be the cafe; although it did not happen for the firft three or four years, owing to the youth and vigour of the plants: but, when they had, in fome meafure, exhaufted themfelves by bearing a few crops, they began to break their buds in the manner above ftated. I therefore made it a practice to train them only to five or fix feet in Summer, and to fhorten them down to one or two, in the pruning feafon; by which treatment they generally broke all their eyes, and produced plentiful crops of fruit.

In one houfe, I tried, for two feafons, to produce crops by laterals; but found that method attended with more inconveniency than the above, from the difficulty of procuring 
curing a proper fucceffion of ftrong thoots to produce the laterals, without which they bear very infignificant clufters.

I alfo, in the other houfe, produced a fecond crop, for two feafons : but, finding it to exhauft the plants very much, I difcontinued it ; the more efpecially, as, having fo many compartments for Grapes, this practice was the lefs neceffary. The method is this:

Juft about the time when the fruit is half ripe, and when the under-part of the thoot is allo ripe to the length of about two or three feet, and the extremity of it in a growing ftate, fhorten it, at about two or three feet above the ripe part. It will pulh again, and will generally bring two clufters. Sometimes, alfo, the fecond and third eyes will pufh, and bring a clufter or two. In winter pruning, fhorten down the firft, or fpring-made part of the fhoot, to two or three feet.

This method may be repeated, with pretty good fuccefs, once in two or three years; but, if done every year, it will (in the courfe of three or four years) occafion the cutting of the plants down to the grownd, 
ground, in order to make them put forth a frefh ftock of wood.

In the event of fevere froft, and the plants being in an early ftate of vegetation; let the border, on the outfide, be covered with a quantity of ftable-dung, or long litter, to prevent the roots from being injured by the weather.

Unlefs the plants are to produce a fecond crop, they muft not be pruned for good fooner than October; and, at the fame time, that operation fhould not be deferred longer than the firft of November, left, when they begin to vegetate, they fhould bleed.

Grafting the Vine is performed with facility; but I do not think it of fuch confequence any where as in the ftove. The method by approach* is certainly to be preferred.

* The common way of performing this method, is, by growing the young plants or fcions in a pot, and engrafting the laft Summer's thoot, on the old ftock, juft about twenty days before the plant begins to vegetate. But, the moft fuccefsful way is, to perform this operation in fummer, about the time the fruit begins to ripen, in the following manner: Apply the middle of a young thoot, whofe bottom part is beginning to ripen, and 
preferred. The frontinacs, mufcadines, and fweet-waters, would be greatly improved, and rendered more durable for this compartment, by being engrafted on the Syrian, or any of the other coarfe growing kinds: but the Syrian is the moft proper for a ftock, of any.

Grape Vines will bear forcing, and laft for many years, if under judicious management: but it frequently happens, (eupecially where the gardener is often changed), that the plants run out of a proper ftock of bearing wood, either for want of keeping the border in a proper condition in refpect of trenching and manuring, or by being irregularly and untimouny forced. To recover which, the plants fhould be cut down to the laft eye on the three loweft thoots of the former year, upon each; the roots fhould be cut to within a yard of the ftem on each fide; and the border fhould be trenched up, and, if necellary,

the extremity in a free, growing fate, to the laft year's wood on the flock; bind up with frands of matting; and apply no clay. The young plant will be perfectly fecure, before the growth is over, the fame feafom. 
cH. 5.]. TANBCS GRAPES. IS RII IS ceffary, renewed, and rendered equal to a new one. See Sect. II. of the prefent Chapter.

The plants will make vigorous roots and branches; and the tbird year afterwards, ill be as good in all refpects as they were in that of their age.

This is not theory; I have been eye. witnefs to the experiment, which has been crowned with fuccefs.

CHAP.

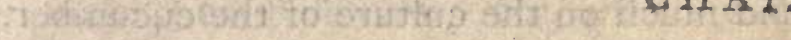

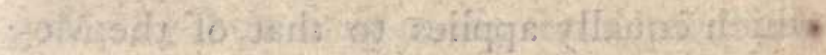

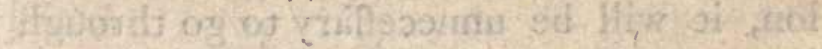

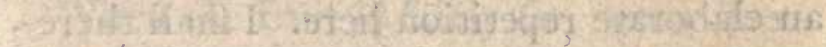

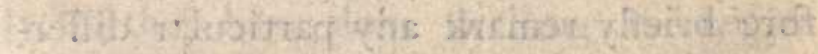

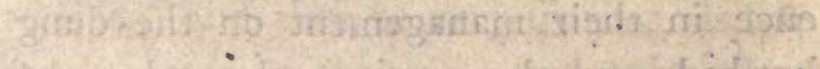

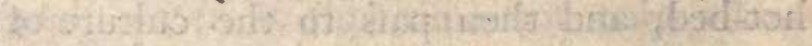




\section{CHAPTER VI.}

MELONS.

7THE cultivation of this much-efteem1 ed fruit is fo general, that hardly a garden is to be met with where it is not followed in a greater or lefs degree, and that too with general fuccefs. As I have been particular on the forcing of cucumbers, as the treatment of thefe and Melons is in many refpects the fame; and as I have faid much on the culture of the cucumber, which equally applies to that of the Melon, it will be unneceffary to go through an elaborate repetition here. I fhall therefore briefly remark any particular difference in their management on the dung hot-bed, and then pafs to the culture of Melons in flued pits.

Let the plants be raifed in the fame (or a fimilar) reed-bed as that of the cucumber; let the bed or beds, wherein they are 
to come to maturity, be made in the fame manner, and a little ftronger, turfed all over, the fame quantity of old tan or light fandy loam be laid on *, moulded and planted in the fame manner, have air admitted freely, and kept moderately moift till they begin to thew fruit. After this, and till the fruit is fairly fet and begun to fwell, be fparing in the waterings, efpecially in damp weather, and alfo endeavour to keep the bed as free of fteam as poffible; thorten the vines which have fruit, at two joints above it, and train thofe that have none, in a regular manner, to the length of feven or eight, and then ftop them, to make them pulh new vines, which will generally fhow fruit at the fecond or third joint.

When the fruit is fairly fet, water freely till they have done fwelling and begin to ripen, and then be very fparing, as too much water at this time not only takes greatly

* One-half frong brown loam, a quarter light black loam, an eighth vegetable mould, and an eighth ftabledung, will make an excellent compoft for Melons; of which quality is that I have ufed for many years, with fuccefs. 
greatly from their flavour, but frequently occafions the burfting of the fruit, which renders them both unfightly and unfit for carriage. Let a piece of nate, tile, or glafs, be laid under each fruit; it both keeps them from damping and partaking of an earthy flavour.

Some, indeed, flate the furface all over, and others cover with ftraw, reeds, mors, \&c.; all which methods I difapprove. The flates being fo near the glafs, draw too ftrong a reflection in hot weather for the plants to bear with patience; and the ftraw, mofs, \&c. contain, and confine too much damp in dull weather; befides, the Nates contribute much to the breeding of the red-fpider*, and the mofs, \&c. to the harbouring of beetles, earwigs, \&c. which

are

* Melons are very fubject to this deftructive infect in hot weather, which is truly a calamity, as nothing will ftop its progrefs but water, which at fome periods of the Melon feafon cannot be applied without doing much mifchief to the fruit; and the leaves and vines being of fo brittle a nature, they cannot be brufhed or handled (although ever fo carefully) without fuftaining lefs or more injury. The liquor (See page 62.) is effectually deftructive of the fpider, but muft not be applied to foliage of any kind. 


\section{cH. 6.]}

are very deftructive of the plants and fruit.

As the fruit approach to maturity, keep the plants moderately thin of leaves, none of which fuffer to fhade them from the fun, and give large portions of air, which will add much to their flavour.

Melons thould be kept regularly and moderately thin of vines and foliage at all times, fhould be frequently looked over, and fhould never be pruned too mucli at a time, as thereby the plants would be much exhaufted, being apt to bleed at every bruife or incifion.

Melons fhould be cut the moment they are ripe, otherwife they lofe much of their flavour: this, in moft kinds, is better known by the fmell than colour of the fruit:

Many of the early kinds, and if early fown, will produce a fecond crop, equal, both in quantity and quality to the firft. For this purpofe, after the firft crop is all cut, the vines fhould be thortened back to the laft live-joint on each, the bed fhould be well-watered, and haded from the midday fun, for eight or ten days; by which 
I3O THE FORCING GARDENER. [B.I, time the plants will begin to pufh and fhow fruit in abundance. Second crops may alfo be obtained by layers; and they will produce very well by cuttings. But in following this latter method, a moderate heat fhould be prepared, in another bed, wherein to ftrike and grow the plants.

Melon feed ougint to be perfectly ripened before fowing, by being kept in a dry place, or worn in the pocket; but it is fafeft not to fow it till a year old, and it will keep freth for feven or eight. If the feed is not perfectly ripened, and faved from fruit which is alfo fo, the plants produced by it will not be fruitful, running much to vines and male-bloom; and any fruit which may be thown are apt to drop atway.

It is pretty generally underftood by gardeners, that melons, like moft exotic annual plants, degenerate, if they are cultivated in the fame foil for any confiderable length of time. Hence it becomes neceffary, either to change or improve the foil, or to exchange the feeds. But the value of good kinds, particularly of the early forts, when 
once got and afcertained, makes the former method preferable to the latter.

At one time, the idea occurred to me, that were the feeds of Melons laid by for a time, to fow them afterwards in the fame garden might anfwer the purpofe here in view. Accordingly, I laid afide, for three years, a part of each kind of my choiceft forts. I then fowed them, and they were evidently improved in quality; which I can account for in no other way, than that in the courfe of this time, I was at much pains and trouble to improve my Melonmould. Perhaps, however, the feeds might: have been partly improved by ag :

I come now to the culture of Melons in flued pits. (See Fig. I. Plate I.) I have already faid, that $I$ do not think thefe pits fo eligible for the production of Melons at an early feafon, as the dung hot-bed, and in page 26 . have given my reafons. I will therefore fuppofe that the pit was alfo built for other purpofes, is employed in the fpring in forcing afparagus, \&c., and is to be employed in producing a late crop of Melons. 
The firft or middle of June will be foon enough to plant*; and at this feafon a very moderate degree of bottom heat will be fufficient; whatever articles the pit has previoufly produced will have been forced on tan or dung, which will alfo now be much exhaufted. Let the heat, therefore, be renewed, by adding and mixing about one-third of new, with the old $\tan$ or dung; level it to the bottom of the flues all around; turfing will be unneceffary; mould to the depth of fifteen inches, which will raife the wliole furface to the height of the top of the flues; and by the tan or dung fubfiding, will again be level with their bottoms before fire heat is neceffary. Place the plants in a row along the middle of the pit, at the diftance of two feet from each other; and attend to them in the articles of water, air, pruning, impregnating $\uparrow, \& c$, in all other refpects as directed

* The plants may be raifed in a hot-bed, or under hand or bell glaffes. I fay nothing of the kinds; every gardener has his favourites, and will judge for himfelf.

+ It is even more neceffary to impregnate Melons than cucumbers, for this plain reafon: The fruit of the cucumber is ufed green, and before it be matured; whereas 
rected for the dung hot-bed, and according to the nature of the feafon, and ftate of the weather, till the firft or middle of September; and by that time it will generally be neceffary to apply fire heat, both on account of cold and damp, which then begin to be confiderable.

The fruit by this time will be far advanced, fome of which will be approaching to maturity; and for the maturation and production of the reft in a tolerable degree of perfection and flavour, let flow fires be made in the evenings, increafing as the feafon advances, fo as to raife the air of the pit at eight at night, and eight in the morning, to about 70 degrees.

Air is effential to the flavour of the fruit; and that it may be admitted in toI 3 lerable

whereas that of the Melon, except for pickling, is ufe. lefs and naufeous, until it be perfectly ripe. Now, it has been afcertained, that the fruit of the cucumber may be produced of a fize fit for the table, although every male-bloom were deftroyed at its firft appearance, and confequently, the embryo fruit were not impregnated. But I have not yet been ablé, either by actual experiment or otherwife, to learn, that a Melon (except of one variety, a fub-hermaphrodite) could be produced in perfection without b eing impregnated. 
I34 THE FORCING GARDENER. [B. $]$. lerable quantity, and at the fame time that the heat may be kept up in dull weather, let a little fire be made in the mornings. Water muft be ufed with caution; the growth of the plants will now be over; and when the fruit hath arrived to its full fize, watering thould be entirely difcontinued.

CHAP- 


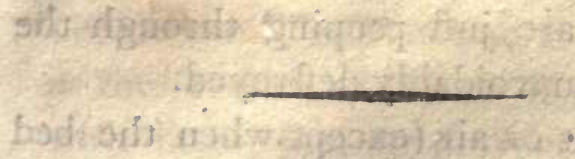

\section{OSCHAPTER VIr.}

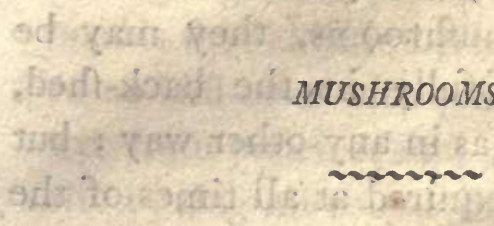

\section{Yane Un HAPTSEGTION I.}

On the Confruction of the Mujhroom-Houfe.

FHIS vegetable is much in requeft in II many families at all times of the year; and fome have compartments built folely for its production; but it is generally produced in the back theds of hothoufes or green-houfes, cellars, ends of ftables, \&c. and fometimes on beds built in the open air, and protected by coverings of ftraw or other litter. This laft is attended with much inconvenience, not only on account of the difficulty of effectually theltering the bed from the inclemency of the weather in Winter, but that in covering and uncovering at the time of gathering the crop, many of the young $I_{4}$ ones, 
ones, which are juft peeping through the furface are unavoidably deftroyed.

Little light or air (except when the bed is in preparation) being effential to the production of mufhrooms, they may be raifed as fuccefsfully in the back-thed, ftable, or cellar, as in any other way; but where they are required at all times of the year, a compartment where fire-heat may be commanded is indifpenfably neceffary. Fig. 2. Plate IV. reprefents the plan of a mufhroom-houfe, wrought by one fire, and divided for the purpofe of producing them in fucceflion, on a conftruction that has given much fatisfaction' for many years. It is of little confequence in what fituation it is placed, provided the bottom be dry; and the roof may either be of llate, tile, or of thatch.

Where there is neither fhed nor ftable, \&c. rather than make up the bed in the open air, and be under the inconvenient neceffity of covering the furface with ftraw, \&c. let a frame in form of the roof of a houfe compored of half-inch boards, be made to any convenient length, and to the width of fix feet at bottom: This two people 
people can lift off and on at pleafure; and in the feverity of Winter it can be covered with litter, \&c. to prevent the froft from deftroying the plants or fpawn. The boards fhould be imbricated and well painted or laid over with pitch, to prevent the wet from penetrating; and a trench hould alfo be dug all round the bed, to keep its bottom dry. Boards thould alfo be made, at two or three different places, to nip for the admiffion of air, when required.

\section{SECTION II.
On Preparing the Mufhroom-Beds.}

DEAUSE the feeds of Murhrooms 1 have not yet been difcovered, fome are doubtful whether there be really any fuch thing; and not a few are of opinion, that this, and many other plants, are produced fpontaneoufly without feeds. Mr Berkeley fays, " The extremely fmall feeds " of fern, molles, mufhrooms, and fome other " plants, are concealed and wafted about " in the air, every part whereof feems re" plete with feeds of one kind or other." 
And Mr Switzer; an advocate for the idea of fpontaneous productions, feems to be of opinion, that fome plants are produced from juices, lodged originally in the ground.

Be this as it may, we know that the Mufhroom may be produced from fpawn; and alfo without any certain vifible ingredient, or origin, from whence it doth fpring. The former, being the moft natural, has hitherto been the moft common method; but of late years, even making, or, as it may be faid, creating Mufhroomfpawn, has become a branch of trade with foine.

According to my mode, the production of the Mufhroom depends almoft folely on the preparation of the bed. Some pay little attention to this matter; and where spawning is uniformly practifed, the lefs is neceffary : but I prefer the method of maling the bed a whole mafs of fpawn. It may be objected, that this method is dilatory: This I grant is the cafe: but if the bed is duly prepared, the time of cutting may be reckoned upon with equal, if not greater certainty, although at a great- 
er diftance; and of what confequence is that? it only requires beginning the fooner to prepare the bed. Beds that are built and fpawned in the common way feldom produce above three or four months together: I have frequently had them producing the year round in great abuudance; and $I$ once had a bed which produced two complete years, and in fuch quantities, that befides generally yielding a difh every day, feveral gallons of ketchup were made from it. However, Muhroom-beds of all kinds are fubject to many misfortunes, and the fpawn is of fo delicate a nature, that it is quickly deftroyed by too much cold, heat, drought, or wet.

My mode of preparing the bed is this: I firft lay about a foot of furnace-afhes, brick-batts, or ftone-chips, for a bottom; then fix inches of horfe-droppings *, taken carefully from the ftable every morning; and kept as whole as pofible: Thefe I fuffer

* I have fourd, that the richer the feeding of the ani$\mathrm{mal}$, the more productive are their droppings ; and therefore prefer the droppings of coach or hunting horfes to thofe of the farm. It may be worthy of notice, that ftone-horfe droppings are the moft productive of any. 
fer not in any wife to heat; and the whole time the bed is in preparation, I expofe it to all the air in my power, provided it be not damp. After this courfe has lain ten or twelve days, is -quite dry, and there is no apprehenfion of its fermenting, let it be covered to the thicknefs of two inches, with half vegetable mould of decayed treeleaves, and half light, fandy loam, which fhould be well mixed together previoufly. But indeed, light, rich, dry mould of any kind will anfwer; being of no other ufe than for the fpawn to run in. Lay on another courfe of droppings in the fame manner; and when it is alfo perfectly dry, and paft fermentation, cover it with the fame mould, as ābove. Lay a third courfe of droppings and mould, in the fame manner, which finifhes the bed. In the making, the bed thould be gently rounded in the middle (efpecially if it is placed out of doors) to run off the wet.

Thus the bed will generally be a month or five weeks in making, and in as much more will begin to produce, unlefs the weather or ftate of the droppings has been unfavourable. 
CH. 7.] MUSHROOMS.

It is obvious, that from the above mode of proceeding, a whole courfe of droppings cannot be laid on at once, unlefs where there are a great many horfes kept, or the bed is but of trifling dimenfions; therefore, when the laft end of the bed is covered, proceed with the firft, if fit, a fecond time, $\& c$. previoufly covering with mould.

\section{SECTION III.}

On the Temperature of the Mufhroom-Houfe.

T T muft here be underftood of fuch as is 1 reprefented by Fig. 2. Plate IV. or of one where fire heat is requifite, and at command. I have found that Murhroombeds produce beft in a conftant heat of about 55 degrees; and the more regular it is kept, the greater will be the fuccefs. Air is of little importance, unlefs to dry off damp.

\section{SECTION IV.}

On Watering the Mufroom-Beds.

7 HIS muft, at all times, be moderately

1 and regularly performed; but it will generally be unneceffary to apply water be- 
fore the bed begins to produce, as the moifture of the droppings is ufually fufficient till that time. Let this be cautioufly performed at firft, until the bed attain to a proper confiftency, and then with a little more freedom. As much water as will fairly wet the furface, once in three days, will generally be found to be fuffcient. But it is fafer to give too little than too much water, particularly in damp weather.

\section{mone \\ SECTION V. \\ On the Pralongation of the Mufforoom-Seafon.}

N moft places the open fields fupply them 1 for two or three months in Summer; yet in very wet feafons they are rarely to be found, if the foil be not of a dry nature: therefore, where there are two or three places appropriated to their production, and where they are in requeft at all times, it might be advifable to have little dependence on the fields, referving the produce of thefe for ketchup, and preparing beds in conftant fucceffion to fupply the kitchen. 
For this purpofe, the compartment where fre heat is at command, thould always be appropriated to the Winter-beds, and the the fheds, \&c. to the Summer ones.

In gathering the crop, care fhould be taken not to pull up or difturb the roots of thofe that are cut, as, there are generally many young ones adhering to, or rifing about them. Muthrooms alfo frequently form, come to maturity, and die away entirely under ground in thefe beds, if fuffered; but they are eafily recognifed, as they are generally very large, and puin up little hills like thofe of moles, above their heads. Difcovering and cutting there fhould be performed with care, that the fpawn may not be injured. 
$\$ 44$ THE FORCING GARDENER. [B:

\title{
GHAPTER VIII.
}

PEACHES AND NECT ARINES.

\author{
mons \\ SECTION I. \\ On the Conftruction of the Peach-Houfe.
}

7 HE conftruction of the compartments

for forcing this much-admired and juftly-efteemed fruit, vary yet more than that of the grape-houfe; and what I have advanced in the firft Section of the Chapter on Grapes, will equally apply here. But there are fome kinds of compartments for the cultivation of peaches in ufe, which I difapprove of, and would wilh to point out. Thefe are, oiled-paper frames, and frames placed againft flued walls, without front flues. I object to the firft, on account of its darknefs, and incapability of admitting the rays of light, and free air; both of which are fo indifpenfably neceffary to the health and vigour of the trees:cond, becaufe the front is the moft valuable- 
CH. 7.] PEACHES AND NECTARINES. I 45

flue in any houfe; both on account of the faving of fuel from the circumftance of its having a greater command on the temperature, (all rarified air afcending), and on account of the injury done the trees by the violent heat of the back flues in keeping up the temperature of the houfe, in ftormy weather; befides, the propenfity of infects to harbour and breed between the trellis and flue, in thefe circumftances.

Fig. 2. Plate II. reprefents the plan of an approved Peach-houfe, wrought by one fire, which communicates firft with the front flue, and returns in the back; and, in my opinion, is beft adapted of any to early forcing. The trees are planted near to the front-wall, and trained to a trellis that covers the whole roof,-an approved me thod, of which fee more in Sect. II. of Chap. XII.

Fig. r. Plate III. is alfo on a conftruction that is perfectly adapted to the cultivation of Peaches. But, as this plan is given purpofely for grapes, it may be neceffary to remark, that the two fires are capable of working to an extent of ten feet more in length, if for a Peach-houfe; and 
\begin{tabular}{l} 
I46 THE FORCING GARDENER. [B. I. \\
\hline
\end{tabular} alfo, that, as the border for the Peachhoufe is to be only three feet deep, it will be unneceffary to found the pillars, which fupport the front wall and flues, any deeper than three feet and a half.

In a houfe of this kind, a trellis is to be fixed againft the roof-beams or rafters, to the extent of half their height; trees planted between the front flue and wall, and trained thereto. Thefe will in nowife fhade thofe on the back. And thus will one houfe be rendered nearly equal to two, as the trees on the front will have a run of eleven or twelve feet.

I conceive this mode to be preferable to the common practice of planting grapevines to run up the rafters in the Peachhoufe; firft, becaufe, by the vines, the Peaches are generally much fhaded; fecondly, the foil for Peaches, and the foil for grapes, thould be formed of different materials, and of different depths; and, thirdly, it is fimply impoffible to make and regulate a climate in one and the fame houfe to fuit both the plants in queftion. Of this the reader may be farther convinced by carefully perufing and comparing the 
CH. 7.] PEACHES AND NECTARINES. I4T

- the Sections on the preparation of the borders, the temperature, and admifion of air, for the Grape and Peach houfes.

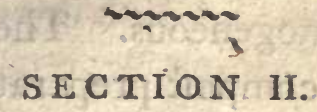

On tbe Situation and Preparation of the Border.

WaT I have faid in Section II.
Chap. V. on the cultivation of the grape, in regard to the fituation of the border, equally applies here, both in refpect to the good and the bad; a repetition of which is unneceffary. I will therefore pafs to the compofition, breadth and depth.

Three fourths ftrong brown loam, an eighth light fandy loam, and an eighth ftable-dung, with about a fortieth part of Thell-marl, was the compofition of the Peach borders at Wemyis Caftle; all of which were made completely three feet deep. The breadth for the narrow houfe, is fourteen feet from the back-wall ; and, for the wide one, all the width of the houfe within, and to the extent of twelve feet without. 
It may be unneceffary to fay, that the compoft is to be well prepared for the plants, by trenching and mixing it thoroughly, and rendering it into a mafs perfectly homogeneous. The neceffity of this, in all compoft preparations, is evident, and ought to be the chief butt of our aim, next to that of fixing on proper materials.

As before hinted, I would not wilh to fay that this compofition only is fitted for Peaches: it may be varied; it may be made ftronger, lighter, richer, or poorer, according to circumftances, and the judgment of the gardener. But I would remark, and obfervation and experience juftify it, that the above may with propriety be deemed a good medium.

For particulars, refpecting the annual management of the furface; \&c. fee the latter part of the fecond Section on the Grape. 


\section{SECTION III.}

On Planting, and the Kinds beft adapsed to the Peach. Houfe.

$\mathbb{1} \begin{gathered}\text { AIDEN, or one-year-trained trees, } \\ \text { are to be preferred to any other. }\end{gathered}$ Riders of the fame age fhould be planted between the dwarfs; except on the front of the large houfe, where they would not have time to do any good before their removal would become neceffary. From twelve to fifteen feet, according as the length of the houfe will beft divide, is a competent diftance between the dwarfs. The feafon is, any time from the firt of November to the firft of March. Fill in the pits with light rich compoft, and fettle the roots with a little water.

The following is a lift of Peaches and Nectarines; out of which, thofe marked thus * ought to be preferred. But even this is difcretionary, and every one has a right to indulge his own fancy, whether in refpect to the choice or amplitude of his collection. 


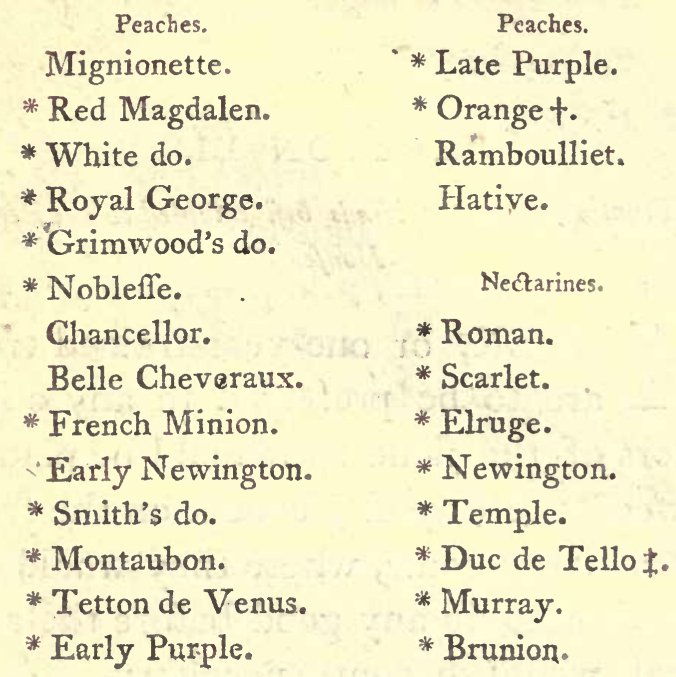

+ This fruit, when ripe, is the moft elegant of any of the Peach kind; is a great bearer, a cling-ftone, and of thefe the beft flavoured I know.

I This is a Spanifh Nectarine; and, of all others, ought to take preference. The fruit is of the moft exquifite flavour, dark purple, a free-ftone; and generally grows to the fize of a nobleffe Peach. 
CH. 7.] PEACHES AND NECTARINES. I5I

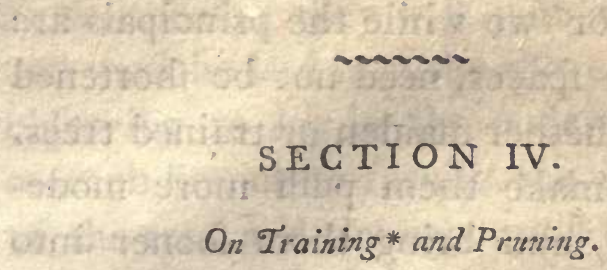

$F^{\text {AN-training is the only way in which }}$ 1 Peaches will do well. Therefore, after planting, and to make the trees put forth vigorounly and fill the trellis from the bottom, (I peak of the dwarfs), head them down to two or three eyes on each fhoot, if maiden, and to the laft eye on each branch, if one-year-trained trees.

The riders being temporary, and placed here only for the purpofe of obtain-

$$
\mathrm{K}_{4}
$$

ing

*. Much has been faid, of late, refpecting training on horizontal trellifes; and fome have even been at the trouble of erecting them in a manner whereby (by the ufe of ropes and pullies) they can deprefs or elevate them at pleafure. This, I confefs, is both minute and reafonable, where it can be practifed. But 1 am inclined to think that it cannot eafily be done without ftraining the tree in the movement; and it is obvious that it cannot be done by any but a fmall trellis placed in the middle of the houfe. After all, the prodyetion of well-fiavoured fruit depends much more on the judicious management throughout, than on what pofition the tręllis be. 
I52 THE FORCING GARDENER. [B. I. ing a crop or two while the principals are filling their fpaces, need not be fhortened fo much, whether maiden or trained trees. This will make them pufh more moderate thoots, and bring them fooner into a bearing ftate; which object muft always be kept in view while they remain here. And, as the treatment of them will, in all other refpects, be the fame as that of the principals, I fhall take no farther notice of them; leaving the thinning away, and final expulfion of them, to the prudence of the gardener.

When the fhoots have arrived to the length of two or three inches, rub off fuch as are placed fore-right or back-right, and lay in the others as they advance, at the diftance of nine or ten inches; being careful not to bundle in the leaves with the tic, and to allow fufficient room for the fwelling of the fhoot: and pinch off all laterals as they appear. When their growth is flopt for the feafon, cut them back from one-half to a third of theil lengths, according to their ftrength; and, in dreffing, bear the fide ones well down, to fill the bottom part of the trellis. 
Next feafon they will pulh vigoroufly, and muft be laid in at the above diftances; obferving to lay in the undermoft thoot on each branch to furnifh the under part of the tree, and the uppermoft for a leader : rubbing off all the intermediate ones, unlefs wanted; but at any rate the foreright ones, as thefe greatly deform the tree. At the end of the feafon, leave them generally at three fourths of their whole length.

If the wood has been well ripened this feafon, the trees will bear a few fruit the following. But, unlefs the trees are very vigorous, a few only fhould be fuffered; paying refpect rather to the furnifhing of the trellis for a crop the fourth feafon, which may reafonably be expected.

For this purpole, lay in the fummer fhoots regularly, at the diftance of fix inches, which forthwith muft be reckoned the medium; and, in the winter pruning, fhorten the fhoots of the extremity of the tree only a few inches each, and lay in thofe of the middle at full length. Obferve this practice till the trees have filled their places; and afterwards Mhort- 
en none, unlefs to fill any cafual vacancy, or in cafe of the extremities of the hoots being injured by bruifes, \&c.

It is a common practice to horten every thoot lefs or more. This may be proper in many inftances, on peaches growing in the open air, as when the extremities of the fhoots have not been fully ripened, and are injured by froft; but it can only be fo far proper in the Peach. houfe, as to caufe the plant pufh thoots to fill a vacancy, or to keep the bottom part of the trellis furnifhed with a fupply of young wood.

Peach-trees require to be frequently looked over in Summer; and divefted of laterals, and water-fhoots from the old wood, whhere not requifite; being kept regularly thin, and neatly dreffed to the trellis, \&c. In tying, however, be careful not to tie too near to the point of the thoot; leaving always a few joints between the laft tie and extremity: alfo, be careful not to bundle in the leaves with the tie.

About the time the fruit is fairly fet, is that for difbudding: and this operation 
is to be performed with great care and nicety. Select what buds on each hoot it may be thought neceffary to leave, and rub off the reft with the finger. Thofe to be left are generally the uppermoft and undermoft, and fometimes one or two about the middle of the fhoot; which laft thould be left in an alternate manner. A wood-bud is frequently placed by the fide of, or between two fruit ; in difplacing of which, be careful not to injure them.

By the timely performance of this duty, much future trouble in pruning may be fpared; and much better, and more vigorous thoots for the production of a crop the following feafon may be obtained, than when the Atrength of the tree is exhaufted in the produce of fuperfluous growth, afterwards to be deftroyed.

When the fruit begins their laft fwelling, let them be expofed to the free action of the fun and air, by picking off every leaf that overhangs them. And, when the leaves begin to drop, aid this effort of nature by fwitching off the leaves gentby, from time to time: an operation more neceflary 
156 THE FORCING GARDENER. [B. I. neceffary here than on the common wall, on account that the wind is not fo much helping to this effect.

\section{SEGTION V.}

On the Temperature of the Peach. Houfe.

HIRE heat thould not be applied fooner 1 than the third feafon; and then only to ripen the wood, in the Autumn, (if neceffary), for the better production of a crop the fourth year. But as, even the fourth feafon, the trees will bear but very gentle forcing, and as I with to be particular on this head; I fhall wave the farther confideration of the temperature of the houfe to the fifth feafon, and thall then fuppofe the forcing is to be commenced on the Ift of February.

Let the fire be made fo moderate the firlt fortnight, that the thermometer may not ftand at eight at night, and feven in the morning, above $45^{\circ}$; and, in the courfe of the fecond fortnight, increafe to $50^{\circ}$; afterwards gradually to $55^{\circ}$; at which point 
CH. 7.] PEACHES AND NECTARINES. I57 point endeavour to keep it till the ftoning is fairly over, and then increafe to $60^{\circ}$; and, towards the fruit's ripening, to $65^{\circ}$; which it fhould never pafs, on account of drawing the young thoots up weak.

It is hoped thefe rules may fuffice for the regulation of fire heat, although the forcing were begun fooner in the feafon. In this cafe, however, much caution is neceflary in the procefs, that by an over-beat at an early period of the year, the plants may not be injured. Indeed, in the whole progrefs of the application of fire heat, the greateft regularity and fteadinefs fhould be obferved; as thefe trees are impatient of fudden checks of any kind, efpecially in the time of fetting and ftoning.

\section{SECTION VI.}

On the Admifion of Air to the Peach-Houfe.

$H^{\text {ROM the time the trees are planted, a }}$ I. large and free circulation hould be encouraged every day, from fun-rife to fun-fet, the whole of the firft feafon; and, when 
when the growth is ftopt, and the wood ripe, let the houfe be expofed in the fame manner as directed for the grape-houfe, in the Section on air, page 106. The fecond feafon, the houfe may be thut up at night from the Ift of March, and afterwards treated as above; and fo of the following.

I come now to the fifth, or feafon of forcing. Let the houfe be thut up at night from the middle of January, and enjoy a large and free circulation through the day till the Ift of February; and then, in a more moderate degree, according to the weather, and paying refpect to the temperature of the houfe, till the bloom begins to open. After this time, lefs or more air muft be admitted. every day, if poffible; as the fetting of the fruit, in a kindly manner, depends much on wholefome air, and a free circulation. In fun-thine, let it be admitted at this time to the extent that the thermometer may not ftand at more than five or fix degrees above the fire-heat medium; and at no time, till the ftoning is over, above ten degrees; but afterwards, in the middle of the day, it may be fuffered to rife to the height of fifteen.

When 
When the fruit begins to colour, the houfe fhould be opened by fun-rife, and thould not be thut till fun-fet, unlefs to defend the fruit from heavy rains; paying little refpect to funfhine at this time: air being as effential to the flavour of the fruit, as the rays of the fun; and the more fo, when thefe are excluded.

After the crop is all gathered, let the houfe be expofed for the Winter, as before.

\section{SECTION VII.}

On Watering, Wafling, and Steaning the Peach-Houfe.

DEACHES, when in a growing ftate, re1 quire plentiful waterings; and the border fhould always be kept in a moderately moift condition : withholding a little in the time of fetting and ftoning, and totally from the time the fruit begins to colour. After the crop is gathered, give a few hearty waterings, to bring the border into a proper ftate for the Winter.

Wafn thrice a-week, with the handengine, from the commencement of the forcing, till the flowers begin to open; 
withhold till the petals begin to decay; wath again till the fruit begins to ripen; and then finally withhold, unlefs the trees are afflicted with the red fpider, \&c. in which cafe, wath every day till they are quite clean.

In the interval of wathing, fteam night and morning, in the manner as directed for the grape-houfe, if not provided with the fteaming apparatus.

In another part of this work, I have faid, that I do not think this apparatus of any confequence, except in the Peach-houfe. My reafons are thefe.-In the grape or pine houfe, there is always a command of fire-heat, at any period of the flowering feafon, to raife a fufficiency of fteam for the purpofe. But, in the Peach-houfe, this is not the cafe: as, in mild weather, and in the flowering feafon, the temperature of the houfe is fuch, as fometimes to require very flow fires; and, of courfe, the flue is perhaps not heated enough, to raife fteam in any great quantity.

It may juftly be faid, that, in this cafe, it is the lefs requifite, as then the artificial air of the houfe approaches nearer to the 
CH. 8.] PEACHES AND NECTARINES. I $6 I$ natural: yet fteaming, at this time, is of in nite benefit to the trees, as it both encourages the fetting of the fruit, and prevents the reeding of the red $f_{i}$ ider; and the engine cannot be employed at this time, for fear of hurting the bloom. Therefore, where there is a range of Peach-houfes, it may be advifable to erect the apparatus: but, for a fingle houfe, or two, I hardly think it worth the expence; as, in the cafe of fteaming by the flues being impracticable, water can be thrown out of a fmall fquirt or fyringe, in the form of dew, againft the bloom.

The idea, however, of fteaming every day without difcrimination, is, in my opinion, ridiculous. Is the world enveloped in a cloud of mift day by day? Does the health of either animal or plant require it? or, could they bear it ? In order to avoid errors, let us follow, as far as the cafe will permit, the dictates of nature; and thus we may alfo fave ourielves the mortification of difappointments. 


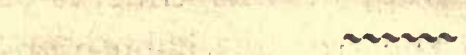 \\ SEGTION VIII. \\ On Thinning and Gatbering the Fruit,}

PIINNING is an indifpenfable duty; 1 as there are many kinds of Peaches and Nectarines which otherwife would foon bear themfelves to death. This operation, however, fhould be performed with caution, and never done for good till after the ftoning is over; as, till then, all danger of dropping is not paft.

My rule for thinning is this:-A fruit for every foot fquare of the furface of the tree for the large kinds, and for every nine or ten inches of the fmall kinds of Peaches, and Nectarines in general. This muft be underftood as for trees in a healthy and vigorous ftate; but, when otherwife, they fhould only be fuffered to produce accordingly. As an inftance :- I once had an Elruge Nectarine, a great bearer, which had a tendency to grow naked of thoots below; I pulled off evefy fruit within fix or eight feet of the groutid one feafon, and it made excellent wood in that part in confequence. : 
CRI. 8.] PEACHES AND NECTARINES. I6 3

So that, it would appear, it were well to be contented with a fair crop; which is better, in the end, both for the tree and its owner.

But, certainly, nothing can be more cenfurable than the practice of thofe who negligently fuffer every fruit the tree may fet, to remain on it ; evidently to the injury of the whole crop, and ultimately to the ruin of the plant. And, of what value or flavour are this multitude of nutmegs, compared with the graceful appearance and relifh of well-fized fruit?

It is cuftomary to let the fruit drop of its own accord, when ripe; and, for this purpofe, the border is covered with mofs, and nets or mats are hung againit the trellis to catch them. I have ever been of opinion, that all kinds of fruits, except grapes, lofe much of their flavour if they are fuffered to remain on the plant till dead ripe; and, in conformity thereto, have made it a practice to pull my Peaches and Nectarines.

I have often been alked, how I came to know when they are fit for pulling? (as handling or feeling them is improper). 
164 THE FORCING GARDENER. [B. I.

This is only attained to by minute obfervation and cuftom, and a thorough acquaintance of the kinds; and, if taking them gently between two fingers, the back of the hand to the tree, and moving them backwards and forwards, does not difplace thofe fufpected to be ripe, pafs by them till next day. In this manner, let the trellis be gone over each morning, and good account will be found in the practice; as not the one-half are loft or bruifed, which are, when fuffered to fall; and the fruit, not being dead ripe, are much fitter for carriage, if requifite. This practice I would recommend alfo, on account that the border, when covered with mofs, emits a bad flavour; and nothing is more conducive to a good one, than the furface being kept clean, and being frequently ftirred up while the fruit are ripening. 
CH. 8. J PEACHES AND NECTARINES. I6 5

SECTION IX:

On tbe Infects that infeft the Peacb. Honfe, and bow to deftroy them.

THESE are, the aphis, the acarus, and 1 the cocci, or fcaly infect; to which may be added, although not an infect, that more deadly malady, the mildew.

In treating of this article in the third and fourth Chapters of this work, I have given ample directions for the fuppreffion and extirpation of the infects; but the mildew, remains to be confidered.

It is evidently an itch or fcurvy in the blood of the tree; occafioned by injudicious management in the culture, a damp fituation, or cankering foil. And although I cannot fay that I ever had it in my power to try experiments for its deftruction, (having never been troubled with it); yet I have endeavoured, and I think fuccefsfully, to prevent its appearance, and that by preparing good and kindly foil for the trees, and paying all due attention to their health and cleanlinefs. I am alfo confident that the wafhing with the liquor 
I66. THE FORCING GARDENER. RE.I.

(See page 62.) has much tended to its fuppreflion.

But, after all, if the border has not been compofed of proper materials, and rendered perfectly dry and comfortable in the preparation, much fear of its appearance may reafonably be entertained. Hence it may juftly be faid, that the beft cure for this malady lies in the prevention of it.

\section{SEGTION X.}

On the Prolongation of the Peach-Seafon, where there is more than one Compartment for its Culture.

THERE there are two Peach-houfes, and a few trees planted againft the open wall in a fouth afpect, the feafon may be prolonged from the firft or middle of June, to the firtt of November, in conftant fucceffion, by beginning to force the firft houfe on the firtt of February, and the fecond about the middle or latter end of March. But where there are three or four * houfes, and a flued wall, the feafon

may

* At Wemyfs Caftle, there were three narrow houfes, a large double houfe, and an extenfive flued wall, for which 
CH. 8.] PEACHES AND NECTARINES. IG' may be fuccefsfully prolonged from the firft of May to the firft or middle of November.

My mode was this: I began to force my firft houfe on the firft of December, and as it was not much to be depended on at that early feafon, my fecond on the firtt of January; my third on the firft of March; and the fourth, I let come of its own accord, without the aid of any fire heat. I never applied fire to the flued wall until the firft or middle of Auguft, and that in order to ripen the wood, and haften the maturity of the late fruit.

I did not reverfe the fucceffive order of the Peach-houfes, and confequently they were always ready to vegetate at the fame time of year, on the application of the fire heat, much lefs to their detriment, in my opinion, than had they been changed in the order of fucceflion.

- I would here obferve, that Peach-trees, if forced every year, will wear out in the courfe of twelve or fourteen; and, therefore, about the eight or tenth year, young L 4 dwarfs

which there were canvas fcreens; alfo a few trees on the common wall. 
dwarfs thould be planted where the riders ftood, and the old dwarfs fhould be converted into riders by degrees as the young ones advance.

The Peach-feafon might be further prolonged by cultivating a few dwarfs in pots or boxes, in the fame manner as is hinted for cherries, Chap. III. Sect. VIII. In this manner, I have witneffed the feafon of this fruit being fo far changed, as that ripe Peaches were produced about Chriftmas * !

\section{SECTION XI.}

On the Cultivation of Peaches and Nectarines on Flued Walls, with Canvas Screens, Nets, छ'c.

$T$ may be faid that flued walls are eflen1 tial to the production of Peaches and. Nectarines in the open air, in the more northern parts of this country, although there are fome fpots, and in fome fituations, where good crops in fome feafons are obtained without them; but to their pro-

- duction

* By Mr Black, gardener at Mordun, near Edinburgh, in I $797-8$. 
CH. 8.] PEACHES AND NECTARINES. I6 9 duction to a certainty, year by year, flued walls are indifpenfably neceffary; and where a fine garden is building, the extra expence in flueing two or three hundred feet of the beft expofed walls, will be found but trifling. If built according to the defign, (See Fig. I. Plate IV.) and worked according to my method as under, the annual expence will allo be trifling.

For fecuring the crop in the Spring, by defending the bloom till fairly fet, from the frofty winds which fo frequently happen at that feafon, canvas fcreens or old nets are neceflary; but the canvas is far preferable, and in the end, little more expenfive than the nets.-There is a kind of thin canvas called Scrim or Ofnaburgh, which anfwers very well, and is fold at about ninepence the fquare yard.

But for the flued wall at. Wemyfs Caftle, I had canvas wove on purpofe, much thinner than any other I have feen, which now, by the action of the weather, is rendered as fine as gauze in comparifon; and which, in 1790 , coft but eightpence a yard. As much as covers a wall two hundred feet long and fourteen high, coft only about 
fifteen guineas, including fpars, cords, and pullies.

The manner in which it was applied is this: The canvas was made into three equal theets, which were joined together every feafon when put on, and unjoined when laid afide; fpars or rafters of two inches fquare were placed at the diftance of four feet from each other, their upper ends being joined clofe to the copping, and their under ends to a ftake drove into the border, at the diftance of a foot from the wall. Thefe were alfo made to remove at pleafure; pullies were fixed to the top of each fpar, and the canvas hoifted thereto by cords a little ftronger than garden line. At firft I clewed it at top; but, a ftrong gale of wind having almoft tore it from the wall, I contrived to clew it at bottom, at the diftance of a foot from the ground. Two people can unclew and hoift, or let down and clew, the whole in fifteen minutes.

When nets are to be ufed, they hould be doubled, in fuch a manner as to render the mefhes as fmall as poffible; and fhould be fupported from the wall about a foot by hooked 
CH. 8.] PEACHES AND NECTARINES. I I

hooked pegs. It is common to hang thefe on in a random manner, but this does not at all anfwer the purpofe intended; which is rather to break the force of the wind, than to prevent froft. By being placed out, at a diftance from the wall, and being doubled as above, the frofty winds are broke ere they reach the tender bloom; and every gardener of penetration will admit, that winds of this defeription are more baneful than even hard frofts.

As, in the preceding Sections, I have given ample directions for preparing the border, planting *, training, watering, wafhing, \&c. it would be futile to repeat them here; and as it may be prefumed the trees will produce no very confiderable crop before the fourth feafon, I will pafs on to that time.

\section{Some}

- Before planting, there fhould be a trellis, or fpars an inch fquare, fixed againft the wall, to the height of the firft courfe of the flue only; this being requifite to keep the young thoots from being fcorched or anywife injured by the fire heat : and by the time it lias returned into the fecond flue, the trees may be dreffed to the wall without danger. 
Some apply fire heat to their flued walls in the Spring. This I pointedly difapprove of, as no fpecies of forcing is fo intricate; the trees being placed between the extremes of heat and cold, and it being quite impoffible to make or regulate a climate for them. All that is neceffary for the production of a crop, is, ripening and hardening the wood in Autumn, and fcreening from frofty and boifterous winds in Spring.

By the time the buds begin to appear turgid in the Spring, let the fcreens be hung up: and, if canvas, let them down in the day, from eight in the morning to five or fix in the afternoon, in mild weather; but if boifterous frofty winds prevail, continue them all day. They thould not be totally removed till about the middle of June; by which time the fruit will be fairly fet, and all danger will be paft.

About the firft or middle of Auguft, according to the feafon and forwardnefs of the fruit and wood, light the fires. Thefe muft be made very moderate at firft, and increafed as the feafon advances. If the: furface of the wall, about the fecond courfe of the flue, is kept milk-warm in the night, it is all that is neceflary. And here obferve, 
ferve, that the quantity of fuel muft not be enlarged in a ftormy night in the fame degree as in a hot-houfe; otherwife, all will be ruined. To attempt making a climate for the trees here is ridiculous, and alfo perfectly unneceffary; the fole intention in the application of fire, being to ripen the young fhoots for the production of fruit next feafon.

The following quantity and proportion of fmall coal is taken at a medium, and what I have found fufficient to work a welldrawing furnace for years, viz. From the time of lighting the fire to about the Ioth of September, four ordinary thovels-full at five, and as much at nine in the evening; from the Ioth of September to the middle of October, fix Movels-full at the above times in the evening; and from the middle of October to the middle of November, fix hovels-full at four in the evening, eight fhovels-full at nine, and three or four at feven in the morning.

The above is only given as a hint; and much is left ta the nature of the feafon, and judgment of the operator. But much care, in this fpecies of forcing, is indifpenfably neceflary to the infurance of fuccels. 


\section{CHAPTER IX.}

\section{PINES.}

\section{PINES. \\ SECTION I. \\ On the Confruction of the Pinery.}

7 HAT few thoroughly underftand the 1 cultivation of this moft admirable fruit, is demonftrated by its being difcontinued in many places where it has been tried for years. Some have alfo given up the cultivation of Pines, becaufe of the expence attending it in refpect of fuel: the wafte of which is greatly occafioned by the conftruction of the fire-place and flues; which are generally ill adapted to the burning of wood or turf, without working the houfe unfteadily, and giving the perfon who attends them much trouble.

Such a furnace, as is reprefented by Fig. I. Plate V. is better calculated for burning wood or turf than any other I know. 
know. And although I never had occafion to ufe that kind of fuel at Wemyfs Caftle, where coal is plenty; yet, when at the Marquis Townfhend's in Norfolk, I was under the neceffity of fubftituting other kinds of fuel for the ufe of the Pine ftoves; and to burn which, I pulled down and altered my furnaces, from the common, to the plan as reprefented by the Plate. The fuel I ufed was turf and fcreened cinders, mixed in equal quantities; and a more fteady fire I have never ufed any where.

Pine ftoves are variounly conftructed. Some are fingle pitted; fome double; and fome are even triple pitted; fome have flues running under, and fome round the bark-bed. I difapprove of thefe; being very dangerous to the roots of the plants, if over-heated. I alfo difapprove of double and triple ftoves; as being very uneafy to work in ftormy weather, and confining a great quantity of ftagnate unwholefome air in dull hazy weather. A ftove, where fire heat may be perfectly at command, and in which a free circulation of 
air can be admitted in all parts, is certainly to be preferred; and none can be fo convenient for this purpofe as a fingle one : and where it is in agitation to erect one, I would recommend fuch as is reprefented by Fig. 2. Plate I.

For the fake of uniformity, if placed in a range of vine and peach houfes, \&c. it may be raifed to the fame height with them; obferving to raife the bark-bed accordingly, the furface of which thould not be farther than four or five feet from the glafs. The fucceffion-houfe may alfo (if requifite) be of the fame conftruction; and a nurfing pit (See Fig. I. Plate I.) will be found to be of great advantage, and anfwer the purpofe perfectly.

The fituation is immaterial, provided the furface be dry, as the bark-bed is raifed above it, and paved. And hence it appears that I do not approve of a border being made in front for the production of grapes to be trained up the rafters, which I efteem as being highly prejudicial to the Pines. For my method of preparing the border, and training vines in the Pinery, 
CH. 9.]

PINES.

177

See Section XII. on the culture of the grapé.

\section{SECTION II.}

On the Preparation of the Bark-Bed.

7 HIS is an article of much confequence
to the welfare of the plants; and if not judicioufly performed, is productive of great evil. It is no uncommon thing to hear of whole pits of Pines being burnt at the root by the over-heating of the bark-bed; and Mr Speechly and others give this as a principal reafon for their ufing oak-leaves. I have grown Pines for many years, and can declare that I never had the roots of a fingle plant injured by bark-heat; and if my method of preparation is ftrictly followed, I can be bold to augur that none ever will. The manner is the moft fimple imaginable.

My opinion, in refpect of the quantity and quality of bottom heat required by the Pine, has been different from that of any other author I have read on the fubject. 
78 THE FORCING GARDENER. [B. 1 . ject. Pine plants, except in f riking of fuckers, \&c. Thould not ftand in a bottom heat above that of blood-heat at any, time, and that too of a mild moilt nature. If the watch-ftick, to the depth of the bottom of the pot, feels juft a little warm when felt with the hand, or applied to the cheek when the body is of a comfortable temperature, it is fufficient; and it certainly confifts with reafon, that the bottom and fuperficial heat thould correfpond at all times. For the more effectual attainment of which, and that the roots may fuftain no injury, the following rules, for turning and trenching the bed, are what I have followed, viz. never to fift the tan in the pit at any time; never to add above an eighth of new, which, if neceffary, give place to by ikimming off a little of the furface of the old; never to fuffer the new tan to lie within a foot of the furface, by which means the pots are entirely plunged in the old; to lay the half of whatever new tan is added, in the bottom of the trench, and divide the other half equally to within a foot of the furface of the bed: in trenching, to throw the fides to the middle, and 
the middle to the fides, that there may be an equal mixture of the old tan. Thus will the bed be of a mild and equal temperature from the firft, and will continue much in the fame ftate for three or four months; and, after the firft filling, is attended with very little expence for new tan.

From the above, it is obvious, that, in filling the pit of a new Pinery, it thould either be done feveral months before the plants are to be placed therein, or hould be well fweated and reduced by turning, in an open fhed, \&c.; but it would be advifable not to plunge the pots above half their depth, for the firft two or three months after filling, in either cafe.

In adding new tan, it fhould always be thrown up in an heap for eight or ten days before it be ufed, in order to drip and fweeten; and thould never be applied frem from the tan-yard; being both wet, and apt to heat violently and cake in the bed, if applied in that ftate.

Some object to tan, on account of the expence and trouble attending the working with it: but, if the above method is 
practifed, thefe will be found to be inconfiderable; and, as the plants require frequent thifting, the ftirring up of the barkbed at that time is a trifling trouble, and fometimes the addition of new tan is unneceffary.

I am convinced there is no ingredient can be fubftituted for tan, that will equally anfwer the purpofe in the Pinery; and therefore would recommend the ufe of it, in preference to all others, where it can be procured on reafonable terms: but lefs or more of it is indifpenfably neceffary.

Oak-leaves are certainly the next beft material; but they are not to be had in many places. Where they are ufed, I would advife that at leaft eighteen inches of well-reduced tan be laid on the furface, wherein to plunge the pots.

A mixture of ftable-dung and tree-leaves of any kind, is the next beft ingredient. But thefe thould be well fermented before they are ufed, and at leaft two feet of reduced tan fhould be laid on the furface. 
Some have underftood the reafon why Pines are planted in pots inftead of the furface of the bed, to be the want of permanent heat in it; that they may be removed with the greater facility in the time of renewing the bark, \&c. This is not my idea of the matter. For were the heat of the bed rendered ever fo permanent, I would rather grow my Pines in pots : and here let me obferve, that I would never with to be concerned in the culture of Pines, unlefs I had at leaft two diftinct compartments for the purpofe. All plants of any kind do not grow alike in their native clime; much lefs the Pine in an artificial one. Hence the neceffity of at leaft two compartments, and growing the plants in pots; that they may be removed and claffed, according to circumftances, with the greater eafe and fafety. Moreover, many plants, in any fituation, do much better in pots than otherwife: of thefe are all the fucculent tribe; and furely the Pine may be reckoned amongft them. 


\section{anome}

SEGTION III.

On Propagating the Plants.

DINES are propagated moft fuccefs1 fully by crowns, produced on the top of the fruit, by fuckers produced from between the leaves, and by fuckers produced from the root of the old plant. Thefe laft are the moft defpifable, and fhould never be ufed except in a cafe of neceffity. The crowns are twifted from off the fruit when ferved at table; the fuckers, by breaking down the leaf immediately under, and moving them gently from fide to fide: but this is not to be done till the under part is ripe and of a brown colour, otherwife the fucker is apt to break by the middle.

Much ftrefs is laid on the article of drying them; fome recommending a week, others a fortnight, and fome the laying them on the fhelves, flues, \&c. of the ftove: but if they are perfectly ripe, and the old plants have had no water for a week or two before they were taken off, 


\section{CH. 9.]}

PINES.

(which they ought not), nothing of this kind is neceffary.

The crowns are gathered one by one, as the fruit is ufed; and fhould be ftuck into the bark-bed till the whole crop, both of them and fuckers, can be potted together Let a few of the bottom-leaves be rubbed off with the thumb, and let the under part of the ftump be fmoothed with the knife; and place them in pots of three or four inches in diameter and five or fix deep*, (according to their fizes), being filled with entire vegetable mould of decayed tree-leaves; in the bottoms of which thould previoully be laid a little clean gravel, of the fize of horfe-beans, to the thicknefs of an inch.

Meantime, let the nurfing-pit be prepared for their reception; and, deviating

$$
\mathrm{M}_{4}
$$

from

* Pots of this proportion are not generally to be had; but where there is a ftock of Pine plants, there fhould be a fet of pots of all fizes made for them on purpofe, three or four inches deeper in proportion to their width, than thofe in general ufe. My reafon for which is, that a handful of clean gravel may be laid in the bottom of each pot, which I find is of infinite fervice to the plant: the Pine requires frequent refrehings with water, but will not bear the fmalleft degree of its ftagnation. 
I84 THE FORCING GARDENER. [B. I. from the rules given in laft Section, let new tan, to the extent of a fifth or fixth part, be added; but fuffer none to lie within ten or twelve inches of the furface. Here plunge the pots quite to the brim, in regular order, at the diftance of two or three inches pot from pot each way, and keep them perfectly level.

It may here be expected, that I fhould fay whether crowns or fuckers ought to be preferred. To be plain, I do not prefer a good fucker to a good crown; for, if the fucker has the advantage of being a ftronger plant, it has alfo the difadvantage of running to fruit more untimoufly than the crown.

\section{SEGTION IV.}

On Preparing the Mould; and what Kind is fittef for the Pine Plant in its different States.

VEgetable mould being a chief ingredient, a ftock of it fhould be provided wherever the culture of the Pine is followed. The kind to be ufed here is that from decayed tree-leaves, and thofe of the oak 
oak are to be preferred; but where a fuffcient quantity of them cannot be had, a mixture with thofe of the afh, elm, birch, alder, maple, fycamore, \&c. and indeed any kinds, that are not refinous, will anfwer very well.

In Autumn, and immediately as the leaves fall *, let them be gathered and thrown together into an heap, and let juft as much light loam, as will ferve to keep them from being blown abroad by the wind, be thrown over them. In this ftate let them lie till May; and then turn them. over and mix them well; they will be rendered into mould fit for ufe by the next Spring; but from fticks, \&c. being amongft them, will always require to be fifted before they are ufed.

Strong brown loam is the next article. This fhould confift of the fward of a pafture if pofible, which hould, previous to

ufing,

* They fhould never be fuffered to lie above a day or two, otherwife they lofe much of their virtue; but Thould be gathered into an heap as they fall, in order to bring on a fermentation while they retain their 12line juices. 
ufing, be well reduced, by expofing it a whole year to the action of the weather.

Pigeon-dung alfo, that has lain at leaft two whole years in an heap, and has been frequently turned, and well expofed to the weather, is to be ufed. Alfo, fhell-marl. And laftly, fea or river gravel, which should be fifted and kept in a dry place; fuch part of it as is about the fize of marrow-fat peas is to be employed.

This is the proportion:-For crowns and fuckers, entire vegetable mould, with a little gravel at bottom, to frike in; afterwards, three-fourths vegetable mould, one-fourth loam, mixed with about a twentieth part gravel, and a little entire gravel at bottom, till about a year old. For year olds, and till fhifted into fruiting pots,one-half vegetable mould, one-half loam; to which add about a twentieth part gravel, and as much thell-marl, with a little gravel at bottom, as above. For fruiting in, one-half loam, a fourth vegetable mould, a fourth pigeon-dung, to which aỏd gravel and marl as above, and lay two inches of entire gravel at bottom. 
Of this compofition has been the mould I have ufed for years, with, perhaps, as general fuccefs as moft gardeners. But my ideas are not fo contracted as to prefume, that this may not be deviated from, in any cafe, or that it cannot be improved. It is given as what I confider to be a good medium foil for the production of the Pine; and with the hope that the candid will apply, improve, or partly reject, according to circumftances and practical obfervation.

SECTION V.

On the Treatment of the Plants the Firft $Y_{\text {car }} *$

F the plants were ftruck (as is directed 1 in Section III.) about the firft of September, the bed will continue of a kindly heat till the firft or middle of November, and muft then be worked over, and about an eighth part of new tan trenched in.

The

* I reckon the year from the Ift of September, fuppofing the crop to be all cut, and the crowns and fuckers to be fruck at that time. 
The plants will alfo have made good roots by this time, but will not generally require frelh potting; therefore, let fuch only as are anywife matted, be put into pots of the next fize immediately above thofe they are in, obferving to take off the matted part only, and put them in, balls entire.

Plunge them to the brim as before, and let them remain till the Ift of March.

At this time, let the bed be worked over as directed in Section II.; let the plants have the mould entirely thaken from their roots, be put into the fame pots, and plunged as before. Here the roots which are frefh are not to be difturbed; only cut away thofe that are wafted, and any rotten part about the bottom of the ftump.

They will now grow vigorouly, and will again require potting about the firft or middle of May; at which time alfo, let the bed be ftirred up to about half its depth, and if necelfary, let a little new tan be worked in. Put the plants into pots of about fix inches in diameter * on a medium, according

* This is always to be underftood as the infide diameter at top, and the particular number of inches fpecified, to be a medium for the plants according to their \{́zes. 
according to their fizes, with the balls entire; and if any of them are matted, difplace that part; plunge them to the brim, at the diftance of about fifteen inches * from centre to centre of the plants, and give a little water.

About the firft of Auguft they will require freth potting, and if there are three compartments, being removed into the fucceffion-houfe. Let the bark bed be worked to the bottom at this time, the plants put into pots of eight inches in diameter, plunged to the brim at the diftance of fixteen inches on a medium, and fettled with a little water.

\section{SECTION VI.}

On the Treatment of the Plants the Second Year.

A Bout the middle of November, the I bark-bed will require to be worked over to laft for the Winter; the plants muft not be fhifted at this time, but let any decayed leaves about their bottoms be twifted

* This muft be underftood of the largeft plants; a foot will be fufficient for the fmall ones. 
ed off, let a little frefh mould be laid on the furface of the pots if requifite, and replunge them to the brim as before.

I would here obferve, that I difapprove of the cuftom of tying up the leaves of Pine plants at the time of fhifting or potting; the intention is to keep them from being bruifed, but they are generally much more bruifed in the tying, than when left loofe. My method has been, to have a perfon ftanding oppofite me in the time of potting, (performed on a ftage or table about a yard high), whofe bufinefs was to hold up the leaves in a loofe though regular manner between the arms, and prepare and hand the pots, while another hands and fets afide the plants. In this manner I have often fhifted an hundred one-year old plants in two hours.

In carrying the plants through the doors of the ftove, the perfon thould turn back foremolt, by which it is eafy to fave the leaves from injury, as in that cafe the pot goes firft, and the leaves are drawn backwards.

By the firft of March, the plants will again require fhifting, and the bark-bed trenching 
trenching as before. Let the plants at this time be fhaked out, and replaced in the fame pots, in entire new mould, cutting off any decayed roots, or the end of the ftumps, and twifting off a few of the bottom leaves, \&c. Replunge them as before, and give a little water.

About the firft of June they muft again be fhifted. Work over the bark-bed to about half its depth, and add a little frefh tan if neceflary; place the plants, balls entire, into pots of about ten inches in diameter, plunge them at the diftance of eighteen inches from centre to centre, and fettle with a little water.

In potting at all times, a few of the bottom-leaves fhould be twifted off, that the plant may make frefh roots to furnith the furface, which alfo tends to keep it fteady in the pot.

SECTION VII.

On the Treatment of the Plants tbe Tbird Year.

BY the middle of Auguft or the firft of September, the plants muft be put into their fruiting pots, and fhould be placed 
in the fruiting ftove; and for their reception, the bark-bed therein muft be prepared, by trenching it to the bottom, and adding about a tenth part of new tan. Put the plants into pots of a foot in diameter, plunge them to the brim, and give a little water. In potting, a fmall ftick fhould be ufed to tindle down the mould between the ball and fide of the pot, fo as to leave no cavity, and this thould be obferved at all times.

About the middle of November, the bark-bed will require to be ftirred to half its depth, and a little frefh tan added; but the plants are not to be thifted at this time; therefore, replunge them to the brim again for the Winter.

It is common at this time, to add a great deal of new tan, in order to keep up a ftrong bottom heat through the Winter; than which, nothing can be more erroneous in my idea of the matter. I have already faid, that the bottom and fuperficial heat ought to correfpond at all times; and if the houfe is to be worked to $60^{\circ}$ only, for the Winter, it certainly follows that a very moderate degree of bottom heat 
is fufficient. The temperature of the houfe being fo much reduced in Winter, is to prevent the plants from ftarting too foon into fruit; and their doing fo, is frequently more in confequence of too much bottom heat, than irregularity in the climate.

By the firft of February, (the beft howing-feafon,) the bark-bed will require trenching; and this is the only time of the year that I would advife a deviation from the rules given in Section II. From this time, the houfe is to be worked as high as $70^{\circ}$; and that the bottom heat may keep regular pace with the fuperficial, new tan to the extent of a fixth part may be added.

Such of the plants as are not fhown at this time, are healthy at the root, and ftand erect and firm in the pot, fhould have a little frefh mould laid on the furface, by the removal of about two inches of the old. But let thofe that are already foozn, and thofe which are anywife unhealthy, or appear ftinted, be foaked out entirely, and replaced with freth mould in 
the fame pots; but none of the roots, unlefs wafted, muft be cut away.

The above, in refpect of the plants that are ßowon, I prefume, has never been recommended before; and I am happy in being enabled to do fo with confidence. It has ever been a matter to be regretted, that Pines, from the want of fun and air in the Winter months, are apt to be ftinted, and how their fruit too foon; and that fruit fo thown, feldom come to be of any confiderable fize or flavour; the plants thus ftinted, being unable to nourifh the fruit; and thefe, from the want of funthine in the early months, coming far fhort in flavour to thofe matured at a later period.

I firft tried the experiment on.a dozen of plants; the half of which were in, and the other half paft the flower, at this time of the year. They were kept back a full month by the operation. Thofe that were paft the flower equalled, and thofe that were only in flower confiderably exceeded any of the others of their forwardnefs at the time of thifting. Being encouraged by my fuccefs, I treated my whole ftock 
of fruiters, in the manner as directed above, the following year; they were kept back to a better feafon, and fwelled their fruit to as good a fize as thofe that fhowed in February.

About the firft or middle of May, let the bark-bed again be trenched to the bottom, a tenth of new tan added, and the plants replunged as before; and no further trouble is neceffary on this head.

\section{andinas \\ SECTION VIIF.}

On the Temperature of the Pinery:

HOR the nurfing-pits, the fires will require to be lighted about the firft of October. Work fo as to keep the thermometer at nine at night, and feven or eight in the morning, as near to $* 65^{\circ}$ as polfible, till the firft of March, and then gradually increafe to $70^{\circ}$, at which continue, till fire heat is unneceflary.

For the fucceflion-houfe, light the fires as above, according to the feafon; keep $\mathrm{N}_{2}$ at

- Fahrenheit's fcale. 
I96 THE FORCING GARDENER. [B. I. at $60^{\circ}$ till the firft of March, and then gradually increafe to $65^{\circ}$ for the feafon.

And for the fruiting-houfe, work to $60^{\circ}$ till the firft of February, and then inftantly rife to $70^{\circ}$; increafe gradually to $75^{\circ}$ till the firft of March, at which work for the feafon.

Although it is not practicable to work to a degree as here ftated, yet the beft en- * deavours fhould always be ufed to do fo; and no perfon thould have the management of the fires, who has not alfo the charge of the houfe.

\section{SECTION IX.}

On the Admifiton of Air to the Pinery.

T Winter, even frofty air thould be ad1 mitted, but in a modérate degree, and always at the top of the houfe; but in frefh weather, at this feafon, air fhould be admitted to the extent that the thermometer may not rife to more than 5 degrees above the fire-heat medium, and that till the middle of March; after which, and 
for the whole feafon, not to more than Io. degrees.

In Winter, I have frequently made fires in the morning, folely for the purpofe of enabling me to admit air, and at the fame time keep up the temperature of the houfe.

Although the Pine (from its nature) does not appear to quickly feel the effects of bad management, there are few plants in reality do it more fo; and too due an attention to the temperature of the houfe, efpecially in Winter, cannot be paid, the want of which is almoft fure to throw the plants into fruit at an untimely feafon.

Very large portions of air fhould be admitted to the fruiting-houfe, while the fruit are ripening; this is not only effential to the flavouring of the fruit, but high. ly conducive to ripening and hardening the fuckers.

Some thade their pines at certain times; but I cannot conceive this to be neceflary, except perhaps in ftriking crowns and fuckers; which, by the erroneous practice of drying them, have been enfeebled. 
On Watering and Steaming the Pinery.

T JTER muft be given fparingly to the plants in dull weather, particularly in Winter. From about the firft of October to the firft or middle of March, once in eight or ten days will generally be fufficient, and that in very moderate quantities ; but from March to October, plentiful waterings will be requifite, and confi. derable quantities at a time, generally once in three or four days.

The crowns and fuckers muft have no water for the firft fortnight after planting; and none over-head the firft Winter, left their hearts thould damp. Indeed I do not advife watering much over-head, except in clear weather, in Winter. But, in the Summer months, my practice has been, firft, to give the quantity requifite to the root, from the fpout of the wateringpot; and then a fufficient quantity to wet every part of the leaves from the rofe. 
My reafon for which is, that I have found the different kinds of Pines require very different quantities of water. The Queen requires a third more than the King, Antigua, or Brown Sugar Loaf; and the Montferat and Green or Stript Sugar Loaf, require a medium quantity between the two. I fpeak of plants in an equal ftate of health and fize.

The fruiting-plants will require very large quantities of water, from the time they are out of flower, till they begin to colour; which fhould then be gradually withheld, and, towards its maturity, totally. This will enhance the flavour of the fruit, and perfect the ripening of the fuckers.

Water frequently with the drainings of a dunghill in the Summer months; but not in Winter: as at this time the plants are in a dormant ftate, they imbibe little nourifhment; and this kind of water caufes a ftench, and produces foul air in the houfe, which cannot be fo conveniently drawn off at this time as in Summer.

I neither think fteaming neceffary nor hurtful to the health of the Pine, except $\mathrm{N}_{4}$ 
in hazy, dull weather in Winter, at which time it is certainly prejudicial. Therefore, if there are grapes in the ftove, regulate this matter for their fakes alone, without referve.

Soft, and zell-aired water fhould be ufed at all times; and fhould be applied either about eight in the morning, or four or five in the afternoon.

\section{SECTION XI.}

On the Maturation and Cutting of the Fruit.

COME kinds put forth fuckers at the 1 bafe of the fruit; which thould be rubbed off as they appear., Others put forth fuckers from the root; and, as thefe are not proper to be taken into the ftock, they fhould alfo be twifted off, or otherwife deftroyed, as they appear.

It is certain, that if a plant were to be divefted of all its fuckers, the fruit would grow to a much larger fize in confequence; but as this would ultimately tend to the extirpation of the whole ftock, it is by no means advifable. However, it is proper to reduce 
reduce the number of fuckers on the plant to two or three at moft. This fhould be done in the May fhifting; or when the fuckers are about half grown. Choofe the beft, and deftroy the others by breaking out their hearts. But where the increafe of the ftock is the object, all fuckers, even of the root, fhould be encouraged.

Some of the kinds grow on long footftalks, which are apt to bend down as the fruit gets heavy. Thefe fhould be fupported to fmall ftakes, \&c.: For if the fruit fall over, the ftalk will be bruifed, and its nourithment will thereby be obftructed.

Pines lofe much of their flavour if they are fuffered to grow till dead ripe: and where the gardener is not reftricted, he fhould always cut them by the time the fruit has attained to a greenifh-yellow colour; and either let them remain in the heart of the old plant, or lay them on the wall-plate, \&c. in the ftove, for a few days afterwards.

If required, Pines may be preferved in good order for feveral weeks after they are cut, in the following manner :-Cut them, ąs above, with the ftalk as long as poffible; 
put it into a bottle of pure water; which renew every two or three days, and at the fame time pare a thin lice off the end of the ftalk; and place it in a temperate and well-aired room of about 60 degrees.

It may be expected here, that I thould fay fomething in refpect of the flavour of the different kinds. This I choofe to avoid, as men's palates are as different as their minds; but I would obferve, that the Queen is moft to be depended on for a fure and regular crop. The Antiguas and Brown Sugar Loaf grow the largeft of any, and make a noble appearance on the table; but they frequently fruit untimounly. I have had a few plants of the Montferat which did not fruit till the fifth year; and I was then under the neceflity of placing them in the green-houfe for a fortnight, in order to give them a check. The King is, of all others, my favourite; and I have been at much pains to difcover the bent of its nature. I find it requires much lefs water, and a greater quantity of gravel, both in the mould and at the bottom of the pot, than any of the others. 


\section{SECTION XII.}

On the Injects that infeft the Pine; and bow to deftroy them.

THESE are, the brown and white fcaly

I infect, of the coccus tribe; to which may be added the ant. But, as I could never difcover that thefe laft do any harm to the plant, and as they are feldom feen if the former be not prefent; I am rather inclined to think, that their prefence is in confequence of that of the coccus, on which they feem to feed. The brown fcale does no other injury to the plant than dirtying it, and therefore is of little importance. But the white fcale, or bug, is of the moft mifchievous nature to the plants; and where it abounds, little good may be expected of them.

For my own part, I have been fo far happy in this refpect, that I have never had it in my power to try experiments for their deftruction, but once; and as I was completely fuccefsful, I thall candidly lay. my method before the reader.

When 
When I went to Wemyis Caftle, the whole ftock of Pines * were infected to that degree, that I had obtained permiflion, and was determined, to throw them out; but having built a nurfing-pit, and not having immediate occafion for it, I bethought myfelf, and treated them in the following manner. I prepared a ftrong heat for them in the bark-bed of the nurfing-pit; thaked out, and cut every fibre from their roots, (whereby they were rendered the fame as fuckers at firft), not excepting thofe that were in fruit, fome of which were juft in flower' dipped them into liquort, the fame as is recommended in Chapter III. Section VII., excepting the turpentine; put them into pots, fix inches in diameter, and plunged them to the brim; kept up a fire heat to about 75 degrees; gave them but little air; fhaded them in funfhine; and gave them plentiful

* Thefe were in a fmall ftove in the old garden; the new garden and hot-houfes not being then built.

+ This experiment gave rife to my trying it for other infects; but I found it ineffectual for the deftruction of the caterpillar and grub, without the addition of turpen. tine. 
tiful waterings over head with the fame mixture reduced to about half its former ftrength.

I continued this treatment for two whole months. At the end of which, I again fhaked out their roots, and wanhed the whole plant in pure water; put them into freth pots, eight inches in diameter; replunged them into a kindly heat in the other nurfing-pit; and treated them in all refpects as other plants. I never faw a veftige of the bug afterwards; and of thofe very plants were produced my principal ftock. A few indeed of thofe that had thown fruit died; but the others brought fuch fruit as might have been expected from plants of their fize, of any other kind. 
206 THE FORCING GARDENER. [Bं, t;

CHAPTER X。

STRAWBERRIES.

7HIS fruit is forced in moft gardens

1 where there are hot-houfes of any kind; and, being generally underftood, with equal fuccefs. I fhall therefore be very brief in treating of it here; the only reafon of my doing fo at all, being to render this work as complete and ufeful as poflible.

Strawberries are brought to early perfection in the pine-ftove, vinery, peach-houfe, \&c. But, in my opinion, the cherry-houfe is the fitteft for its production, as the climate there coincides more nearly with its nature. As a compartment wholely for its ufe, flued pits are beft adapted; and might be advantageoufly employed, in the 
latter part of the feafon, in the production of melons, \&c.

In any fituation, the plants fhould have plenty of free air, efpecially when fetting and ripening; and be abundantly fupplied with water till the fruit begin to colour; after which, very moderately.

My method of preparing the plants for forcing is this :-In the middle of July, or firt of Augurt, (when the runners of Strawberries out of doors are producing fine young plants), fill pots, of ten or twelve inches in diameter, with ftrong, rich loam; and plant three or four in each : fettle them with a little water; and place them behind a wall, \&c. to thade them, till the plants have taken root; after which, plunge them to the brim in any dry open fituation in. the garden.

Drefs off their leaves in Autumn; cover them with a little litter in Winter, to prevent the pots from being wafted by the froft ; pinch off any flowers that may appear in the Spring; keep them clear of weeds, \&c. in Summer, and in dry weather refreh them with a little water; and in 
208 THE FORCING GARDENER. [B. I Autumn drefs off the leaves, \&c. as before. They will be fit for forcing any time after Chriftmas._Of all the kinds, the fearlet is to be preferred.

As the plants are of no ufe after being forced, a quantity thould be prepared as above, every feafon, where they are in requeft. 


\section{CHAPTER XI.}

THE GREEN.HOUSE.

\section{nesene \\ SECTION I. \\ On the Confrucion of the Green-Houfeo}

THIS compartment being an object of 1 tafte alone, is more fubject to diverfity in its conftruction, and that too with more propriety, than any other in the garden. And although the gardener (if a judge) fhould have the fole direction in building the different fpecies of forcinghoufes; yet the fancy of the proprietor, I fpeak in general terms, in refpect of the Green-houfe or Confervatory, may be more fafely indulged in: fince nothing is at ftake here in comparifon to what is in the pinery, grape-houfe, or peach-houfe.

Many Green-houfes are not paved. This, in my opinion, is erroneous; as the water that drops from the plants, in watering, caufes much damp in. Winter, which is 
very prejudicial to the health of the plants. Water fo fpilt thould be inftantly wiped up; and this cannot be done where the floor is of earth or fand. The floor thould therefore be bedded on brick-bats, ftonechips, furnace afhes, \&c.

Air and light, in Winter, being of the utmoft confequence to the health of the plants, the free admilfion of them thould be ftudied in the conftruction; and, at the fame time, that wherein a great deal of fire heat may not be required, which tends to draw the plants up weak in Winter and Spring.

Plate VI: reprefents the plan of an approved Green-houfe, for breeding and bringing young plants to an early flowering ftate. But where elegance in the building is ftudied, and the front is to be of free ftone; architecture and mafonry may have their full fway , in any of the orders but

that

* The Green-houfe at Wemyfs Cafle is fuppofed to be the moft elegant of any in this country. The front is of freeftone : and done to the Corinthian order, in the lighteft manner. The windows are circular; whofe width is fix feet and an half each, and the pilafters onJy eighteen inches. - It is placed in the centre of the principal range of hot houfes, and has a very fine effect. 
that of the Gothic, without much inconvenience to the plants: but this laft, from the conftruction of its arches, is of too dark a nature for their welfare*.

\section{SECTION II.}

On the Temperature of the Green-Houfe.

I ITtLE fire-heat is necellary here; ex1 cept in the time of a fevere ftorm, or in long-continued dull weather, to dry off damp. In the former cafe, the thermometer, in the night, fhould not ftand above 50 degrees at any time; nor thould it be under 40 degrees, as otherwife many tender plants might fuffer. In the latter cafe, it may fometimes be advifable to light pretty

- ftrong fires, in order that large portions of air may be admitted: at which times, if the thermometer ftand above 35 degrees, it is fufficient.

$$
\mathrm{O}_{2} \quad \mathrm{SEC}-
$$

* In fome late defigns, where an elegant Greenhoufe has been wifhed as a centre-piece, I have thewn a glafs, inftead of a flate or lead roof; a matter of evident utility, as thereby the plants enjoy both a perpen. dicular and horizontal light. 
On the Admifion of Air to the Green-House.

A IR and light are of the greateft conA fequence to the welfare of the plants; and ought to be encouraged at all times. In fome Green-houfes, it is common to cove at night with canvas, mats, \&c. in order to fave fuel in winter. Thefe thould always be removed betimes in the morning, to admit the rays of -light as they break from the horizon; and fhould never be put on at night till the twilight, to exclude them. A free and large circulation of air muft be admitted, according to the weather; even frofty air in Winter muft not be entirely excluded, efpecially in funfhine.

In the Spring, keep the houfe cool and well-aired; otherwife the plants will grow both too tender and too rapidly, to bear the weather when fet out of doors, without being much hurt at firft : and for feveral weeks previous to the plants being put out, 
CH.II.] THE GREEN-HOUSE.

the houfe thould ftand open, to its fulleft extent, both night and day. Let it alfo remain open for feveral weeks after taking the plants in, in Autumn, left they begin to grow, which is not advifable at this time.

\section{SECTION IV.}

On Watering the Green Houfe.

A CCORDING to the variety and nature A of the plants herein contained, fo is that of the quantity and frequency of watering: and hence the impropriety, nay impoffibility, of any rule being given.

- The judgment and difcretion of the gardener muft here be entirely relied on; but a few hints may be ufeful. Plants are like infants : they will complain when hungry or thirfty; and, like them, too, fhould be timouny prevented by the indulgence and care of the nurfe. Is it not painful to think, that an infant fhould cry and endure pain for what it cannot exprefs? Even fo with a plant. I have often felt much pain in feeing a plant flagged for want of that

$\mathrm{O}_{3}$ very 
very element without which it could not long exift; and the more fo, if want of attention was the caufe.

On the other hand, an infant may be much hurt (nay, killed) by being too much glutted with food or drink, efpecially if of a bad quality. So it is with a plant. Therefore, the niceft obfervation is necerfary, to difcover their natural inclinations; and which fhould be treated and encouraged in a kindly manner at all times.

In Winter, and when the plants are in a dormant ftate, it is fafeft rather to give too little than too much water; and the contrary in fummer, and when the plants are in a vigorous growing ftate.

A practice too commonly prevails, of placing a flat or faucer under the pots, efpecially of plants kept in the drawingroom or parlour; which may be very proper, for the fake of the furniture; but which is too generally of mifchievous confequence to thefe fhrubs. If the faucers were emptied fo foon as the fuperabundant water has filtered through the earth of the pot into them, it were well; but if left there to ftagnate, it muft of neceflity ope- 
CH. II.] THE GREEN-HOUUSE. 215

rate to the deftruction of the roots, and ruin of the plants.

In the fpring, when in the houfe, and in dry weather in Summer, when out of doors, they thould be occafionally wafhed with the hand-engine, in order to refrefh and keep the foliage clear of duft, \&c. and in Winter, any water that may be fpilt in watering fhould be carefully wiped up, to pre vent noxious damp.

SECTION V.

On the Compoft Mould to be ufed in the Green-Houfe.

WHAT I have faid in the laft Section, in refpect of the nature and inclination of the plants, might with equal propriety be faid here. I will therefore only drop a few hints on this fubject.

Many kinds of mould are neceffary, to form the many different compofts that are required; and where there are a great variety of plants, and their culture is indurtrioufly ftudied, the following ought not to be wanting:-

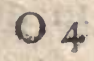

Clay, 
Clay, gravel, fand, "ftrong loam, light loam, peat-earth, mofs, marl, vegetable mould, lime, and rotten dung. Out of which, according to the nature of the plant, may be formed a compoft of any kind for its ufe. But of this, a novice cannot be fuppofed a competent judge: Some practice, and much obfervation, are meceffary requifites.

\section{mones \\ SECTION VI. \\ General Obfervations.}

T $T$ is neceffary to put out the greater part 1 of Green-houfe plants in the Summer months, in order to harden and keep them in thape; but they thould not be fet out before the frofts are quite over, which is feldom before the firtt or middle of June. For two or three weeks, they thould be placed behind a wall, or other fence, to thade them from the violence of the fun, and keep them from being fcorched, or otherwife injured by the weather. After which, they may be placed in any form or fitua- 
CH. II.] THE GREEN-HOUSE.

tion which fancy requires; provided the expofure is fuch, that they may enjoy at leaft one-half of whatever funfhine there is. Here let them remain till the end of September or Ift of October, according to the weather.

Some of the tender kinds will require to be let ftand longer in the houfe in the Spring, and taken fooner into it in $\mathrm{Au}$ tumn, than the others.

The beft time for general fhifting or potting, is, when they are removed out of or into the houfe; but individuals may be frefh potted at any time.-The luxurious growing kinds fhould be rather under-potted, and kept in ftiffith foil; which will tend to check their growth.

Thefe plants look much better, when of an ordinary fize, than when fuffered to grow tall, and with naked ftems. Therefore, they fhould be frequently headed down and trimmed; fo as to make them put forth young fhoots in every part, if polfible. They fhould alfo be divetted of all dead branches and leaves as they appear, at all times.-Young plants of all the kinds that will, thould be fruck every

fearon; 
feafon; and the others thould be propagated by layers, budding, or grafting, in order to keep up a ftock.

On the ftage, they fhould be placed, in manner of an amphitheatre; regular, thin, and the kinds thould be as much intermixed as poffible, which gives the better effect to the whole. They thould be frequently turned round to the fun, in order to make them grow upright and equal on all fides.

The flower there plants grow, the better; provided they do grow, and are healthy.

The aphis and thrips are often very troublefome in the Green-houfe; which fhould therefore be frequently fumigated. with tobacco, in order to deftroy them. 


\section{CHAPTER XH.}

EXPLANATORY OF THE PLATES.

\section{SECTION I.}

\section{Explanation of Plate $I$.}

FIGURE I. reprefents the plan and 1 fection of two nurfing-pits, on a conftruction that will equally anfwer the ftriking of young Pine-plants and forcing Afparagus, Cucumbers and Melons, Strawberries, French-Beans, Sallads, Flowers, $\& c$.

For the conveniency of fhifting the tan, \&c. the pit is funk to the depth of $a$ yard below the ground level, but where the fituation is not perfectly dry, this is not advifable; therefore, if the fituation is damp, the pit fhould be built on the furface, and a loping bank fhould be raifed 
all round, to the height of a yard, againft the fides and ends; and this I chiefly advife, on account of the value of the front flue, which may be fo eafily rendered ferviceable in raifing early fallads, \&c. on a well-prepared border immediately adjoining thereto, as hinted in the note, page Ig.

Here the furnaces are placed behind, communicating firft with the front flues, which return in the back, fingly. The furface of the bark-bed is level with the bottom of the flues all round, a cavity feparates the front flue from the bark-bed, and confequently no apprehenfion of burning need be entertained. The inner wall of the flue is a brick on edge, and for the fake of ftrength, the outer wall a brick on bed.

Although in this defign the divifions are but thirty feet long each, yet were a greater extent required, they might be made forty, as a furnace is perfectly capable of working that much, if the pit is of the fame width.

One length of a fath is fufficient here, and they are worked in the manner of a 
5. 12.] EXPLANATION OF THE PLATES. $22 Z$ common hot-bed, with faftenings at top to keep them from nipping down.

Fig. 2. reprefents the plan and fection of a fingle-pitted Pine-rtove, on an improved and much approved conftruction, either as a fruiting or fucceffion houfe, worked by two fires, and having a thed behind, which will be found a great conveniency in many refpects; fuch as the keeping of moulds, tan, \&cc.; and it is alfo well adapted to the cultivation of mufhrooms.

The bottom of the bark-bed is level with the circumjacent ground; and its furface is gently elevated, to the intent that the plants, when properly arranged, may enjoy an equal thare of fun and light. Some pay little refpect to this article, keeping the furface of the bed perfectly level, and placing the plants indifcriminately therein; but my method has been to arrange the plants in manner of an amphitheatre, that they might enjoy the rays of the fun more equally.

Trellifes are placed againft the backwall, ard upright fafhes in front, whereon to train the vines in this compartment; which is preferable to the method of train- 
ing them up the rafters, as is generally practifed. (See Section XII. on the Grape.)

Here mut be two lengths of fanes on the roof; the under ones fhould all be made to move either up or down, and the upper ones to move down alternately, to the extent of half their lengths at leaft. It is immaterial whether the upright fafhes are made to nip or not, as by moving the under ones of the roof upwards, bottom air can be admitted equally well.

Here alfo would fallads, \&c. fown on a well-prepared border, clofe by the front wall, reap great advantage from the heat of the front flue, which in this compartment requires to be kept very' hot all the Winter and Spring months, having the greatert command on the temperature of the houfe.

SEGTION II.

Explanation of Plate II. .

HIgure I. reprefents the plan and fec1 tion, and alfo the elevation of the front wall of a Cherry or Fig houfe, worked 
C. I2.] EXPLANATION OF THE PLATES. 223

by one fire, that communicates firft with the front flue, and has two returns in the back wall; which returns are made on the fuppofition of its being converted into a Peach-houfe at pleafure; but while it is appropriated to the cultivation of cherries or figs, the back flues fhould be fhut by a damper. See Chap. III. Sect. I.

The trees are trained to a trellis placed againft the back wall, and if the border is not occupied by French beans, fallads, flowers, \&c. a row of dwarf ftandards may be planted in front, within two feet of the fue. Two rows of ftrawberries may alfo be placed on thelves hung againft the upright fafhes in front.

The front fiue is run here in the fame manner as in the nurfing-pits, and confequently the fame advantage ought to be taken of it, in refpect of making a border for raifing early fallads, \& c. in front of the houfe.

It ftands on pillars and arches, which laft ought to be made as obtufe as polfible; but where lintels can be procured, they are preferable, and flould not be more than fix inches thick. The pillars thould 
be no thicker than the length of a brick at moft, that all the fpace poffible may be allowed the roots of the plants.

The faithes thould be of two lengths on the roof here, all of which ought to be made to move, but the upright ones may be made dead.

Fig. 2. reprefents the plan, fection, and elevation of the front wall of an approved peach-houfe, which is alfo worked by one fire, communicating firft with the front flue, and returning in the back. The front wall and front flue ftand on pillars, which ought either to be lintelled, or obtufely arched. The trees thould be planted near to the front wall, and trained to a trellis that covers the whole roof. This is a cardinal improvement in the culture of early peaches and nectarines, as their fize, colour, and flavour, are thus greatly enhanced: and if an impartial comparifon is made, it will be found, that by training peaches in this manner, a much greater quantity of fruit may be obtained for the fum expended in erecting the houfe, than by training them on the back-wall. There are evidently many more fuperficial feet in 
c. I2.] EXPLANATION OF THE PLATES. 225 the roof, than in the furface of the back ivall, of any hot-houfe.

The fafhes are all to be made moveable; both up and down, for the admiflion of air at top, bottom, and middle.

In the plan of there houfes, I have thewi no back-thed; but, if one is not erected, which in fome fituations may be very inproper, the flock-bole thould be inclofed with a wall, arched over, and a trap-door made to go down in manner of a thip's hold, over which, when not at work, may be laid a little mould, \&c. for concealment.

But where the appearance of the furnace is immaterial, it is of no confequence whether it be covered over or not; as, if the furnaces are built according to Fig. I. Plate V. they will be found to draw roell in any fituation.

Fig. 3. reprefents part of an efpalier rail on an improved confruction. Here the pofts are fet in blocks of ftone, which are placed under the furface of the border; and, for durability, the ends of the potts are burned, and run in with pitch. 


\section{sent

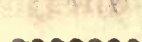 \\ SECTION III. \\ Explanation of Plate III.}

$H^{I G .}$ I. reprefents the plan and fection 1 of an approved Grape-houfe; worked by two fires. Here the front wall, and front flue, ftand on pillars which thould either be lintelled or obtufely arched, as above hinted. The vines are to be planted within a few inches of the front wall, and trained to a trellis which covers the whole roof.

Some build their front walls and flues on the furface, without fupporting them: this is by no means advifable; as, in this cafe, there is no poflibility of effectually renewing or trenching the border without endangering the wall and flue, which operation frequently becomes neceflary.

In this houfe, there are no upright fafhes; the length of the roof being of the greateft importance here. In houfes where grapes are trained on the roof, and which have upright fafhes, we generally find that part but indifferently covered with wood or 
C. 12.] EXPLANATION OF THE PLATES. 227

fruit; befides, it alters the pitch of the roof, which in a houfe for a principal Summer crop is certainly of importance.

Here muft be two lengths of farhes; all of which ought to be made to move at pleafure, in order to admit an equal and free circulation of air.

A houfe on this conftruction is alfo perfectly adapted to the cultivation of peaches; than which, I know not a fitter receptacle for the production of a principal crop; and, if requifite, it might be extended ten feet more in length, as the fires would command a fufficient heat for peaches.

In this cafe trees are to be trained againft the back trellis to the top, and on the front one to half its height only, that the trees on the back trellis may not be Ihaded by thofe on the front.

Fig. 2. alfo reprefents the plan and fection of a grape-houfe, which is divided, in order to afford a fucceffion of fruit. The front wall and flue ftand on pillars, that the roots may have a free range; the plants being planted near to the fromt wall, 
and trained to a trellis fixed to the roofbeams.

The fanhes are alfo to be double on the roof, and made all moveable, that air may be freely admitted in all parts of the houfe.

Fig. 3. reprefents the elevation of the front wall of either houfe, being the fame, except in length.

\section{SEGTION IV. \\ Explanation of Plate IV.}

HIG. I. reprefents the plan and vertical I fection of two divifions of a hot-wall, on a new and much-improved confruction.

Here the flue makes four returns; decreafing gradually towards the top of the wall, which is neceflary to the diftribution of an equality of heat to the furface; and here alfo the upper courfe of the flue is carried much nearer to the top of the wall than is generally done, which is of great utility in ripening the extreme fhoots of the tree, thefe naturally growing later 
C. 12.] EXPLANATION OF THE PLATÉS. 229

and more fpungy than thofe of the other parts.

Some who give defigns for hot-walls, advife building the breaft of the firft flue a brick on bed, and that of the other a brick on edge, witlout decreafing the depth of the flues as they afcend, in order to give an equality of heat to the furface. But this matter is better accomplifhed by the gradual diminution of the flues, as here fhewn, though the breaft of all the flues are a brick on bed. A wall of this kind is more fubject to the viciflitudes of the weather than a flue in a hot-houfe; and, confequently, the breaft of the flue being a brick an bed, will keep a more conftant heat, when once warmed, than when on edge. To prevent accidents, however, a trellis thould be fixed, or fpars an inch thick, nailed againft the firft courfe of the flue, whereon to drefs the trees; above which they may be dreffed to the wall without the leaft apprehenfion of danger. (See Chap. VIII. Sect. XI.)

Fig. 2. reprefents the plan and fection of a mulhroom-houfe, worked by one fire, and divided for the purpole of producing them $\mathrm{P}_{3}$ in 
in fucceffion, on a conftruction that has given fatisfaction for many years.

Little fire heat being required here, the flues of both divifions are gathered to the furnace, which works them both equally; and by the help of dampers, the one can be worked higher or lower than the other, with the greateft facility; or by ftopping the vent clofe, the one can be worked altogether independent of the other.

It is a matter of little importance in what fituation this houfe is placed, provided the bottom of the murhroom-beds be rendered perfectly dry, by draining, if ne= ceffary.

\section{SECTION V.}

Explanation of Plate $V$.

$H^{I G .}$ r. reprefents the plan, and horizon1 tal and vertical fections of a Furnace, on the beft conftruction yet difcovered for the ufe of hot-houfes; and to which, from a conviction of its utility, I would ferioufly advife a ftrict conformity. It is 


\section{c. 12.] EXPLANATION OF THE PLATES. 231}

laid down by a large fcale, which, I hope, will be found legible to, and underftood by every operative perfon, without the minu. tiæe of explanation. But i remains for me to give fome directions for the working of it, and to defcribe that which confitutes its principal difference from the common furace.

In the common hot-houfe furnace, the grate occupies the whole fpace allowed for the fuel, and is alfo generally placed on a level with the bottom of the flue, its entrance being thereby eafily choaked, which occafions what is termed an illdraiving furnace. And where the bottom of the flue is elevated above the grate, the confequence is worfe; in which cafe, the fire burns with fuch rapidity, that it is hardly poffible to regulate the climate of the houfe to the degree required; befides, there is a great wafte of fuel.

This is obvioufly occafioned by there being no fpace allowed for the fuel but the furface of the grate, through which, and confequently through the whole fire, the current of air muft pafs into the flue; whereby it is fuddenly exhaufted, and the 
flue heated to a much greater degree than required.

In thefe furnaces, the fire will not laft above three or four hours; which, in ftormy weather, and in Winter, occafions a conftant attendance, perplexity, and the impoffibility of regulating a climate in the hot-houfe. But all thefe objections are obviated by the furnace as here reprefented. Here the grate does not occupy one-third of the fpace allotted for the fuel; and, dt the fame time, is fuffciently large to kindle the whole mafs; which, when kindled, will keep of a moderate and equal temperature for many hours together. Here, alfo, the operator is not troubled with frefh lighting the fires every day; $-I$ have frequently known them to keep fire for ten days together without any addition of fuel. My method of regulating and working this furnace is as follows:

As after the firft lighting for the feafon, there is always fire remaining in the back part of the furnace, in kindling-up in the evening, \&c. clear all the athes from off the grate, and the fpaces at the fides 
C. 12.] EXPLANATION OF THE PLATLS. 233 of it, and bring forward two or three Shovel-fulls of fire to the front; behind which, throw the quantity of fiefh fuei required, thut the door clofe, and in the fpace of an hour or fo, revifit it to fee how the fire is burning. If it is burning too flow, ftir it up by applying the fire-poker (the end of which is turned up) underneath the grate, clearing the interftices of the bars the whole length; but if it is burning too rapidly, open the furnacedoor a little way; by which means the current of air will be divided, part of it pafling over, and part of it through the fuel. In the fpace of another hour, again pay it a vifit; (having previoully confulted the thermometer in the hot-houfe); and if the fire is confuming too faft, open the furnace-door accordingly; but if too flow,

- Thut it clofe altogether.

This method is much preferable to that of working by dampers, it being very difficult to hit on the exact proportion of the aperture to be left in the vent; be fides, whatever air paffes through the vent muft alfo pafs through the fuel, and that too with greater velocity than when the

damper 
234 THE FORCING GARDENER, [B. I, damper is not fhut at all, fince by the partial contraction of the vent the current will be increafed.

In moderate weather, I have generally found two fires fufficient for twenty-four hours; or rather, Itrictly fpeaking, a fire and an half: viz. a full fire, according to the feafon and temperature the houfe is worked to, about four or five in the evening, and half as much at nine at night. In fevere wcather, three fires at moft; viz. one at four in the evening, one at nine or ten, and one at fix or feven in the morning. But here obferve, that in this cafe, the furnace-door will generally require to be opened quite, after the fire is fairly kindled; as the flue will be kept conftantly hot, by the flow foaking heat of the furnace. And this is none of the leaft of the advantages which this furnace has over the other, as hereby the climate of the houfe is regulated, even in the moft ftormy weather, with a much greater degree of exactnefs.

By a fmall variation in the confruction of this furnace, almoft any kind of fuel may be ufed with fuccefs. Turf and fcreened 
fcreened cinders mixed in equal quantities make an excellent fire, and for which there need be no alteration made in this plan; but for turf or wood alone, the furnace fhould be made at leaft a third larger, and the grate confiderably fmaller.

Cinders, with a fmall portion of coal, or charcoal of pit-coal, is certainly the kind of fuel to be preferred to all others; on account that it caufes little fmoke, and confequently the flues keep the longer clean. It might therefore be proper, where there is a confiderable extent of forcing, to collect or purchafe cinders, or to have charcoal made on purpofe.

Fig. 2. reprefents the Winter pruning of three vine plants, and part of a fourth and fifth, according to my method. (See Chap. V. Sect. V.).

Plate VI. reprefents the plan, fections, and elevation of a green-houfe on an improved conftruction for breeding young plants, and bringing them to an early flowering ftate. See more on this fubject in Chap. XI. Sect. I. 


\section{SECTION VI.}

General Obfervations on the Conftruction of Hot-boufes.

Tound recommend the greateft fub1 ftantiality in the conftruction of all hot-houfes. The materials ought to be of the beft kind, the wood well-feafoned, and the workmanthip well performed, in a plain and neat manner. The joiner ought to be very attentive in making true and handfome joints, otherwife he may expect them to grin in his face before the end of the Firf year. The painter, too, ought to be careful in the performance of his part; if the colour is not well prepared and carefully applied, it will fcale off by the heat of the fun in Summer. But in order to keep the wooden part of hot-houfes in good repair, they require to be painted on the outfide every fecond year, and on the infide eyery fixth or feventh.

In glazing, I would feriouny recommend crown glafs, being far fuperior to the common; it admits much more light in dull weather, 
C. I2.] EXPLANATION, OF THE PLATES. 237

weather, and in funfhine allows of a larger portion of freth arr, and of kecping up the temperature at the fame time, which is certainly a great object in forcing. Befides, it is furnifhed as cheap as the common.

The price of the fuperficial foot of glafs varying according to the fize of the fquares, it is of importance not to make thefe too large; for inftance, a fquare which is twelve inches on the fide, and which contains juft a foot of glafs, is fold at tenpence; ( $\mathrm{F}$ fpeak of third crown); whereas, two fquares eight and a half by eight and a half inches each, and which contains the fame quantity to a mere fraction, is fold at fixpence halfpenny. So that the fmaller the fquare, the cheaper is the fuperficial foot of glafs; and this is occafioned by the fmall fquares being cut from the broke or wafte of the large ones, which, if the manufacturer has no market for, he is under . the neceflity of re-melting.

From the above, I would not wifh to infer that the fquares thould be made too fmall, as thereby the roof would not only be darkened by too many laps, but there would be too many aftragals in the fafh, 
and, confequently, the faving in glafs might be more than counterbalanced by the price of the fafh-work. The panes fhould be made perfectly fquare, however, and that for the following reafon:-I find they generally fplit longitudinally, if not broke by accident; which is occafioned by the wood, \&c. fwelling and contracting by the influence of the weather. The pane is not a whit the worfe; and, if it was perfectly fquare at firft, is as ufeful in the fame place as ever, by being taken out and reverfed. For this purpofe, the laps fhould be made half an inch at firft, and will now be a quarter, which is fufficient.

I would here obferve, that I difapprove of the method of puttying up the laps in glazing, as thereby foul air is confined in the houfe. The hot-houfe as much requires a free circulation of frefh air at all moments, as the dwelling-houfe; nay, more fo: Do not the flues make foul air in the houfe every moment they are at work?

Earthen flues, that is, flues whofe walls are of brick, and covers of tile, are to be preferred to all others; as they keep the moft conftant and agreeable heat of any, 
C. I2.] EXPLANATION OF THE PLATES. 239

and are alfo beft adapted to the purpofe of fteaming, where required. The foles of the flues thould be fupported from their foundations, in order that the heat may efcape from under them, and be diffufed through the houfe. A cavity of three inches is fufficient for this purpole; but the wider the fpaces between the pillarets, the better. Confequently, where pavement-flags can be had, they thould be ufed; if not, large tiles thould be made purpofely.

Where fre-brick and fire-clay can be procured, all hot-houfe furnaces, and about ten feet of the flue next to them, fhould be built therewith. This is more expenfive at firft; but in the end will be found to be a great faving, as they will laft for many years without needing repair.

Neat wooden or leaden fpouts fhould be carried under the eafing, and conducted to a ciftern placed in fome convenient part of the hot-houfe. No water is equal to that which falls from the heavens; and a very confiderable quantity may be collected in this way. 
In very wide houfes, it is cuftomary to erect light wooden or iron pillars to fupport the rafters, which are frequently a greater nuifance than ornament. This is done, not altogether becaufe of the inability of the rafters to bear the weight of the fathes; but becaufe the rafters fall down in the middle, which they would even do by their own weight, and obftruct the free running of the fafhes, in the admiflion of air, \&c. There is a method of obviating this matter, and rendering the pillars ufelefs; which, though very fimple, is perhaps not generally underftood, and therefore may be worth the relating.

Suppofe the rafter nine inches deep at either end, let it be made ten in the middle, rounding it gradually away to the extremities; whereby, when it comes to. fettle, the furface will become perfectly ftraight. This muft be underftood of the upper furface of the rafter and the fafhbeds, and not of the under fide; which laft will become roundion as it fubfides. This is what is termed, "cambering the raf"ter." 
In trellifing, iron-wire is a great improvement, efpecially when placed on the roof, as in Fig. I. Plate III. It is not only more durable than wood, but is nearly as cheap at firft, and is much lighter and neater. It fhould be well painted, to prevent it from rufting.

Hot-bed frames thould be made with fcrew-bolts at the corners, in order that they may be laid up when not at work, which is a great prefervation to them. They generally experience more decay by being toffed about and expofed to the weather in Winter, than in all the time they are at work in Spring and Summer.

I fhall conclude this Chapter by obferving, that, where there is an extenfive variety of hot-houfes, it is not only more convenient, but alfo more elegant, to have them ftanding in a range, than detached from each other. In this, uniformity ought to be ftudied. For inftance, if there is a green-houfe, place it in the centre; and the other forcing houfes in pairs, right and left, correfponding with each other refpectively.

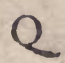

Although 
242 THE FORCING GARDENER. [B. I.

Although I have made the grape and peach houfes fifteen feet high each, and the pine-ftove only twelve; yet, for the fake of the above uniformity, the ftove might be made of equal height with them; obferving to raife the bark-bed in the fame proportion, that the pine plants may not ftand too far from the glafs. 


\section{BOOK SECOND.}

THE

\section{FRUIT GARDENER.}

\section{CHAPTER I.}

ON THE MAKING OF FRUIT-TREE BORDERS; PLANTING AND TRAINING FRUIT-TREES AGAINST WALLS, ESPALIERS, \&c.

\section{SECTION I.}

On the Conftruction and Situation of Garden-Walls and ESpaliers.

7 HIS is a matter of great importance:

1 A garden without thelter and a tolerably good foil, fo far as refpects the production of fruit, will remain, comparatively, a wildernefs. Therefore, the greateft, care is neceflary in the choice of the fite Q2 of 
of the garden; and it is frequently very difficult to find both a fheltered fituation and a kindly foil. The laft object, however, in my opinion, ought to give way to the firt, for the following reafons :-In a complete garden, different kinds of foil are abfolutely neceffary, particularly for the fruit-tree borders; and were the foil ever fo bad, there is no difficulty in rendering it otherwife, in the fpace of a few months; but where thelter is wanting, many years, even where the foil is good, are requifite to the production of it, in a tolerable degree.

A fine * garden is certainly a great luxury; and furely nobody would be at the expence of building and planting one, who

* The garden at Wemyfs Caftle is placed in the middle of a plantation whofe trees are an hundred feet high; for the fite of which, and alfo the fhrubbry, the whole ground was to clear. The half at leaft of the foil now within the walls was brought from the fields. The fruit-tree borders were all entirely made, and generally cut out of the rock; none of which are lefs than a yard deep. This was done merely for the fake of thelter; as there are fituations hard by, where the foil is excellent, but without fhelter. The garden was begun and finifhed within fixteen mpnths. 
who would not alfo wifh to fee it in perfection, and partake of its fruits. As, then, as it is prefumed, it will never arrive. to that perfection in this country without fhelter, which it may with it ; it is furely preferable to lay down a garden in a theltered fituation with a bad foil, to laying it down in an unfheltered one with a good foil; fince the one may be remedied in a few months, and the other, perhaps, not in a lifetime.

The happieft fituation for a garden is, a gently elevated hill, having a fouth, foutheaft, or fouth-weft afpect, encompaffed on all fides with plantations at the diftance of about one hundred yards from its walls. In this cafe, it thould be made a parallelogram, whofe breadth is equal to twothirds of its length, (according to the fize required), extending in length from eaft to weft. This is not only the handfomeft and moft-approved form of a garden; but it gives greater length of a fouth afpect than when made fquare. If the garden is very extenfive, it fhould be equally divided by a wall running north and fouth. 
Between the fore-mentioned plantations and walls, fhould be made a belt of low fhrubbry, walk, and border; that the walls may be covered on all fides with fruit-trees.

Brick is certainly the beft material for the conftruction of garden-walls; as being both better adapted to training, and of a more kindly nature for the trees, than Itone: and where the wall is not entirely compofed of brick, it thould at leaft be lined*. But where thefe cannot be pro-

cured,

* We have heard much of late, concerning the propriety of conftructing garden-walls of brick: I have faid above, that brick is certainly the beft material. I faid fo, in my firft edition of this work, five years ago; and from every obfervation I have made, in a pretty extenfive practice, I venture to hazard the fame opinion now. That black whin-flone is the next beft material, I am fully perfuaded: not altogether becaufe that black abforbs heat more than any colour, having proved black bricks to be fuperior; but that this fpecies of ftone is lefs porous than thofe of the free-ftone kinds. I have moreover found, that although brick is more porous than ftone in general, and confequently, abforbs moifture more readily; yet it alfo fooner expels moifture than Stone of any kind. Perhaps, therefore, if we wifh to arrive at the climax of perfection in this particular, we onght to put our garden-walls in mourning! 


\section{CH. I.] WALL-TREES.}

cured, and the wall is to be built of ftone, it fhould not be built in that rough, and irregular manner, which is too prevalent; but fhould be neatly done in courfes of not more than fix inches, and the furface in fome meafure fhould be dreffed with the iron, and rendered fomewhat fmooth for the trees being trained againft, without the fear of having their bark ruffled in windy weather.

Much has been faid concerning copping of garden-walls : fome advifing that there be no projection; and others three, four, and fome fix, inches of projection; in order to throw the drip off the foliage. All. which, in my opinion, is of no importance whatever. The quantity of rain that falls on a two-foot wall is but trifling; and does it not frequently happen, that the wind dafhes it againft the tree ere it fall to the ground, in either cafe *?

\section{Q4}

The

* A temporary copping of boards, projecting perhaps a foot, is certainly of infinite fervice to the trees in the fpring, while in bloom, in diverting or repelling the perpendicular frofts: But thefe frofts are lefs hurtful than frofty winds, which fall not perpendicularly. Therefore, as a complete remedy for both, I would advife the application of canvas fcreens, or nets, as recommended in Sect. XI. of Chap. VIII. 
The handfomeft and moft ufeful manner of copping is, to bevel off the ftone to the thicknefs of two inches on each fide of the wall, and give it as much projection; with a groove underneath, as is commonly practifed.

The moft eligible height for a gardenwall, and that which fuits the generality of fruit-trees beft, is fifteen feet; but where uniformity is ftudied, the height of the walls thould correfpond with the extent of the garden, or rather with the apparent extent. However, I would wifh the extremes to be fixed at ten and eighteen feet. I would be underftood here, as fpeaking of the height above the furface. And let it be obferved, that no garden-wall fhould be founded lefs than three feet, moft kinds of trees requiring a yard of foil.

Efpaliers are not only ornamental, but ufeful, in the garden, and are much to be preferred to ftandards; which both overfhadow the crops, and are liable to be thaken with boifterous winds, much to their detriment in the flowering and fetting.feafons. But, being neatly dreffed to a rail, many kinds of apples and pears will produce 
produce as well in this manner, as if trained to a wall.

Efpaliers are generally, with the greateft propriety, run parallel to the walls on the oppofite fide of the walk, and at the diftance of three or four fect from it. They are alfo run on each fide of the other principal walks which divide the garden, at the above diftance from their edges; which, when well covered with healthy trees, form handforme avenues.

For a reprefentation of part of an approved efpalier-rail, fee Fig. 3. Plate II.

\section{$\operatorname{sensen}$ \\ SECTION II.}

On the Breadth, Depth, and Compofition of the different Borders, for Apricots, Apples, Cherries, Figs, Pears, and Plums.

$\mathrm{R}^{\mathrm{Y} \text { the rules of proportion in laying out }}$ 3 of gardens, the border fhould be as broad as the wall is high; and the walk half as much. In this rule there is no variation, unlefs the wall is lefs than twelve feet in height, which, in my opinion, ought feldom to be the cafe; but if it is fo, the border 
border fhould not be lefs. For efpaliers, twelve feet is the medium breadth.

The depth for apricots, apples, cherries, and figs, thould be from two to three feet; that is, three feet at the wall, and two at the walk: and for pears and plums, four at the wall, and three at the walk.

If the fituation is wet, and the bottom a cankering gravel or clay, which is far from being an eligible fituation for a garden, drains muft be run along the front of the border to the depth of the bottom, to carry off the wet; and a kindly bed muft be made for the foil. This is moft generally done by paving with ftone or brick, but it is attended with an enormous expence; and if the bottom is not previoully rendered quite dry by draining, it is of little ufe. Therefore, let the draining be carefully performed; and practife the following method in making a bottom: which will be found to be preferable to any pavement, and much lefs expenfive.-

Let the bottom be laid, in a floping manner, from the wall to the drain, having a fall of fix inches. Firft, lay two inches of good loam, of any kind, which fpread fmooth, 
fmooth, and pafs the roller over; then, the fame quantity of clean pit or river gravel, which alfo gently fettle with the roller; over this, lay a fecond courfe of loam, to the depth of an inch only, and likewife pals the roller over it. All this muft be done while the materials are in a pretty dry ftate. But now the whole is to be made a little moift, and rolled till the furface becomes glazed; after which, water and roll alternately till it acquires a hard, fhining confiftency, and the gravel is in a confiderable degree appearing through the loam.

Thus will a bottom be formed, which no roots will penetrate, of a more kindly nature, and at a much lefs expence, than brick or ftone.

The fitteft compofition for apricots, apples, cherries, and figs, is-three-fourths light fandy loam, and one-fourth ftrong clayey loam, mixed with a competent quantity of ftable-dung, cow-dung, and marl, in comport; the apricots and figs requiring confiderably more dung than the apples and cherries. For pears and plums - threefourths 
fourths ftrong clayey loam, and one-fourth light fandy loam, mixed well with compoft, as above.

Yet I would by no means with to infer, that of fuch compofition only thould fruit borders be made; it being clear to demonfration, that trees thrive and produce fruit well, in different foils : but where the above materials can be procured, I would recommend a near conformity to this compofition, breadth, and depth.

To follow this mode of preparing fruittree borders, it is neceffary to clafs the different kinds of trees; that is, to keep the pears and plums by themfelves, and alfo the apples, cherries, \&x. by themfelves. And this may eafily be done, although fome of each are placed on the fame afpect; it is only determining on the quantity and fpace to be allowed for each kind, before preparing the border.

The compoft fhould be duly prepared before planting, by trenching and mixing it well two or three feveral times. And, in order to keep the mould in beart, a little well-reduced dung, or other compoft manure, fhould be digged-in each feafon; 
being careful not to injure the roots of the trees in the operation.

\section{SECTION III.}

On the different Kinds of the above Trees adapted to this Climate; the Afpect they ßould be placed in; and the Diflance from eacb other, according to the Heigbt of the Wall, छे.

7 HE following is a lift for the walls, 1 and the afpect they thould be placed in; out of which, thofe marked thus* are to be preferred.-But obferve, I do not wifh to dictate in this: every one has a right to choofe the kind that, fuits his fan$\mathrm{cy}$, and to place it in the fituation or afpect. in which it moft likely will fucceed.

Names. Apples.
Afpect.

S.

S. E. W.

S. E. W.

S. E. W.

S.

S.

S.

N. E. W.

Names. 
Names.

Afpect.

Apples.

* Wheelers do.

E. W.

* Nonpareil do.

S.

Nonfuch,

N. E. W.

Hawthorndean, N. E. W.

Apricots.

* Orange,

Ropnan,

* Bruffels,

* Breda, Turkey,

* More Park,

Cherries.

* May Duke, Arch-Duke,

* Holeman's Duke,

* Black Heart,

* White do.

Harrifon"s do.

Kentifh,

* Morella,

Figs.

* Blue Ifchia,

* Brown do.

* White do.

Black do.

* Black Genoa,

Brown Naples,
S. E. W.

S. E. W.

S. E. W.

S. E. W.

S. E. W.

S.

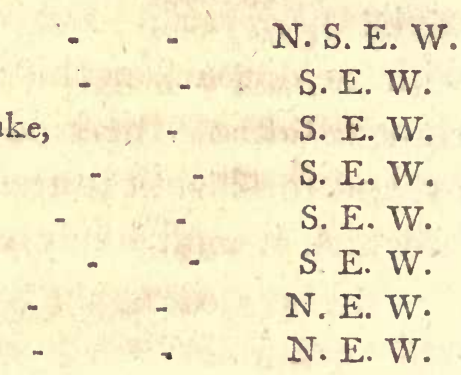


Names.

Pears.
* Jargonelle, Summer Bergamot,

* Autumn do.

* Swifs do.

Orange do.

* Ganfell's do.

* Creffane do. Chaumontelle,

* Burie de Roy, Terling, Swan Egg,

* Grey Achan, Colmar, St Germain's,

* Green Yair,

* Black Worcefter, Cadilac. Warden,
Afpect.

N. S. E. W

S. E. W.

S E. W.

S. E. W.

S. E. W.

S. E. W.

S.

S.

S. E. W.

S. E. W.

E. W.

N. E. W.

S. E. W.

E. W.

N. E. W.

N. E. W.

N. E. W.

N. E. W.

\section{Plums.}

* White Magnum Bonum,

S. E. W. Red do.

E. W.

* Green Gage,

* Yellow Gage, S.

* La Royale, S. S.

* Imperatriee,

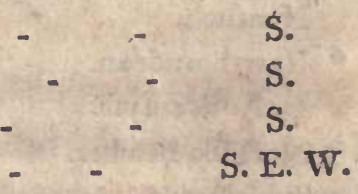


The following is a lift for the efpaliers; and, as thefe are generally equally and freely expofed, may be placed indifcriminateIy.-

\section{Apples.}

* Ribfton Pippin. Kentifh do.

* Oflin do. Englifh Codling.

* Kentifh do.

* Royal do. Dutch do.

* Royal Ruffet. Wheeler's do.

* Summer Pearmain.

* Royal do.

* Loan's do.

Green Leadington.

* Grey do. Yellow do.

* Summer Queening.

* Winter do.

* Yorkfhire Green. Nonfuch.

* Hawthorndean. Lady Wemyfs.

* Norfolk Beafing. Strawberry. Purfemouth.

Cherries.

* May Duke. Black Heart.
* Kentilh.

* Morella。

\section{Pears.}

* Crauford.

* Jargonelle.

* Yair.

* Black Worcefter.

* Cadilac. Warden.

* Achan. Moorfowl Egg. Drummond. Summer Bergamot. Scotch do. Lammas.

\footnotetext{
Plums.

* Orlean.

* White magnum bonum. Red do. do. Drap d'Or.

* Wine Sour.

* Damafk.
} 
The following is what I efteem a proper diftance at which the above, trees fhould ultimately ftand on the wall : but, as they will be many years in filling their fpaces, and as in moft kinds a few crops may reafonably be expected before that time, riders of cherries, pears, and plums, may be placed between them.

For a wall twelve feet high:-the apples to be placed at twenty; apricots, thirty; cherries, twenty; figs twelve; pears thirty; and plums, twenty feet apart. And for a wall fifteen feet high-apples, fifteen; apricots, twenty-four; cherries, fifteen; figs, ten; pears, twenty-four; and plums, fifteen feet apart. And fo in the fame proportion for walls of any height from ten to eighteen feet, which, as I have already hinted, ought to be the extremes.

For efpaliers:-apples, thirty; cherries, twenty; pears, thirty; and plums, twenty feet apart. But thefe fhould be planted at double thickners, placing two of a kind 
together, that, in thinning them out, any of the kinds may not be extirpated.

Maiden trees, of all the kinds, ought to be preferred; and the feafon for planting is, any time from the firft of December to the firft of March.

The Apples thould be chofen of fuch as are worked on crab ftocks raifed from feed, and the Pears on free ftocks, alfo raifed from feed. Sucker-ftocks of any kind are to be rejected, on account that they caure the plants to run much into unprofitable wood. The plants of all the kinds fhould be clean, healthy, and well-rooted.

The pits fhould be filled in with rich light mould, and that for all the forts without exception; as all trees are found to ftrike root moft kindly in light foil, although their nature may require a very different kind afterwards. Care fhould alfo be taken not to place them too deep; if the ftem is covered two inches higher than it was when ftanding in the nurfery, it is fufficient. It fhould be placed two or three inchès clear of the wall; for, if placed too 
near, that is, touching it, it has the effect of throwing the branches forward when they come to be of ftrength; fo that they are with difficulty kept properly dreffed. To fay that the roots of the plants are injured more or lefs by its being placed a few inches nearer to, or farther from the wall, would be abfurd; and yet this has been advanced.

Let them be fettled with a little water, and duly attended to with that element in dry weather, the whole of the firft Summer. Alfo, let a little mulch be laid round each of them; which will tend to keep their roots from being injured by the froft in Winter, and the early part of Spring, and alfo from being fcorched by the fun in Summer.

\section{SEGTION IV.}

On Training the different Kinds of the above Trees on Walls and Espaliers.

I. APPLEs. THESE trees may be trained either in the horizontal or fan manner, with facility. But I $\mathrm{R} 2$ prefer 
prefer the fan manner, not only for them, but for all other trees planted againft walls; for thefe reafons, viz. We can make the tree fill its fpace fooner by one-third of the time, and can alfo fupply the lofs of a branch with greater eafe at any period of its age. But for Apples on efpaliers, or on very low walls, the horizontal method of training is to be preferred; as the height of the efpalier, \&c. will not admit of fan training in a handfome manner. I thall, therefore, firft treat of fan-training, as for walls, and then of borizontal training, as for efpaliers.

Fan-Training.-After planting, let each of the thoots be headed down to three eyes, in order to make them purh Atrong, and furnith the wall from the bottom; and when the young thoots have grown fo long as to admit of being laid in, lay one on each fide, that is, the loweft, perfectly horizontal, and divide the intermediate ones equally at the diftance of ten or twelve inches. In the Winter, thorten them all back to from one-half to twothirds 
thirds of their lengths, according to their ftrength.

Next feafon, they will pufh vigorounly. The undermoft thoots on each fide are to. be continued in a horizontal direction, as before; and the others thould be laid in at the diftance of from nine to twelve inches, according to their ftrength, and kind of the trees, fome growing more grofs, both in wood and foliage, than others; and, in Winter, they are to be fhortened back about one-fourth of their lengths on a medium. Whatever laterals appear on them at any time hould be inftantly pinched off.

Next feafon they will puifh ftrong fhoots; and many of the kinds will begin ta thew fruit-fpurs on the laft year's wood. They will alfo purh many fuperfluous thoots; which mut be pinched off at the fecond joint, by the time they have grown to the length of eight or nine. Some rub off thefe as they appear; but as this frequently ruffles the bark, and thereby injures the tree, it is better to pinch them as above in Summer, and cut them clean off in the 
Winter pruning : but if they pufh a fecond time in the courfe of the Summer, they are, in that cafe, to be rubbed off as they appear.

Continue the undermoft fhoot on each fide in the fame horizontal direction, which is to be invariably done till the trees meet each other; and lay in the reft at the diftance of twelve inches on a medium. And, in the Winter pruning, thorten the ftrongeft and fartheft extended fhoots only a few inches each, and lay the others in at full length; unlefs it is neceffary to fhorten fome of them a little, for the purpofe of making: fhoots to fill any thin part.

This is forthwith to be done in the Winter prunings, never fhortening for any purpofe but that of filling the wall regularly; and the medium diftance at which the branches are to be placed from each other, is nine inches in the fmall, and twelve in the large growing kinds. At this time, alfo, are the fuperfluous fhoots, that were produced and thortened in Summer, to be cut neatly off; unlefs there be fruit-fpurs formed, or forming on their under parts, 
which in many of the kinds frequently happens.

Next feafon, moft of the kinds will produce a few fruit, and will forthwith make more moderate fhoots and plentiful fruitfpurs : and muft henceforth be treated in all refpects as for laft year; obferving to drefs them neatly and regularly to the will at all times, and diveft them of the fuperfluous and lateral fhoots, as above directed.

Horizontal Training.- Young trees which have tbree thoots are to be preferred; but if there are but two, the weakeft muft be cut clean away, and the other retained, whereof to form the tree. But, for the fake of brevity, I will fuppofe the tree confifts of three thoots.

After planting, let the middle thoot be headed down to nine inches; and let the two fide ones be laid in at full length, in a horizontal and parallel direction, within nine inches of the ground, if polfible; and if their extremities are anywife bruifed, horten them back a few inches, that they may pufh freely; but this is never to be repeated unlefs in like circumftances.

$\mathrm{R}_{4}$

When 
When the young fhoots are of fufficient length, train that from the extremity of the principal ftem or leader in an upright, and the two immediately below it, in a horizontal direction, right and left, and parallel to the two undermoft branches of laft year; which, as the ftem was headed down to nine inches, will allo lie at or about the fame diftance refpectively. Produce the young thoots from the extremities of laft year's branches in the fame direction; and pinch off all the others, both on thefe and the Atem, as directed for fan training.

As the horizontal hoots are never to be thortened unlefs their extremities are bruifed by accident or hurt by the froft; and as all fuperfluous and lateral fhoots fhould be treated in manner as directed above; it may be unneceffary to fay more of thefe. I thall therefore confine my obfervations to the ftem or leader.

As the branches are to be produced from the ftem, and laid in (if polfible) at the diftance of nine inches on a medium; and as, in moft kinds, more than two pairs cannot be produced each feafon without running the rifk of irregularity; the ftem. muft 
muft be headed down to eighteen or twenty inches, year by year, till the horizontal branches arrive at the top of the rail, \&c. But this muft be underftood of apples in general, and that too when they are in a moderate ftate of health and vigour; for fome kinds, and indeed any, when in a huxuriant ftate, will generally produce three pairs of fhoots on the ftem; which, in that cafe, muft be left from thirty to thirty-fix inches in length.

Great care fhould be taken, when laying in the horizontal fhoots which iffue from the ftem, that they be not fplit away in the operation. I generally lay them in the manner they will beft lie, till they are fufficiently hardened to bear being laid in, in their proper pofition; and I likewife generally lay in or referve all the fhoots, that iflue from the ftem, till that time, (whether needful or not), in order to guard againft accidents.

II. Apricots. - As thefe trees bear both on fpurs and the young fhoots of laft year, fan-training is certainly to be preferred. Therefore, after planting, let them be head- 
ed down, and treated the two firft years, in all refpects as directed above for apples; laying the fhoots in at the diftance of nine inches on a medium. But this is to be underftood of the principal branches: for when thefe trees arrive at a bearing ftate, they frequently make fruit-fpurs, or hoots of a few inches in length; which may alfo be fuffered to lie at the diftance of a few inches from each other. They alfo frequently make their fruit-fpurs in clufters: in which cafe, they are to be neatly thinned out; generally referving thofe which lie neareft to the wall, that the fruit produced on them may be benefited by its influence. Indeed, although fpurs which ftand at a diftance from the wall frequently produce bloom in abundance, it is feldom the fruit fets or comes to maturity on them: and therefore they may be confidered as fuperfl.ious fhoots, and thinned away with them in the Winter prunings; unlefs they are fufficientiy long to admit of being laid in, and the fcarcity of bloffom on the trees renders this advifable.

The brest wood produced in Summer is to be thortened back to two or three joints, 
as directed for the apples; and alfo neatly cut away in Winter; unlefs bloom appear on them, which frequently happens if the tree be not in too luxuriant a ftate.

In pruning of Apricots, the greateft care fhould be taken, at all times, to make clean and handfome wounds; and alfo to prevent bruifes of any kind, either by the knife, hammer, or by nails bearing againft the branches, which are of much injury to the trees, they being apt to canker and gum at the nighteft bruife.

III. Cherries. - Thefe thould alfo be trained in the fan manner on the wall: and as all the kinds, except the Kentifh and Morella, are apt to produce large cluftered fpurs when of age, and in a proper bearing ftate, they are to be allowed a diftance of from nine to twelve inches between the principal branches; obferving to lay them in, and fhorten them in the manner as directed above for apples. The breaft wood, laterals, \&c. are alfo to be treated in the fame manner at all times; and the fame care is to be obferved in refpect of wounds and bruifes as hinted above 
above for the apricots; Cherries, and indeed all kinds of ftone fruit, being apt to canker and gum at every bruife.

The Kentifh and Morella kinds, bearing: principally on the young fhoots of laft ycar, they fhould be trained much in the manner of peaches, (See Chapter VIII. Section IV.) and are to be laid in at the diftance of fix inches on a medium, divefting them of all lateral and fuperfluous thoots, as above.

On efpaliers, I have feen the attempt made to train Cherries horizontally, but I never faw it accomplifhed handfomely; and would therefore advife fan-training, as above.

IV. Figs.-Thefe trees, bearing on the young wood of laft year, being naturally apt to run upwards, and put forth fuckers from the root annually, fhould be trained in an upright manner refembling that of the vine. The foliage being very large, they require to be laid in at the diftance of a foot or fifteen inches between the young thoots: and as the diftance between thefe is the principal object here, it is immate- 
rial how neat they lie to, or even if they cover of crofs the old ones. . Thefe trees are apt to grow to the extremities, and confequently run into naked branches in the centre; a fuccefion of young fhoots from the bottom fhould therefore be conftantly encouraged.

When the trees arrive at a bearing ftate, which they generally will do in the courfe of four or five years, and as they fhow the fruit which is to be ripened next year on the fhoots of this; let fuch as are not wanted for furnifhing any part of the tree with wood, be ftopped about the middle or end of July: which will caufe them to fhew and fet their fruit fooner, and thereby be better eftablifhed before the Winter frofts fet in, than when the fhoots are fuffered to grow late in the feafon. On the open wall, this is of beneficial effect, though unnecellary in a forcing-houfe.

V. PEARs.-There, of all others, do beft, and make the handfomeft trees, in the horizontal manner; but they will fill their fpaces fooner by a third, if not one half of the time, by fan-training, which is certainly 
certainly a great object. On efpaliers, however, horizontal training is moft advifable; and alfo on very low walls.

As I have been pretty explicit on both thefe methods in the firft head of this fection, it will be unneceflary to repeat them here. I fhall only, therefore, briefly remark any particular difference to be obferved in the training of apples and Pears in either manner.

Moft kinds of Pears being apt to make longer fpurs than apples, the branches are to be allowed two or three inches more of room between them refpectively: and as their fpurs are alfo apt to grow more cluftered than apples in general, thefe are to be more carefully thinned in aged trees; obferving to retain fuch parts of them as lie neareft to the wall, in that operation.

As Pears are not fo apt to thow fruitfpurs on the bottom-part of the breaftthoots fhortened in Summer, as apples, thefe are generally to be cut clean off in the Winter pruning; thus giving the more room to the real fpurs, and preventing a profufion of ufelefs and fuperfluous thoots from rifing the following feafon. This 
matter is but too feldom attended to in general.

As moft kinds of Pears (efpecially if in proper foil) grow more luxuriantly when young than apples; in fan-training, the leading branches, which require to be fhortened for the production of thoots to fill the wall, may be left at greater lengths in general ; and in horizontal training, the ftem or leader may alfo be left ten or twelve inches longer in Pears than apples, as they will generally produce a pair more of horizontal thoots from it. The Jargonelle, however, ought to be an exception from this rule; as I have feldom found it produce more than two pairs of thoots from the ftem, in a regular manner, annually.

VI. Plums.-Fan-training is alfo to be preferred, for the reafons already given; neverthelefs, they will make very handfome trees in general the horizontal way. In either cafe, they are to be treated much as already hinted; laying in the branches of the fmall growing kinds at the diftance of feven or eight inches, and the others at nine or ten apart. 
The fpurs in moft kinds are apt to grow in clufters, and at a confiderable diftance from the wall; which thould be thinned in the manner as directed for the apricots, as being nearly allied to them in their nature. In fan-training, the leading branches for the production of thoots to fill the wall, will generally require to be fhortened about half their lengths, efpecially in the fmall kinds; and in the borizontal way, more than two pairs in the fmall kinds, and three in the others, will feldom be produced from the ftem annually; which, of confequence, muft be thortened to about fixteen or eighteen inches in the one cafe, and to about twenty-four or thirty in the other.

\section{nomon \\ SECTION V.}

General Objervations on Training and Pruning, and ots Thinning and Gathering the Fruit, $\xi^{2}$.

HE health and beauty of a wall-tree 1 depends more on the regular arrangement of the young, than of the old wood: and confequently, fhould be neatly and regularly 
regularly dreffed at all times; but more particularly in the latter part of the feafon; that every advantage may be taken in ripening, not only the fruit, but the fhoots and fpurs for the production of a crop the following feafon.

We too frequently fee thefe trees totally neglected in the latter part of the feafon; particularly apricots, cherries, plums, \&c.; which, when the crop is gathered, are generally no more thought of, or attended to: but this is very erroneous, as moft of thefe trees grow a deal afterwards; and if the extremities of the thoots are not kept dreft to the wall at this time, they will neither be ripened for the production of a crop, nor for enduring the winter frofts.

Great care fhould be taken that no part of the branches be bound with the fhred. or tie, and that the heads of the nails do not bear againft them; which, if they do, are fure to induce canker. My rule is, to drive the nail rather in an oblique direction, inclining its head from the branch; and to allow as much room in the fhred or tie as will at leaft admit another fhoot $\mathrm{S}$ of 
of the fame fize along with it; and alfo, never to drive nor fuffer a fingle nail or fhred to remain on any part of the tree, that is not abfolutely wanted.

It is common to tie efpalier trees with willow thoots; but I prefer tying with ftrands of frefh matting. For I have often feen branches much injured by the willow thoots, when bearing hard againft them, or if neglected to be cut away in the Winter pruning; thefe being of a hard wirey fubftance, and lafting over year. But in ufing matting, no danger of this kind need be apprehended; as the ftrands are not only foft and pliable, but will not laft above a year.

Winter pruning and drefling thould be performed in good time, that is, before the buds begin to vegetate; otherwife they are in danger of being rubbed off in the operation. In ordinary feafons, apricots, cherries', pears, and plums, thould be finithed by the firft, and apples and figs by the end of March.

In horizontal training, it frequently happens that the buds on the ftem do not break regularly; and fometimes a bud 
will remain in a dormant ftate the firft, and pufh the fecond year; which if it does not, make an incifion crofswife to the depth of the bark, immediately above it : it will not fail to puth the following feafon.

In what is termed a bark-bound tree, (in which cafe, it has a fickly appearance in general, hard and Thrivelled bark; makes weak fhoots, with the leaves of a languid colour, and the ftem and branches frequently covered with mofs), it is a good practice to rip the ftem lengthwife, to the depth of the bark: but this is to be performed on apple and pear trees only; ftone-fruit, from their aptnefs to gum, not admitting of this operation with propriety.

When a tree is in too luxuriant a ftate, and does not fet to fruit, the knife fhould be ufed fparingly, keeping it rather thick of wood (but regular) for a feafon or two; and at the fame time let a trench be dug round its ftem, at the diftance of four or five feet from it, fo as to cut quite through all its roots. The check, which it thereby receives, will generally throw 
it into a bearing ftate in the courfe of a feafon or two.

In pruning, be careful to make clean and handfome wounds at all times; ufing the knife chielly; but the faw in amputating ftrong branches, and drefling the edges of the wound, thus made, fmooth with the knife. In lopping branches from the ftem, or twigs from-larger branches, cut always in to the level of the bark, leaving no ftub. And, if from the pofition of the wound on large branches, or on the ftem, particularly in aged trees, there is reafon to doubt its healing eafily; let it be laid over with a little tar; which afterwards keep in a found ftate, in order to exclude moifture till the wound is quite healed, and Akinned over with frefh bark.

It frequently happens, that after much pains has been taken in rearing and training a tree, it turns out to be of a very different kind from that for which it was planted: which is a great difappointment, as perhaps it occupies a fpace upon a much better afpect than it deferves; and were it to be removed, would occafion an 
unfightly blank on the wall for feveral years, until a young tree filled its place. But, to remedy this, at leaft in a confiderable degree, it is more advifable to ingraft or inoculate (according to the kind of tree) proper kinds upon its branches: in a borizontal-trained tree, near to the ftem; and in a fan-trained tree, towards the bottom and lower extremities.

On the ftems or branches of trees which have become naked of thoots through age, buds or grafts may be inferted, in order to reftore them to regularity; but if the tree is not in a healthy, clean ftate, this labour would be in vain. In fome cafes, if the tree in queftion be of a good kind, it may be more advifable to head it down entirely, that a ftock of wood may iffue from the bottom, afterwards to be trained regularly : obferving, however, not to cut belowe the original bud or graft.

In this variable climate, our profpect of a crop is frequently blafted in Spring, while the trees are in bloom and fetting, efpecially in apricots, cherries, and plums. To fecure which, canvas-fcreens being applied, or nets fufpended, as directed in

$$
\mathrm{S}_{3} \quad \text { Chap. }
$$


Chap. VIII. Sect. XI. will be found of infinite advantage, and preferable to the common method of fcreening with firboughs.

Apples, apricots, and pears, in favourable feafons, are apt to fet more fruit than the tree is able to fuftain, or hould be allowed to produce : the fruit hould therefore be regularly thinned; the apples and pears when about half grown, and the apricots when the ftoning is fairly over. But, as no fixed rule can be given for this operation, the difcretion of the gardener muft be relied on; and the health and vigour of the trees muft determine to what extent it is to be performed. In the More Park apricot, however, a fruit for every ten or twelve inches fquare of the fuperficial content of the tree, when in a healthy ftate, will be a good medium. This, by many, is efteemed the richeit of all ftone-fruit, when well ripened, and ate off the tree.

What I have faid in Chapter VIII. Section VIII., in refpect of gathering peaches and nectarines, will equally apply here in refpect of apricots and plums.

Jargonelle 
Jargonelle pears, and fome of the kinds of bergamots, thould be ate off the tree, or at leaft within twenty-four hours after being pulled, as they lofe much of their flavour by keeping. The other kinds of apples, and pears in general, thould not be gathered till their pips are of a blackifhbrown colour, and they fhould then be laid in the ftore-room; which, for that purpofe, fhould be fitted up with hallow thelves, fo as to admit of but one courfe of the fruit, and room for the hand.

Hence it would appear, that I difapprove of what is termed fweating of thefe fruits: -they generally retain an ill flavour ever after.

The greateft care fhould be taken to prevent bruifes in thefe fruits, and they thould be frequently looked over and picked. The ftore-room thould alfo be kept well aired, and fecured from froft. 


\section{SEGTION.VI.}

On the Infects which generally infe $\mathrm{l}$.Wall-Trees; and bow to deftroy them.

7 THESE are, the green-fly, red-fpider, caterpillar, grub, ear-wig, wood-loufe, and wafp.

The green-fly is eafily deftroyed by a fumigation of tobacco; but this is fometimes performed with difficulty on open walls. My method is this:-Sprinkle the tree gently with water from the engine; then fumigate for the fpace of eight or ten minutes with the bellows, when the vermin will be quite fick; and afterwards give a hearty wathing with the engine; by which means they are dafhed to the ground, which dig over in order to bury them. This operation thould be performed in a calm morning or evening; otherwife the fmoke is immediately diflipated, and, of confequence, is the lefs effectual.

The red-fpider and grub are kept under with the engine in Summer, and effectually deftroyed in Winter by the liquor, fee Ghap. III. Sect. VII., which is to be applied 
plied in a milk-warm ftate with the fpunge, as there directed. It muft alfo be applied. at leaft a month before the buds begin to vegetate.

For enfnaring and catching the ear-wig and wood-loufe, the following is my method :- Take a quantity of water reeds or ftrong wheat ftraw, and cut them into lengths of five or fix inches; place them all over the furface of the tree, between the branches and wall, allowing two or three to every fquare yard; alfo lay a quantity on the ground at the bottom of the wall. In thefe the infects take fhelter fo foon as the morning fun appears on the furface of the wall; which, in an hour or two after, are to be blown into a bottle having a little water in it, replaced as before, and this fhould be repeated every morning in the fame manner till they are quite eradicated; which will generally be very foon accomplifhed, as they may be taken in vaft quantities in this manner.

The only fure method of keeping the wafps under, is by deftroying their nefts *; but in rugged and rocky places this is not eafily accomplifhed. They are alfo enfna-

* See Chapter V. Section X. red 
red in great quantities by placing phials filled with honey and water, or fugar and fmall beer, againft the walls; alfo, by fufpending fmall fticks covered with birdlime, over which a little honey and water is poured at times.

The green-fly preys moft on the peach, plum, and cherry; the red-fpider on the apple, cherry, peach, and plum; the grub on the apricot and cherry, and fometimes on the apple and pear; and the ear-wig, wood-loufe, and wafp, on the fruits of all.

Wafhing with the garden engine is of infinite fervice to wall-trees, and fhould be frequently performed in dry weather in the Summer months: it both refrefhes, and keeps the trees clear of duft, \&c., and alfo tends, in a great meafure, to fupprefs infects of all kinds, particularly the red-fpider.

Wanhing the ftem and branches of trees, which are anywife mofled, with foap-fuds and fulphur, is alfo of great utility, and fhould be performed in Winter or early in the Spring; previounly rubbing off the mofs with the hand, and bruming the branches clean with a brufh, fuch as is ufed for cleaning of plate, \&x. 


\section{CHAPTER II.}

CULTURE OF ORCHARD FRUITS.

\section{SECTION I.}

On tbe SITUaTion for Orchard:.

Q RCHARDS in this part of the united kingdom (Scotland) are an object of trivial concern at prefent; for, excepting thofe of Clydefdale, fome in the Carfe of Gowrie, and a few near Jedburgh, there are none of any note. It is certain, we (in Scotland) need not expect to cope with our fifter country, in this refpect; but it is equally certain, there is a poffibility of imitating, and even nearly approaching her, in the productions of the Orchard; or at leaft fo far as to anfwer the confumpt of the country, in good feafons.

The productions of thofe in Clydefdale, which in fome feafons is aftonithing, are a proof in point, and thefe are neither exten' five, nor (excepting one) even kept in to- 
lerable order. They are, however, capable of very great improvement, and with little expence and labour might be rendered productive in treble or quadruple proportion, on an average of years.

Their fituations, and indeed the whole bank of the river, from the Falls of Clyde to Hamilton, and thence to Bothwell Caftle, \&c. are fo peculiarly adapted to the purpofe, that I am convinced the proprietors could not occupy their land in any other way that would give a fourth of the return. The banks are in general fteep, and in many places inacceffible to the plough; and thefe very fteeps are beyond all other fituations defirable for that purpofe, efpecially thofe on the north fide of the river, being expofed to the fun, the banks reflecting his rays, and rendering the fituation in fome degree as if the trees were planted againft a wall.

In this tract we find many acres covered with broom, bramble, brufhwood, \&c. which at prefent do not bring the proprietors, perhaps, ten thillings an acre; and which are fo admirably fituated, and the foil fo congenial, that were they convert- 
ed into orchards, might, in a few years, bring fifty pounds on an average *.

This peculiarity of fituation is not confined to Clydefdale. There are many other dales in Scotland equally well adapted to the purpofe. But dales, and thofe through which a river meanders, are to be chofen in preference to all other fituations: Becaufe, firft, their banks afford fhelter from the winds by their frequent windings and turnings; fecondly, their fteep fides confine and reflect the rays of the fun, whereby the climate is rendered more mild and warm than in other fituations; and, thirdly, there is a conftant vapour or effluvia arifing from the river, which is particularly grateful to the trees while in bloom and fetting; and alfo tends to foften the climate at that feafon of the

year,

* There is a proof of more than I fay, on the fpot lately improved by $\mathrm{Mr}$ Harvey of Brownlee: it is a very fteep bank, was overrun with bramble, briar, \&c. and does not contain above an acre and an half, the far greater part of which is not yet arrived at a full bearing ftate; yet, this fpot for fome years back, has produced from feventy to one bundred pounds a year to the proprietor, who, as an improver in this, as well as many other refpects, is a Gentleman of much merit. 
year, which is frequently inimical to the fetting of fruit in other fituations.

In this cafe, the moft defirable fituation is the North, Eaft, or Weft bank*, from the verge of the river (including the haugh or holm, if fuch there be) to within a few yards of the termination of the bank, more or lefs according to its fteepnefs, fo that the trees, when full grown, may be within its level, and thereby be fcreened from the Northern and other prevailing winds.

The haugh or holm on the oppofite fide of the river, and alfo the banks, if not very fteep, in many cafes may anfwer very well; but if the bank is very fteep, and the foil not particularly inviting, its occupation as an orchard will be attended with inferior fuccefs.

Many dales without a " river meander" ing," may alfo prove excellent fituations; and many fpots in any dale may prove more fo than others; which may be occafioned by the fuper-excellence of foil, congeniality of fubfoil, peculiarity of expofure,

* Suppofing the river to run parallel to any of thefe afpects, or to any afpect from Eaft to Wert. 
CH. 2.] THA ORCHARDS.

fure, eafe of accefs, happinefs of Ahelter, \&c. But,

Unßpeltered plains are fituations, where fuccefs in rearing and bringing orchards to a ftate of maturity, will ever be precarious in this country:

\section{SECTION II.}

On tbe Soiz for Orcbards.

THE foil moft properly adapted to apples, 1 is a brown loam of a middling texture, and which is at leaft eighteen inches deep, over a bottom of dry fand, gravel, or foft clay; in which they are found in the higheft health, and of greateft durability. Neverthelefs, they will do well in many foils, fuch as fandy loams, gravelly loams, chalky loams, clayey loams, \&c. which are of various depths, and which are alfo incumbent on various fubftrata, as chalk, limeftone, dry rock, fand, clean gravel, \&c. But if the bottom is wet, and the fubfoil a till, retentive clay, or irony gravel, clay, \&c. little good may be expected 
expected of them for any length of time, if the upper foil be ever fo good.

That moft properly adapted to Pears, is a ftrong clayey loam, a yard in depth, over a bottom as above. The fame exceptions as above, are alfo to be confidered.

Cherries and Plums are of little importance compared with Apples and Pears, being of no ufe whatever, unlefs there is an immediate confumption for them, from the circumftance of their not keeping. The foil which anfwers Apples and Pears, will anfwer Cherries and Plums refpectively, and equally well.

It would be vain to attempt rearing ani orchard, where the bottom is not either naturally dry, or is previouny rendered fo by draining; and this is to be obferved in all cafes and fituations whatever.

This reflection more naturally occurs in refpect of flat or hollow ground, than otherwife; but it is as frequently neceffary on fteep banks, which are often interfperfed with fpouty or fpringy fpots, occafioned by the different ftrata of which the higher ground is compofed. To enter, however, into a fyftematic mode of draining; 
draining, would be foreign to the fubject here; and the reader is referred to $\mathrm{Mr}$ Elkington's, as explained by $\mathrm{Mr}$ Johnftone; being at once the molt effectual and leaft expenfive method.

\section{SECTION III.}

On the Kinds of MANURE fit for Orcbards.

Rchard ground fhould be moderately enriched with the kinds moft properly applicable to the foil. Compoft is to be preferred to fimples.

If the foil is of a cold nature, a compoft of lime, ftable-dung, pigeon-dung, foot, athes, \&c. is to be advifed; if light and hot, cow-dung, hogs-dung, loamy marl, pond-mud, fcouring of ditches, \&c.; or, as fimples, any of the kinds which is beft calculated to correct or enrich the foil. Marls are eminently ufeful, and, in general, are to be preferred to lime, being lefs apt to canker the roots of fruit-trees. 


\section{SECTION IV.}

Of the KlNDs of Orchard Fruits.

HE kinds in cultivation at prefent, 1 in my opinion, are too numerous. They are alfo very indiftinct, being confufed and mifconftrued, by the many provincial names which are given for the fame fruit. He who plants an orchard, has the undoubted right of indulgence in this refpect. The following lift is given as the one which I would adopt, were I in the predicament, preferring thofe marked $*$, viz.

\footnotetext{
Apples.

* Ribfton Pippin.

* Onlin do.

* Royal Codling. Kentifh do.

Dutch do.

* Royal Ruffet.

* Royal Pearmain. Loan's do.

* Summer do.

* Golden Rennet.
}

Apples.

Kentifh Rennet.

* Leadington. Summer Queening. Winter do.

* Yorkfhire Green. Margill.

Nonfuch.

* White Hawthornden.

* Norfolk Beafing. Strawberry. 
CH. 2.]

Pears.

Drummond.

* Longueville.

* Jargonelle.

Lammas.

Crauford.

* Green Yair.

* Achan.

* Scotch Bergamot.

Summer do.

Worcefter.

Cadilac.

Warden.

Cberries.

* May Duke.

* Black Heart.

- Kentifh.

* Morella.

Plums.

* Wine Sour

* Orleans.

* Green Gage.

* Blue do.

* Yellow do.

* White \& Red Màg. Bon。

* Damak.

\section{SECTION V.}

\section{Culture.}

DEfore planting, the foil is to be

O trenched to its full depth; and the manure well incorporated with it in the operation.

Maiden trees of all the kinds are to be preferred, having boles of three, or four feet in length, the apples being worked on crab, and the pears on free ftocks. The diftance at which they thould ultimately ftand is, thirty feet either way, for Apples 
and Pears. For Plums and Cherries, fix feet lefs refpectively.

As I by no means approve of a mixture of crops, or even of an under crop as a reimburfement for prefent expence, I would advife planting four trees for one that is to Atand for good; that is, at fifteen feet each way for Apples and Pears, and at twelve for Plums and Cherries. Three of thefe muft be confidered and treated as temporary trees from the beginning, and ought to be chofen of the leaft durable, and at the fame time, fooneft bearing kinds; fuch as the Nonfuch and Hawthornden apples; Crauford and Yair pears; May Duke and Morella cherries, \&c. which may be interfperfed as temporaries amongit all kinds without difcrimination.

The feafon for planting is from November to March, with equal fuccefs. The pits thould be filled in with light compoft of earth and manure, for all kinds, except. the Nonfuch Apple, which is moft durable, and alfo generally moft fruitful without manure at any time; wherefore, in the annual drefling, manuring, \&c. this 
tree is to be an exception, fo far as not to injure the others by its treatment or neglect.

If the firf Summer proves dry and hot, let the trees be frequently watered; and, in order to retain the moifture, let a little dung or other litter be kept round them on the furface.

The only indulgence which I would fubfcribe to, in refpect of an under crop is, a fingle row of Beans, Cabbage, Carrot, Peas, Potatoes, Turnip, \&c. in the centre between the trees, and that only for a few years, and with a view of defraying the expence of hoeing and keeping the ground clean of weeds, \&c. which is invariably to be done for the firft ten or twelve years, or till the temporaries are removed. By this time the principals will be fo far eftablifhed in the foil, and advanced in frength and fize, that the ground may fafely be laid down in grafs, fo to remain, that their roots be no further difturbed for feven or eight years; after which, it is to be periodically broke up every fifth or fixth, and moderately manured. 
Previous to this, let a moderate quantity of manure be digged in every fecond year, obferving to dig deepeft, and apply moft of the manure beyond the extremities of the roots, thereby preparing food for them as they advance.

The criterion for relinquirhing the practice of under cropping, is, when the roots of the trees refpectively come into contạct.

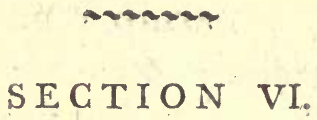

On PRUNING, Ec.

Udicious pruning is of the utmoft - confequence, both to the welfare of the tree, and to the production of beautiful and well-fized fruit. That old trees produce diminutive fruit, is not, perhaps, altogether becaufe of their age, but becaufe of the want of judicious and timely pruning; and as old, or at leaft eftablithed trees; are the furent bearers in general, it is fubject of regret that fo many inftances are found of total neglect in this particular. 
particular. In all the Clydefdale orchards, there is not one tree in fifty in proper order in this refpect.

From the day the tree is planted, to the day in which it is no longer fuffered to " encumber the earth," it fhould undergo an annual vifitation of the "pruning hook," which fhould be in the hand of one " who knoweth the fruitful and profitable branch, from the unfruitful, and that which is naught, and perifheth."

This operation, however, is to be performed with caution and moderation, efpecially on young trees; as too free an ufe of the knife is attended with the confequence of too great a profufion of young fhoots the following feafon. The tree fhould be kept moderately thin, and frée of branches crofling one another, endeavouring to have every part of it regular, and fanned out towards the extremities; alfo, thinning out the cluftered fpurs (as in many kinds they form too thick) regularly, and cutting out fuch as are rotten, bruifed, \&c.

Let the temporary trees be thinned away, as the principals advance towards $\mathrm{T}_{4}$ each 
each other, and, by the time their extremities meet, let them be entirely ftubbed up.

In aged trees, which have been neglected, and are too thick of wood, fpurs, \&c. the pruning faw and knife thould be ufed with freedom at firft, and that in every part of the tree, without difcrimination of fruitful or unfruitful branches.

By the judicious performance of this operation, it is incredible in what aftonifhing degree a tree will renew its age; and will forthwith for many years flourifh, and produce excellent crops of fruit.

The feafon for performing the above operations, is any time from October to March, but after that time it is not advifable to handle fruit-trees, as the buds then begin to vegetate, and are eafily difplaced.

It is no uncommon thing to fee apple, pear, and plum trees, \&c. in a great meafure deftroyed by mo/s. This is moft generally occafioned, by the roots having toucbed a cankering bottom; but it is alfo frequently occafioned by the tree being kept too thick of wood, and confequently of foliage, which confines ftagnant air about 
about its branches, in dull hazy weather. It is of lefs bad confequence, if this is confined to the trunk, or ftrong branches only; but if the extremities and fruit-fpurs are affected, the juices will be obftructed in their circulation, and confequently the fruit will be more immediately injured.

Therefore the mofs thould be rubbed off every pruning feafon, and the branches and fpurs thould be anointed every fecond or third, with a folution of fulphur and foapfuds, in the following proportion, viz. one pound foft foap, one pound flowers of fulphur, fix gallons river or rain water, boiled all together for half an hour-applied when milk warm with a fpunge.

If the trees are afflicted with the caterpillar, or grub, which is frequently the cafe, the liquor, fee p. 62 , muft be ufed inftead of the above, being careful to anoint the eyes of the buds, as it is there the eggs of the infects are chiefly lodged, whence they iflue with the young fhoot, and inclofe themfelves in the leaves, on which they feed, or perforate to the very great injury, and frequently the total deftruction of the foliage; 
foliage; and confequently to the detriment and ultimate ruin of the tree.

\section{SECTION VII. \\ Of $G_{A T T L E}$ in Orchards.}

T $T$ is a prevalent cuftom to pafure in orchards.-I difapprove of the practice. It is too frequently the caufe of total neglect of the fruit; the trees being often left unguarded, and confequenly much damaged by the cattle browfing on the branches, and rubbing themfelves againft the boles.

Pafturing of theep is attended with equally bad (if not worfe) confequences; ás nothing is more pernicious than the oil or greafe, which exudes from their wool, in rubbing themfelves; which, if often repeated on the fame tree, and this is almoft always the cafe, this animal inftinctively following example, more than any other, has the effect of completely clofing the pores of the trunk fo rubbed, much to its detriment. 
But I have other objections than thefe to this practice, viz. $x / t$, Until the trees have been about fifteen years in the ground, are well eftablithed, and the temporaries are all removed, the ground fhould not be laid down in grals. $2 d l y$, If planted with the view of being an Orcbard only, the trees will neceffarily ftand fo thick, and the herbage be fo much thaded, that it will be of little value, and of very bad quality for pafture. Lafly, I confider it as being prejudicial to the roots of the trees, particularly in ftiff wet foils, to be pent up in the earth, and retarded in their annual progrefs by the weight and conftant treading of the cattle.

Wherefore, I would rather advife, that the under crop be ufed as cut grafs, (which generally comes very early), and this is found to pay better than pafturing; the firft cutting, which is always had before the trees are full in leaf, being equal to the whole value of the pafture. 
On the Cultivation of SMALI F $F_{\text {RUIT. }}$

THE method of planting ftandard Fruit1 trees, to divide the quarters of the kitchen-garden, is now juftly exploded. They are found to injure the under crops much. The method of planting currants and goofeberries round the edges, and to fubdivide the kitchen-garden, is alfo juftly exploded; and they are now generally planted in quarters by themfelves : fo are rafpberries and ftrawberries.

And thus an opportunity of changing crops is afforded, as the beft method is to make new plantations of ftrawberries every fourth or fifth year; and of currants, goofeberries, and rafpberries, every feventh or eighth. The three laft named, having much the fame effect on the foil, may not take place of one another with propriety; but may with ftrawberries, and alfo ftrawberries with any of them. 
The ground thould be trenched, and moderately enriched with any of the kinds of manure moft properly applicable to the foil ; which, for currants, goofeberries, and rafpberries, if not a perfect fand, cankering gravel, or wet, ftubborn clay, will (with proper culture) produce them abundantly. Strawberries are an exception. They are moft productive of fruit,-and leaft fo of ftraw, on a ftrong loam, and in an open expofure. Neverthelefs, we find them prolific, with proper culture, in many different foils.

If the ground is broken out from grafs, let the turf be chopped well; bury it in the bottom of the trench, and the manure one fpit deep. If from ground which has been under tillage or kitchen crops, bury the one-half in the bottom, and the other at one fpit deep; obferving to divide and break the foil well in the operation.

The methods of producing young plants of all the kinds being univerfally known, it would only be wafting time in faying more in that refpect, than that they fhould be clean, healthy, and well rooted. 
To enumerate the kinds would be an endlefs takk, particularly of goofeberries; nor would it be at all fatisfactory, almolt every one having their favourites. But it cannot be doubted that the rage for multiplying the varieties of this fruit has been carried too high of late years; and that many of our old kinds far excel the new ones, in réfpect to flavour.

\section{Currants and Goofeberries}

Should be planted at from four to fix feet apart each way, according to the quality of the foil. The feafon is any time from November to the firft of March.

Currants and goofeberries produce both on fpurs, and on the fhoots of laft year; but the fruit on the latter is always largeft. Therefore, the fhoots to be retained hould be left at full length; and the plant ought to be regularly thinned out, leaving thefe generally at the diftance of from nine to twelve inches apart, and twifting off all fuckers, \&c. from the root, which take greatly from its ftrength.

Goofeberry plants, in particular, thould be kept free and open in the middle; nor is 
a Winter pruning fufficient; but they fhould have a Summer dreffing alfo, when the fnperfluous thoots are to be rubbed off. This, however, is not fo neceffary for currants. Indeed, they generally fwell their fruit larger if thaded in a moderate degree, though it muft be allowed the flavour is not fo high, as when the plant is kept more open and free of luxuriant hoots.

Some goofeberries are of the weeping kind, and when heavy laden, the fruit is frequently much injured, and even dathed off by the branches dragging on the ground. To prevent which, a hoop thould be faftened to ftakes or pegs drove into the ground, and at the diftance of a foot from it; to which let the branches be dreffed in a regular manner.

\section{Raspberries}

Are alfo to be planted at from four to fix feet apart each way, according to their kind, and the quality of the foil. In good land, the Antwerp kinds require at leaft fix feet : the common, a foot or two lefs, as they do not grow fo luxuriantly. I have feen a quarter of Antwerps, which avera- 
ged ten feet in height each hoot, and proportionally ftrong; fome of which girted above three inches. They grew in a mixture of peat-earth and fandy loam of confiderable depth.

Rafpberries bear entirely on the fhoots of laft year, which are plentifully produced from the root every feafon. In Winter dreffing, the old fhoots are to be cleared away, and alfo the major part of the new, retaining three or four of the ftrongeft only, otherwife the plant would become a perfect bufh next feafon.

The moft fimple, and beft mode of fupporting them is, by twifting the fhoots loofely together, and tying the extremity with a piece of fpun-yarn, or ftrands of frefh matting.

\section{Strawbierries}

Are to be planted, either in July or Auguft, or in March or April, according to the forwardnefs of the feafon, in rows from twenty-four to thirty inches afunder, according to the kinds and quality of the foil, and at from fix to eight inches in the row; kept clean of weeds at all times; the 
Atraw cut in October; the rows rutted on each fide, left fix inches broad, and the intervals dug a full fpade deep. A night dunging each feafon, or a good one every fecond, will be fufficient to keep the land in heart.

Where the fituation is particularly inviting, and (which fometimes happens) the culture of any other crop would be attended with more difficulty; ftrawberries may be fuccefsfully continued on the fame fpot for many years, by reverfing the rows and intervals every third feafon.

This is attended with no manner of trouble, the runners planting themfelves. But when new plantations are to be made, fuch runners, after having ftruck root in July or Auguit, are the fitteft plants for this purpofe, and fhould then be tranfplanted.

It is obfervable, that ftrawberries planted in manner as above, that is, in rows, are much more prolific of large fruit, than when planted thick in beds. In fingle detacbed rows, they are ftill more fo; and are with propriety run round the alleys of the kitchen-garden, in the double cha- 
racter of edgings, "ornamental and fruit"ful."

Some, who are fanguine of the produce of their ground, introduce kitchen-crops of all kinds amongtt their currants, goofeberries, and rafpberries, and frequently with too little difcrimination of which is the intended crop. Why are they planted by themfelves at all? Is it not that they may be produced in the greater perfection? If fo, why with open eyes thwart the original intention, by robbing the ground with burdenfome crops of vegetables?

Neverthelefs, I wih not to fee an inch of land loft. There is certainly a medium. A fingle row of beans, broccoli, cabbage, cauliflower, carrot, turnip, potatoes, \&c. in the centre between the currant-trees, \&c. being fown or planted, would be conform to ftrict prudence. And here they would be of the very beft quality, if the foil were congenial to their natures, as they would have full room to extend.

I have feen excellent vegetables produced in this manner; but at the fame time 
have feen much injury done the fruit, by its being too long perfifted in. Till the fourth year, it may be practifed; but not longer. Indeed, there would little (perhaps no) profit attend the practice after this time, as the fruit would fuftain more injury than the value of the vegetables would indemnify; and thefe laft would be leflened in value, by being overfhadowed by the trees or buthes. 



\section{BOOK THIRD.}

THE

\section{KITCHEN GARDENER.}

\section{INTRODUCTION.}

TECESSITY, which is juftly faid to be 1 the mother of invention, is the firft and grand ftimulus to induftry. Hence the caufe, why the northern nations are farther advanced in the arts of gardening and agriculture than the fouthern, moft probably is, that the foil and climate are generally lefs favourable, and confequently lefs productive of the neceffaries and comforts of life.

As commerce extended, and mankind began to have more intimate intercourfe with one another, not only their real but imaginary wants were mutually difcover- 
3IO THE KITCHEN GARDENER. [B. 3 。

ed, and the means of gratification employed. The progrefs was long fowly progreffive in our ifland; but now a fpirit of ufeful improvement hath manifefted itfelf in all orders of the community, unknown to other ages. The branches of gardening and agriculture have made rapid progrefs; but an ample field is ftill left open, in which the ingenious and induftrious may difplay their talents and perfeverance.

The various modes of raifing food for man, by cultivating the earth, are to be comprehended under the two general heads, Gardening and Agriculture. Thefe go hand in hand, being nearly allied to one another; the chief conftituent difference being in the implements ufed, and the manner of employing them. In the one, the labour is chiefly manual; but in the other, the far greater part is performed by aid of cattle.

The plough is a moft ufeful inftrument, but it is not fo efficacious on a fmall fcale as a fpade. Hence the fuperiority of the garden over the field, in refpect to the fuperabundance of its produce.

The more we do for the foil, the more grateful 
grateful will it be in return; and prudence, as well as intereft, fhew the neceflity of fkilful induftry, whether in gardening or in agriculture, and fpur on to improvement.

A juft knowledge of the value and effect of manures, their application, the quality, nature, and pulverization of the foil, is the grand bafis of agricultural improvement, and lead to all fubfequent difcoveries. Thefe can be more minutely followed in gardening than in agriculture, and alfo with lefs rifk of difappointment. Hence have the difcoveries and improvements in gardening generally been the forerunners of thofe in agriculture.

Inafmuch as not only garden vegetables, but grain, produce moft abundantly on what is termed new land, effectual plowing, digging, trenching, \&cc. would appear to be of the utmoft importance. This matter is fufceptible of being more effectually performed in gardening than in agriculture, and is another reafon why the garden is more productive than the field.

A third reafon, in fome inftances, may be local-fituation, fhelter, \&c. But this 
does not always hold good, as many kinds of vegetables, particularly thofe moft ufeful, are found to do as well, if not better, in an open field-garden, than in one which is Beltered.

Garden land is generally higher rented than that of the farm; a much fmaller quantity is appropriated to the maintenance of a family; the occupier is under the neceflity of ufing all diligence, induftry, and perfeverance; and of working and manuring his ground to the utmoft of his ability in the hope of a return. Thus may another reafon be deduced why the garden is more productive than the field. And, laftly,

Private gardens, being both an object of utility and amufement to the proprietor, are generally placed in the moft favourable. fituations, well kept, manured, \&c.

Neverthelefs, the efforts of the moft fkilful, in the culture of the more tender efculents, are often baffled; more efpecially if his foil be not congenial for the purpofe. And who is he that can withftand all the cafual occurrences of weather, and viciflitudes of a variable climate? In fine, 
gardening and hufbandry, labour under many difadvantages in this country, unknown on the continent, particularly in the earlier part of the feafon. Not fo much that the weather is more fevere, which indeed may be queftioned, but that it is more changeable, and that we are lefs favoured with the vifits of that refulgent luminary; the firft ftimulus, the very efence of vegetation.

To remedy, then, as far as may be in our power, the difadvantages under which we labour, let us endeavour to render the climate more falubrious by the bigh cultivation of every fpot of ground, in whatever way it may be employed; which unqueftionably hath a good effect, and goes far towards the attainment of this defirable object.

Draining comes firft in point. For, while latent water remains in the body of the foil, we may defpair of ever rendering it productive, in a fuperlative degree, of either vegetables*, grain, or timber. And

happy

* According to the general acceptation of the word; for vegetables embraces the vbole of one of the kingdoms of nature. 
3 T4 THE KITCHEN GARDENER. [B. 3 ; happy is it for this country, that now a method of performing this frequently neceffary operation, is difcovered and divulged to the world, than which, perhaps nothing. could be a more valuable acquifition.

The reader will probably perceive, that I allude to Mr Elkington's, as explained by $\mathrm{Mr}$ Johnfton. He is referred to it.

Next to this, effectual ploughing, digging, trenching, incorporating, and aërating the foil, would feem to ftand forward and demand our particular attention. Let us beftow it. Let us not exhauft one part of the foil, while another remains in a ftate of inactivity, and is, perhaps, at the fame time equally capable of production. But rather let us bring up what probably has never, or at leaft for years paft, been accuftomed to the dividing rutt of the coulter, the penetrating tbruft of the Spade, and confequently, the produce of "food for man and beaft;" and which, by being frefh and unexhaufted, may afford a timely relief to that which is the contrary, overburthened, perhaps, by long and fucceflive production. 
But while we fearch after, and bring up this " hidden treafure," let us not be too fanguine. Let us be careful not to bring up in mixture with it, what would not fail to thwart our beft intentions, - cankering gravel, irony till, or corroding fand.

What next comes in point, and is eminently ufeful, whether for improving this new acquifition, or refrefhing, and in a great meafure reftoring, the exbaufted foil, is the difcreet application of manure. There are many kinds of this moft ufeful ingredient. The judicious will always apply that which is moft evidently calculated to enrich and divide the foil, if over tenacious, or which will add adhefion to, and alfo enrich it, if too light and porous.

Next follows, fkilful, and moderate cropping. In refpect of the former, practice and experience alone can enfure fuccefs, and the attainment of perfection. In refpect of the latter, whoever fhall bear in mind, that it is as neceflary for land to reft from producing, as for man to reft from labour, and that it is of as bad confequence to overburthen land with crops at any time as man with labour, will not fail to tread the right 
316 THE KITCHEN GARDENER. [B. 3 .

right path. Farther, it is certainly preferable to have an article good in quality, than twice the quantity which is, perhaps, neither nutritive nor wholefome. The judicious will proportion the reeight of crop to the ftrength and ability of the foil.

And this leads to another confideration, namely, that of weeds. Of all things in nature, where art hath connection, the moft difgufting is that of a garden of weeds, a thing inconfiftent in itfelf, and alfo with common fenfe. Do we fow or plant with the intention of reaping? Do we with to raife wholefome and well-ripened crops? Do we look for re-imburfement and compenfation for expence and labour? And do we, at the fame time, negligently fuffer weeds to impoverifh the foil, and rob the crop of the nourifhment neceffary to fuftain and bring it to perfection, and confequently produce the defired return?-Let us beftow the attention this fubject would feem to deferve, and we thall conclude, finally, that fuccefsful cultivation and production of vegetable food, in a great meafure, depends on the following defiderata : 
B. 3.]

INTRODUCTION.

A juft knowledge of the quality of the foil; effectual draining; effectual plowing; effectual digging; effectual trenching; difcreet manuring; moderate cropping ; careful weeding; induftrious reaping; and judicious fallowing. 
318 THE KITCHEN GARDENER. [B. 3.

\section{CHAPTER I.}

ON THE PROPER DEPTH AND SITUATION OF GARDEN IAND.

7 HAT kitchen vegetables do beft on 1 what is termed new land, is a generally-received opinion, and plainly demonitrated in many inftances. It is alfo a common complaint among gardeners, that their ground, from what is termed worn out, will not produce certain kinds of vegetables: not that it is poor and hungry, or altogether unadapted to the production of them, having perhaps formerly produced the very articles in great abundance; but that the furface has been many years under thefe crops, and that they have not a fufficient quantity of ground for a proper change. In walled gardens this complaint is moft general; and it would appear to be occafioned by the expence of inclofing a fuffciency of ground to ferve the family, or of compofing a body of foil of a competent depth. 
That many kinds of kitchen vegetables do as well (if not better) in an open fieldgarden, as in one that is inclofed with high walls, and theltered, and perhaps thaded, with trees, is an undeniable fact : and, were it not for the production of the finer fruits, there would be little ufe in rearing garden-walls at all. But the ground thus inclofed is certainly. occupied with more propriety in the production of vegetables than of any other crop.

And, as it is prefumed, the ground thus inclofed is to be occupied as a garden many years; that the walls have been built at a confiderable expence; that the ground is trenched, walks made and laid out at a confiderable expence alfo; and that, above all, it is defirable to have a fupply of wholefome vegetables for the ufe of the kitchen, while the ground is thus occupied; - I thall drop a few hints on the method of obtaining this end, and which I have partly practifed * with fuccefs.

Firft,

* I fay partly practifed, becaufe the operation of it requires many years, and it has happened, (by $\mathrm{my}$ change of fituation), to be out of my power to follow it 
Firft, then, it is neceffary to have a depth of foil from twenty-four to thirty-fix inches; which, in many inftances, is not attainable without much expence and la bour: but which, however, if the above object is kept in view, ought to be a fecondary confideration, as it requires but once doing; and the matter of from ten to twenty per cent. on the expence of the garden, will, in moft cafes, be fufficient for its accomplifhment. In this cafe, it is obvious, that whatever the depth of the natural foil lacks of twenty-four inches, is to be fupplied by forcing, that is, carrying in foil from the adjacent fields: for it is not advifable to trench up and mix much of the fub-foil (of whatever texture it be) with it. Indeed, in many cafes, gardens are almoft ruined by the injudicious admixture of the fub-foil with the furface mould.

Secondly, Situation is to be confidered. In page 245 , I have already dropped fome hints

fully out in practice. But I hope the theory will be found to be reafonable, and confiftent with both horticular and agricultural improvement; and that it will be followed out by fome of the many ingenious improvers f land wherewith the country abounds. 
CH. I.] THE KITCHEN GARDENER. 32 I hints on this head; and would here further obferve, that in few inftances is it advifable to lay down a garden on a level fpot, fuch feldom having a dry bottom, and being drained with more difficulty, if requifite, than when there is a declivity. A north afpect is allo to be avoided, and preference thould be given to a fouth, fouth-eaft, or fouth-weft : but even an eaft or weft afpect, in many cafes, may prove excellent fituations. A declivity of from a foot in twelve to a foot in thirty or forty will generally anfwer; but about one in twenty-five has the happiert effect.

The rule I had laid down; and which I have partly practifed, is this, viz. To take three crops off the firft furface, then trench three fpit deep, by which the bottom and top is reverfed, and the middle remains in the middle; take three crops off this furface, and then trench two spit, by which the top becomes the middle, and the middle the top; and take alfo three crops off this furface, and then trench three spit, whereby that which was laft the middle, and now top, becomes the bot- 
tom, and that which is now the bottom, and was the furface at firft, now becomes furface again, after having refted fix years. Proceed in this manner alternately; the one time trenching two fpit deep, and the other three: by which means the furface will always be changed, and will reft fix years and produce three.

Hence will there always be new foil in the garden for the production of wholefome vegetables; and hence alfo will much lefs manure be required, than when the foil is fhallow and the fame furface conftantly in crop.

I have faid above, that the foil hould be from twenty-four to thirty-fix inches deep : and I would not advife that it be much more, or at leaft that it be trenched. to a greater depth; as thereby the furface might be buried too deep from the action of the weather and influence of the fun, and confequently would be crude and unmeliorated.

* I prefume the appellation is confiftent with the idea we have of New Soil, as certainly in reality there is no fuch thing; but, by this procefs, it wilk be in a great meafure renovated. 
unmeliorated for fome time after trenching up.

In fituations where the foil is only fo deep as to allow of trenching two fpit, and expence in making it deeper is grudged, the above hint may alfo be followed with advantage : as by regularly trenching every third or fourth year, the ground will reft half its time; and, if judicioufly managed, and cropped in proper rotation, wholefome vegetables may be produced on it for many years fucceflively.

In many inftances, it may be inconvenient, nay improper, to trench the wbole garden over in the fame feafon; nor do I wifh to advance fuch a propofition: one half, or a third, at a time, may be more advifable, and alfo more convenient; of which, circumftances alone can determine. But I would here obferve, that, in cafes where the bottom is wet or tilly, in trenching at any time, care fhould be taken to go exactly the fame depth with each trench; a matter of evident benefit; for, if the bottom be left rough and uneven, and if galls 
324 THE KITCHEN GARDENER. [B. 3 . are left between each trench, water will ftagnate in the foil, and, of confequence, by fouring it, injure the crop, whether of trees or vegetables. 
CH 2.] THE KITCHEN GARDENER. 325

\section{CHAPTER II.}

ON THE NATURE AND VARIETY OF GÁRDEN LAND;

WITH THE MEANS OF IMPROVEMENT.

T $T$ is a happy circumftance, that in many 1 inftances we meet with different foils in the fame acre. In the fame garden they fhould never be wanting; and where nature (or natural caufes) hath been deficient, recourfe muft be had to art; inaimuch as the variety of fruits and vegetables to be cultivated, require a variety of foils to produce them in perfection.

It would be abfurd, however, to imagine, that for every particular vegetable there is to be a particular foil prepared. The variety of foil in any garden may with propriety be confined to the following:Strong clayey loam; light fandy loam; (which are the two grand objects): a compofition of one-fourth ftrong, with threefourths light loam; half ftrong, and half light; and one-fourth light, and threefourths ftrong. Which, by a proper treat-

$$
\mathrm{X}_{3}
$$

ment, 


\section{THE KITCHEN GARDENER. [B. 3.}

ment, and with the proper application of manures, may be rendered productive of any of the known and commonly cultivated vegetables, in the higheft degree of perfection.

But, in order to improve a foil, we muft be guided much by its nature, fo as, if porfible, to render it ferviceable in a general intention. And hence, our duty is, to endeavour to hit on that happy medium which fuits the generality of efculents, in the formation or improvement of the foil in the kitchen-garden. Such a foil fhould be fufficiently tenacious to adhere to the roots of plants, though not fo much fo as to be binding, which would certainly retard their progrefs and extenfion in queft of food. Hence, a loam of a middle texture, rather inclining to fand, may be denominated the moft happy foil for the purpofe here in view; and that on a double account, viz. The greater part of the valuable kinds of kitchen vegetables delight in fuch, and it is worked at lefs expence than a ftiff foil; neither in fevere droughts. is it fo apt to crack or be parched; nor in 
CH. 2.] THE KITCHEN GARDENER. 327 hard frofts is it fo apt to throw or fpew tender plants or feeds out.

If foils be too frong, the tender roots of plants pufh weakly in them, ficken, canker; and perifh; and if a foil be too light, and if it be poor withal, plants depofited in it will purh their roots far, and in vain, in queft of that ftability and nutriment which is neceffary and effential to their fupport. So that, if the butt of our aim be perfection in the production of wholefome and well-matured vegetables, we muft put afide carelefs indifference in the formation of a proper foil; nor truft entirely to the force of dungs, were they even to be had in the greateft plenty; for thefe, by too free an application, have an effect on the quality of efculents, not altogether falutary.

Wherefore, that our efforts may be attended with fuccefs throughout, let us beftow a moderate and prudent expence in the firft outfet, on compofing or fo improving the foil to be appropriated to this purpofe, as that, in our beft judgment, it may fully anfwer the intention. For,

Forming and compofing the foil of a garden, is certainly more eafily accom$\mathrm{X}_{4}$ plifhed 
plifhed before, or at the time the walls are building, than afterwards : and we often find, where that matter has not been properly attended to at firft, and where even the expence of doing it afterwards would be chearfully beftowed, the principal obftacle is the cutting-up of the lawns, fhrubbry, walks, \&c. Thefe confiderations, however, ought to give way to the more folid advantages to be derived from the improvement of the kitchen-garden; the more efpecially, as in the courfe of a feafon, and at a trifling expence, they may be replaced in all refpects as they were before.

In many cafes might the foil of the garden be improved in a very confiderable degree at a fmall expence. Thus, where the bottom is wet, and the fub-foil of a cankering nature,-by judicious draining, which is certainly one of the greateft improvements in this cafe: where the foil is fubborn,-by the addition of fmall gravel, fea fand, wherein is a confiderable quantity of fmall pebbles and thells, coal afhes, limegravel, 
gravel, pounded brick-bats *, brick-kiln afhes, \&c. \&cc. and, above all, by being carefully laid up in ridges in the Winter months, and indeed at all times when not in crop, in fuch a manner as to give the greateft extent of furface for the weather to act upon: where the foil is'a poor fand or gravel, \&c.-by the addition of clay, or ftrong clayey loam, fcourings of ditches which run through a clayey fub-foil, pondmud in a like fituation, or fcrapings of roads, which lie in a clayey diftrict, \&c.

Soils that abound with metallic fubftances, and which generally make them ap. pear of an iron colour, are termed foxbent or till. Thefe fubftances are often found to be intimately mixed, or rather confolidated with the foil, in confiderable maffes, which are adhefive and very ponderous. Such foils are the moft unfavourable to vegetation of any; and are quite ineligible for

* I have witneffed the effects of pounded brick-bats and brick-kiln afhes in mixture, which were applied freely, in fertilizing a cold, wet, back.lying, clayey field, in an aftonifhing manner, by a fingle dreffing. This is a proof that clay, after being burnt, is completely changed in nature and effect. 
for the purpofe here in view, without being much improved. For this purpofe, lime will be found the moft ferviceable of all things, if judicioully applied, and the foil be frequently turned over by digging or trenching; fo as that the foil and the lime may be intimately mixed together, and that the atmofphere may have full effect upon them: for without this, the lime will not operate fo effectually, nor will the tilly particles of the foil be divided or meliorated fo well.

It may feem unneceffary to obferve, that according to the quantity of irony matter contained in the foil, lime will be required to reduce it. In order to afcertain this quantity, a magnet will be found ufeful; and, by one of the maffes being calcined, and then reduced to a powder, will feparate the irony particles from the foil or refiduum; thowing the proportion of iron, and of earth. Thus we may judge, what quantity of lime will be required to fertilize the foil; taking for the extremes in ordinary cafes, and fuppofing the lime of a middling quality, I 50 and 400 Winchefter bufhels an acre; applying the lime in a quick 
CH. 2.] THE KITCHEN GARDENER, 33F

quick or powdered ftate, and properly working the foil; being careful, in the firft place, to drain it of fuperabundant moifture.

Ridging-up of land, as above hinted, has the happieft effect, efpecially for ftiff foils, and fhould never be omitted when the ground is not under crop. In dead fandy loams, alfo, and in cankering gravels, it is of infinite advantage for meliorating them: but in very light fandy foils, it is not advifable to carry this practice to too great an excefs. For it is a fact proved by experience, that, by expofing foil to the fun's rays in part, by throwing it into a heap, whereby it is alfo partly fhaded, and trenching it once a month, will fooner reftore it to fertility than any other procefs, exclufively of adding frefh matter.

And thus, if any ingredient, noxious to vegetation, abound in the foil, it may be expelled, or exhaled, by the action of the atmofphere; more particularly if the foil undergo a Summer, and alfo a Winter fallow. In the latter cafe, however, care fhould be taken to have the furface incruited by froft as often as poffible, by turning it, and giving it a new furface each fucceeding thaw. 


\section{H A P T ER III.}

ON MANURES, AND THEIR APPLICATION.

7 HOSE moft to be preferred for the 1. ufe of the kitchen-garden are-itable-dung, cow-dung, hog-dung, theep-dung, pigeon-dung, foot, lime, loamy marl, fhellmarl, fea-weed, wood-afhes, whin-afhes*, fern-athes, coal-athes, vegetable mould of decayed tree-leaves; and vegetable mould of decayed vegetables of all kinds, as cabbage leaves, haulm, weeds, \&c. to which may be added with much propriety, although a fluid fubftance, the richeft of all, and that in which is moft of the food of vegetables, viz. the drainings of the dunghill.

Manures

* I have witneffed the aftonifhing effects of whinathes alone, in producing herbage in a five or fix fold degree; which was the more obvious, on account that the field on which they were applied was much alike in quality, (a ftiff, wet, clayey loam), and the afhes were applied partially. The effect was vifible for feveral fucceffive years, Alfo, on the timber-trees, with which the field was afterwards planted. 
CH. 3.] THE KITCHEN, GARDENER. 333

Manures are to be applied either as fimples or compounds; but the latter method is certainly the moft eligible. For certain it is, that if they have not undergone a proper fermentation, their effects are, giving a rank and difagreeable flavour to fruits and vegetables; and if an immoderate quantity is applied, of producing a confderable degree of unwholefomenefs, and tainting the juices of all plants.

A combination of ftable-dung, fea-weed, lime, and vegetable mould, which has lain in a heap for three or four months, and has been two or three times turned during that period, will make an excellent manure for moft kinds of garden-land. Alfo, cow-dung, hog-dung and theep-dung, mixed with foot or any of the kinds of afhes. Pigeon-dung, marl, and vegetable mould, well mixed, will alfo make an excellent manure for heavy land; or even for lighter foils, provided the pigeon-dung be ufed fparingly.

Neats-dung, that is, of cows and oxen, and hog-dung, being nightly fermented, will compole a very fit and rich manure for light, hot foils. For thofe of a dry, abforbent 
334 THE KITCHEN GARDENER. [B: 3 .

abforbent nature, perhaps none would anfwer better, or laft longer, by reafon that they retain moifture for a greater length of time, and alfo ferment more lowly, than other dungs.

Pigeon-dung, lime, foot, athes, \&c. fhould never be applied as fimples; the quantity of them required being comparatively fmall, and the regular diftribution difficult, without the admixture of other matter. But thefe thould generally be applied in comport, of good earth, turf, or fward, or of cow or other dung of a cool nature : applying them in quantity according to the cold, or the hot nature, of the foil to be manured; allowing the compont a fufficient time to incorporate, and mixing it thoroughly.

Marl is an excellent manure for almoft any foil; and may be applied as a fimple with as much propriety as any of the kinds of cattle-dung, or even vegetable earth. The kind called thell-marl is much to be preferred; and thould be freely applied to ftrong lands, but more fparingly to light: the loamy kind being beft adapted to light lands. 
CH. 3.] THE KITCHENGARDENER. 335

Stable-dung, if ufed as a fimple, fhould not be applied in too-rank a ftate, nor fhould it be too much fermented. It fhould generally lie in a heap for two or three weeks; during which time it fhould be turned once or twice. A ton of it in this ftate, is worth three that has been ufed in the hot-bed, and is a year old. This manure, and indeed dung of any kind, when applied as fimples, fhould never be carried from the heap to the ground, till it is to be digged in; as, by its expofure to the air, the virtues evaporate, and it is the lefs effectual.

The neceflity of the inftant application of fea-weed after landing, if ufed as a fimple, is even greater than the above; as it inftantly corrupts, and its juices flow downwards, and are loft. If this manure is ufed as a compound, the heap wherein it is compounded thould be more frequently turned on its account; that none of the juices may be loft, but that the other part of the compoft may abforb them.

Horfe-dung, and the dung of theep, deer, rabbits, \&c. are moft eligible for cold, wet foils; and all thefe, or any of thefe in comport! 
336 THE KITCHEN GARDENER. [B. 3 . compoft with lime, will be found beneficial. For fuch foils alfo, a compont of coalathes, pigeon-dung, and lime ; or of woodanhes, whin afhes, fern-afhes, and ftabledung; or, of deer-dung, rabbits-dung, foot, and burnt fward, \&c. will make a good manure.

Manures being valuable in proportion to the falts and the oils they contain, are to be applied in quantity according to their quality. Hence, the dung of pigeons fhould be ufed in much fmaller proportion than that of horfes, it containing a greater quantity of volatile falts; and fo the athes of vegetables containing a portion of fixed alkaline falts, being more powerful, are to be applied in fill fmaller quantity. So alfo, lime, being the moft powerful of the calcareous kinds, thould be applied, in ordinary cafes, in much fmaller quantity than marl.

Vegetable mould may either be ufed as a fimple or a compound, and is to be applied with equal propriety to all foils. None can be hurt by it in any degree; fince almoft every plant will grow luxuriantly in it entirely, without the aid of any 
foil or manure whatever. It feems to be the ambrofia, and the dunghill drainings, the nectar, of vegetable life. The latter, however, if too freely indulged in, is rather of an intoxicating nature.

The importance and effect * of manure being now generally credited and acknowledged, (at leaft much more fo lately than heretofore); it would appear to be the indifpenfable duty of every gardener and cultivator of the earth, to be careful in the collection of it, and alfo to diftribute it with fkilful frugality. For this purpofe, a well, ciftern, \&c. hould be contrived fo as to collect the dunghill drainings; and in the application of manure of any kind, the greateft care fhould be taken to divide it equally, according to the quantity to be applied.

All animal fubftances, when properly applied, are good manures; and as animals

* We may briefly define the effect of manures, when properly applied, thus: Correcting tenacity, crudity, and porofity in the foil ; exciting its fermentation, communicating nutritive matter, and affording nourifhment to the roots of plants ; thereby promoting vegetation, and their perfection. 
$33^{8}$ THE KITCHEN GARDENER. [B. 3 . derive their fuftinence, either immediately, or ultimately, from vegetables, thefe, when properly decompofed, become great promoters of vegetation. Hence, dungs in general are fuperior to other manures; and are the more valuable in their kinds, according to the proportion of oils they contain, which are moft eafily reducible, by the nitrous acid of the air, into that fpecies of mucilage, allowed to be the effential pabulum or nutriment of plants. Our duty, therefore, is to collect thefe with care, and apply them with attention.

The dunghill may alfo be confiderably increafed by throwing the haulm, ftalks, and leaves of all vegetables into a common heap, letting them remain till well rotted, and afterwards mixing them with lime, marl, athes, foot, \&c. or in the procefs of collection. Watering the whole frequently with the drainings of the dunghill, would greatly enhance its value. Like a good roaft, it thould be well bafted with its own drippings *.

C. H A P-

* An obfervation that lately excited a hearty laugh from an epicure. 
CH. 4.] THE KITCHEN GARDENER. 339

\section{CH A P T E R IV.}

CULTURE OF KITCHEN VECETABLES.

SEGTION I.

ARTICHOKES.

7THIS plant will grow freely in light 1 loam of any kind, provided it be well enriched with compoft, ftable-dung, marl, or fea-weed. It requires a depth of foil from twenty-four to thirty inches, to produce it in perfection. In ftiff wet lands, artichokes frequently perifh in winter.

It is propagated with facility by offsets from the old ftools, which are produced every fpring in great abundance, and are to be planted in patches of two or three plants each, at the diftance of four feet, patch from patch each way, watered frequently in dry weather, the firtt fummer, and kept clean of weeds.

As this plant is very tender, and eafily killed by froft, the rows, \&cc. Thould be $\mathrm{Y} 2$ carefully 
carefully covered with ftable-dung, or other litter, in the early part of winter, -which is preferable to the method of digging out trenches, and moulding up with the earth dug therefrom, as, by that mode, the roots are doubly expofed. In a thoufand inftances were the whole ftock of Artichokes killed, by the early fetting in of the froft in 1796, which lafted but three weeks, and was far from what may be termed fevere. And many of thefe were landed up; but none that were well covered fuffered.

In proceeding to cover up the plants with litter, \&c. let the decayed ftalks, and alfo the ftrong outfide leaves be removed; then lay the litter in a ridge all along on the rows, of breadth fufficient to cover the extremities of the roots, and to the thicknefs of about ten or twelve inches.

In fpring, $i$. e. about the firft or middle of March, the littery part of the covering is to be removed, and the fmall, or rotten part thould be digged in, previounly reducing the number of plants on each ftool to three or four of the ftrongeft; as otherwife

they 
CH. 4.] THE KITCHEN GARDENER. 34I they would grow too thick, and the heads, in confequence, would be rendered fmall.

One hoeing will generally be fufficient for the feafon, as hardly any weed will grow under their foliage, and thefe will foon cover the whole ground.

The above culture is to be repeated every feafon, for the old ftools; and where a fucceffion of Artichokes are in requeft, a few young ones thould be planted every year. They will produce in autumn, in fucceflion to the old ones, and laft till the froft deftroys them.

Old ftools thould not be fuffered to remain above feven or eight years in the fame fpot, otherwife they produce diminutively.

SECTION II.

ASPARAGUS.

7 HIS vegetable is moft fuccefsfully pro1 duced on a light fandy loam of at leaft two feet in depth. And the beft manures, in this cafe, are - a compoft of ftable or cow dung, hogs-dung, fea-weed, marl, 
and vegetable earth; or ftable-dung and vegetable earth; or, fea-weed and any of the above.

Strong loam does not anfwer well for Afparagus; but it may be much improved by the addition of gravely loam, light fandy loam, fea gravel, brick-bats pounded and mixed with the kiln-afhes, \&c. In this cafe, the beft manures are-a compoft of vegetable earth, foot, pigeon-dung, and any of the kinds of afhes; or, ftable-dung, feaweed, and Thell-marl ; or, fheep-dung, feaweed, and marl; or, fea-weed, ftable-dung, or thell-marl, as fimples.

As Afparagus does not come to maturity for feveral years; and as there is no poffibility of effectually manuring it after fowing or planting, without hurting its roots, which are very brittle, the greateft care is necelfary in preparing the ground for its reception, which hould be trenched at leaft two feet deep, and the manure well mixed with the foil in the operation.

It is common to raife Afparagus on a feed-bed; and tranfplant it into beds four feet wide, with alleys of two feet between them. In fome inftances, the beds 
are only two feet, and contain but two rows, with alleys alfo of two feet. This method is preferable to the former. But the molt approved, is, to drill in the feed where it is to remain, in fingle rows, a yard apart and an inch deep; fowing pretty thick, in order to infure a crop *: even, four feet apart for the rows would not be too much.

I have feen an inftance where a piece of ground was equally trenched and manured; the one-half of it was drilled at one yard, and the other at two apart; that which ftood at two yards, as I was affured by the proprietor, produced a greater quantity of grafs on the fame quantity of ground than the other, and the buds were much larger.

That Afparagus, which is fown where it is to remain, will be ftronger, againft the third year, than that which is tranfplanted, I have myfelf proved in more than one inftance; and would therefore advife this. practice in preference to the other.

If the fpring proves dry after fowing, the rows hould be frequently, refrefhed

$$
\text { Y } 4
$$

with

* The middle of March or firt of April, is the proper feafon for fowing. 
344 THE KITCHEN GARDENER.

[B. 3:

with water. When the plants have arrived at the height of three inches, thin out the rows to about five or fix apart, and draw a little mould to the Atems of thofe left. Keep clean of weeds for the remainder of the feafon, and indeed at all times; frequently ftirring the furface, which will greatly promote the growth of the plants.

The beft manures, and moft proper application, for the rows or beds of Afparagus, is-the drainings of the dunghill, which may be applied at any time; feaweed, which may be applied at any time from October to March, and thould be fpread on the furface as it is carried from the thore; a compoit of lime and dung, or dung and marl; and ftable-dung alone, which fhould he fpread on the furface about October or November, and let remain till the firft of March.

This laft is the common method of manuring Afparagus land: but there are many who do fo merely becaufe they fee others do it; and who imagine it to be done in order to preferve the plants from the effects of froft, and of confequence they choole the moft littery part of the dung for 
CH. 4.] THE KITCHEN GARDENER, 345 this purpofe. This idea is erroneous; and I have fufficiently proved that Afparagus roots will in nowife be injured by the fevereft froft. Plants of the firft year, however, may with propriety be covered, to prevent their being fpewed out of the ground; but, otherwife, it is not neceffary to their prefervation. In the very fevere Winter of 1794-5, there was no covering of any kind on my Afparagus, nor was it even what is termed landed $u p$.

Inftead of landing-up in Autumn, having previoufly cut the haulm down to the ground, clear the furface of weeds, \&c. and ftir it up to the depth of two or three inches with the fork; that it may the more freely receive, not only the juices of any manure that is applied, but be more readily acted upon by the weather. In Spring, if it has been covered with ftable-dung or fea-weed, gather off the rough part of it, and flightly point in the fmall; at the fame time thedding a little mould on the rows, being careful not to go too near the roots of the plants, as thefe, if poffible, hould never be difturbed. This operation is to be performed 
346 THE KITCHEN GARDENER. [B. 3 .

formed about the firft or fecond week in March.

It is a common practice to plant or fow other crops on the beds, or between the rows of Afparagus. This may be proper for the firft year or two, if done in moderation, introducing a row of cauliflower. Turnips, \&c. in the middle of each interval of the rows, or in the alleys between the beds. But after this, it becomes altogether improper, as by the time the roots begin to fpread, in either mode of fowing or planting, they ought; on no account, to be difturbed; more particularly if it be wifhed to rear large, handfome grafs.

Afparagus beds thould not lie above eight or ten years; but where it is cultivated in rowes, it may lie confiderably longer. However, where the forcing of the roots is practifed, it is feldom fuffered to lie even that time; as plants of from four to eight years old are fitteft for this purpofe.

In refpect of cutting, the third year thould arrive at any rate, even if the grafs is fufficiently ftrong the fecond, (which, however, is feldom the cafe): becaufe, by being cut too foon, it weakens the roots much; 
CH. 4.] THE KITCHEN GARDENER. 347 much; and the encouragement of thefe, till the grafs is perfectly eftablithed, is a principal object.

We often fee blanks in Afparagus beds, \&c. that are producing, which were not originally in them, or before the grafs was begun to be cut. This is occafioned by injudicious cutting; and not, as is generally fuppofed, by accidental natural caufes: and what occafions it is evidently, that, in cutting, all the flalks of fome of the plants are cut; which, although they may put forth the next Spring, (but this they will in fome inftances do in Autumn. See note, page Ir.), do fo in a very weak manner, and perifh in the following Winter. Wherefore, care thould be taken to leave at leaft one or two buds to each plant in order to draw nourifhment to, and encourage the growth of the roots.

In cutting, be careful not to injure the young buds rifing about thofe fit to be cut, nor to wound the crown of the root. The roots of few plants take worfe with wounding than thofe of Afparagus, which, from their fucculent nature, bleẹd more or leîs at every bruife. 


\section{SECTION III.}

\section{BE A N S}

TO beft in ftrong land; but are fuc1 cefsfully produced on almoft any kind of garden ground. In gardening, the land is feldom manured for a Bean crop, as they generally follow that of cabbage, cauliflower, \&c. which are commonly planted on well-prepared ground.

Beans may be tranfplanted with fuccefs, and where they are required at a very early feafon, the following method hould be practifed:

Sow, of the early Mazagan, in large pots or boxes, being filled with rich mould, about the firft of November; place them in the green-houfe, peach-houfe, \&c. or under a frame and lights, and fo, as that the plants may enjoy the free air and light, and grow flowly; when they come up, refrefh moderately with water; keep them here, or in a like fituation, till the firft of March; and then plant them out 
CH. 4.] THE RITCHEN GARDENER. 349

under a wall having a fouth afpect, or other well-theltered warm fpot, enjoying the full. fun, all along in a row at two inches apart; taking them carefully out of the pots or boxes, with their fibres entire.

For a fecond crop, fow of the Mazagan or Lifbon kinds, on an early border, in a fouth afpect, in rows twenty inches apart, about the firft of January. And $\%$ for fucceflional crops, fow or plant in an open expofure, of the Long-pod, Windfor, Sandwich, Toker, \&c. in rows from twenty-four to thirty inches apart, Ifrom. the firft of February to the firft of June, at intervals of about three weeks.

The crops are invariably to be kept clean of weeds, and earthed up at two different times, viz. firft, when the plants are about two inches high, and, laftly, when they are about ten or twelve.

Topping the early crops, about the time the pods are diftinguiphable on the lower part of the ftalks, is of advantage; the pods will fwell confiderably fooner in confequence. 


\title{
SEGTION IV.
}

\author{
BEET.
}

F this plant, there are two kinds in cultivation for the ufe of the kitchen, viz. the Red, for its roots, and the Green, for its leaves, which are ufed in manner of fpinage. The former, however, being moft in demand, I will chiefly confine my obfervations to it.

The foil which fuits this plant beft, is a light dry loam, of at leaft eighteen inches in depth. On ftiff, thallow foils, the roots canker and get forked. In all cafes, the ground fhould be deeply digged or fubtrenched, and hould be well broke in the preparation. It is better not to apply manure at the time of cropping with beet, but the land fhould be in good heart.

The feafon for fowing is from the middle of March to the firft of May; taking, for the fitteft time, the firft week in April. 
CH. 4.] THE KITCHEN GARDENER. 35 I

After digging, \&c. roll the ground lightly, or tread it fmoothly with the foot; then draw drills an inch deep, and twelve or fourteen inches apart, according to the quality of the foil; fow the feeds thinly; cover them in, and fmooth all with the rake.

When the plants have arrived at an inch or two in height, thin them out to five or fix apart in the row; and keep them clean of weeds at all times. Beet may be preferved in Winter, by being ftored in the manner of carrot. See Section IX. of this Chapter.

The Green fort may be raifed much in the manner as above; but as the tops only are ufeful in the kitchen, it is not necerfary to take equal pains in preparing the ground. It is much like fpinage in its manner of growing, and is generally ufed in the fame intention. In gathering the leaves, care fhould be taken not to injure the crown of the root, as in that cafe, it would bleed much. 


\section{anove \\ SECTION V:}

BROCOLI

Elights in a ftrong loam, but will do well in any common garden land, if well enriched with ftable or cow dung. Where a fucceflion of it is required, a little fhould be fown on an open light fpot about the middle of March or firft of April, and planted out about the firft or middle of May, on an open rich fpot, in rows two feet apart, and eightéen or twenty inches in the row. The principal crop is to be fown about the firft or middle of May, and planted out in July; and a later crop may be fown in the end of June, and planted out in Auguft: Strong loam in an open fituation is the moft eligible foil.

All the crops fhould be fown thinly in free foil and an open fituation. If otherwife, they will require to be pricked out into nurfery beds, in order to ftrengitien them, and that they may be furnifhed with good roots. 
CH. 4.] THE KITCHEN GARDENER. 353

The brown, green, or purple kinds, anfwer beft for early crops, and the white, for the principal and late.

Keep them clean of weeds, and when the plants are fairly eftablithed and begin to grow, let a little earth be drawn up to their ftems, which will greatly promote their growth. Before the leaves expand fo as to cover the ground, let them be finally moulded up; and this is to be obferved alfo for cauliflower, cabbage, favoys, \&c.

In fine feafons, it will fometimes happen, that the early crops of brocoli get too forward, and are unfit to ftand the Winter frofts. When this appears to be the cafe, in the end of October or firft of November the plants thould either be lifted entirely and fougbed in on another fpot, or they fhould be beeled and laid over in a floping pofition where they ftand. Being thus checked, and their hearts guarded from the weather, they will better endure the feverity of Winter. 


\section{SECTION VI.}

BRUSSELS SPROUTS.

THIS is a good vegetable for Winter

I and Spring ufe, and is much admired by many. The fprouts which iffue from the ftem are the eatable part, and are fine delicate greens; good fubftitutes for brocoli.

The foil, fituation, and the culture that anfwers for brocoli, will alfo anfwer for this plant in all refpects.

\section{SECTION VII.}

\section{CABBAGE.}

CABBAGE is plentifully produced on garden land of almoft any kind; but moft abundantly on a ftrong loam of eighteen to twenty-four inches in depth.

The land thould always be manured for this crop, as one of the leguminous kinds 
CH. 4.] THE KITCHEN GARDENER. 355 hould follow it. If it is a light fand, \&c. cow dung, hog dung, or loamy marl, is moft eligible ; if a ftrong loam, ftable dung, fea weed, or thell marl, as fimples; or a. compound of all thefe, or of any of thefe with theep dung, pigeon dung, vegetable mould, or of any of the kinds of athes; if a clay, ftable dung, fea weed, thell marl, or Theep dung as fimples, or a compound of lime, ftable dung, fea weed, pigeon dung, and vegetable mould, or of thell marl, ftable dung, fea weed, any of the kinds of afhes, and vegetable mould; or of any two or more of the above.

The fame manures for the fame foil, will equally anfwer for cauliflower, greens, favoys, \&c.

There are many kinds of cabbage in cultivation; but thọfe moft efteemed for the garden are, the Early Dwarf; Early York; Early Sugarloaf; Late ditto; Batterfea; Red, for pickling; and the large broad Dutch for cattle.

For an early crop, fow of the Dwarf, York, Early Sugarloaf, or Batterfea, (but the true Early York is to be preferred), on a light open fpot about the firit or fecond 
$35^{6}$ THE KITCHEN GARDENER. [B. 3 . week in Auguft; and about the firft of October plant them out on an early border, or other warm fpot, at the diftance of a foot each way, that in Spring the one row may be cut up for Greens, which are then in general requent, and the other may be retained to come to maturity; and for a fucceflional crop, plant of the fame fowing and kinds, and alfo on the fame or a fimilar fituation, about the firft or middle of February, at the diftance of eighteen or twenty inches each way.

For crops to fucceed thefe, fow of any of the above kinds every three or four weeks from the firlt of February to the firft of June, on an open fpot of light land; and plant, when fit, in an open and free fituation, at the diftance of from eighteen to twenty-four inches each way, according to the kinds, and quality of the foil.

The Red kind is to be fown in Auguft or February; and hould be planted out in October or April, on an open fpot at the diftance of two feet each way.

The broad Dutch is to be fown about the firft of september, and planted out in 
CH. 4.] THE KITCHEN GARDENER. 357

March; or in the beginning of February, and planted out in April; on a well-expofed fpot, at the diftance of thirty inches each way.

The two laft kinds, being generally left in the ground for Winter and Spring ufe, and from the length of their ftalks, are frequently much injured by the feverity of froft, fhould be laid over in an oblique direction, which both fecures them from froft, and from the bad effects of blanching rains, in rotting their hearts.

\section{SECTION VIII. \\ CAULIFLOWER.}

7 HIS vegetable being much efteemed,

1 there are few who are not provided with hand or bell glaffes for its early production. For this crop, the plants fhould be fown on a light open fpot, about the latter end of July, or firft of Auguft; and when they are fit for pricking out, fhould be put fingly into pots of four inches diameter, filled with rich mould, and placed

$$
\mathrm{Z}_{3}
$$


$35^{8}$ THE KITCHEN GARDENER. [B. 3 . in a peach or vine houfe that is not at work, or under a frame and lights, where let them enjoy free air, and be moderately refrefhed with water. In very fevere weather, defend them from froft, and from blanching rains, \&c. till the middle of February or firft of March; and thén plant them out on an early and well-enriched fpot, placing two under each hand, and one under each bell glafs. If, however, there is a fufficiency of plants, it may be advifable to place one more in each, than is requifite to remain for good; as early cauliflower frequently ftart or button about the firft of April, and if one or more of them does not, it is but the trouble of pulling them out again.

For a crop to fucceed thefe, plants of the fame fowing, and which have been treated in all refpects as above, may be planted in a like fituation and foil, in the open air, about the firft or middle of March, at two feet apart each way.

For fucceffional crops, fow as hirted in the note, page 19., or on a night hot-bed. about the firft of January, and when fit, plant them out in an open rich fpot of loamy 
CH. 4.] THE KITCHEN GARDENER. 359

loamy land. Sow again about the middle of March, and when fit, plant as above. And laitly, fow about the eighteenth or twentieth of May, and alfo plant as above, or on a wall-border, which has an eaft or weft afpect.

In the Summer months, water frequently in dry weather. Do not plant too deep, otherwife the hearts of the plants will not only be liable to rot through damp, but become an eafy prey to lugs, \&c.

In the heat of Summer, it is a good practice to break down one or two of the larger leaves, over, and fo as to cover the flower. This will prevent it from being fcorched, will keep it longer from blowing, and preferve it of a more delicate colour.

The, laft crop will come in about the firft of October, and if a fufficiency was planted, will laft till the froft deftroys it. It is common to preferve thefe in cellars or other out-houfes, or in back-fheds of hot-houfes, \&c. by taking them up roots and all, and laying them in fand, \&c. or by placing them in vine-houfes, peachhoufes, hot-bed frames, \&c. \&c. in all

$$
\text { Z } 4
$$

which 
360 THE KITCHEN GARDENER. [B. 3 . which methods care thould be taken to keep them as dry as poffible, and to diveft them of any leaves which decay.

The foil that produces this vegetable beft, is a loam neither light nor ftiff, of at leaft eighteen inches in depth, and which is well enriched with any of the common manures ufually applied to fuch fơils. Of this, fee the article Cabbage.

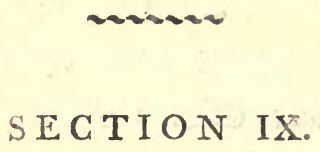

CARROT.

7 HIS, above all other vegetables, de. 1 lights in nere land, and that which produces it beft is a light, fandy loam, of eighteen or twenty inches in depth as leaft. Carrots thould never be fown with manure of any kind at the time of fowing; being produced beft and cleaneft on land that has been manured for the preceding crop.

The beft crop I ever faw, was growing on a fpot of ground (a fandy loam, and rather poor), which was trenched three 
CH. 4.] THE KITCHEN GARDENER. $36 r$ fpit deep, and which a fpade or plough had never previoufly penetrated into, above nine inches.

For an early crop, fow of the early horn, or orange kinds, on a flight hot-bed, about the middle of January; or on a light, early border under hand-glaffes, \&c. about the firft of February. Let them be frequently refrefled with water, expofed to the air in frefh weather, and kept clean of weeds; alfo thin them out to about three inches fquare.

The principal crop thould be fown about the firft or middle of April, in an open expofure, in drills an inch deep, and at the diftance of twelve or fourteen apart. The long red, or orange kinds are fitteft.

The chief property of this vegetable is the length and cleannefs of the root; and for the attainment of perfection in this refpect, the land Thould be trenched or fubtrenched to the depth of eighteen inches at leaft, and well broke in the operation of trenching. Before drilling, the furface - fhould be lightly rolled, or evenly trodden with the foot, otherwife the feed is apt to be unequally buried. 


\section{THE KJTCHEN GARDENER. [B. 3:}

When the plants have arrived at the height of two or three inches, thin them out to the diftance of five or fix apart; but this operation thould not be performed in very dry weather, or when the ground is in a dry Atate, efpecially if the plants have rifen thickly, as thereby the remaining ones will be much hurt, thofe which are pulled out, both loofening and leaving the ground about them full of holes to the depth of their extremities. The ground fhould be immediately handhoed, whether it be foul or clean of weeds, and that with the view of clofing the holes about the remaining plants. For want of the above precaution are many crops of carrots much injured.

Keep them clean of weeds at all times, and pull out fuch as run to feed, thefe being both ufelefs, and greatly exhaufting the ground.

Such part as are to be preferved for winter or fpring ufe, fhould be built in realls of about thirty or thirty-fix inches thick, with dry clean fand. If thicker, they are apt to heat. They thould alfa be taken up when the ground is in a dry ftate, if poffi- 
CH. 4.] THE KITCHEN GARDENER: $3^{6} 3$ ble; but if this is not the cafe, they thould, previous to building, be laid thin in the barn, thed, \&c. for eight or ten days. The fituation where they are to be ftored, fliould be cool, dry, well aired, and capable of being defended from froft.

SEGTION X.

\section{CELERY.}

7 HIS vegetable is much in requeft in 1 moft families; and in many, as long a fucceffion of it as can be produced is required.

For the firft crop, fow about the firft of January, either as hinted in page I9., or on a hot-bed; for a fecond, by the firft of February as above, or on an early border having a fouth afpect, and cover either with a frame and lights, or hand-glaffes, \&c. for a third, by the firft of March, alfo on an early border; and for a fourth and laft, about the firft of April on an open fpot. This will generally be the crop moft to be depended 
depended on, the others frequently running to feed.

In all which cafes, light rich mould is to be chofen. I have found vegetable mould of decayed tree-leaves, of infinite advantage for the early crops.

The manner of planting, fituation, and foil, for all the crops, thould be the fame, and the following is moft approved: The plants in all cafes are to be pricked out into nurfery beds, which Arengthens them much, and makes them put forth fine young fibres; and when they are fit for planting they are to be planted in rows, twenty inches afunder, and eight inches in the row, acrofs trenches of eight feet wide, having fpaces of four feet between them, whereon to lay the mould that is dug out of them, which is to be done to the depth of fix inches only, this, together with the depth of the foil of faid fpaces, being fufficient for moulding up with. This is to be underftood, however, of land that is at leaft two feet deep, and which lies dry; as, on the contrary, the plants are to be planted on the furface, and the fpaces between, are 
CH. 4.] THE KITCHEN GARDENER. $3^{6} 5$. to be a foot or two more, to afford a fufficiency of foil for blanching with.

The foil beft adapted to the production of Celery, is a rich loam of a middling texture; and the fitteft manure is a compofition of ftable dung, and vegetable earth; but ftable dung alone, which is pretty well reduced, will do very well. Light fandy loam well enriched with cow dung, will alfo produce Celery in abundance. Celery grows well, and arrives to a good fize, in peat-earth.

In moulding up, a dry day is always to be chofen, and too much is never to be applied at a time, left the hearts of the plants be covered, in which cafe they are fure to rot, if damp weather enfue. Celery may be fuccefsfully preferved for many months in fand, \&c. in the fame manner as carrots. See the preceding fection. 


\section{SECTION, XI.}

\section{CARDOONS}

A RE in requeft in many families. A They are mont fuccefsfully produced on a deep fandy loam, not too rich.

Prepare fingle trenches, in manner as is practifed by many for celery, at the diftance of four or five feet from centre to centre, and juft as deep and wide as a fingle fpit will make them, laying the mould in the interfpaces. Point in a little compoft manure in the bottom; draw a drill an inch deep in the centre of the trench, and drop the feeds at two inches apart. The feafon is, from the middle of May to the middle of June.

When the plants are two or three inches in height, thin them out to about nine or ten apart. Mould up in all refpects as for celery, with this difference only, that the leaves mult be gathered, and tied together each time with a bit of old matting, otherwife the mould would get between them in the procefs of blanching.

Cardoons 
CH. 4.] THE RITCHEN GARDENER. 367

Cardoons may alfo be preferved in winter, in the fame manner as carrots, celery; \&c.

\section{SEGTION XII.}

FRENCH BEANS

A RE moft fuccesfully produced in a A1 rich, light, dry loam, and are moft prolific without manure, at the time of fowing or planting.

For an early crop, fow in a hot-houfe, hot-bed, or under hand-glaffes, of the Speckled Dwarf, about the firft of April, and plant them out, when fit, at the bottom of a wall or other fence, having a fouth afpect. For a fecond crop, fow in drills two feet apart, of the Speckled Dwarf, Batterfea, Negro, Liver-colour, \&c. on an early border, or other warm fpot, about the middle of April or firft of May; for a third crop, of the fame kinds, on an open expofure about the middle of June; and for a fourth and laft, of the Scarlet or White Runners, on a like fituation, in drills three feet apart, about the firft or middle 
of July. Thefe muft have fticks to run on, and will generally produce till froft deftroys them.

Keep them clean of weeds, and let them be earthed up, firft, when the plants are about three inches high, and finally, when about nine or ten.

\section{SEGTION XIII.}

\section{GARLICK}

WILL. grow freely, on almoft any $\checkmark$ kind of garden land. Plant the cloves in rows twelve inches apart, and fix in line, any time from the firft of March to the firft of May.

It requires no other attention than being kept clean of weeds, and being lifted when the leaves begin to decay.

\section{SECTION XIV.}

\section{GREENS,}

THAT is, Savoys, Cale, or Kail, Ger1 man Greens, \&c., are cultivated in all refpects much in manner of cabbage; and 
CH. 4.] THE KITCHEN GARDENER. 369 are generally planted in an open and wellexpofed fituation. The times of fowing are February, March, May, June and Auguft; and of planting, March, May, July, Auguft and September. But where a conftant fucceflion is required, they may be planted every three or four weeks from February to September. The diftance is from twelve to twenty-four inches each way, according to the ftrength of the land, feafon of the year, fize and age they are fuffered to grow to, \&c.

\section{SEGTION XV.}

\section{HORSE-R ADISH.}

7 HIS is, a wholefome root, is much 1 ufed, and in conftant demand. It does beft on a rich fandy loam, but will grow freely enough in common garden earth of any kind, provided it be a foot in depth.

It is propagated moft fpeedily by parting the crowns of the roots into flips; but any part of the root, having an eye, will A a grow 
grow and become a plant. The feafon is October, November, March, or April.

Plant in trenches fix or eight inches deep, fifteen apart, and fix inches afunder in the trench; or in deep drills; or with the fetting ftick, according to the fize of the roots or nlips.

This plant requires no other culture than being kept clean of weeds; and where it is required in perfection, new plantations being made every three or four years.

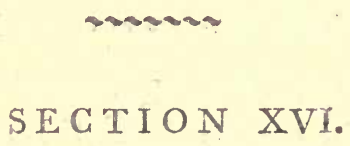

\section{IEEKS.}

THIS is a hardy vegetable, and does 1 well on moft kinds of garden land, but is produced in greateft abundance on a frong loam. The ground hould always be manured for this crop, efpecially if for spring ufe, as, in that cafe, leeks exhauft the groind much. It may be any of the kinds moft properly applicable to the foil. 
The feed is to be fown on a bed of light, rich loam, at any time from the firft of February to the firft of April. The true Scotch (broad-leaved or flag) Leek is to be preferred. The feafon of planting is, from the firft of June to the firft of $\mathrm{Au}$ gult; and they are to be planted in rows twelve or fourteen inches afunder, and five or fix in the row. The moft approved method is to make deep holes with the fetting-ftick, thruft the plant to the bottom, and let the hole remain open. This is done with the view of faving time in drilling, as it is found the plants frike root as faft this way as if the earth were clofed about them; and fo afford an opportunity of blanching equally well.

A crop to come in, late in the Spring, may be fown in May, and planted out in the end of Auguit or firft of September, according to the feafon.

Keep clean of weeds; and top the leaves three or four different times in the courfe of the feafor, which makes them put forth new heart leaves, and confequently fwell the ftalk to a much greater fize than they otherwife would:

$$
\text { A a } 2 \quad \text { SEC }
$$




\section{SEGTION XVII.}

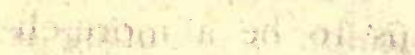 \\ QNIONS.}

7 HIS is a valuable vegetable, as moft L people are fond of it. It requires a ftrong rich loam to produce it in perfection; but in wet feafons, we frequently fee good crops raifed in light land.

In all cafes, the land fhould be well enriched with manure, which, however, fhould not be applied at the time of fowing; the beft mothod being either to fallow or take a light crop immediately before, when the manure thould be applied; which may be any of the kinds beft adapted to the nature of the foil. If this is not the cafe, and if manure is to be applied at the time of fowing, compott is to be preferred to fimples.

A fixed feafon for fowing can hardly be determined, as in all cafes we frequently fee the crop blafted in Summer, either with too much wet or drought, in which 
CH. 4.] THE KITCHEN GARDENER. 373 lätter cafe, it is fure to be deftroyed by maggots. Amongft the beft crops I ever. faw, were fown about the middle of January. The middle of February of firft of March, however, feems to be a more eligible time, as the weather is then generally more favourable for fowing fmall feeds.

I have alfo both raifed, and frequently feen, excellent crops of Onions that were fown about the firft of Auguft; in which cafe, about the finft of May following, when they begin to fhoot, their hearts fhould all be picked out to prevent them from running to feed. This, in fact, feems to be the fureft way of obtaining a crop on light land; but in wet land it is not advifable.

Onions thould be fown either on fourfoot beds, or in drills a foot afunder, and thould be thinned out to five or fix inches fquare in the one cafe, and three apart in the row in the other. The kind beft adapted to this climate is the Strafburgh, for although the Portugal, \&c. will grow freely enough, it feldom ripens well, and confequently does not keep.
A a 3
Onions 
Onions may be fuccefsfully tranfplanted; and when it happens that there are blanks in the beds or drills, this thould be practifed, that there may be an equal crop on the ground.

In all cafes, let the ground be kept clear of weeds; and about three or four weeks before the crop is fit for pulling, let their ftems be all broke down, or in other words, laid. This is moft fpeedily performed by two people taking each the end of a rod, and walking flowly up the alleys or rows, holding the rod at fuch a diftance from the ground as to generally ftrike the plants at the height of four inches above the butb. This is of great ufe, particularly in wet or late feafons, as the growth is thus diverted from the leaves, and the bulb fwells fafter in confequence.

It is of importance that Onions be taken up and boufed in a comfortable, dry ftate; therefore, when the crop approaches to maturity, advantage thould be taken of favourable weather, to have them pulled and prepared for ftoring, by turning them over frequently, and fpreading them thin in a dry, airy place. Being frung, and 
CH. 4.] THE KITCHEN GARDENER. 375.

hung up in a fhed or loft that may be defendea from froft, is as good a mode of prefervation as any other.

Crops to pull green, for Winter and Spring ufe, thould be fown, thickly, about the end of July or firft of Auguft. None of the kinds are fo fit for this purpofe as the Strafburgh. The Welfh Onion has been much ufed in this intention, but is now generally out of repute.

\section{SECTION XVIII.}

\section{PARSNIP.}

7 HE cultivation of this root is fo near-

1 ly fimilar to that of carrot, that it would only be wafting time in faying more of it, than that the feafon of fowing is from the firft of March to the firft of May; and that, as the leaves grow more grofs than thofe of carrot, they are to be allowed an inch or two more between the plants in the row.

This root, however, although now much out of ufe in the kitchen, is of a very nou-

$$
\text { A a } 4 \text { rifhing }
$$


376. THE KITCHEN GARDENER. [B. 3 . rifhing quality; and for cattle feeding, is known to be very profitable. As carrot is good food for horfes, fo Parfinip is good: food for kine; and it is a productive crop. even on indifferent foil.

\section{SEGTION XIX.}

\section{PEAS.}

7 HESE are in general requeft from the 1 month of June till November, if the weather will permit. The moft fuccersful way of producing the early crops, is this: Of the true early frame (or Charlton, if thefe are not to be had) fow a quantity in boxes or large pots, \&c. about the firft of November, and place them either in a peach-houfe or hot-bed frame, \&c., where they may enjoy plenty of air and light, and grow nowly; keep them here till the middle of February or firft of March, and then place them out of doors in a warm and free fituation; let them be covered with mats at night, and even in the day at firlt, if the weather prove

ftormy, 
CH. 4.] THE KITCHEN GARDENER. $3 / 7$

ftormy, obferving to harden them by degrees; and when the weather is mild enough, let the mats remain off at night occafionally; continue this treatment till the firft of April, and then draw drills three inches deep, on a warm light border in a fouth afpect, in which plant them an inch apart, obferving to take them carefully out of the boxes, \&c. that none of them be bruifed.

Peas, fown tbickly in a warm, well-expofed fpot, being kept under bell or hand glafs, and defended from the feverity of froft by mats, \&xc. through the winter; and being hardened in fpring, and tranfplanted as above, will alfo fucceed well, and come in at an early feafon.

For fucceffional crops, fow firft, of the fame kind, and on the fame border, or a fimilar, about the firft of January; fecondly, charltons, and alfo dwarf marrows, on an open fpot about the firft of March; thirdly, dwarf or tall marrows, blue Pruflian, or any of the other kinds, fo foon as the laft appear above ground, which repeat till the firft or middle of June; but the laft fowing or two, fhould be of charlton or framing, 
378 THE KITEHEN GARDENER. [B.3. as thefe anfwer beft for both early and late crops.

Peas do well on almoft any kind of garden-ground, but they are moft prolific in ftrong foils. The land is feldom manured for them, as they generally follow fome crop that required manuring or fallowing.

The beft method is to fow in double drills ten inches apart, if they are to be fticked; as one row of fticks placed in the middle will generally ferve both the rows of peas. The diftance in this cafe is, from four to five feet between the centre of the double lines, according to the fize of the kinds. For fingle rows, a foot lefs refpectively.

Keep clean of weeds, and earth up, firft, when the plants are about two inches high; fecondly, when about eight or ten; and laftly, when they begin to flower.

Late crops of peas are generally much afflicted with the mildew, which retards their growth, and prevents them from filling. Perhaps the beft remedy is, to fow thefe crops in rich, light, dry loam, and an open, expofed fituation. 


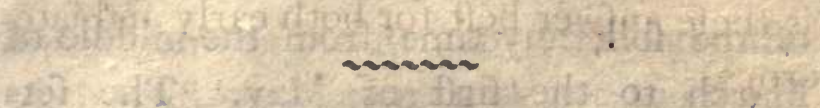 \\ SECTION XX. \\ POTATOES}

RE an abundant crop on moft kinds A of garden land, but they are cleaneft on light loams. In gardening, the ground is fometimes manured for this crop, and fometimes not; if fo, a moderate dunging with any of the kinds beft adapted to the nature of the foil, will generally anfwer.

The object, in gardening, is generally a few early ones, except fometimes for the fake of changing crops. For this purpofe, plant of any of the early kinds on a warm border, or other theltered fpot, in rows eighteen or twenty inches afunder, and fix in row, about the firft of March. Sooner is attended with bad confequences: the feed will feldom begin to vegetate before that time, if planted ever fo foon, and if hard froft or much wet enfue, it will be much injured.

For a principal crop, plant on a free and open expofure, in rows from twenty to thirty inches afunder, and from fix to twelve in row, according to the kinds and quality 
of the foil, any time from the middle of March to the firft of May. The fets fhould generally be buried three inches deep; and they may be put in either with a blunt-ended dibble; or they may be laid in drills; following the former method in light, and the latter in ftiff, foils.

Keep clean of weeds; and when the plants have arrived at the height of three inches, let a little earth be drawn to their ftems, and when to nine or ten, let them be moulded up for good. Any weeds that appear afterwards, are to be pulled with the hand. The hoe muft not be ufed after their roots begin to run.

Much has been faid refpecting cutting of Potatoes for feed; fome recommending planting them whole, and others cutting them into fingle-eyed fets; fome cutting them two or three weeks before planting, and others planting as they are cut. My method is this: Cut the large ones into four or five; the middle-fized into two or three; and the fmall, plant whole. Plant within forty-eight hours of cutting, and not fooner than twenty-four: whereby the fets are of a moderate fize and ftrength, 
CH. 4.] THE KITCHEN GARDENER. $38 \mathrm{I}$ nor is there any wafte; are fufficiently dried to refift corruption, and not. too much to prevent inftant vegetation *.

The method of planting the fhoots is juftly exploded. I have, for one, given it fair and frequent trials, and I am convinced it is of little utility.

The curl is a difeafe, which has given the cultivators of this plant much trouble, nor has there, as yet, perhaps, been any effectual remedy difcovered $\uparrow$.

It has been fuppofed to be occafioned, either, $I f$, by an infect being lodged in the

eye

* By comparifon, and obfervations made laft feafon in different parts of the country, I am convinced of the utility of ufing fcoops for taking out the eyes or fets, in times of fcarcity; as the remaining part of the root may be ufed for cattle or pigs. The fcoop, however, flould be of the deepeft fort, that is, rather more than a hemifphere, whofe diameter is an inch; for if that lower, the fet will be too weak.

+ I have juft learned, that a refpectable gentleman in the neighbourhood of Edinburgh, is convinced, by actual experiments made by himfelf, that the caufe of the curl, lies' in the feed being over ripened; and he advifes, as a remedy for this difeafe, that potatoes, intended for feed, hould not be planted before the I 5 th of May; and they thould be taken up in a much greener ftate than thofe intended for culinary purpofes. 
382 THE KITCHEN GARDENER. [B. 3 .

eye of the fet, fince frequently we find clean and infected ftems ifluing from the fame root, and which continue diftinctly fo throughout. $2 d l y$, By being planted in too heavy or wet land. $3 d l y$, By being planted in too poor and hungry land. $4 t h, B y$ the fame land having been too frequently and too recently cropped with potatoes. And laftly, as is the moft general opinion, for want of changing the feed.

At any rate, it is a malady, which every one ought to endeavour to remedy. What follows are given as hints with that intent, and which, it is hoped, the candid will apply, or improve, as they may feem to merit.

In refpect of the firft opinion, whether it be really an infect, or whether it be not rather in confequence of the fet being, by fome unknown caufe, difeafed, merits inveftigation. That it is an infect, I cannot bring myfelf to think. But that it may proceed from difeafe in the fet or root, feems to carry reafon along with it. What might occafion this difeafe, may either proceed from the feed being injured by froft, by damp, mould, or being over dried. And it is well underftood, that, from no 
CH. 4.] THE KITCHEN GARDENER. $3^{8} 3$

difeafed feed, fhoots or fpawn, need we ever expect to raife plants as healthy, or that fhall ever become fo, as from clean, frefh, and well-matured feed, \&z.

In refpect of the fecond and third opinions, as in fact they embrace the fame thing, fince they imply, that neither of the fituations are congenial to the nature and inclination of the plant in queftion, I have juft to fay, that if a plant thall be ftinted in growth, from any caufe whatever, difeafe will inevitably follow. On annuals of a quick growth, fuch as the plant in queftion, this is fooner perceptible than on others.

In refpect of the fourth opinion, which cerrtainly carries with it a frong prefumption of the cafe, if we admit there is propriety in changing crops, and that all culinary plants, which are not natives, degenerate lefs or more, if continued in the fame foil fucceflively, we may reafonably fuppofe it probably proceeds hence. And yet it hath been proved, in fome inftances, that this is not the cafe, by potatoes being continued for many fuccellive feafons on the fame fpot; without any appearance of the curl, although they degenerate in fize and thape. 
$3^{84}$ THE KITCHEN GARDEINER. [B. 3 .

In refpect of the laft and moft prevalent opinion, viz. for want of changing the feed, by which is to be underftood, from one farm, \&c. to another, or from one country or diftrict to another, much might be faid on both fides of the queftion. But I muft beg to fay, that it by no means carries conviction to me, that this is the caufe, or indeed, that it can poflibly operate in the fmalleft degree towards it. On the contrary, the curl has frequently been brought to places where it was never known before, by this miftaken notion.

But, may not the feed be as effectually changed on the fame farm, or garden, if of any confiderable extent, as by being carried from one parifh or country to another? Are potatoes improvable, like wine, by being fea-borne, or land-borne, without being afterwards planted in foil, different from that in which the laft grew? Certainly no. And fhall he who has his feed brought from land, non-defcript, and which he never faw, be certain of planting again in that which is effentially different in quality? May it not as probably happen, that, per chance, he fhall plant in land exactly 
CII. 4.] THE KITCHEN GARDENER. 385

exactly fimilar to that in which his feed was produced?

I therefore hold, that he who thall be at all due pains in faving wholefome feed, by divefting the crop intended for this parpole, of all infected plants, fo foon as they appear; fecures it from frof, damp, or much drought, till planted; plants no weak, or infignificant fets; plants an freth, well-broke, moderately-enriched land, of a midling texture, rather light than otherwife; allows a fufficiency of room; and keeps clear of weeds; bids fair for overcoming the anxiety attendant on this malady $*$

\section{SECTION XXI.}

SALSAFY, SCORZONERA, AND SKIRRET.

7 HESE are all cultivated alike, and

1 much in manner of Carrot and Parfnip. A free, light, deep foil, and an expo$\mathrm{B}$ b

fed

* But the reader may fee more on this fubject, in a paper written by myfelf, intituled, "An Inquiry into "the caufe of Difeafes in Plants; with hints for their "Cure or Prevention;" lately publifhed in Edinburgh. 
386 THE RITCHEN GARDENER. [B. 3 . fed fituation, are moft eligible. The feafon for fowing is all the month of April; fowing in drills an inch deep, and twelve or fourteen apart; thinning out to five or fix afunder, in line; and keeping clean of weeds.

Thefe roots may alfo be preferved in Winter, as already hinted.

\section{SECTION XXII.}

\section{SHALLOTS}

AE a precarious crop, being equalIl ly fubject to injury by too much drought or wet. A rich dry loam and free expofure are moft eligible. A fixed feafon of planting can hardly be determined, and it is moft advifable to perform this operation at different times, viz. November, January, and February.

Plant either in four feet beds at eight inches fquare, or in rows a foot apart, and four inches in the row.

Keep clean of weeds, and whenever any of the plants begin to canker and become maggoty, 
CH. 4.] THE KITCHEN GARDENER. 387 maggoty, pull them up; as otherwife the whole will be quickly affected. Neither fhould the crop remain in the ground after the leaves begin to decay, but fhould be taken up, gradually dried in an open thed, \&c. and afterwards ftored in manner of anions.

\section{SEGTION XXIII.}

\section{SPINAGE.}

$H^{\text {OR the Summer crops, all foils will }}$ 1 anfwer; but for the Winter, light rich loam, and a dry fituation are fitteft. Manure is feldom applied, except for the fake of what is to follow; yet, by a moderate dunging, the Winter crops are much benefited, and will grow more luxuriantly in Spring.

For the Spring and Summer crops, fow of the round-feeded kind, thinly, in drills a foot apart, from the firft of February to the firft of Auguft, at intervals of ten days each; and for the Winter, of the prickly kind, any time from the middle of July to $\mathrm{B} \mathrm{b} 2_{2}$ the 
388 THE KITCHEN GARDENER. [B. 3 . the middle of Auguft, alfo in drills as above. Some prefer fowing broadcaft; but I believe it is a matter of little importance, provided the plants are kept equal. ly clean, which mode be practifed. By fowing in drills, however, the crop is gathered with lefs difficulty, and is much eafier kept clean. Being of a quick growth, weeding or hoeing is feldom neceffary for the Summer crops. For the Winter, once or twice will generally be fufficient.

Spinage may fuccefsfully be tranfplanted; by which method alfo, a fucceflion may be had of the fame fowing.

\section{SECTION XXIV.}

\section{SEA CALE.}

7 HIS vegetable is moft fuccefsfully 1 produced in light rich fand, of fif-teen or eighteen inches in depth. It will do pretty well, however, on all lightifh loams, that are well mixed with fharp or drift fand. In ftiff foils, it makes little progrefs, 
CH. 4.] THE KITCHEN GARDENER. 389 progrefs, and is alfo apt to perifh in Winter.

The manmer of culture is fimple; and the plants may either be raifed from feed, or by offsets from the root, which come up in abundance in Spring, and are the eatable part of this vegetable. The moft eligible method is to fow or plant (in March or April) in rows, a yard afunder; and the plants are to ftand, for good, at the diftance of ten or twelve inches in the row. As the fprouts rife in the Spring, let a little earth be drawn to their ftems, in order the fafter to blanch them, and render them fit for ufe.

Keep clean of weeds at all times, and in Autumn or Spring let a little compoft manure, or well-rotten dung, be flightly pointed in, fo as not to injure the roots; at the fame time fhedding a little mould on the rows; following much the afparagus mode of culture.

$\mathrm{B} \mathrm{b}_{3}$

SEC- 


\section{SECTION XXV.}

\section{TUR N IPS.}

$7 \mathrm{HE}$ lightert foil in the garden is 1 generally beft adapted to their culture, and it fhould alfo be well enriched. If it is to be manured for the turnip crop, compoft is preferable to fimples. In either cafe, all the kinds of afhes, foot, and pigeon-dung, are to be avoided. Strong loams, however, if not wet, are abundantly productive of this vegetable, provided they be well broke in the operation of digging, trenching, fallowing, \&c.

The firft of March is foon enough to fow, as we feldom fee plants fown fooner come to any good; they generally run to feed and canker. A few may be fown on an early border, but thefe are not much to be depended on; an open fituation being the beft at all times of the feafon.

For producing a conftant fucceffion, make it a rule to fow fo foon as the laft appears above ground; and repeat this till the firft of Auguft. The early white 
CH. 4.] THE KITCHEN GARDENER. $39 I$

Dutch is generally fown for the Summer crops, and the yellow * for Winter, for table and market ufe. They are generally fown broad-caft, and thinned out to from nine to fifteen inches apart, according to the quality of the foil. In gardening, however, Turnips are alfo frequently fown in drills, from twelve to twenty-four inches apart, and fingled out to fix or eight in line.

In all cafes, the plants fhould be carefully kept clean from weeds; and in dry weather, the early crops thould be frequently refrefhed with water.

The fly is often very troublefome, but as they only prey for a few days on the infant plants, the moft effectual way to fecure a crop is to fow thick, thereby fatiating them. Neverthelefs, they frequently deftroy them in patches, and fome $\mathrm{B}$ b 4

in

* It is fingular, that Yellow Turnip fhould be fo little ufed in England. In London, I believe, it is hardly known. Yet it is certainly much fuperior to the white, both in point of flavour and nutriment; nor is it injurable by froft in the fame degree. For cattle feeding, three loads of yellow are equal to four of white; and they are generally a more certain crop, and alfo more productive. 
392 THE KITCHEN GARDENER. [B. 3 . in that cafe, fotw again on the fame fpot; but this is feldom attended with fuccefs, as they are either deftroyed again by the fly, or do not keep pace with the other part of the crop, fo as to make this an object worth the trouble.

Before concluding this chapter, I would obferve, that all feeds and plants fhould be committed to the ground as it is turned over, or as foon after as conveniency will permit. It is then in the moft active ftate, and vegetation inftantly commences. Neither fhould ground ever be digged in a very wet ftate, except, perhaps, fometimes in fallowing. 
CH. 5.] THE KITCHEN GARDENER. 393

\section{CHAPTER V.}

CULTURE OF SAILADS AND HERBS.

SECTION I.

\section{SALLADS.}

Chervil, Grefs and Muftard.

THESE articles are all raifed much

L in the fame manner; and where there is the conveniency of a few handglaffes, a hot-bed frame, or hot-houfe of any defcription, with the addition of a few boxes, tubs, or large pots, may be had every day in the year, in abundance, by the trouble of fowing once a-week, or ten days, as occafion thall require. To fay more of them, would be trifling with time.

Endive. 


\section{Endive.}

Although I have ranked this vegetable as a fallad, it is alfo frequently ufed in the kitchen; and by many is much in demand.

It fucceeds beft on a light, dry, loam. On wet land, it feldom fails to rot in autumn. Neither fhould the ground be manured for this crop at the time of planting.

For the firft crop, fow of any of the kinds, preferring the green curled however, in a light open fpot, about the firft of June, and plant about the firft or middle of July, in rows from fifteen to eighteen inches apart, and nine in the row, on an open expofure. For a full crop, fow alfo of any of the kinds as above, about the middle of July, and alfo plant as above, about the middle or latter end of Auguft.

A late crop may be fown about the middle of Auguft, and planted out in September, on a light, dry border, in a fouth arpect.

Some plant Endive in drills or trenches, and others on the furface. In dry foils, the 
CH. 5.] THE KITCHEN GARDENER. 395

the former method is advifable; but in wet ones, the latter mode fhould be practifed.

Keep the plants clean of weeds; and let them be earthed up at two or three different times, in order to blanch the leaves. This is alfo effected by tying them up, but in wet feafons they are apt to rot. Endive may be fuccefsfully preferved in Winter, by being laid in dry fand, in the cellar, fhed, or under a frame and lights, \&c. In this latter intention, however, the beft method is to form the plantations of Endive into beds anfwerable to the fize of the frames; placing thefe on late in Autumn, on the approach of bad weather; and admitting air freely at other times.

\section{Indian Gress}

Is often ufed in fallads, and makes a beautiful garnifh. The flowers are the ufeful part for this purpofe, and the feeds make a fine pickle. Any foil will anfwer; and the moft eligible fituation is againft a dead fence, or unfightly wall, which it will rapidly cover and beautify.

The 
The feafon for fowing, is any time from the middle of February to the firft of June, in drills an inch deep, and in manner of peas, \&c.

\section{Lettuce}

Is fuccefsfully cultivated on all foils, in all fituations, and almoft at all feafons. The times of fowing are from January to October, at intervals of from one to four weeks, according to the feafon and demand; and of planting, from the firft of February, to the firft of November, at intervals alfo as above.

The kinds are numerous; and thofe moft to be preferred, are the true green cofs, hardy green, and brown Dutch, for ftanding the Winter. Thefe are to be planted in October, or keginning of November, at the bottom of a wall or other fence having a fouth afpect and dry bottom; or under a frame and lights, hand-glaffes, border in the peach or vine houfe, \&c. \&c. in which cafe they are to be duly refrehed with water, have air freely admitted to them in frefh weather, and to be defended from fevere frofts, or blanching rains. 
CH. 5.] THE KITCHEN GARDENER.

Lettuce is frequently forced on hot-beds in the Spring. In this practice it is neceffary to beware of too much heat; to refrefh duly with water; and to admit large portions of air in frefh weather; for this plant will bear but little artificial warmth with patience.

\section{Parfley}

Is both ufed as a fallad and in the kitchen, and is in conftant demand. Some force it in hot-beds, \&c. but a Winter ftore is better fecured by covering with a frame and lights, or hand-glaffes, part of the preceding Summer's crop; which, for this purpofe, fhould be fown about the firft of June. Other crops are to be fown in beds, or rows round the quatters, walks, \&c. of the garden, from the firt of February to this time, as circumftances thall direct, and of the kinds moft in demand.

The Hamburgh Parfley is an excellent diuretic, and is ufed in foups, in the manner of carrot, \&\&c. It hould be fown in March, in drills an inch deep and a foot apart; and when fit, Mould be thinned out 
to three or four in line. A few drills may be fown in July, for Winter and Spring ufe, where a fucceffion is required.

\section{Purfane}

May alfo be raifed in all refpects, in manmer of chervil, crefs, \&c. Being of a fucculent nature, it likes a dry fand the beft. It does not ftand froft well, and therefore fhould not be fown out of doors, fooner than the firft of April.

\section{Radis}

Is plentifully produced on all foils, and is fown from January to September, with fuccefs, at intervals of from one to three weeks. The fhort-top and falmond are moft proper for early Spring; the white and red turnip for Summer; and the black Spanifh for Winter ufe; but thefe three laft named will ftand the Winter in general, and for this purpofe thould be fown on light foil, about the firft of September.

Being theltered with a frame and lights, or hand-glaffes, would be of advantage for 
CH. 5.] THE KITCHEN GARDENER. 399 the white and red turnip kinds; in which cafe, air muft be freely admitted in frefh weather, and water moderately applied.

In the latter end of Spring, the fhort-top, and falmond kinds frequently get fticky, and run for feed fooner than fucceffional crops can be got forward, in fultry weather. To remedy this inconveniency in a great meafure, it may be gratifying to the admirers of this fallad to know, that by clofely pinching off the tops, drawing them upwards half an inch, fo that the tapfibres be juft broke, and letting them remain till wanted, they will keep frefh and good above a week afterwards, until the fucceffional crops come forward.

In forcing of this fallad on dung-heat, what is faid above refpecting lettuce, will apply.

\section{SECTION II.}

POT HERBS.

\section{Bafil.}

7 HIS is a tender exotic, and requires

1 artificial heat to forward it in Spring. About the firft of March, fow, either on a gentle 
400 THE KITCHEN GARDENER. [B. 3 , gentle dung-heat, in a vine or peach houfe, or as hinted in page 19, in rich, light mould; and tranfplant, when fit, on a well-expofed, rich, light fpot of ground, in rows a foot afunder, and three inches in the row.

Of this plant there are two forts, the tall and the bufs; and they are both ufed in the fame intention. For foups, \&c. they are much in demand, on account of their high flavour.

Such part as is to be kept for winter ufe, fhould be cut over, fo foon as full in flower, and gradually dried in an open thed, \&c.

\section{Borage.}

This is both ufed as a potherb, and for cool tankards. It thould be fown in a light, dry fpot, in March, April, May, and June. Wherever it has been fown laft year, will, if let ftand till of maturity, be hown this; nor is it eafy to clear the foil of it, as its feeds lie long in the earth, keep frefh, and fo fpring again. 
CH. 5.] THE KITCHEN GARDENER. $40 I$

\section{Fennel}

May either be raifed from feed, or may be propagated by flips of the root. It will grow freely, in any foil that is not very ftiff.-A few plants of it will ferve a large family.

\section{Marigold}

Is to be fown in the fpring months, in two or three fucceflions, from the middle of February, to the firft of May. The flowers only are ufeful.

\section{Marjoram, Savory and Thyme.}

The fame culture anfwers all. Sow in beds of light earth, in a free fituation, about the middle of March, or firft of April. When the plants are a few inches high, thin them out to fix apart each way; or tranfplant into rows nine or ten inches afunder, and three in line. If the knotted marjoram, or fweet favory are wanted early, a little may be raifed in manner of the Bafil as above.

$$
\text { C c }
$$


Green Thyme, pot Marjoram, and Winter Savory, may be kept freth all winter, if required, by being theltered with hand-glaffes, a frame and lights, \&c. but when properly dried, they have the fame effect in foup, broth, \&c. and this is feldom practifed. Thefe laft are moft generally propagated by flips, planted in April, July, or Auguft, in light, rich earth, at fix inches apart.

\section{Mint,}

That is, fweet, or fpear mint, is propagated moft fpeedily by flips of the root. The feafon is March or April. It may either be planted in rows, nine or ten inches afunder, or on four foot beds. Rich, light loam will produce it in higheft perfection.

If it is wanted early, a little forced on a night dung-heat in manner of a.fparagus, either under a frame and lights, or handglaffes, will generally ferve till it comes in the natural ground.

\section{Sage.}

This plant is propagated, either by nips of the root, or by cuttings, with facility. 
¿H. 5.] THE KITCHEN GARDENER. 403

For the former method, March or September is the feafon. For the latter, any time from May to Augurt. Sage thrives, and alfo ftands the Winter beft in lightifh, fandy loam, and a free expofure. Its leaves for Winter ufe, are to be cut when full in flower, and gradually dried in a thed, \&c.

\section{Sorrel}

Will grow almoft any where, nor is it eafily eradicated from the foil afterwards. Slips planted in March, or indeed any time, will not fail to grow vigoroufly. The French and the common forts are both propagated alike.

\section{Tanjy and Tarragon.}

What has been faid above will apply here, except that Tarragon will fometimes, if in a wet fituation, perifh in Winter. 
404 THE KITCHEN GARDENER. [B. 3. CHAPTER VI.

ON THE ROTATION OF CROPS.

A $\mathrm{S}$ in agriculture, fo in gardening, a A proper rotation of crops is of great importance, and the reafonable and ufeful practice of cropping a part of their ground every feafon, with fome of the fpecies of grain or graffes, is becoming prevalent among market gardeners; which, befides being ufeful for their cattle, is found of infinite advantage to their ground.

This matter, however, can by no means be fo effectually accomplifhed in the garden, as in the farm, for thefe reafons : it is fmaller, and the articles to be fcultivated are more numerous, and alfo more a-kin to one another.

The different articles, however, might with propriety be claffed in this cafe, as, Brocoli, Cabbage, Cauliflower, and Savoys; Beans, French-beans, and Peas; Carrot, Beet, Parfnip, and Turnip; Leeks, Onions, Shallots, 
CH. 6.] THE KITCHEN GARDENER. 405 Shallots, \&c. Celery, Endive, and Lettuce, \&c. \&c.

Celery is an excellent preparative for afparagus, onions, or cauliflower; turnip, or potatoes, for cabbage or greens; brocoli or cabbage, for beans or peas; cauliflower, for onions, leeks, or turnip; afparagus land that has lain long, for carrot or potatoes; (currant, goofeberry, rafpberry, and ftrawberry land, may anfwer the fame purpofe); turmip, for celery or endive; peas, \&c. for clover, as a reftorative, with which barley or oats might be fown.

In this latter cafe, however, the two preceding crops fhould not be manured, as otherwife, at leaft in moft inftances, the barley, \&cc. would be apt to grow rank, to the detriment of the clover.

After the land has lain one or two feafons thus, it will again be fit for the reception of an efculent crop, of any kind, as carrot, afparagus, potatoes, \&c.

Clover, with barley or oats, may alfo - very properly be laid down as a reftorative for land of any kind, which has been long under efculent crops without a proper

$$
\text { C c } 3
$$

cbange, 
406 THE KITCHEN GARDENER. [B. 3 . change, and is confequently foul and cankering.

If it is fuffered to lie two feafons, the land will again be prepared for culinary vegetables of any kind.

As a change for land as above, and which cannot be fpared from efculent crops above one feafon, a crop of barley, oats, rye, or wheat, as a cleanfer, may be advantageoufly taken; which will, in a great meafure, refrefh, reftore, and again render it fit for the production of wholefome kitchen vegetables.

In all cafes, a ftudied rotation is to be advifed, and fuch an one as that no crop of the fame clafs may immediately follow another. For the more effectual accomplithment of which, the garden thould be regularly divided into quarters, numbered, and a journal kept, wherein is recorded what refpects the cropping, manuring, trenching or fallowing of each of them.-Thus :-

No. I. (1793.) Subtrenched after afparagus, for carrot, without manure. Wineer fallowed. (I794.) Early cauliflower, with a moderate dunging, 2d Mar. Yellow turnip, with a compoft drefling, 2oth July. 
CH. 6.] THE KITCHEN GARDENER. 407

(I795.) Onions, without manure, 8th Feb. Cabbage, with a light dunging, 5th Oct. (1796.) Charlton peas, for a late crop, without manure, Ioth June; trenched three fpit deep, in Dec. Winter fallowed. (I797.) Potatoes, with a moderate dunging, 2oth Mar. German greens, without manure, roth Sept. : intended for leeks next June.

This fketch is taken from my Journal formerly kept, and is here given as an example only; which every judicious gardener is requefted to alter or improve, as he may find convenient.

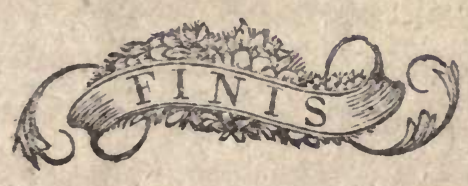

NeILL \& Co.
Printers. 

PI.ATE.I.

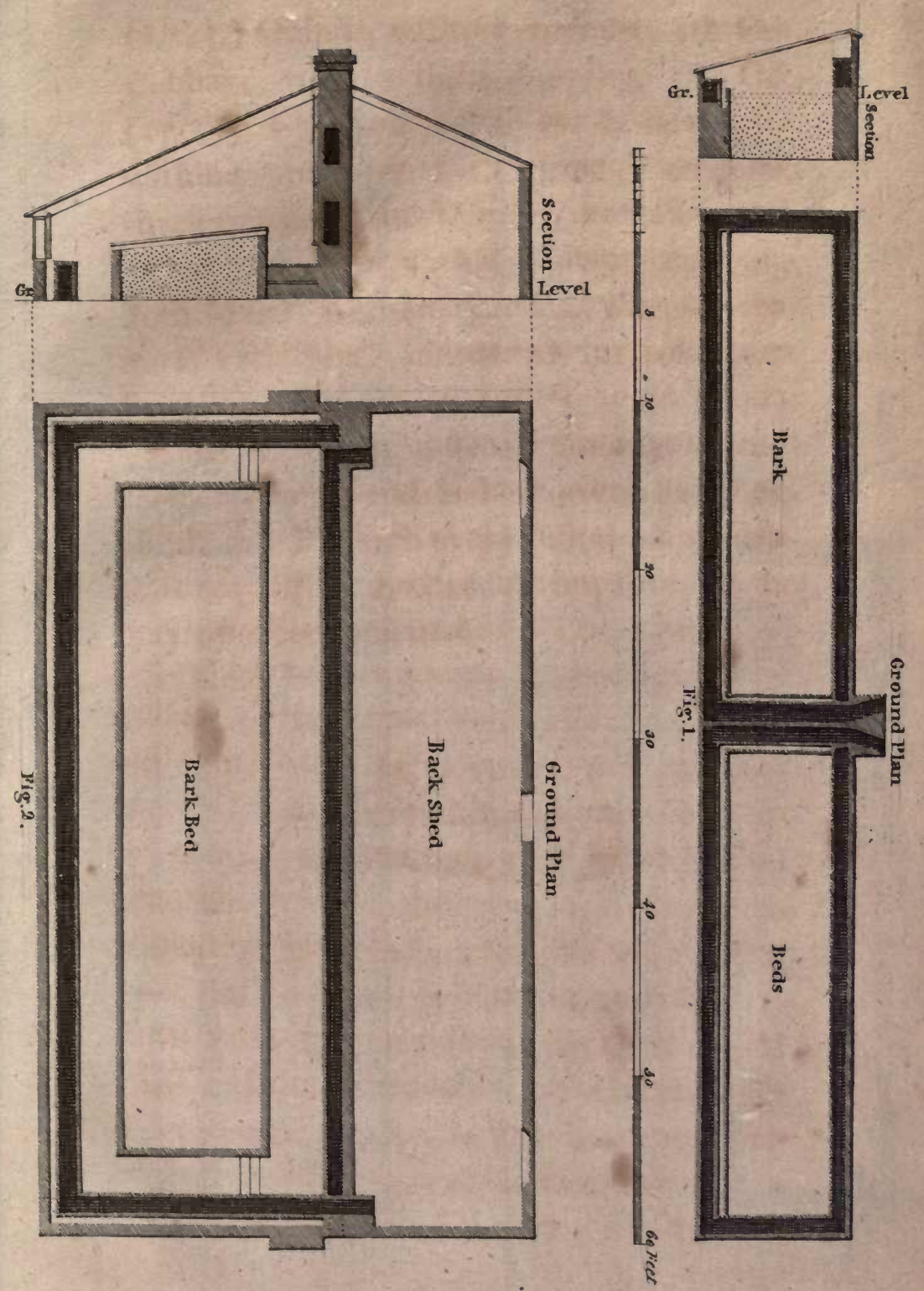



PI.ATE.II.
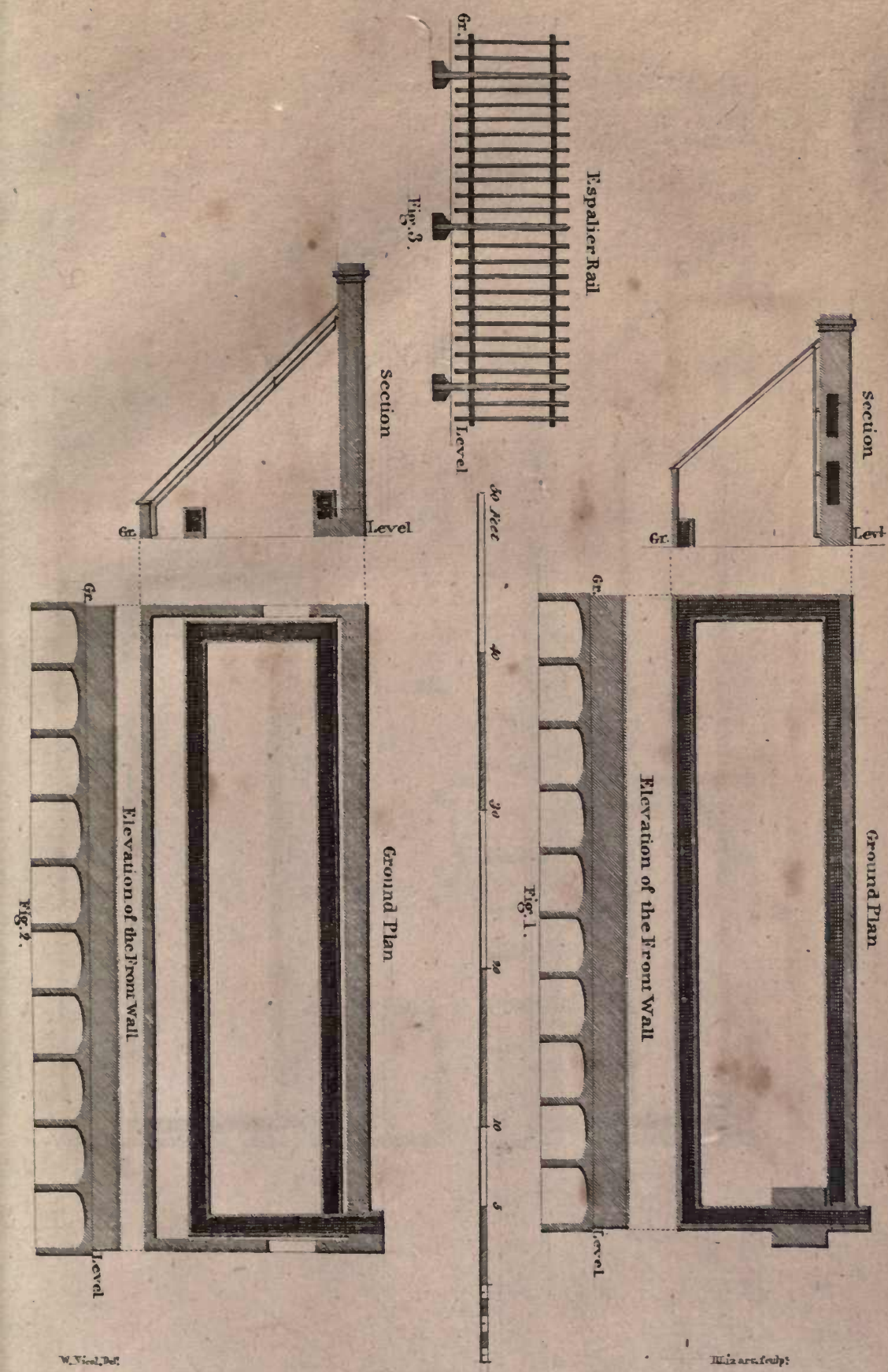


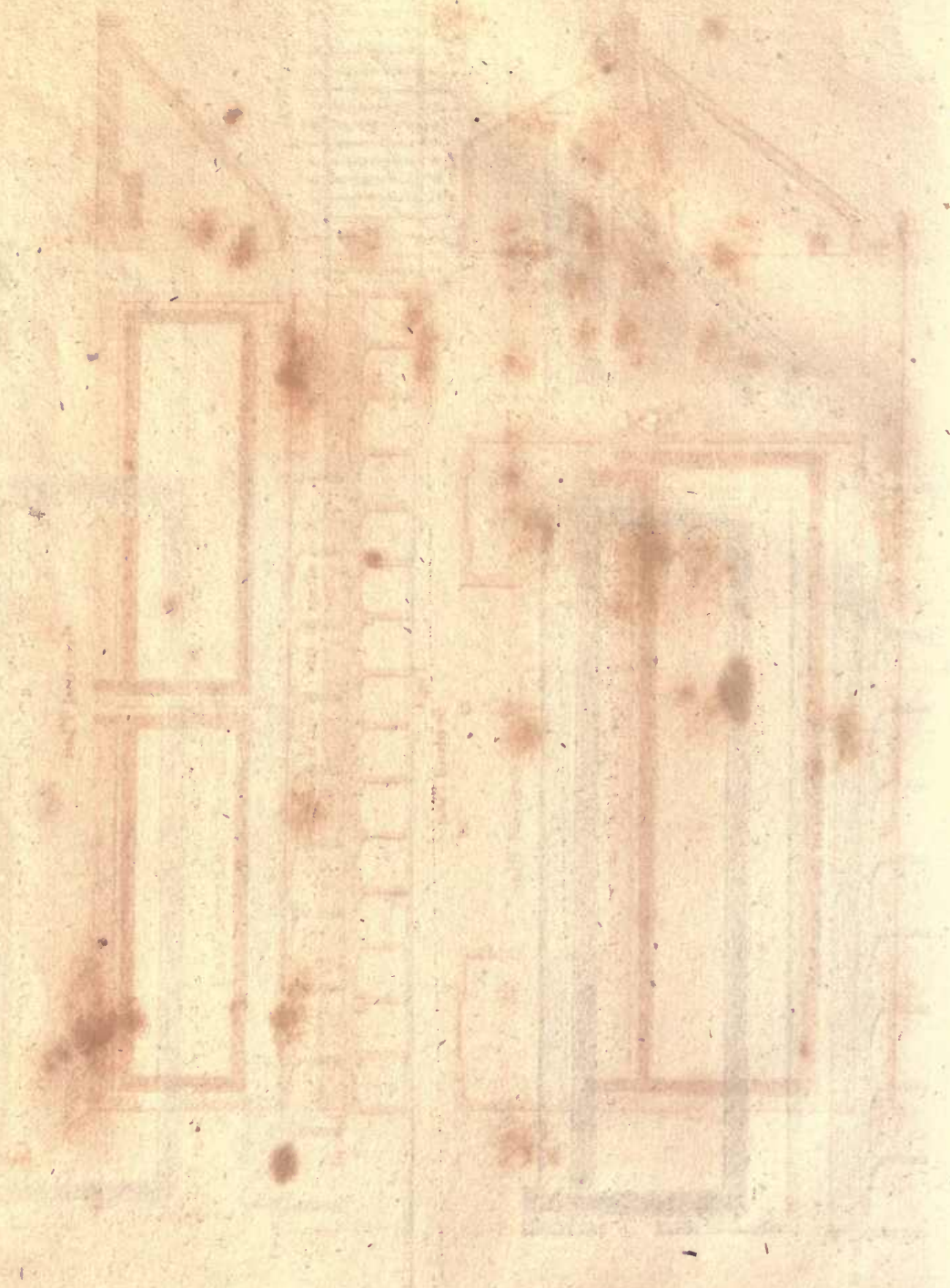




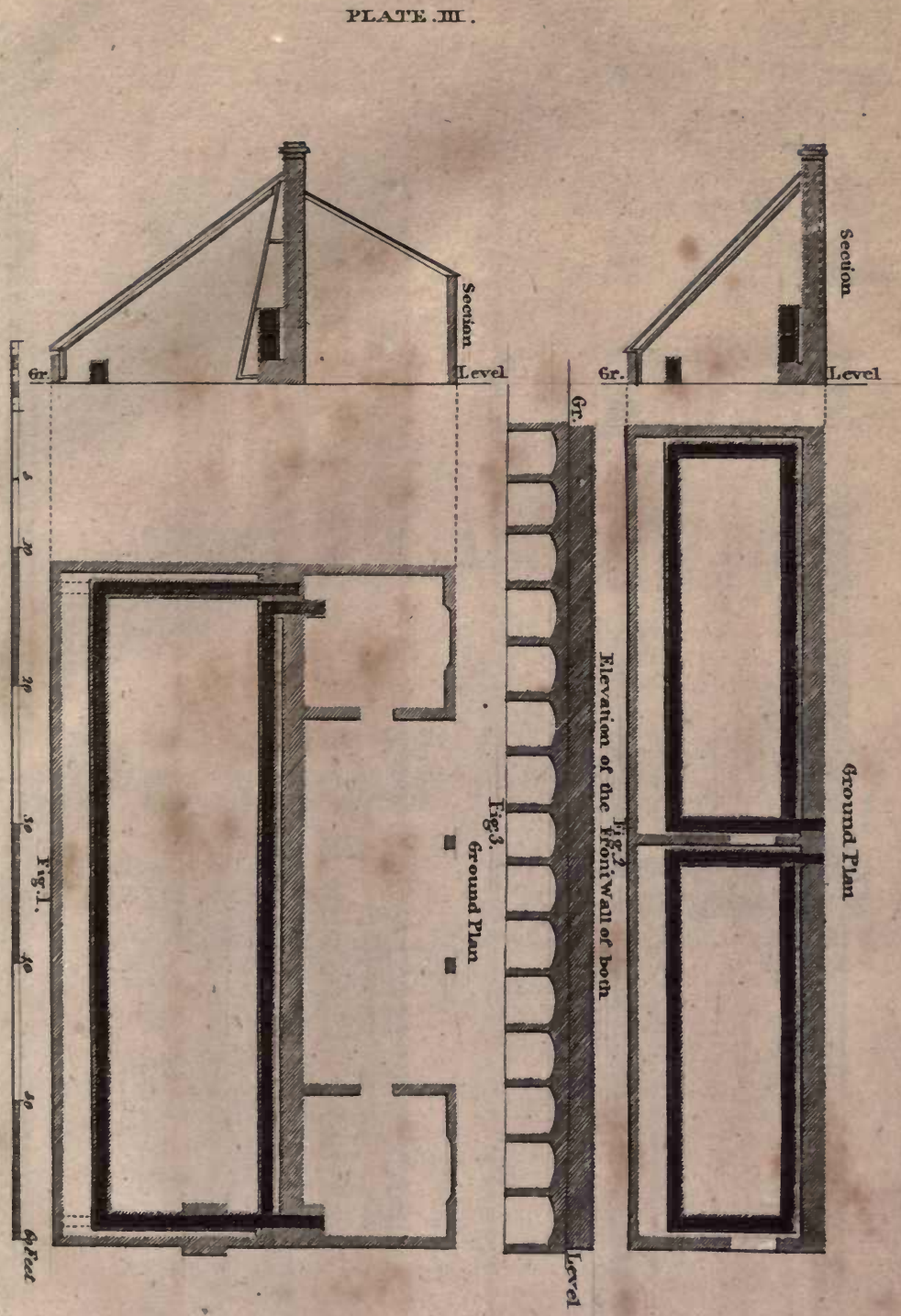

Tr. Theal. Den

N.Liear : feadp' 


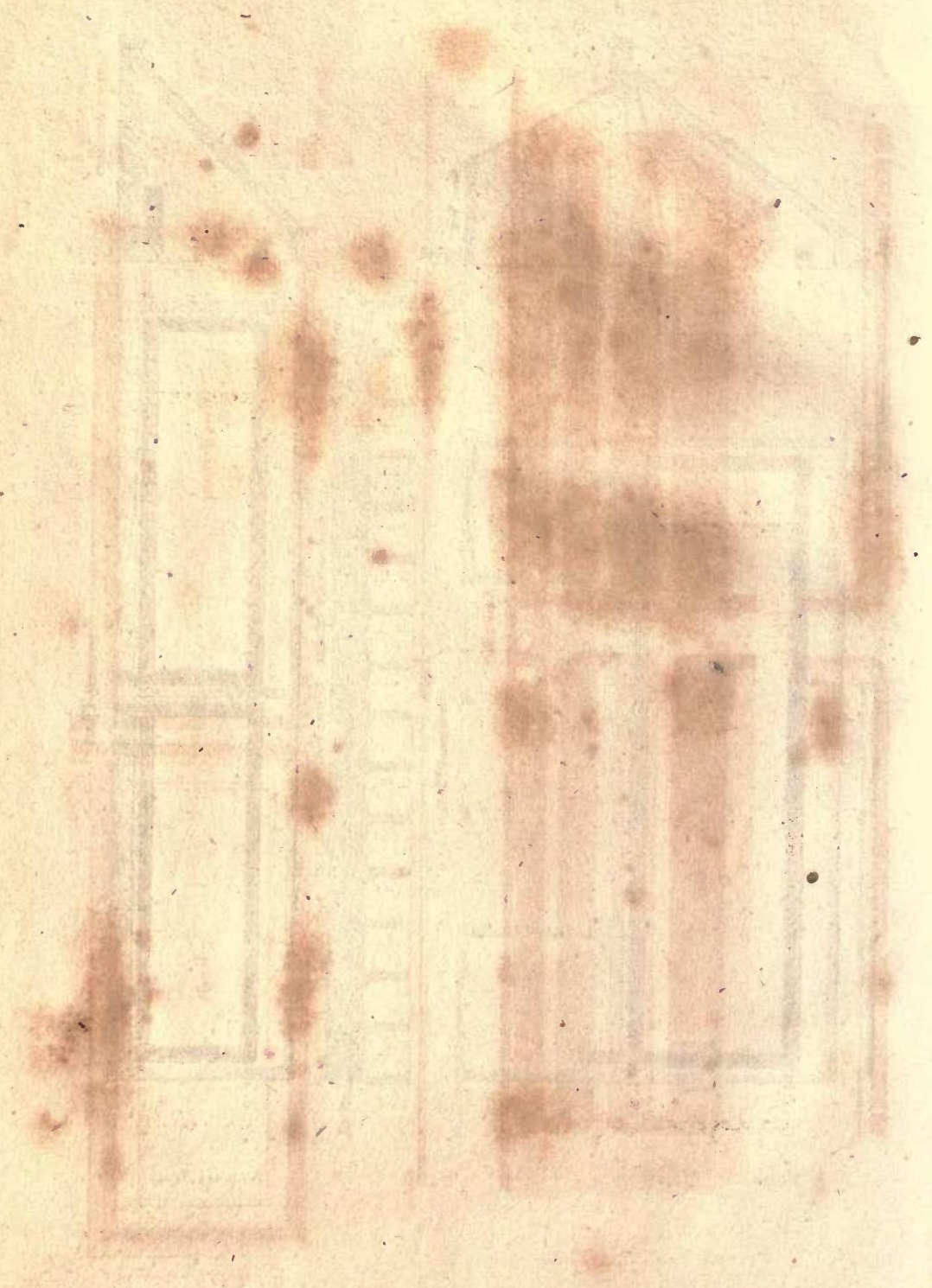


PI.ATV. IV.

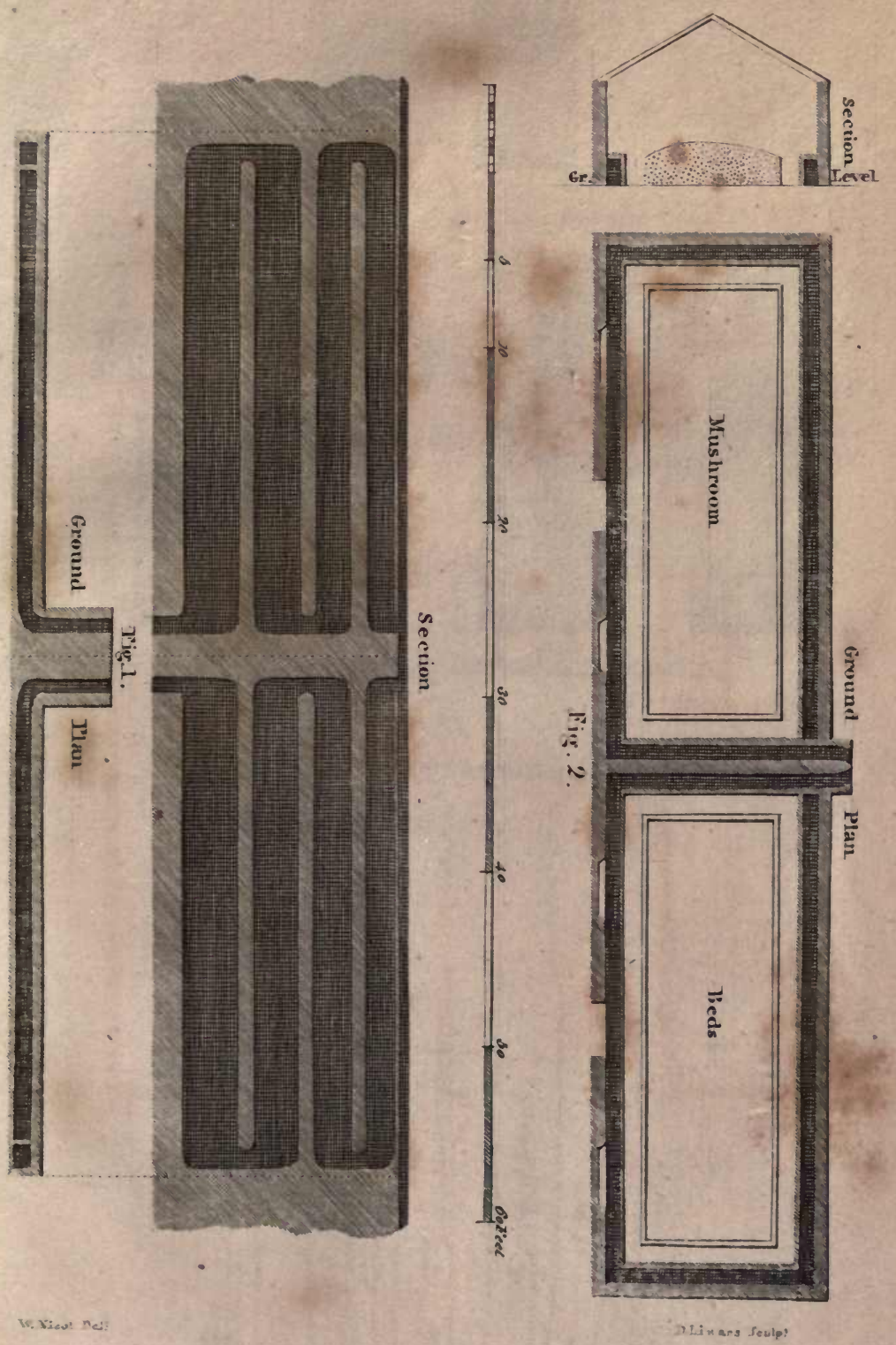




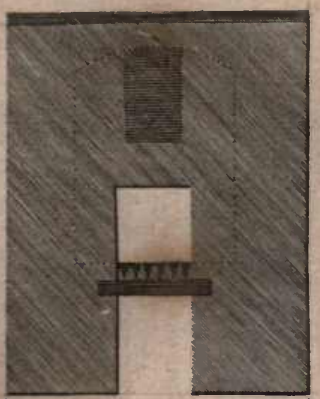

Horiz ontal Section

Fig: 1.

Ground Plan

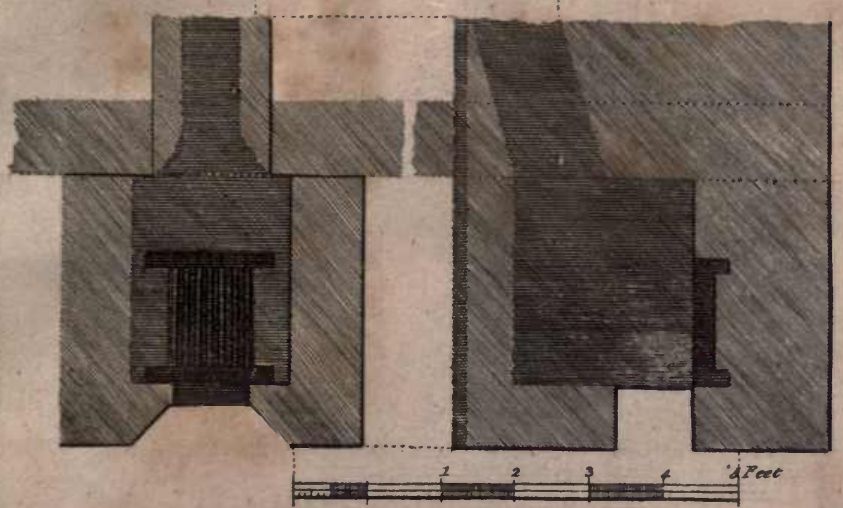

Winter Yruning

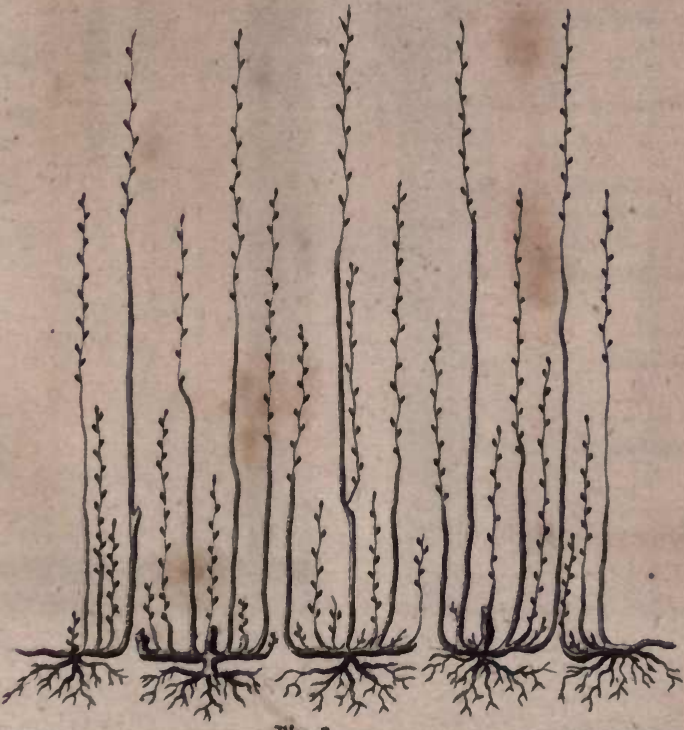


,

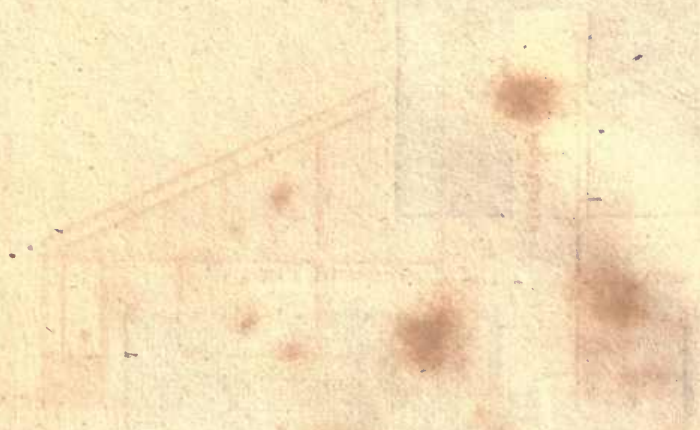

and

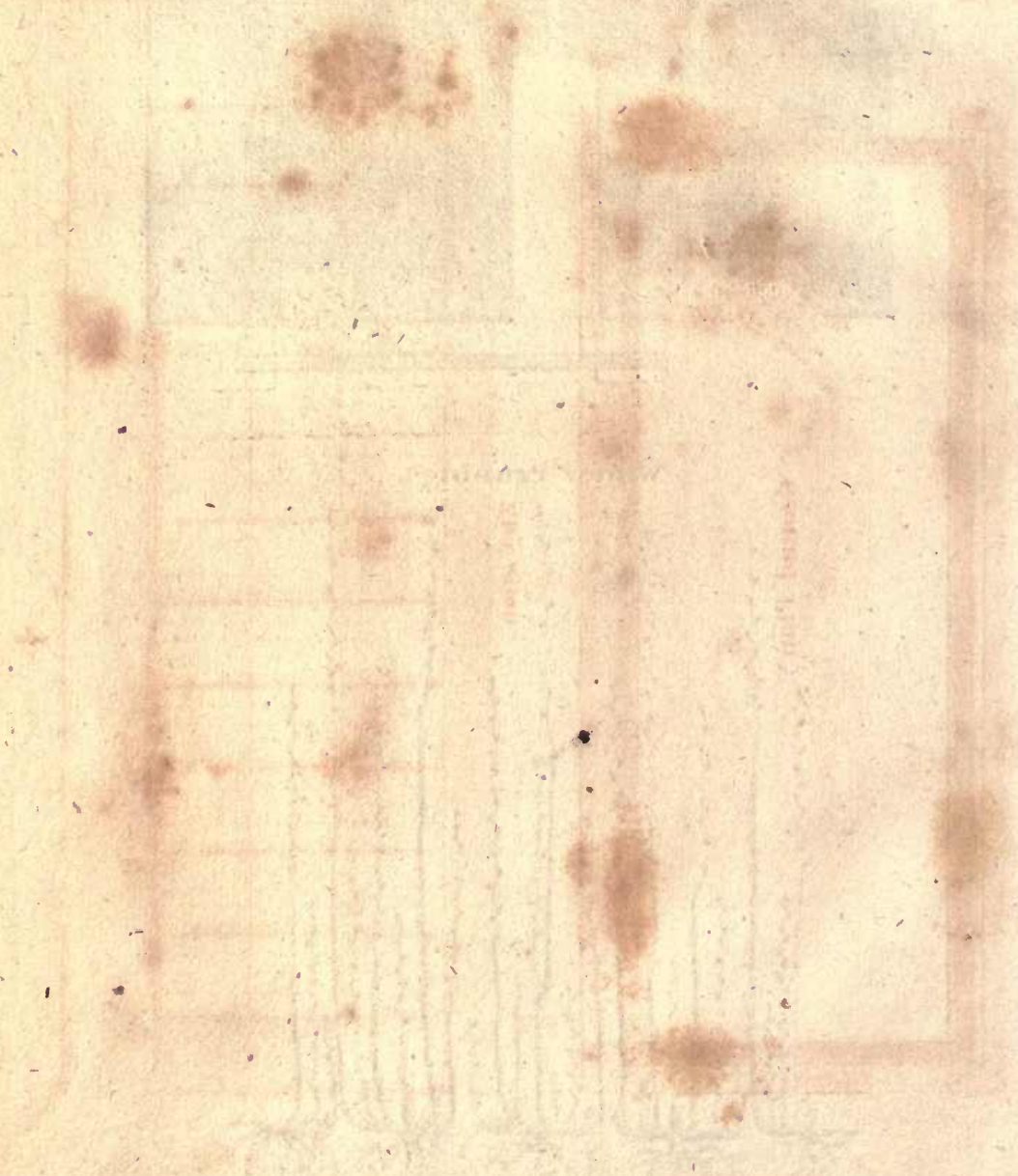


PI.ATE. VI.

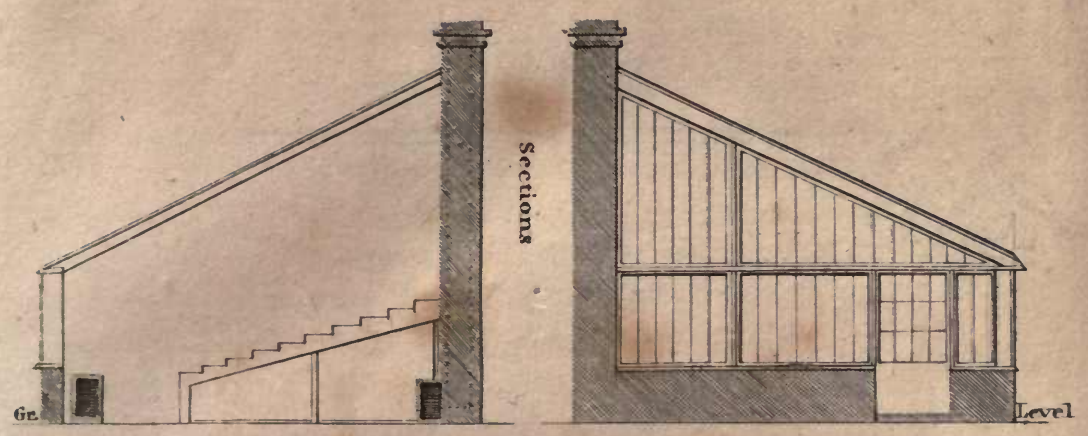

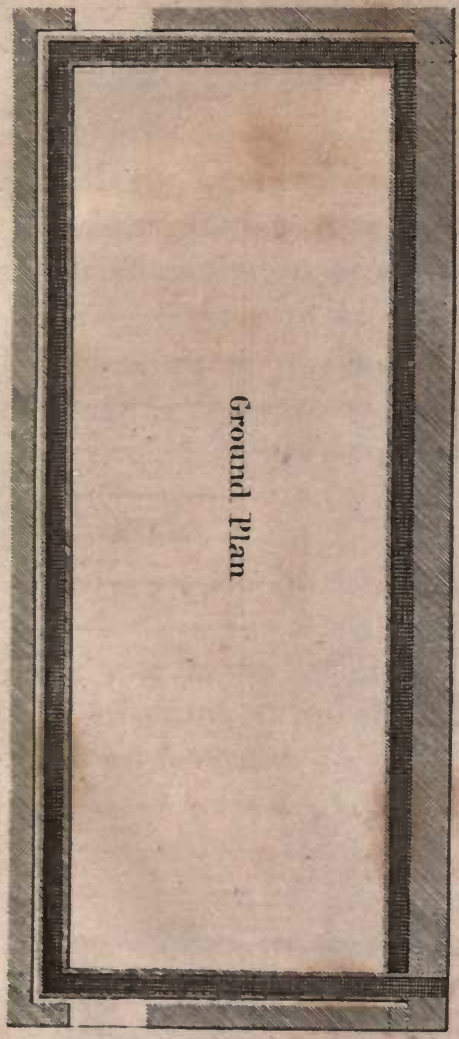

W.YYicoL.Delt

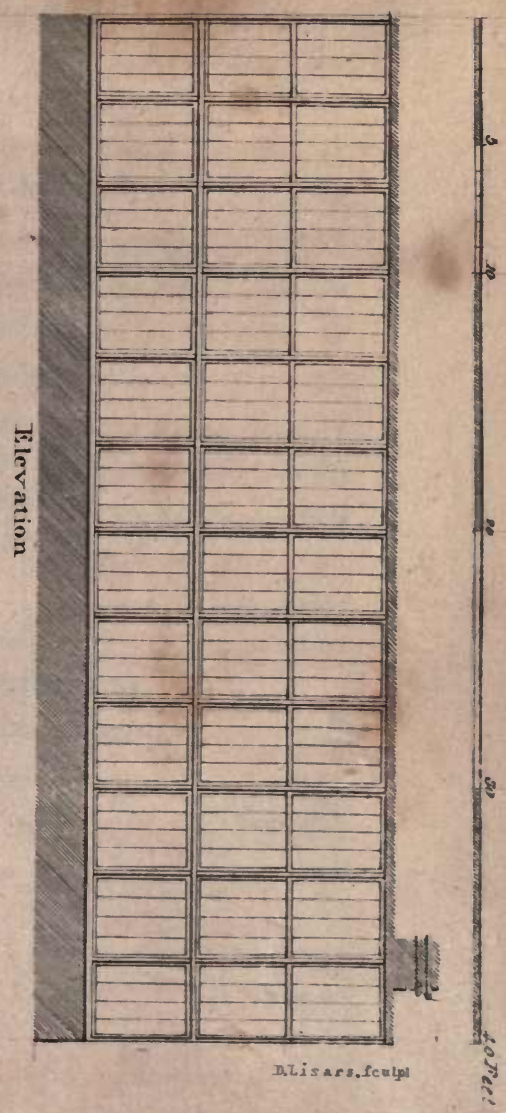



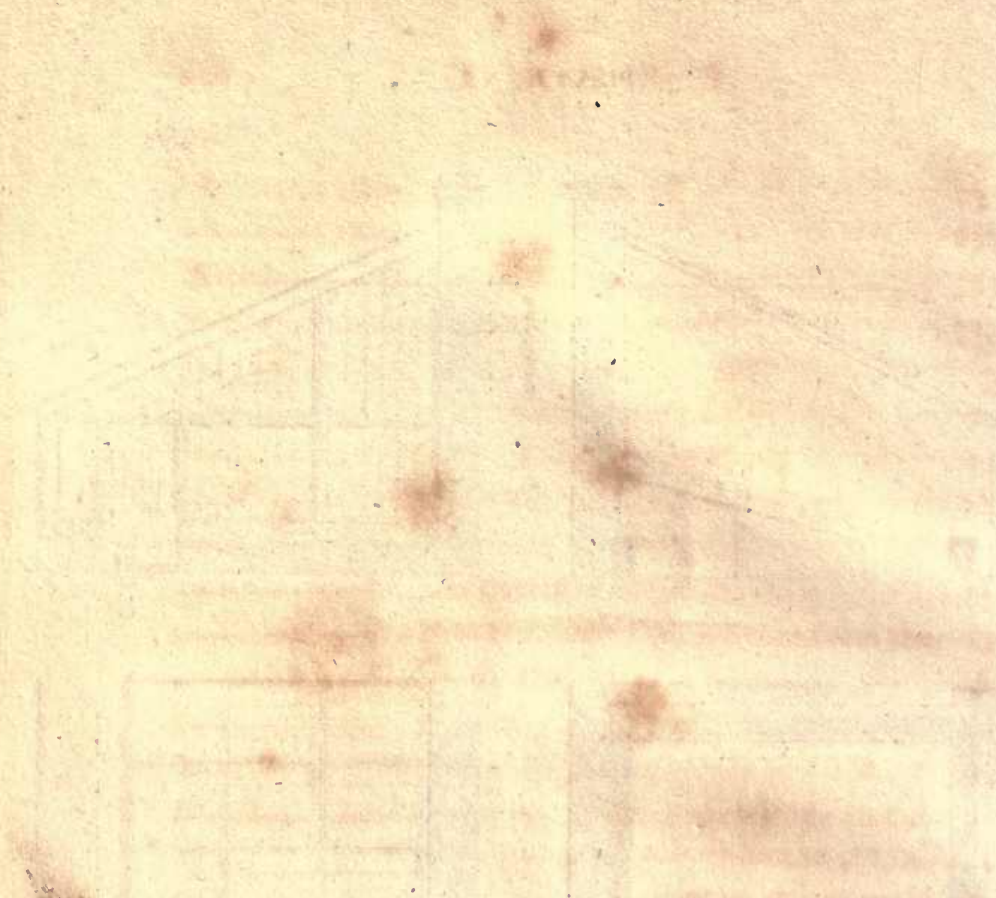

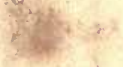

$\alpha$

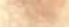

Q4.

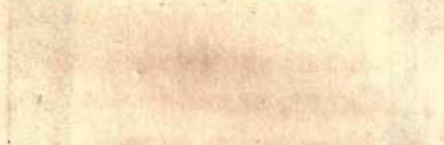

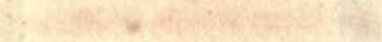

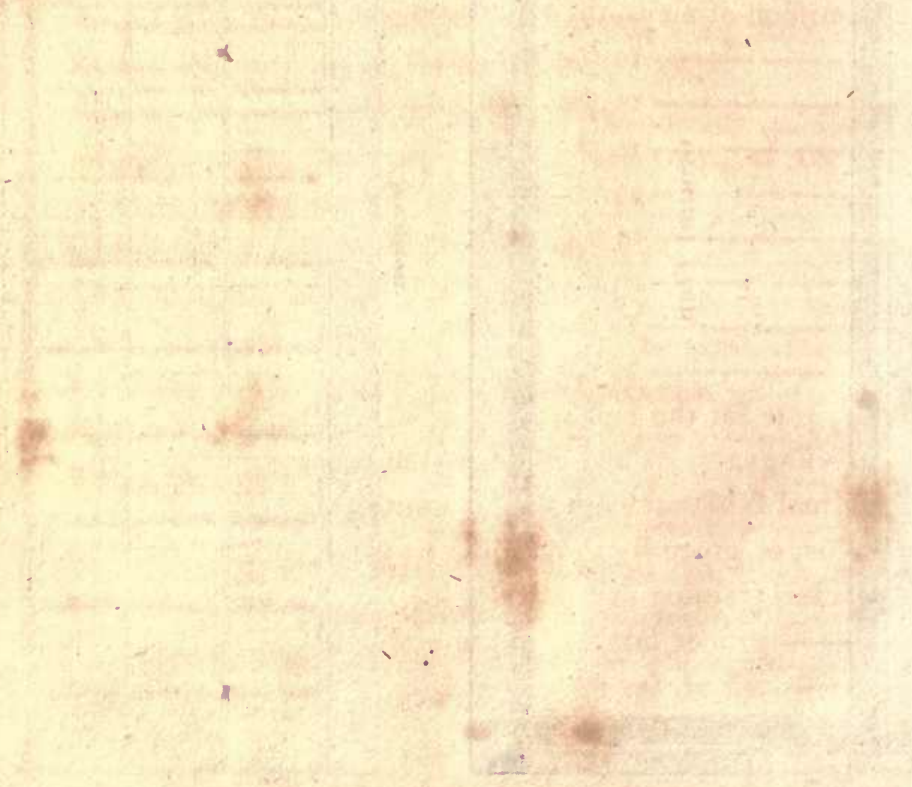




\section{N D E X.}

A.

Page.

A $\mathrm{C}_{\mathrm{ar}} \mathrm{s}$, or red-fpider, how to deftroy the, - $6 \mathrm{I}$ Accident worth relating,

Admiffion of air to the afparagus bed, to the cucumber bed, to the cherry-houfe, to the fig-houfe, to the grape-houfe, 42

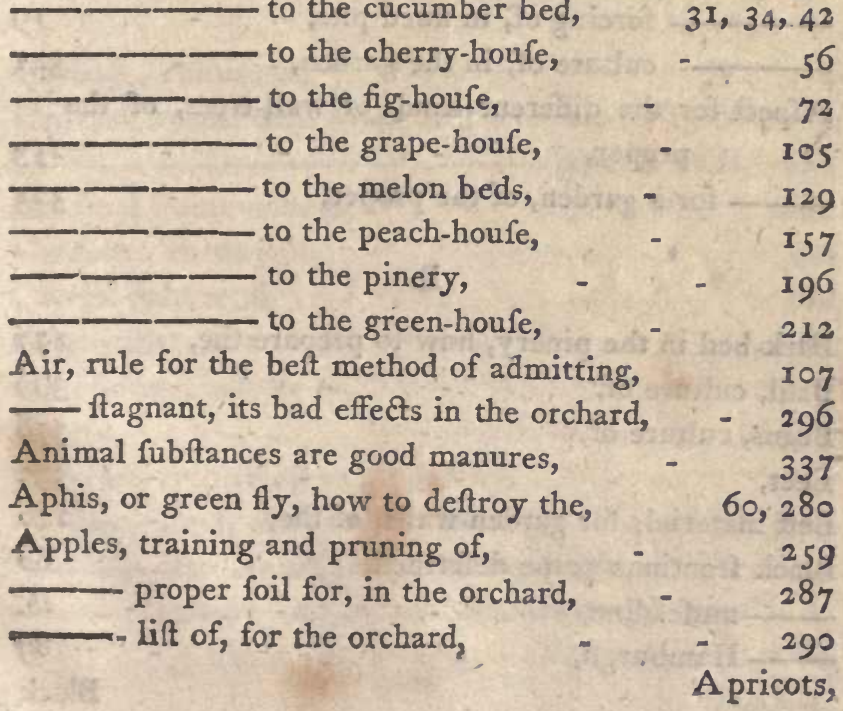


Apricots, training and pruning of,

\section{—— thinning of,}

Artichokes, culture of,

Afhes of whins, an excellent manure,

- how to draw off rank fteam from the, $\mathbf{I}_{5}$

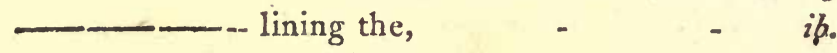

_- watering of the, _ _ _ r

- buds, when fit to cut, - - it.

- twifting off the, preferable to cutting them, - _ $\quad$ Iy

_.. how to produce a fucceffion of, _ _ $\quad i b$.

-__ mould fitteft for, in forcing, - $\quad 18$

____- forcing of, in flued pits, _ $\quad 19$

- culture of, in the garden, - $34 \mathrm{r}$

Afpect for the different kinds of wall-trees, of the proper, $\quad-\cdots \quad$ - $\quad$ - 253 for a garden, of the proper, $\quad 32 I$

B.

Bark-bed in the pinery, how to prepare the, Bafil, culture of,

Beans, culture of,

Beet,

Beft materials for garden-walls, of the, - $\quad 246$

Black frontinac grape defcribed, $\quad 88$

-_ mufcadine, 
Black mufcat of Alexandria, _ _ $\quad 92$ - clufter, - - - $\quad$ - $\quad i b$.

- Conftantia, - $\quad-\quad-\quad 4 \quad 93$

Book I. introduction to, - a I

Borage, culture of, - $\quad$ - $\quad$ - $\quad 400$

Border in the cherry-houfe, preparing of the, $\quad 47$

- fig-houfe, how to prepare the, 68

- grape-houfe, preparation of the, $\quad 77$

- peach-houfe, - - 147

Borders for fruit-trees, conftruction of, - $\quad 243$

- of their breadth and depth, 249

- method of forming a bottom

for, $\quad 250$

Bricks, the beft material for garden-walls, $\quad 246$

Brick-bats are an excellent manure for clayey land, 329

Brocoli, culture of, $\quad-\quad \ldots \quad 352$

Bruffels-fprouts, culture of,

\section{C.}

Cabbage, culture of,

Canvas-fcreens, their great utility on hot-walls, \&c. 169 - _ garden walls, 247

Cardinal impravement,

Cardoons, culture of,

Carrot, culture of, 366

Catterpillar, how to deftroy the, 360

Cauliflower, culture of,

Celery,

Cherries, culture of, in hot-houfes,

kinds of, fitteft for forcing,

training of, in the forcing-houfe,

- culture of, in the confervatory, peachhoufe, \&c. 
Cherries, training and pruning of, on walls and efpaliers,

_- lift of, for the orchard,

Page,

Cherry-houfe, on the conftruction of the,

- on the temperature of the,

on the admiffion of air to the,

Chervil, culture of, watering and fteaming of the,

Clydefdale orchards, of their fituation and improve- ment, of the neglect of,
Compoft for melons,

281
$-\quad 295$
$-\quad 127$
$-\quad 148$
$-\quad 215$
$-\quad 249$

_- manures are to be preferred to fimples, 333

Conftantia grapes defcribed,

Confruction of the pine-ftove, of the, _ $\quad 22 \mathrm{I}$

Crefs, culture of, garden walls,

Crops, on the rotation of,

Crown-glafs, its ufe in hot-houfes,

Cucumbers, forcing of,

early crops of, belt produced on $\mathbf{a}$ dung hot-bed,

- late crops of, moft fuccefsfully raifed in flued pits,

_ - feed beds for, when to prepare, 
Cucumbers, pruning of, of the infects that infeft, and how to de-

\section{froy them,}

Culture of orchard fruits,

Curious circumftance,

Currants, culture of,

\section{D.}

Deviation from a common method,

Directions for managing the new hot-houfe furnace, $23 \mathrm{I}$ Difbuding of peaches and nectarines, - $\quad 154$ Diftance at which peaches fhould be planted, wall-trees in general fhould be

$$
\text { planted, }
$$

efpalier trees in general fhould be

$$
\text { planted, }
$$

orchard trees in general fhould be

\section{planted,}

Draining, of its utility in the orchard, 288

- - kitcher garden, - - 328

Drawing-room, of plants kept in the,

Dung hot bed, culture of cucumbers on a, how to prepare,

Dung-hill, how to prepare the,

Duty of every gardener,

\section{E.}

Earwig, how to deftroy the, $28 \mathrm{r}$ Effect of manures defined, 
Endive, culture of,

Engraft grape-vines, how to,

Enlarge the mould-hills in hot-beds, how to,

Efpalier-rail, conftruction of an,

Efpaliers, fituation of,

- ornamental and ufeful in the garden,

-__ of their fituation,

Experiment, on a dozen of pine plants;

Explanation of Plate firft,

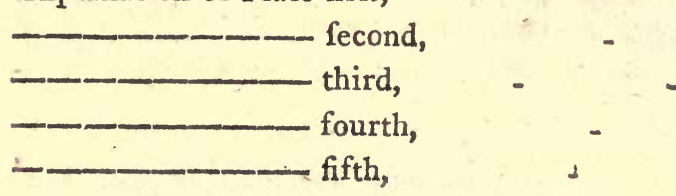

Fennel, culture of,

Fertilize land, how to, by aëration, Figs, culture of, in the hot-houfe,

- training and pruning of, in the hot-houfe,

Fig-houfe, conftruction of the, on walls and efpaliers, 258

- on the temperature of the,

- admiffion of air to the,

- watering and fteaming of the,

Fire-heat, a command of, neceffary in the grape-

- bricks, their ufe in the conftruction of furnaces, flues, \&c.

Fit mould for cucumbers,

Flued pit, beft adapted to forcing of afparagus, 
Flues, of their conftruction,

Page.

Forcing of cherries, when to commence,

$23^{8}$

is an outrage done nature,

54 of ftrawberries,

118

206

Frame for cucumbers, fize of a,

French beans, culture of,

367

Frivolous affertion,

Frontinac grapes defcribed,

88,89

require a greater degree of heat

than other kinds,

104

are more fubject to the red fpider

than other kinds,

114

Fruits, culture of fmall, 300

Fuel for hot-houfes, of,

Furnace, plan of a, defcribed,

\section{G.}

Garden-walls, on the conftruction of,

happieft fituation for the, defcribed,

engine, of its great utility,

Garlick, culture of,

Goofeberries, culture of,

Gothic green-houfes not advifable,

Grapes, culture of, in the grape-houfe,

planting of,

training and pruning of,

on thinning the clufters of,

fhould hang on the tree till dead ripe, 114

- how to prolong the feafon of, forcing of, in the pine-ftove,

- how to próduce fecond crops of, how to engraft,

Grape-houfe, on the conftruction of the, 
Grape-houfe, on the fite for a,

Page.

on watering and fteaming the,
the infects that infert the,

Grape-vines, how to propagate, 105

- feafon for planting,

\section{defcription of,}

Greek grape defcribed,

Green-houfe, on the conftruction of the,

- at Wemyfs Caftle, of its elegance, 2 ro

- temperature of the, admiflion of air to the,

- on watering the, plants, general obfervations on,

Greens, culture of,

Grizley Frontinac grape defcribed,

H.

Hamburgh grapes defcribed,

Fiand-engine, ufe of the, in the hot-houfe, - $\quad 59$

Happieft foil for the kitchen garden, of the, $\quad 326$

Harvey, $\mathrm{Mr}$, of his fuccefs in rearing orchard fruit, 285

Height of garden-walls, of the proper, - 248

Herbs, culture of, $\quad$ - $\quad$ - $\quad 393$

Horfe-raddifh, culture of, - $\quad 369$

Hot-bed for cucumbers, how to conftruct, $\quad 29$

Hot-beds, the propriety of finking, confidered, 27

- culture of cucumbers in, : $\quad 29$

melons in, . . . $\quad 126$ 


\section{N D E X.}

Hot-beds, how to enlarge the mould-hills in,

Hot-bed frames, conftruction of, .

Hot-houfes fhould face the meridian fun, $\quad 7^{\circ}$

beft furnace for the ufe of, defcribed, $23^{\circ}$ of the fitteft fuel for, - $\quad 235$

general obfervations on the confruction

$$
\text { of, }
$$

Hot-walls, management of,

_- plan of the, defcribed,

\section{I.}

Important rule,

Impregnating cucumbers, of,

$3^{2 x}$

39

I 32

Improvement, cardinal, in the culture of early

$$
\text { peaches, }
$$

of the Clydefdale orchards,

288

of garden land, of the means of,

321

Indian-crefs, culture of,

Infects that infert cucumbers, how to deftroy the, 45 cherries, and how to deftroy them, 60

\begin{tabular}{lr}
\hline grapes, & II 4 \\
\hline peaches, & 165 \\
\hline pine apples, & 203 \\
\hline wall-trees, & 280 \\
\hline Introduction to Book Firf, & 1 \\
Iron-wire, its ufe in trellifing, & 309 \\
Irony foils, how to improve them, & $24 \mathrm{r}$ \\
\end{tabular}

\section{K.}

Kail, culture of,

Kindly fteam in hot-beds, a good fymptom,

$\mathrm{Dd}$ 
Kinds of peaches and nectarines for forcing, Kitchen vegetables do beft on new land,

Page:

culture of, I 50 $3^{18}$

I.

Leeks, culture of,

Lettuce,

Light foils, of the manures for,

370

396

Lime, of its operations on the foil,

333

- the quantity requifite to fertilize tills,

Line the cucumber bed,

Liquor for deftroying infects, how to prepare,

Lift of grapes,

- - peaches and nectarines,

- wall-trees,

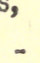

150

_- efpalier trees,

253

-_- orchard fruits,

256

290

Lombardy grape defcribed,

\section{M.}

Manure fit for orchards, of the,

_- garden land,

Manures and their application, of,

Manuring, new method of,

Marigold, culture of,

Marjoram,

-

$40 \mathrm{x}$

Maturation of pine apples, of the;

$i b$.

Melons, culture of, on the dung hot-bed, -

200

126 in flued pits, of impregnating,

Method of impregnating cucumbers, 


\section{N D E X.}

Method of deftroying infects on fruit trees,

Page.

62

cultivating cherries in the peach-houfe, confervatory, ftoves, \&c. $\quad-\quad 64$

propagating grape-vines, $\quad 8 \mathrm{I}$

- effectually deftroying wafps, - $\quad 114$

producing fecond crops of grapes, $\quad 122$

melons,

129

improving melon feeds, _ $\quad$ 130

deftroying the pine bug, \&c. _. $\quad 204$

- working the new hot-houfe furnace, $23^{2}$

- cambering rafters, of the, o 240

forming a bottom for fruit-tree borders,

the beft, - - 250

- deftroying the green-fly, - 280

Mildew, how to cure the,

earwig and wood-loufe, $28 x$

Mint, culture of,

165

Moft proper time for watering plants, - $\quad 43$

Mould fitteft for forcing afparagus in, - $\quad 18$

$\longrightarrow-$ cucumbers, - $\quad 3^{6}$

- the border in the cherry-houfe, $\quad 4^{8}$

$\longrightarrow$ vinery borders, = $\quad 7^{8}$

- - melons, - - 127

-

—_ pine apples, _ - $\quad 184$

-

Mufcadine grapes defcribed, $\quad 87$

Mufcat grapes, - 92

Mufhrooms, culture of, $\quad$ : $\quad$ I35

Mufhroom-houfe, on the conftruction of the, ib.

- frame, how to confruct, $\quad 13^{6}$

- beds, how to prepare, $\quad$ I37

watering of the, - $\quad$ r $4 \mathrm{r}$ 
Mufhroom feafon, how to prolong the,

N.

Nectarines, culture of, in the peach-houfe,

Nets, their ufe on hot walls, \&c.

Nonfuch apple, fingular habit of the,

O.

Obfervations, genera1, on green-houfe plants,

Of the proper temperature of water for plants,

Old tan, ufe of, in the hot-bed,

- peculiarly adapted for forcing afparagus in, 18

Onions, culture of,

On the proper application of manures,

Orchard fruits, culture of,

$$
\text { of the kinds of, }
$$

Orchards, of the fituation for,

kinds of manure for, 
P.

Page.

Parfley, culture of,

Parfnip,

Pafturing cattle in orchards, bad effects of,

- iheep

397

375

298

Patience in plants, of, $i b$.

Peaches, culture of, in the peach-houfe, on the flued-wall,

Peach-houfe, conftruction of the,

- - temperature of the, 144 admiffion of air to the, 156

\section{watering and fteaming the,}

Peach feafon, how to prolong the,

Pears, compofition of the borders for,

- training and pruning of, againft walls and efpaliers,

- of the proper foil for,

- lift of, for the orchard,

Peas, culture of,

Pine-apples, culture of,

- plants, how to propagate, mould fitteft for,

Pinery, culture of grapes in the,

- conftruction of the,

- temperature of the,

- admiffion of air to the,

watering and fteaming the,

Pines, maturation and cutting of, 376

- Thould be cut before they are dead ripe, 201

- - manner of preferving them frefh, 202

- how to deftroy infects that infert, - 203

Pine-itove, plan of a, deicribed, $\quad 22 \mathrm{I}$ 174 182 184 II9 174 195 196 198 200 Plates, 
Plates, explanation of the,

Plan of the cherry-houfe defcribed,

grape-houfe
hot wall,
mufhroom-houfe
Plums, compofition of the borders for,

-_ training and pruning of, againft walls and efpaliers,

- lift of, for the orchard,

Potatoes, culture of,

Pot herbs,

Pots for pines defcribed,

Portugal grape defcribed,

Practice, an erroneous, cenfured,

Precious ingredient,

Proper depth of garden land, of the,

Pruning cucumbers, of,

cherries in the forcing-houfe, of,

figs in the hot-houfe, of,

grape vines, of,

in the pinery, method of,

peaches and nectarines,

winter, of vines, exemplified,

- wall-trees, general obfervations on,

- - goofeberries and currants, of,

R.

Radifh, culture of, Rafpberries, culture of, 
Receipt for the deftruction of infects on fruit-trees, 62

Red-fpider, how to deftroy the,

Red Frontinac grape defcribed,

- raifin,

Ridging-bed for cucumbers, how to prepare,

Ridging land, of the effects of,

Rotation of crops, of the,

Royal mufcadine grape defcribed,

404

Rule for thinning of peaches and nectarines,

proportioning garden-walls and borders, 249

— turning and trenching the bark-bed, $\quad 178$

- the beft method of admitting air,

S.

Sage, culture of,

Sallads,

Salfafy, - -

Savoys, -

Savory, -

Sea-cale, -

Sea-weed, an excellent manure,

Seafon of grapes, how to prolong the,

__ peaches, ___

for thifting green-houfe plants,

- orchard trees, 292 pruning orchard trees,

Sections of a furnace explained,

Shallots, culture of,

Situation of gardens, of the proper, 
Skirret and fcorzonera, culture of,

Soil for orchard fruits, of the proper,

Page,

- in the garden, of the variety of,

Sorrel, culture of,

Spinage,

Squares of turf, the $r$ ufe in the conftruction of hot-

beds,

St Peter's grape defcribed,

Steam, quality of, for the hot-houfe, confidered,

- how to draw off, from the hot-bed,

Steaming the cherry-houfe, of,

-_ apparatus, of the utility of the,

___ grape-houfe, of,

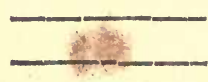

peach-houfe, of,

Strawberries, forcing of,

_ culture of, in the orchard,

- produce beft in fingle rows,

Succeflion of cherries, how to produce a,

Sweet water grape, defcription of the,

T.

Tan, old, its ufe in the hot-bed,

Tanfy, culture of,

Tarragon, - - -

$i b$.

Temperature of the afparagus hot bed,

- _ - cucumber-bed, 
Temperature of the fig-houle, of the proper,

Temporary trees, of planting in the orchard, 292

Thinning the clufters of grapes, on, 2 - insis

- peaches and nectarines of, $\quad 162$

- wall-fruit in general, of, $\quad 272^{\circ}$

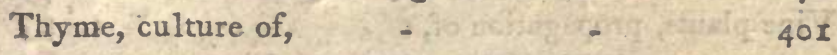

Tokay grapes defcribed, th 2 - 90,91

Training cucumbers, of, 43

cherries in the forcing-houfe, of, $\quad 50$

- _ figs, ______- -69

- grape-vines, of, 3 in 94

- in the pinery, method of, I20

-.- of peaches and nectarines,

CA w wall and efpalier trees, on, $\leftarrow \quad 259$

-

$\begin{array}{ll}\text { Treatment of pine plants the firft year, } \quad-\quad & 272 \\ & -\quad 187\end{array}$

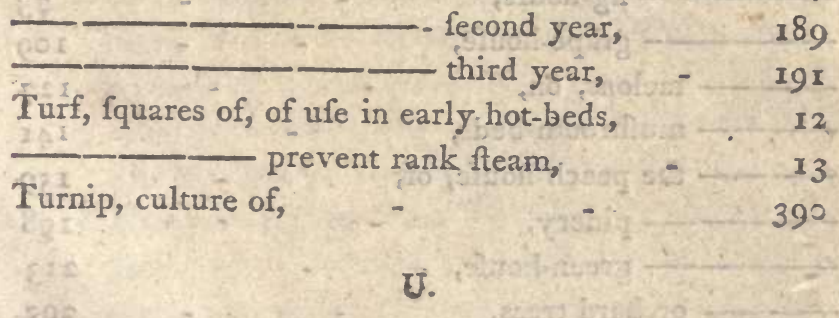

Uniformity in the confruction of hot-houfes, of, 241 \begin{tabular}{ll} 
Unhheltered plains, unfit for rearing orchards in, $\quad 287$ \\
\hline
\end{tabular} Ufeful hints, 
Value of manures, of the,

Variety of garden land, of the; and how to improve it,

Vegetable mould, how to make,

Vegetables, kitchen, do beft on new land,

Vegetation, of the foils moft favourable to,

Vine-borders, compofition of,

W.

Wafps, effectual method of deftroying,

114

Water, molt proper time for the application of,

- 33,34,
grape-houfe,
melons, on,
mufhroom-beds,
- the peach-houfe, of,
- pinery,
White fweet water grape, defcription of the,

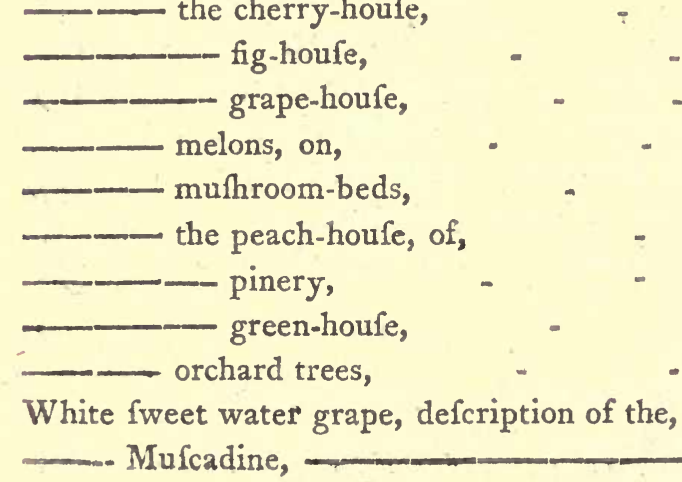


White Frontinac grape, defcription of the,

-_- Hamburgh, _—_ 89

-- Tokay, —- 90

…-Paffe mofque, —_ _

-__ Raifin, _- _ 90

Winter-pruning of vines exemplified, $\quad 235$

Wire, iron, its ufe in trellifing, - $24 \mathrm{r}$

Wood-loufe, how to deftroy the, _ $\quad 28 r$

The Bookbinder will place all the Plates in their order at the end of the Volume.

BOOKS publifhed by WILLIAM CREECH,

\section{Edinburgh.}

I. A new and improved Edition, greatly enlarged, of Lee's Introduction to Botany; with an Appendix; a Gloffary; and an Englifh Explanation of the Latin Botanic Terms. 8vo. with a newly-engraved Set of Plates. $-6 \mathrm{~s} .6 \mathrm{~d}$. in boards.

2. Obfervations on Plants. By M. Von Ullar. Tran1lated from the German; with Additions, by J. G. Schmeiffer, F. R. S. \&c. 8 vo. -3 s. 6 d. in boards.

3. The Sexes of Plants vindicated. By John Rotheram, M. D. \&c. 8vo.-1 s. 6 d. fewed.

4. Dickfon's Hufbandry of the Ancients; being a TranAlation of the Rei Ruftica Scriptores; with Notes, explanatory of the Terms, and Obfervations on the Modern Practice compared with the Ancient. 2 vols. 8vo. -12 s. in boards. 


\section{$\left[\begin{array}{ll}2 & \end{array}\right]$}

5. A Treatife on Modern Agriculture. By the fame Author. 2 vols. 8vo. with Plates. - I2 s. in boards.

af Complete Sets of the Ancient and Modern Agricul: ture, uniformly bound, in 4 vols.-Price L, I, $8 \mathrm{~s}$.

6. Prize Effays, and Tranfactions of the Highland Society of Scotland; with an Account of the Inftitution, and principal proceedings of the Society, by Henry Mackenzie, Efq; 8vo.-7 s. in boards.

The above Volume contains Effays on fubjects of Agriculture, Fifheries, Manufactures, and other important fubjects, applicable to the kingdom at large.

7. The Farmer's Magazine, for 1800 and 1801 . Two vols. 8vo.- I 7 s. in boards, or 16 s, done up in Nos. and Nc. IX. Being the firft for 1802.-Price $2 \mathrm{~s}$. Sewed. ** No. X. Will be publifhed on Monday, zd May. 8. A new Edition of Lord Kames's Gentleman Farmer. 8vo. with Plates. -7 s. in boards.

5. Mineralogy of the Scottilh Inles; with Mineralogical Obfervations, made in a Tour through the Mainland of Scotland; and Differtations on Peat, Kelp; and Coal. By Robert Jamefon, F. R. \& L. S. S. \&c. Two vols. 4to. illuftrated by Maps and Plates, L. I, II s. 6 d. in boards.

$+t+$ The Mineralogy of the Shetland Inlands, and of the Ifland of Arran; with Obfervations on Peat, Kelp, and Coal, may be had feparate, in 1 volume Royal 8vo. with Maps and Plates.-Price $7 \mathrm{~s}$, in boards.

In the Press, and speedily will be publifsed,.

Handfomely printed in Two Volumes Octavo, A new Edition, being the Fifth, corrected, and confiderably enlarged, including all the Modern Difcoveries, and illuftrated by a new fet of Copperplates,

Eizments of Chemistry, in a new fyftematic order. $\therefore$ By M. Lavoifier. Tranflated from the Frenth by Robert Kerr, F. R. \& A.S. S. \&.c. \&c. 




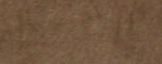

(4.

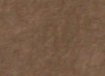

$\left(\frac{1020}{20}\right.$

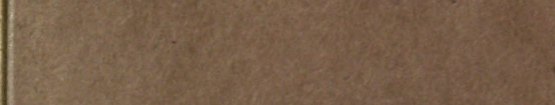
13 Wista

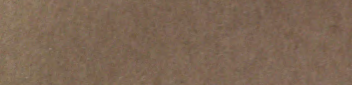

$\sin x=20$

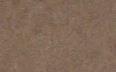

inise

$x^{2}+2$

$\cdot \cos x=50$

(3)

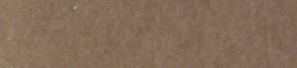

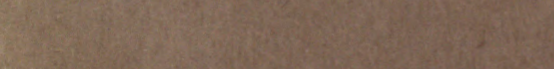

(3)

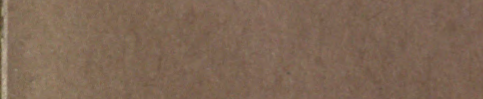

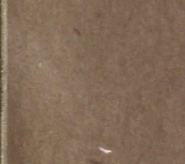

8.

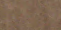






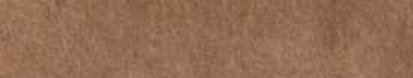

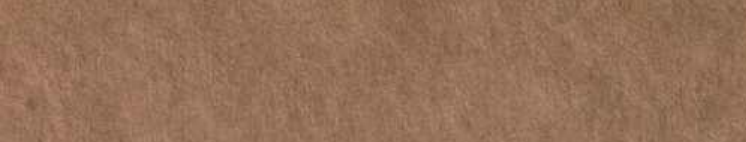

(1)

A.

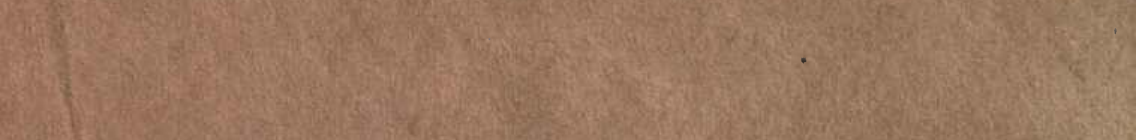

20.

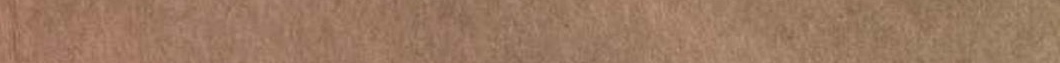
1.5.

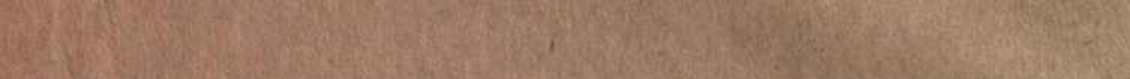

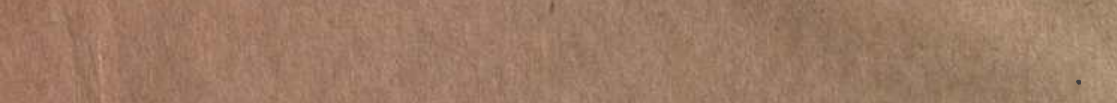
Q

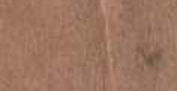

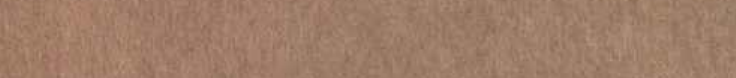
W.

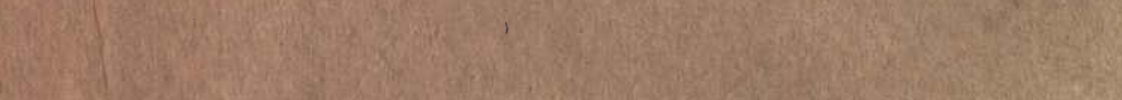
Whet a

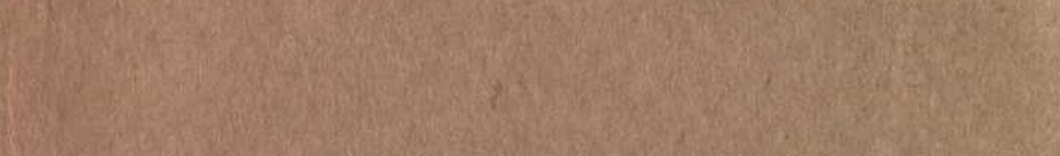

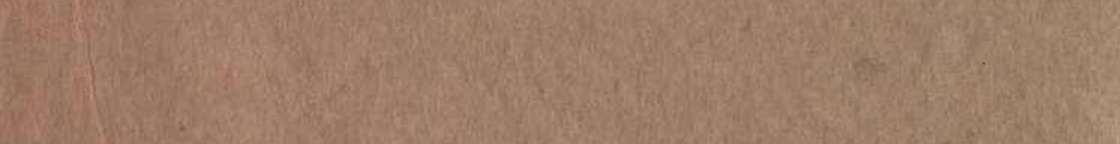

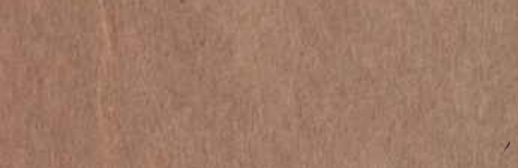

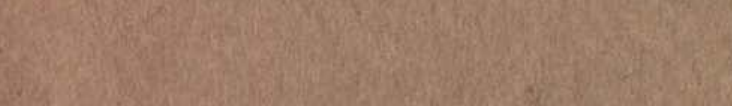

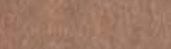
Wy

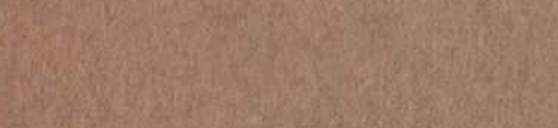

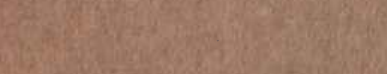

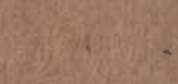

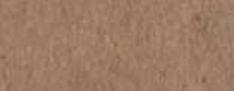

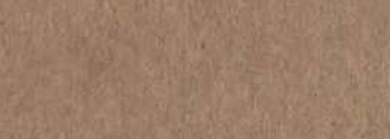

(1)

(2).

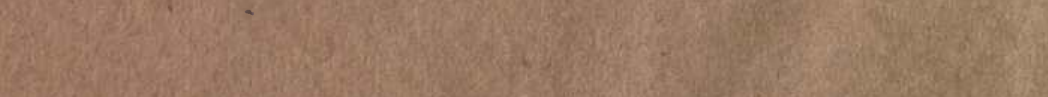
4.

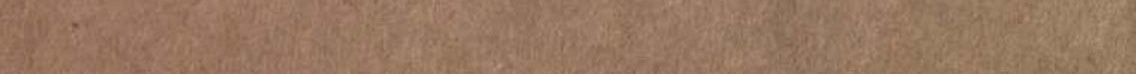

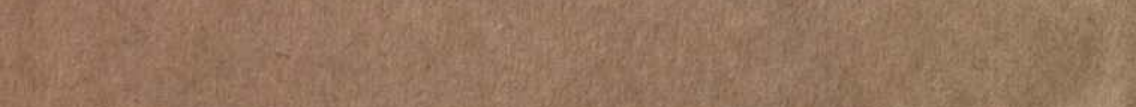

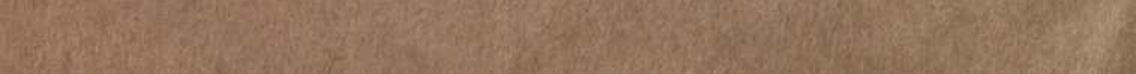





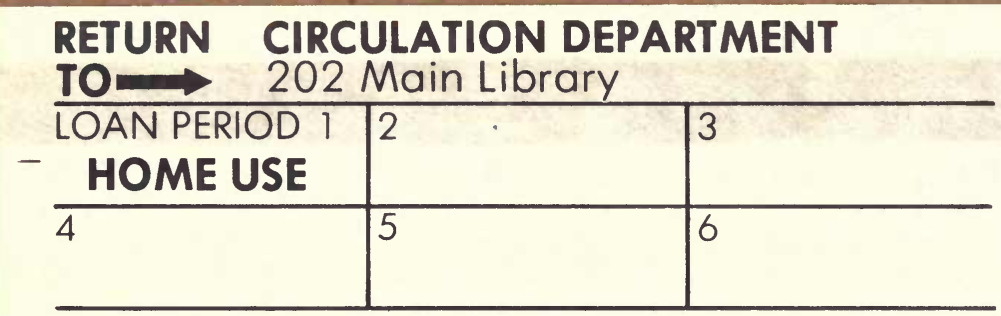

ALL BOOKS MAY BE RECALLED AFTER 7 DAYS

1-month loans may be renewed by calling $€ 42.3405$

1-year loans may be recharçed by bringing the books to the Clrculation Desk

Benewale and recharges may be made 4 days prior to due date

DUE AS STAMPED BELOW

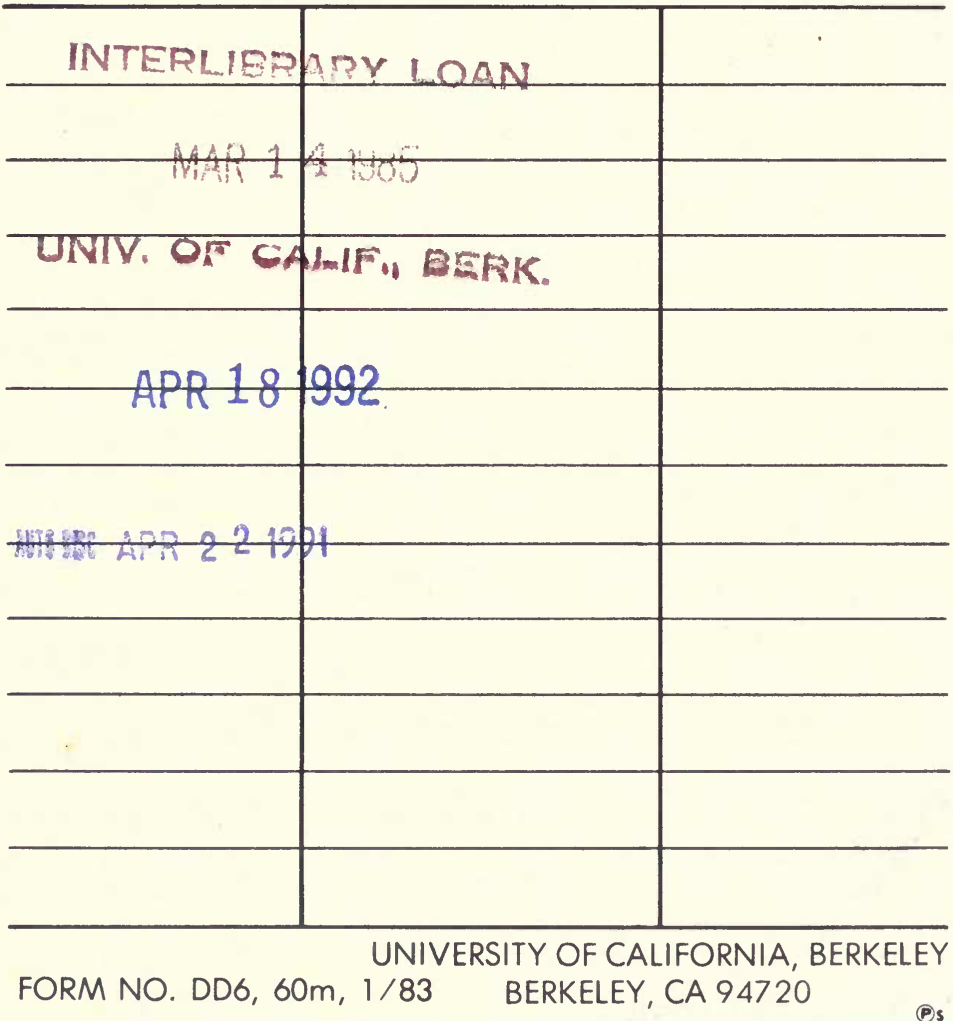




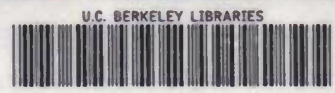 \\ C031.33890?}

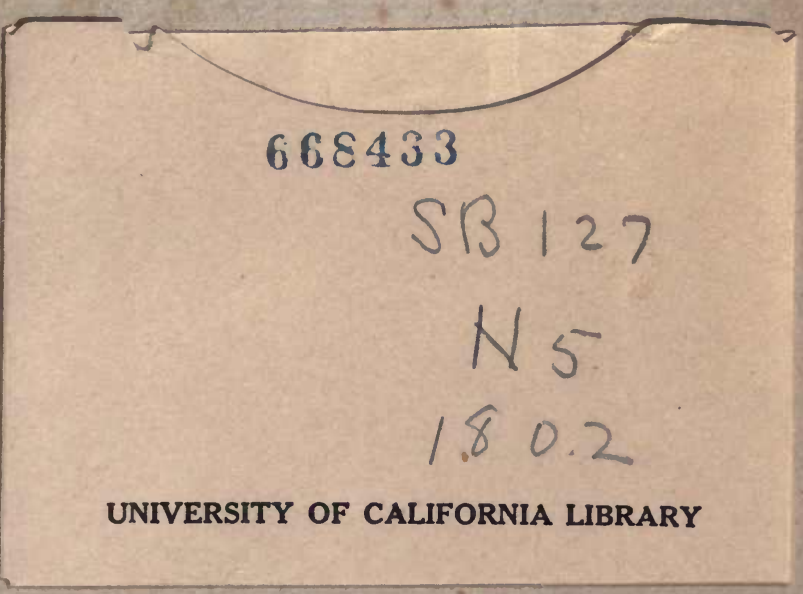


